\title{
EMPIRICAL APPROACH TO SATELLITE SNOW DETECTION
}
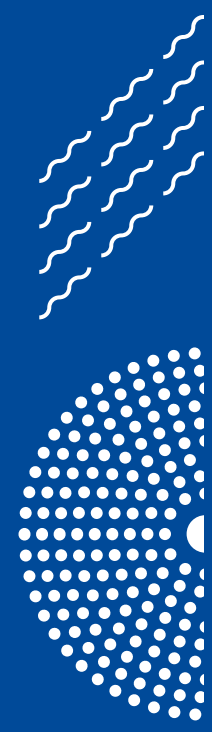


\title{
FINNISH METEOROLOGICAL INSTITUTE
}

\section{CONTRIBUTIONS}

No. 171

\section{EMPIRICAl Approach to SATELlite SNOW DEtection}

\section{Niilo Siljamo}

\author{
Institute for Atmospheric and Earth System Research \\ Faculty of Science \\ University of Helsinki \\ Helsinki, Finland
}

ACADEMIC DISSERTATION in meteorology

Doctoral dissertation, to be presented for public discussion with the permission of the Faculty of Science of the University of Helsinki, in Auditorium P674, Porthania, on the 18th of September, 2020 at 13 o'clock.

Finnish Meteorological Institute

Helsinki, 2020 


\begin{tabular}{|c|c|}
\hline Author & $\begin{array}{l}\text { Niilo Siljamo } \\
\text { Meteorological Research } \\
\text { Finnish Meteorological Institute, Finland } \\
\text { niilo.siljamo@fmi.fi }\end{array}$ \\
\hline Supervisors & $\begin{array}{l}\text { Dr Otto Hyvärinen } \\
\text { Weather and Climate Change Impact Research } \\
\text { Finnish Meteorological Institute, Finland } \\
\text { Professor Heikki Järvinen } \\
\text { Institute for Atmospheric and Earth System Research (INAR) } \\
\text { University of Helsinki, Finland }\end{array}$ \\
\hline Pre-examiners & $\begin{array}{l}\text { Professor Kari Lehtinen } \\
\text { Department of Applied Physics } \\
\text { University of Eastern Finland } \\
\text { Assistant Professor Jaan Praks } \\
\text { Department of Electronics and Nanoengineering } \\
\text { Aalto University, Finland }\end{array}$ \\
\hline Opponent & $\begin{array}{l}\text { Dr Patricia de Rosnay } \\
\text { Coupled Assimilation Team Leader } \\
\text { Earth System Assimilation Section } \\
\text { European Centre for Medium-Range Weather Forecasts } \\
\text { Reading, UK }\end{array}$ \\
\hline Custos & $\begin{array}{l}\text { Professor Heikki Järvinen } \\
\text { Institute for Atmospheric and Earth System Research (INAR) } \\
\text { University of Helsinki, Finland }\end{array}$ \\
\hline
\end{tabular}

ISSN 0782-6117

ISBN 978-952-336-119-5 (paperback)

ISBN 978-952-336-120-1 (pdf)

DOI 10.35614/isbn.9789523361201

http://ethesis.helsinki.fi/

Edita Prima Oy

Helsinki 2020 
Julkaisija IImatieteen laitos

(Erik Palménin aukio 1)

PL 503, 00101 Helsinki
Julkaisun sarja, numero ja raporttikoodi

Finnish Meteorological Institute

Contributions 171, FMI-CONT-171

Päiväys

Syyskuu 2020

\section{Tekijä(t)}

Niilo Siljamo

\section{ORCID iD 0000-0003-3909-8650}

\section{Nimeke}

Empiirinen lähestymistapa satelliittilumentunnistukseen

\section{Tiivistelmä}

Lumipeitteellä on huomattava vaikutus säähän, ilmastoon, luontoon ja yhteiskuntaan. Pelkästään sääasemilla tehtävät lumihavainnot (lumen syvyys ja maanpinnan laatu) eivät anna kattavaa kuvaa lumen peittävyydestä tai muista lumipeitteen ominaisuuksista.

Sääasemien tuottamia havaintoja voidaan täydentää satelliiteista tehtävillä havainnoilla. Geostationaariset sääsatelliitit tuottavat havaintoja tihein välein, mutta havaintoresoluutio on heikko monilla alueilla, joilla esiintyy kausittaista lunta. Polaariradoilla sääsatelliittien havaintoresoluutio on napa-alueiden läheisyydessä huomattavasti parempi, mutta silloinkaan satelliitit eivät tuota jatkuvaa havaintopeittoa. Tiheimmän havaintoresoluution tuottavat sääsatelliittiradiometrit, jotka toimivat optisilla aallonpituuksilla (näkyvä valo ja infrapuna).

Lumipeitteen kaukokartoitusta satelliiteista vaikeuttavat lumipeitteen oman vaihtelun lisäksi pinnan ominaisuuksien vaihtelu (kasvillisuus, vesistöt, topografia) ja valaistusolojen vaihtelu. Epävarma ja osittain puutteellinen tieto pinnan ja kasvipeitteen ominaisuuksista vaikeuttaa luotettavan automaattisen analyyttisen lumentunnistusmenetelmän kehittämistä ja siksi empiirinen lähestymistapa saattaa olla toimivin vaihtoehto automaattista lumentunnistusmenetelmää kehitettäessä.

Tässä työssä esitellään kaksi EUMETSATin osittain rahoittamassa H SAFissa kehitettyä lumituotetta ja niissä käytetyt empiiristä lähestymistapaa soveltaen kehitetyt algoritmit. Geostationaarinen MSG/SEVIRI H31 lumituote on saatavilla vuodesta 2008 alkaen ja polaarituote Metop/AVHRR H32 vuodesta 2015 alkaen. Lisäksi esitellään pintahavaintoihin perustuvat validointitulokset, jotka osoittavat tuotteiden saavuttavan määritellyt tavoitteet.

\section{Julkaisijayksikkö}

Meteorologinen tutkimus

\begin{tabular}{|c|c|c|}
\hline Luokitus (UDK) & & Asiasanat \\
\hline $551.321,551.322,528.8,004.021$ & & Lumi, kaukokartoitus, \\
\hline & & lumentunnistus \\
\hline ISSN ja avainnimeke & & ISBN \\
\hline $0782-6117$ & & 978-952-336-119-5 (paperback) \\
\hline Finnish Meteorological Institute Contributions & & $978-952-336-120-1$ (pdf) \\
\hline DOI & Kieli & Sivumäärä \\
\hline https://doi.org/10.35614/isbn.9789523361201 & Englanti & 55 \\
\hline
\end{tabular}


Published by Finnish Meteorological Institute

(Erik Palménin aukio 1), P.O. Box 503

FIN-00101 Helsinki, Finland
Series title, number and report code of publication

Finnish Meteorological Institute

Contributions 171, FMI-CONT-171

Date

September 2020

\title{
Author(s)
}

Niilo Siljamo

ORCID iD 0000-0003-3909-8650

\section{Title}

Empirical Approach to Satellite Snow Detection

\begin{abstract}
Snow cover plays a significant role in the weather and climate system, ecosystems and many human activities, such as traffic. Weather station snow observations (snow depth and state of the ground) do not provide highresolution continental or global snow coverage data.

The satellite observations complement in situ observations from weather stations. Geostationary weather satellites provide observations at high temporal resolution, but the spatial resolution is low, especially in polar regions. Polarorbiting weather satellites provide better spatial resolution in polar regions with limited temporal resolution. The best detection resolution is provided by optical and infra-red radiometers onboard weather satellites.

Snow cover in itself is highly variable. Also, the variability of the surface properties (such as vegetation, water bodies, topography) and changing light conditions make satellite snow detection challenging. Much of this variability is in subpixel scales, and this uncertainty creates additional challenges for the development of snow detection methods. Thus, an empirical approach may be the most practical option when developing algorithms for automatic snow detection.

In this work, which is a part of the EUMETSAT-funded H SAF project, two new empirically developed snow extent products for the EUMETSAT weather satellites are presented. The geostationary MSG/SEVIRI H32 snow product has been in operational production since 2008. The polar product Metop/AVHRR H32 is available since 2015. In addition, validation results based on weather station snow observations between 2015 and 2019 are presented. The results show that both products achieve the requirements set by the H SAF.
\end{abstract}

\section{Publishing unit}

Meteorological Research

\begin{tabular}{|c|c|c|}
\hline Classification (UDC) & & Keywords \\
\hline $551.321,551.322,528.8,004.021$ & & snow, remote sensing, \\
\hline & & snow recognition \\
\hline ISSN and series title & & ISBN \\
\hline $0782-6117$ & & 978-952-336-119-5 (paperback) \\
\hline Finnish Meteorological Institute Contributions & & $978-952-336-120-1$ (pdf) \\
\hline DOI & Language & Pages \\
\hline https://doi.org/10.35614/isbn.9789523361201 & English & 55 \\
\hline
\end{tabular}


To my family: Pilvi Kaisla Oula Sameli Hilla 



\section{PREFACE}

I have always wanted to be a scientist. At first, theoretical physics was tempting, but it turned out to be too theoretical. Then, a friend said that I should change to geophysics because there are field trips. I managed to get a degree and soon after I got a job at the Department of Meteorology of the University of Helsinki: sea ice remote sensing or something like that. Some years later, I got a new job at the FMI, but UV-database development was not as exciting as promised. It was time to move on to remote sensing of snow. I'm still sitting in the office (at home for the last six months), but, at least, there have been some snow pits on the way.

This work has progressed at a slow and not that steady pace. In the beginning, there were no deadlines. Now, there are doctoral schools, expiration times, and the thesis is just the beginning. I'm probably a relic from the old world, but I managed to finish in less than 25 years. I want to thank my latest supervisors Otto Hyvärinen and Heikki Järvinen for their advice and patience during these years. I also would like to thank my earlier supervisors who have retired or changed positions.

I want to thank the members of the Satellite and Radar Applications group and the fine folks from the coffee breaks. Especially, I am grateful to my Head of Group Terhikki Manninen for her advice and support. I wish to thank the people at the Numerical Weather Prediction group for their comments and suggestions. I want to thank my colleagues at the FMI Meteorological Research and, of course, my co-authors.

During the years, I have been supported by the staff of the LSA SAF and $\mathrm{H}$ SAF. I'm grateful for the discussions with Samantha Pullen and others at the Met Office. The Finnish Meteorological Institute has provided an excellent working environment during the last 20 years.

There is also life outside of work. I wish to thank my dear friends Merikki and Esa who have been moving farther and farther away but never too far for a phone call. Timo has always been able to suggest interesting and funny films, TV shows, books and games. Of course, I want to thank all my other friends near and far (if that rings any bells).

And then there are the relatives. I want to thank my parents and sisters and their families and also my wife's parents and sisters. Finally, and most importantly, I would like to thank my family: my wife Pilvi for her patience and support and my children Kaisla, Oula, Sameli and Hilla for just being there. My life would have been pretty dull and boring without all of you.

Niilo Siljamo

Helsinki, 2020 



\section{CONTENTS}

$\begin{array}{ll}\text { Preface } & 7\end{array}$

$\begin{array}{ll}\text { List of acronyms } & 11\end{array}$

List of original publications and author's contribution 13

1 Introduction $\quad 15$

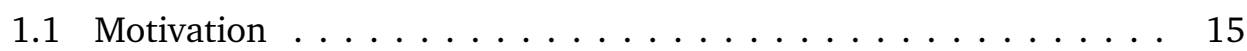

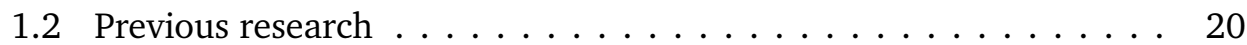

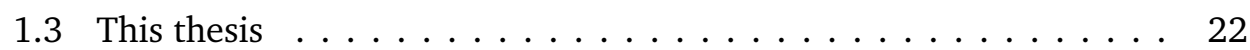

2 A view from above $\quad 26$

3 Algorithms 34

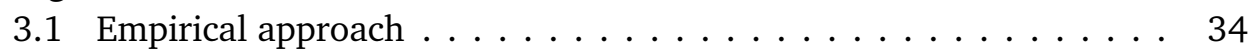

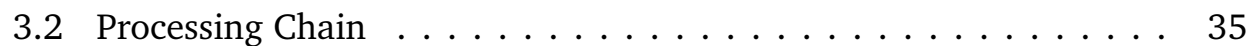

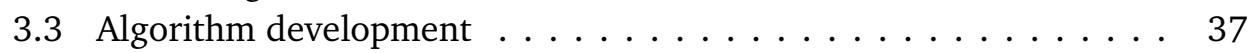

4 Validation $\quad 41$

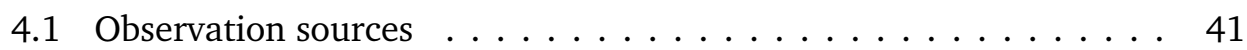

4.2 Validation measures . . . . . . . . . . . . . . . . . . . . 43

4.3 Validation results ........................ 45

$\begin{array}{llr}5 & \text { Future } & 48\end{array}$

6 Conclusions $\quad 49$

$\begin{array}{ll}\text { References } & 51\end{array}$ 



\section{LIST OF ACRONYMS}

AVHRR Advanced Very High Resolution Radiometer

ECMWF European Center for Medium-Range Weather Forecasts

EUMETSAT European Organization for the Exploitation of Meteorological Satellites

FCI Flexible Combined Imager

EO-1 Earth Observing-1

FMI Finnish Meteorological Institute

GAC Global Area Coverage

GOES Geostationary Operational Environmental Satellite system

H SAF SAF on Support to Operational Hydrology and Water Management

IMS Interactive Multisensor Snow and Ice Mapping System

H31 H SAF MSG/SEVIRI Snow Extent

H32 H SAF Metop/AVHRR Snow Extent

HRV High Resolution Visible

JPSS Joint Polar Satellite System

LSA SAF SAF for Land Surface Analysis

LST Land Surface Temperature

METimage Meteorological Imager

MODIS Moderate Resolution Imaging Spectroradiometer

MSG Meteosat Second Generation

MTG Meteosat Third Generation

Metop-SG Meteorological Operational Satellite - Second Generation

Metop Meteorological Operational Satellite

NDSI Normalized-Difference Snow Index

NESDIS National Environmental Satellite, Data, and Information Service

IR Infrared Radiation

NIR Near-Infrared Radiation

NOAA National Oceanic and Atmospheric Administration

NPP National Polar-orbiting Partnership

NWP Numerical Weather Prediction

PDU Product Dissemination Unit

SAF Satellite Application Facility

SEVIRI Spinning Enhanced Visible and Infrared Imager

SMHI Swedish Meteorological and Hydrological Institute

SNORTEX Snow Reflectance Transition Experiment

SWE Snow Water Equivalent 
SWIR Short-Wavelength Infrared Radiation

VIIRS Visible Infrared Imaging Radiometer Suite

VISSR Visible and Infrared Spin Scan Radiometer 


\section{LIST OF ORIGINAL PUBLICATIONS AND AUTHOR'S CONTRIBUTION}

I N. Siljamo and O. Hyvärinen (June 2011). 'New Geostationary SatelliteBased Snow-Cover Algorithm'. J. Appl. Meteor. Climatol. 50:6, pp. 12751290. DOI: $10.1175 / 2010$ JAMC2568.1

In Paper I, the author developed the algorithms and took part in validation of the product. The author wrote most of the paper.

II N. Siljamo, O. Hyvärinen, A. Riihelä and M. Suomalainen (2020). 'Metop/AVHRR snow detection method for meteorological applications'. $J$. Appl. Meteor. Climatol. Submitted February 2020

In Paper II, the author was responsible for development of the algorithms, validation of the product, making most of the visualizations and writing most of the paper.

III I. F. Trigo, C. C. Dacamara, P. Viterbo, J.-L. Roujean, F. Olesen, C. Barroso, F. Camacho-de-Coca, D. Carrer, S. C. Freitas, J. Garcia-Haro, B. Geiger, F. Gellens-Meulenberghs, N. Ghilain, J. Meliá, L. Pessanha, N. Siljamo and A. Arboleda (2011). 'The Satellite Application Facility for Land Surface Analysis'. Int. J. Remote Sens. 32:10, pp. 2725-2744. DOI: 10 . 1080 / 01431161003743199

In Paper III the author was responsible for writing most of the section describing snow products and providing the snow product validation results.

IV O. Hyvärinen, K. Eerola, N. Siljamo and J. Koskinen (2009). 'Comparison of snow cover from satellite and numerical weather prediction models in Northern Hemisphere and northern Europe'. J. Appl. Meteor. Climatol. 48:6, pp. 1199-1216. DOI: 10.1175/2008JAMC2069.1

In Paper IV, the author took part in the writing and provided the LSA SAF data.

V K. Anttila, T. Manninen, T. Karjalainen, P. Lahtinen, A. Riihelä and N. Siljamo (2014). 'The temporal and spatial variability in submeter scale surface roughness of seasonal snow in Sodankylä Finnish Lapland in 2009-2010'. J. Geophys. Res. Atmos. 119: pp. 9236-9252. DOI: 10.1002/2014JD021597

In Paper V, the author took part in the field measurements during the SNORTEX campaign and had a minor part in the writing. 



\section{INTRODUCTION}

\subsection{MOTIVATION}

Weather has a large impact on society, the economy and everyday life of the people. For that reason, people have been trying to forecast weather for thousands of years. Weather forecasting based on science began when the speed of communication reached the level which allowed collecting observations from larger areas.

Later, the invention and development of computers allowed Numerical Weather Prediction (NWP). Modern NWP is based on large masses of observations of weather and surface parameters which are used in determining the initial state for the weather models (i.e. data assimilation). As it is said by Pullen et al. (2010), snow is an extremely important component of the land surface system. While it has a large impact on many radiative and hydrological properties, especially important is the way snow changes the surface albedo.

Snow has a strong impact on ecosystems, as well (Niittynen et al. 2018). The importance of snow is quite well summarized in the short Nature Climate Change editorial 'Let it snow' (2018): "The changing nature of snow under anthropogenic warming - including coverage, duration and melt characteristics - stands to exert substantial impacts across physical, biological and socio-economic systems. However, our understanding of these impacts is often constrained by inadequate snow observations, limited in both spatial and temporal resolution."

Changes in snow cover can have drastic effects on the surface properties and the energy and mass balance on the surface. For example, snow has a much higher albedo than snow-free surfaces, which changes the shortwave radiation flux when a larger part of the incoming radiation is reflected from the surface. Snow also behaves as temporary water storage (measured as Snow Water Equivalent (SWE)) as falling snow stays on the surface until the snow melts and the water runs off. The phase changes between vapour, liquid and solid forms release or absorb energy. The physical properties of the snow cover change over time (grain size, density, snow depth and so on). Snow cover and its properties are discussed in more detail in, for example, the recent thesis by Leppänen (2019).

At the same time, snow cover is very variable both spatially and temporally. Snowfall may be very uneven by itself and also other weather conditions may change the way snow accumulates. For example, wind may create large snowdrifts and move the snow away from other places. On the other hand, melting snow cover is often uneven and patchy as melting advances faster in some spots and slower in others. Still, even a thin snow layer changes the surface properties. Differences in e.g. topography and vegetation (especially forests) can change the development of the snow field. Especially in the margin of the snow-covered area, snow may appear and disappear rapidly. 
Because snow-covered and snow-free surfaces have different properties, information about snow coverage would be beneficial for many applications. Usually, necessary observations can be obtained from synoptic weather stations, which, however, may be far from each other especially in uninhabited remote areas. Often, the only available snow measurement from a weather station is snow depth. While suitable for many applications, it does not say much about snow coverage, especially when the snow depth is small or snow cover is not continuous.

As a further hindrance, snow depth is often not reported from snow-free weather stations. This is unfortunate because there are weather stations which do not measure snow depth at all and these two cases are essentially impossible to distinguish from each other.

Even though weather observations from weather stations, radiosondes, ships, buoys and aeroplanes are a necessary part of the modern weather forecasting, there are still large gaps in the observation networks, especially in remote areas and oceans. These can be partly covered by remote sensing methods, such as radars and satellites which provide excellent but usually indirect observations in good spatial and temporal resolution for many kinds of applications. There are organizations (such as European Organization for the Exploitation of Meteorological Satellites (EUMETSAT), National Oceanic and Atmospheric Administration (NOAA)) which operate weather satellites specifically for this purpose.

On the surface, the general features of the snow cover are easy to see by any observer. In open areas, including grasslands and other areas without trees or shrubs, the surface can be snow-free, completely snow-covered or more or less partially snow-covered. From satellites, open areas are relatively easy targets even though vegetation can be a challenge when the snow depth is small or snow cover is patchy.

On the other hand, in forests and shrublands snow cover should be considered in two parts, snow on the surface and snow on the canopy, which can both be snowcovered or snow free. In typical weather satellite resolutions, these two may be difficult to handle separately. Thus, a satellite pixel classified as fully snow-covered may be snow-covered on the surface, on trees or both.

Some weather stations observe and report the state of the ground (defined in WMO 2015), which can be interpreted as an estimated snow coverage (no snow, less than half, over half, full snow cover). Unfortunately, at the moment these observations are only available from manned stations which are expensive to operate and are often replaced with automatic weather stations.

Typically, weather satellite radiometers measure the radiation on a few separate radiation bands. In general, older but still operational weather satellite instruments (e.g., Advanced Very High Resolution Radiometer (AVHRR)) provide 
data on 4-5 bands or channels, while more modern instruments (such as Visible Infrared Imaging Radiometer Suite (VIIRS)) may provide 10-25 channels or even more. For research purposes, hyperspectral instruments, such as Hyperion onboard the Earth Observing-1 (EO-1) satellite, which provides 220 channels, can provide excellent data.

Even though both snow and clouds as seen from space are quite similar in the visible parts of the spectrum, there are clear differences in the Infrared Radiation (IR) wavelengths. An example of this is shown in the image pair in Fig. 1, which covers southern parts of the UK one day after heavy snowfall on December 10, 2017. Heavy snowfall caused material damages, traffic delays and hundreds of school closures. Two different versions of the same Suomi-National Polar-orbiting Partnership (NPP)/VIIRS scene are presented. In the true colour image, both snow and clouds appear practically white, even though for human observer there are subtle differences in the structural patterns. Snow and clouds are slightly different when IR channels are employed. Even though for human analysts the differences are easy to recognize, it is quite a complicated task to convert that knowledge to a format suitable for computers.

Clouds and snow are usually both highly reflective in the visible band of the electromagnetic spectrum, but in Near-Infrared Radiation (NIR) or ShortWavelength Infrared Radiation (SWIR) bands snow is highly absorptive, as seen in Fig. 2. Normalized-Difference Snow Index (NDSI), which is defined as:

$$
\text { NDSI }=\frac{R_{\text {visible }}-R_{\mathrm{IR}}}{R_{\text {visible }}+R_{\mathrm{IR}}},
$$

where $R_{\text {visible }}$ is reflectance on the visible band and $R_{\mathrm{IR}}$ reflectance on the IR band, is based on this difference. Depending on the instrument and the measuring bands available, pixels which are highly reflective on visual bands (either snow or clouds) can be classified as snow-covered if the NDSI value is over a suitable threshold and snow-free if NDSI is lower than the threshold.

NDSI or similar ratios have been used for snow detection quite a long time (Hall and Riggs 2011). However, NDSI snow detection needs improvements in local scale (discussed e.g., in Härer et al. 2018). In ideal conditions, NDSI provides good results, but in practice, the conditions are often far from ideal. For that same reason, reliable modelling of the radiative properties of the snow cover is difficult. In operational systems, there may be timeliness requirements which prevent the use of complicated and time-consuming methods. Therefore, an empirical approach can be beneficial in satellite snow detection.

In Europe, EUMETSAT is the organization responsible for the operating of the weather satellites. It operates both geostationary (e.g. Meteosat Second Generation (MSG)) and polar-orbiting (Meteorological Operational Satellite (Metop)) 


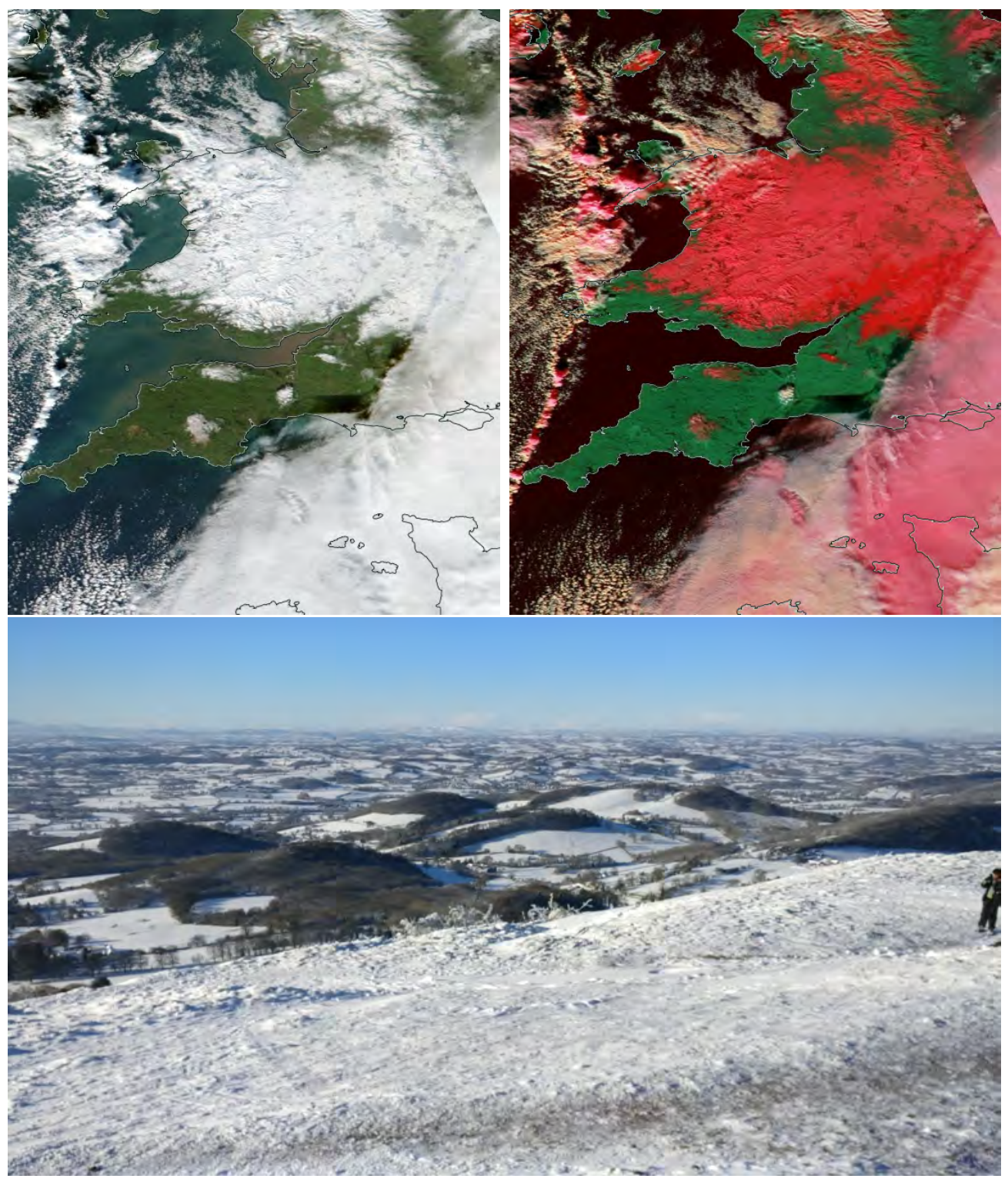

Figure 1 Example images from Suomi-NPP/VIIRS for December 11, 2017, one day after heavy snowfall in large parts of the UK. On the top left true colour corrected reflectance, on the top right corrected reflectance for bands M3-I3-M11 (490-1610$2250 \mathrm{~nm}$ ). Snow and clouds appear white on the left, but on the right the snow is bright red, clouds either white or pink. On the bottom, a view towards west from the top of The Beacon in Malvern, UK, which is located in the middle of the snow-covered area seen on the top. Suomi-NPP/VIIRS images by NASA Worldview. Photo: Niilo Siljamo (NS). 


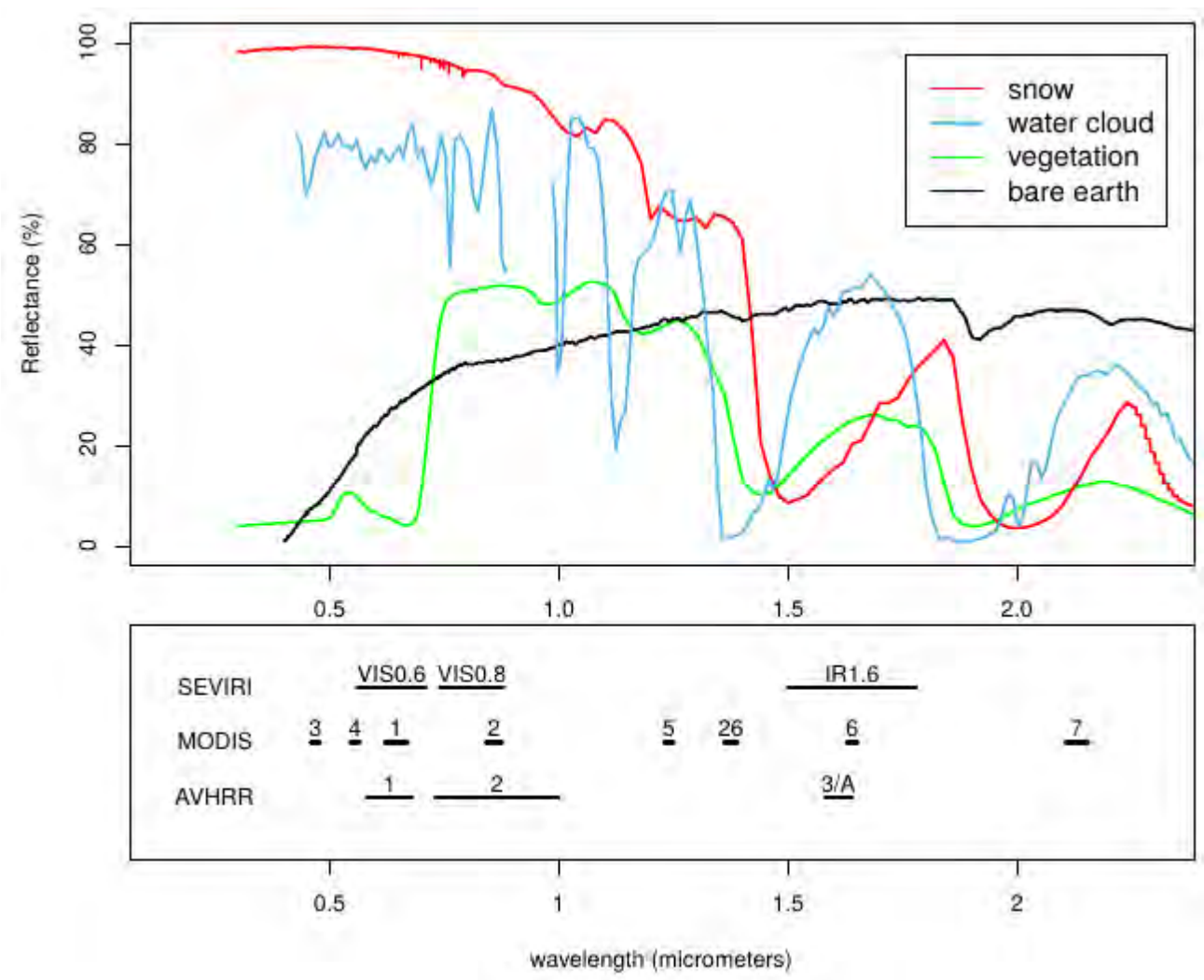

Figure 2 A rough sketch of the spectral reflectances of common ground types and a water droplet cloud with the channels of common meteorological satellite instruments. The reflectances of ground types are based on Baldridge et al. (2009) and the reflectance of a water cloud is based on an arbitrary image taken on 12 June 2010 02:08 UTC near Barbourville, Kentucky, United States using the hyperspectral Hyperion instrument onboard the EO-1 satellite. (Image from Hyvärinen 2011)

weather satellites. It provides data and products based on satellite data for many applications from the EUMETSAT Central Facility. In addition, there are several Satellite Application Facilities (SAFs), which are a distributed network of partly EUMETSAT funded consortiums responsible for operational, research and development activities (EUMETSAT 2020). They develop and produce additional products for specific user groups. For example, SAF on Support to Operational Hydrology and Water Management (H SAF) produces snow (such as SWE and snow extent), soil moisture and precipitation products. SAF for Land Surface Analysis (LSA SAF) 
provides shortwave and longwave radiation, albedo, wildfire, vegetation and Land Surface Temperature (LST) products. The SAFs focus on the use of the EUMETSAT satellite data, but in some applications, other data is used as well. The satellite snow product development and validation presented in this thesis has been done at first as part of the LSA SAF and later in the H SAF.

\subsection{PREVIOUS RESEARCH}

Remote sensing satellites can be used to cover the gaps in snow coverage observations. Even though the spatial resolution of the typical weather satellites is not suitable for high-resolution (about $100 \mathrm{~m}$ or better) snow coverage observations, at least the presence of snow can be detected. There are many previously published snow products and algorithms for different instruments onboard different satellites each with different purposes and merits (see e.g., Paper II). Several binary (snow/no snow) satellite snow products are available and there are also some fractional snow cover products developed e.g., by Metsämäki et al. (2012).

One well-known snow product is the Interactive Multisensor Snow and Ice Mapping System (IMS) which is provided by NOAA/National Environmental Satellite, Data, and Information Service (NESDIS) (Helfrich et al. 2007; Ramsay 1998), which is a high-resolution multisensor snow product. The IMS product is not based on a fully automatic algorithm; instead, the production employs human analysts who merge data from many different sources, including in situ data. Some validation results for IMS are presented in Chen et al. (2012).

There are many cryosphere products for polar-orbiting satellites operated e.g., by NOAA and EUMETSAT. As part of the AVHRR processing packages, there are often snow products (e.g., Dybbroe et al. 2005). Another method is suggested by Hüsler et al. (2012) for snow detection over the European Alps.

Snow products based on Moderate Resolution Imaging Spectroradiometer (MODIS) data have been described by e.g., Miller et al. (2005) and Notarnicola et al. (2013a,b). MODIS instruments are onboard the Terra and Aqua satellites which are nearing the end of their lifetime. MODIS will be superseded in many applications by the VIIRS onboard the NPP and the Joint Polar Satellite System (JPSS) satellites which have similar channels suitable for snow detection as MODIS (Miller et al. 2006). A snow product for VIIRS is published by Key et al. (2013). More details of the VIIRS snow detection are presented in Riggs et al. (2015). Riggs et al. (2017) describes both MODIS and VIIRS snow cover products. Snow products based on multiple instruments are presented e.g. by Hori et al. (2017) where an algorithm, product for AVHRR and MODIS and validation results from 38 years are presented. 
There are also some projects which provide or plan to provide snow products based on one or more satellite instruments (e.g., CryoClim (Solberg et al. 2009) and ESA CCI Snow (Wunderle et al. 2019)). The main product is often SWE, but also snow extent products are provided.

For other polar-orbiting instruments, Selkowitz and Forster (2015) presents a method for automatic mapping of persistent ice and snow for Landsat TM and ETM+. There is also a similar Sentinel program. Both Landsat and Sentinel have a repeat interval of several days which limits their use in daily snow detection.

Geostationary orbit does not provide good coverage in polar regions, but there are several satellites (such as Geostationary Operational Environmental Satellite system (GOES), Meteosat, FY-2, Himawari) with instruments which are well-suited for snow detection in mid-latitudes. Romanov et al. (2003) use GOES data for snow fraction detection and Li et al. (2007) uses it for snow and cloud detection. For MSG/Spinning Enhanced Visible and Infrared Imager (SEVIRI), there are several snow extent products, such as the one presented in Paper I (H SAF MSG/SEVIRI Snow Extent (H31)). Wang et al. (2017) suggest a fractional snow cover product for the FY-2 Visible and Infrared Spin Scan Radiometer (VISSR).

There are also other satellite instruments which can be used for satellite snow detection. For example, microwave radiometers are often used for snow products. While microwave radiometers do not require external illumination (i.e., sunlight) and cloud cover is transparent in microwave wavelengths, the spatial resolution of the microwave radiometers is quite coarse (10-15 km or more) when compared to visible and IR band radiometers. Also, microwave radiometers struggle with thin snow layers, especially in wet conditions, (Takala et al. 2009) and that is a limiting factor in meteorological applications where even a thin snow layer should be detected.

Quite often the primary snow product available is not snow extent or snow detection product. Other products can be used to estimate snow coverage with limitations. For example, SWE products such as the one presented by Takala et al. (2011), may need ancillary data in the product generation (in this case weather station snow observations).

In a recent paper, Walters et al. (2019) describe shortly the snow model used in the Met Office Unified Model and the Joint UK Land Environment Simulator. Recent developments of introducing the $\mathrm{H} 31$ product (the product described in Paper I) into that system was presented by Pullen et al. (2019). Similar trials using a variant of the H SAF Metop/AVHRR Snow Extent (H32) product are underway at the Finnish Meteorological Institute (FMI). 


\subsection{THIS THESIS}

The aim of this work was to develop daily operational satellite snow detection products for optical radiometers onboard the EUMETSAT MSG and Metop satellites as part of the LSA SAF and later the H SAF. During this work, two new snow detection methods were developed.

In the MSG satellites (pictured in Fig. 3), the radiometer is SEVIRI, which has 12 channels in optical and IR bands. In the first generation Metop satellites (Fig. 4), AVHRR is used. It has only 6 channels in optical and IR bands and channels $3 \mathrm{~A}$ and $3 \mathrm{~B}$ can not be used simultaneously. The properties of both AVHRR and SEVIRI channels are presented in Table 1.

These two different satellite snow detection products and algorithms used in processing them are presented in Papers I and II. These products were developed as part of the EUMETSAT-funded projects (SAFs) where the author has been responsible for the development of the snow detection products based on visual and IR channels. The products the author has been developing are targeted for operational meteorological applications, such as NWP where the accuracy of data is

Table 1 AVHRR and SEVIRI channels and frequencies. AVHRR resolution in nadir is $1.1 \mathrm{~km}$. AVHRR channels $3 A$ and $3 B$ are not available at the same time. SEVIRI resolution in nadir is $3 \mathrm{~km}$. SEVIRI channel 12 is a so-called High Resolution Visible (HRV) broadband channel which has a $1 \mathrm{~km}$ resolution. The channels used in the H SAF MSG/SEVIRI H31 (1, 2, 3, 4, 9, 10) and H SAF Metop/AVHRR H32 $(1,2,3 A, 4,5)$ algorithms are in bold.

\begin{tabular}{lc|lc}
\multicolumn{2}{c|}{ Metop/AVHRR } & \multicolumn{2}{c}{ MSG/SEVIRI } \\
Channel & Frequency $(\mu \mathrm{m})$ & Channel & Frequency $(\mu \mathrm{m})$ \\
\hline \hline $\mathbf{1}$ & $\mathbf{0 . 5 8 - \mathbf { 0 . 6 8 }}$ & $\mathbf{1}$ & $\mathbf{0 . 5 6 - \mathbf { 0 . 7 1 }}$ \\
$\mathbf{2}$ & $\mathbf{0 . 7 2 7 - \mathbf { 1 . 0 0 }}$ & $\mathbf{2}$ & $\mathbf{0 . 7 4 - \mathbf { 0 . 8 8 }}$ \\
3A & $\mathbf{1 . 5 8 - \mathbf { 1 . 6 4 }}$ & $\mathbf{3}$ & $\mathbf{1 . 5 0 - \mathbf { 1 . 7 8 }}$ \\
3B & $3.55-3.93$ & $\mathbf{4}$ & $\mathbf{3 . 4 8}-\mathbf{4 . 3 6}$ \\
& & 5 & $5.35-7.15$ \\
& & 6 & $6.85-7.85$ \\
& & 7 & $8.30-9.10$ \\
$\mathbf{4}$ & $\mathbf{1 0 . 3 0 - \mathbf { 1 1 . 3 0 }}$ & $\mathbf{9}$ & $9.38-9.94$ \\
$\mathbf{5}$ & $\mathbf{1 1 . 5 0 - \mathbf { 1 2 . 5 0 }}$ & $\mathbf{1 0}$ & $\mathbf{9 . 8 0 - \mathbf { 1 1 . 8 0 }}$ \\
& & $11.00-\mathbf{1 3 . 0 0}$ \\
& & $12(\mathrm{HRV})$ & $12.40-14.40$ \\
& & & $0.4-1.1$
\end{tabular}




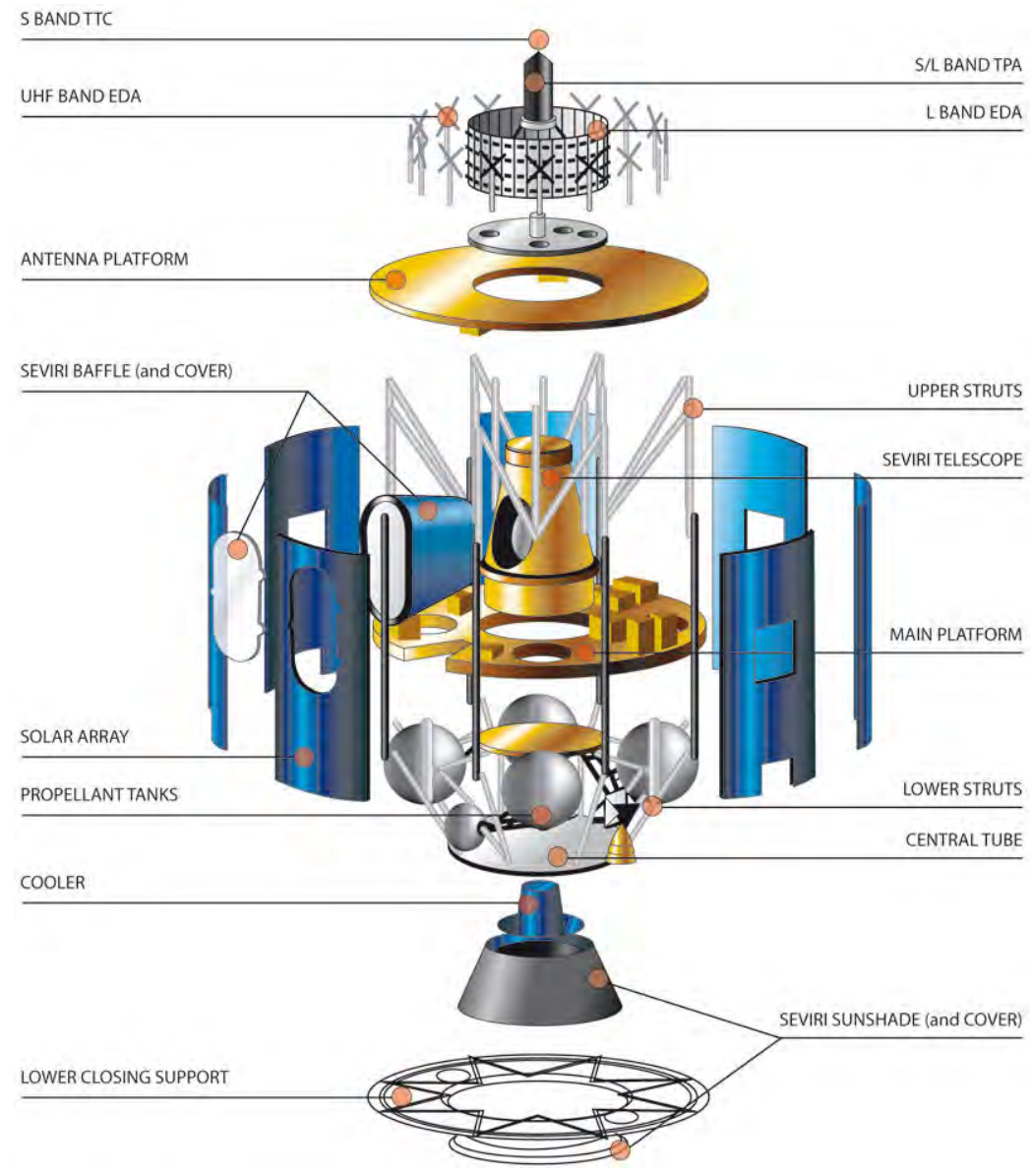

Figure 3 Schematic picture of the geostationary MSG satellite which has the SEVIRI instrument on board. Image CEUMETSAT 2020

preferred to the completeness of the coverage. Paper III and Paper IV describe the background of the work in a larger context and Paper $\mathbf{V}$ touches on the practical side of the snow research.

The author gained practical experience of snow measurements in the Snow Reflectance Transition Experiment (SNORTEX) campaign near Sodankylä, Finland during the winters 2008-2010 when he took part in snow measurements in situ (e.g., snow pit measurements). Some of these measurements are described in Paper V. The SNORTEX campaign is described in more detail in Manninen and Roujean (2014). During the SNORTEX campaign, aerial photos were taken by a directly downward-pointing automatic camera system described in Manninen et 


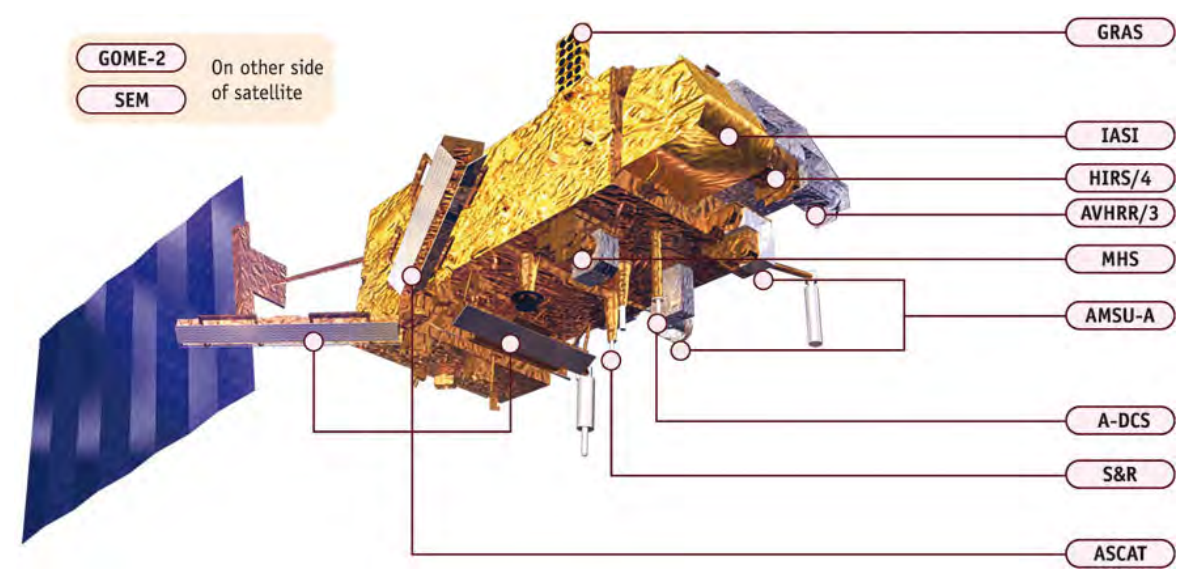

Figure 4 Schematic picture of the polar-orbiting Metop satellite which has many instruments onboard. Only the AVHRR/3 instrument is relevant in this work. Image CEUMETSAT 2020

al. (2009) and Manninen et al. (2012). Some of these photos are shown later in Figs. 6, 8, 10 and 11 which present examples of the different features of the snow cover.

Before SNORTEX, the author participated in an aerial measurement campaign in Sodankylä in spring 2004. It was an especially educational experience to see the complexity of the snow cover from a helicopter flying at different altitudes. During that campaign, the author took photographs which illustrate the typical features of the snow cover in boreal forests which must be taken into account when developing satellite snow products.

In situ observations from weather stations can be complemented by a wide spectrum of snow measurements made during snow measurement campaigns. Paper $\mathrm{V}$ describes snow surface roughness measurements which were made as part of the SNORTEX campaign. Some experiments to measure snow coverage using different methods were also made during and after SNORTEX, but these results have not been published.

Two of the SAFs are relevant for this work. At first, snow products were developed by Swedish Meteorological and Hydrological Institute (SMHI) in the LSA SAF which is still processing the products described in Papers I and II. During the development of the first version of the MSG/SEVIRI snow product, FMI took over the responsibility of these snow products. Paper III gives a general view of the LSA SAF after the first products, including one snow product (MSG/SEVIRI, Version 1), had reached operational status. The paper also presents validation 
results based on comparison with the NOAA/NESDIS IMS product, which were updated for a slightly longer period in Paper IV. Later, all LSA SAF snow products were transferred to $\mathrm{H}$ SAF even though the processing and distribution of the transferred products remain in the LSA SAF.

Paper IV presents comparison results of several snow products based on satellite data and NWP model analyses before the development of the products described in Papers I and II. In that paper, two pure satellite snow products (MODIS and MSG/SEVIRI, Version 1), two NWP snow analyses (European Center for Medium-Range Weather Forecasts (ECMWF) and HIRLAM) and the IMS snow product were compared. The results suggested that NWP snow analysis would greatly benefit from satellite-based snow cover information.

The targeted users of the snow products developed in the LSA SAF were NWP and other meteorological applications. Discussions with NWP experts confirmed that they prefer uniform single instrument products that do not employ other data sources, such as surface observations. This has been kept in mind during the development of the H31 and H32 products. Often, these requirements exclude snow products which are calibrated by surface observations (e.g., SWE).

The first version of the MSG/SEVIRI snow product was a simple by-product of cloud masking, which had practically no room for improvements in the snow detection. The idea of an empirical approach (described in more details in Chapter 3 and Paper II) to the satellite snow detection had been formed and the algorithm development started before the writing of Paper IV. The second redesigned version of the MSG/SEVIRI snow detection algorithm (and operational code) was developed in 2007. The necessary review process of operational products with validation is time-consuming and the second version did not reach operational status until April 2009. This product is currently available as H SAF H31 (MSG/SEVIRI) snow extent product and is described in Paper $\mathbf{I}$.

A similar snow detection product was planned for the Metop satellites. The first Metop satellite reached operational status in May 2007, but the development of the Metop/AVHRR product did not start until some time after the MSG/SEVIRI product reached operational status. The same development philosophy was used and the production of the current H SAF H32 (Metop/AVHRR) snow extent product started in 2016. The year 2015 was backprocessed. Operational status was reached in July 2018. This product and validation results based on weather station data are presented in Paper II.

In the following chapters of this thesis, the focus is on the empirical approach to satellite snow detection development described in Papers I and II. 


\section{A VIEW FROM ABOVE}

The introductions of Papers I and II describe shortly the characteristics and the difficulties of the snow cover measurements from the viewpoint of the satellite snow product developer.

Snow cover is highly variable both in time and space. The photo in Fig. 5 shows many typical variable features that complicate snow detection. First, there are scattered clouds and shadows of clouds, which can be a source of misclassifications, especially in cases when small clouds cover parts of the grid cell. Secondly, the patchwork of fields, forests and towns create small scale variability which is easy to recognize in high-resolution images such as aerial photos, but in lower resolution weather satellite imagery these small-scale features blend into each other.

In general, much of the surface variability is in the scales much smaller than

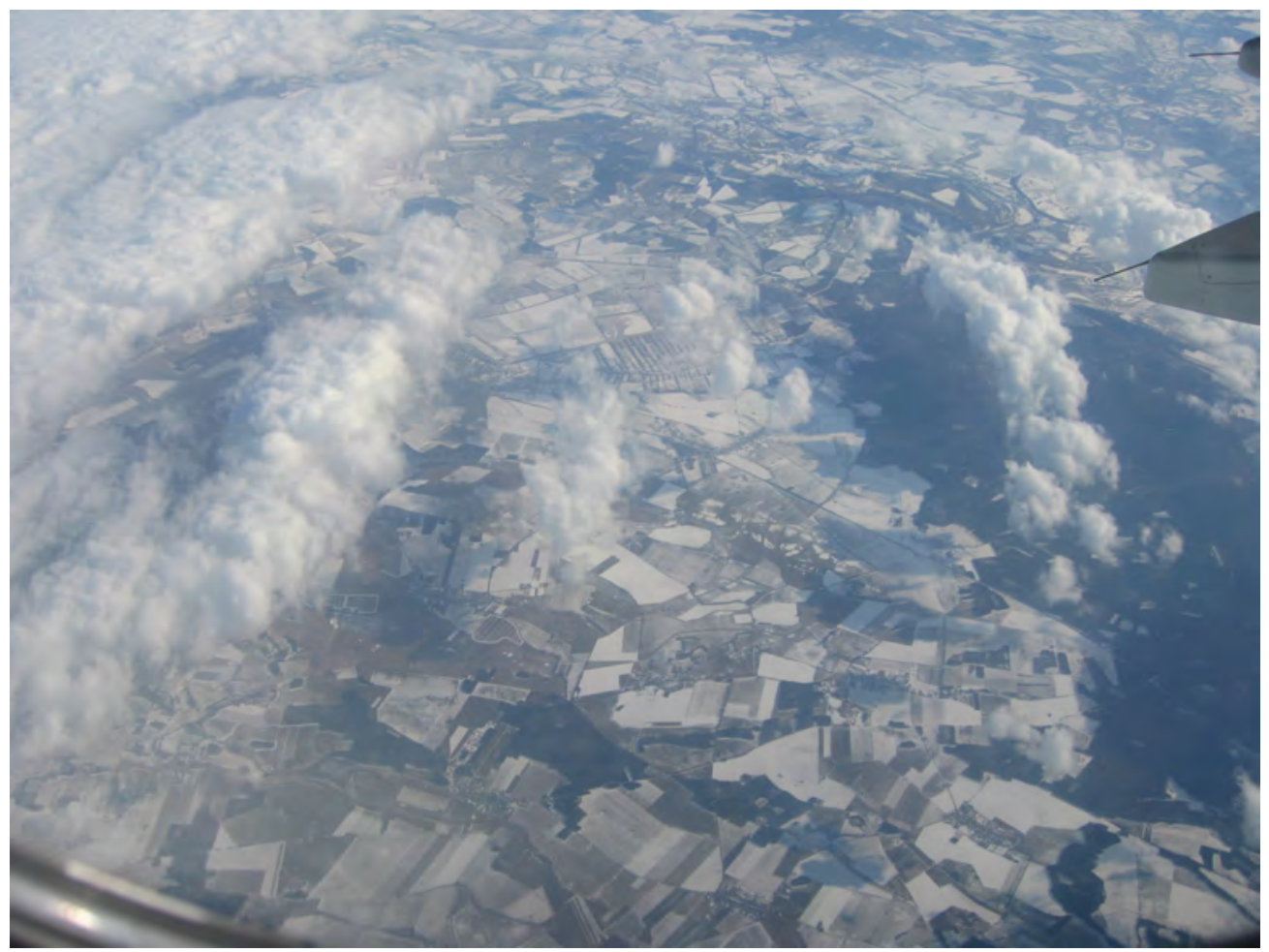

Figure 5 Aerial view of the snow-covered landscape in Germany in March 2006. The photo shows the highly variable and almost chaotic nature of the snow-covered view seen from satellites. Many features complicating the snow detection are present, such as clouds, shadows, variable vegetation and forests. Photo: NS. 

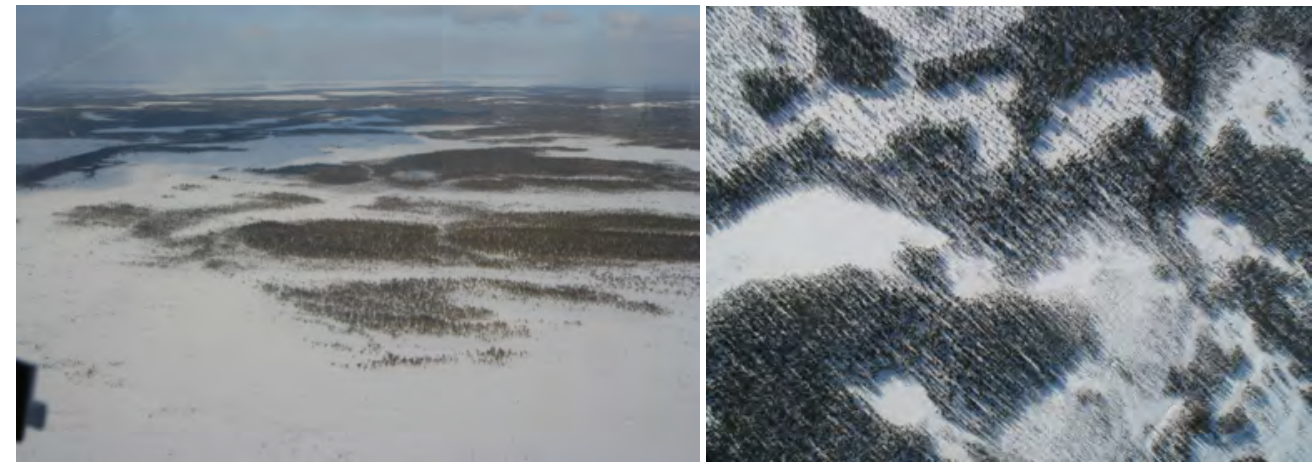

Figure 6 The size of the trees and tree densities vary in forests. A single satellite pixel is usually a mixture of forests, fields, lakes and other land cover types. Photo: left NS, right FMI.

satellite resolution (Metop/AVHRR $1 \mathrm{~km}$ at nadir, MSG/SEVIRI $3 \mathrm{~km}$ at nadir), especially when the satellite is near the horizon. The surface inside one satellite pixels is practically always a mixture of open areas, forests, lakes and built-up areas when larger water bodies are excluded. This is especially relevant for geostationary satellites, such as MSG, because much of the seasonal snow is near the edge of the detection disk where the resolution can be much lower (about $6 \mathrm{~km}$ in Britain and about $10 \mathrm{~km}$ in Southern Finland for MSG/SEVIRI). Still, there is annual seasonal snow in the flatland areas in lower latitudes in the Middle East, the Tibetan Plateau and, as an example from Africa, in Lesotho in southern Africa (Wunderle et al. 2016), which snow cover algorithms should detect.

Forests are highly variable in themselves (see e.g., Crowther et al. 2015). There are many kinds of trees which form the canopy and changing understory with twigs and shrubs. Sometimes trees grow in dense forests, but in other areas, trees are sparse and even then small in size. Deciduous forests are often practically transparent from satellites during the winter when trees are leafless, but evergreen forests can prevent snow detection almost completely. The photos in Fig. 6 present the effect of variable forest density and tree size in Finnish Lapland. The effects of the vegetations, especially the forest canopy, are discussed in Manninen and Jääskeläinen (2018) where they show that snow is darker at the forest floor than in open areas even when the snow itself is not different. This effect is visible in the photo presented in Fig. 11.

Two especially interesting phases of the seasonal snow cycle from the snow detection point of view are new snow on bare ground and the melting season when bare patches start to appear in the continuous snow cover. New snow layers may be very thin and may not cover the surface completely. This is especially 

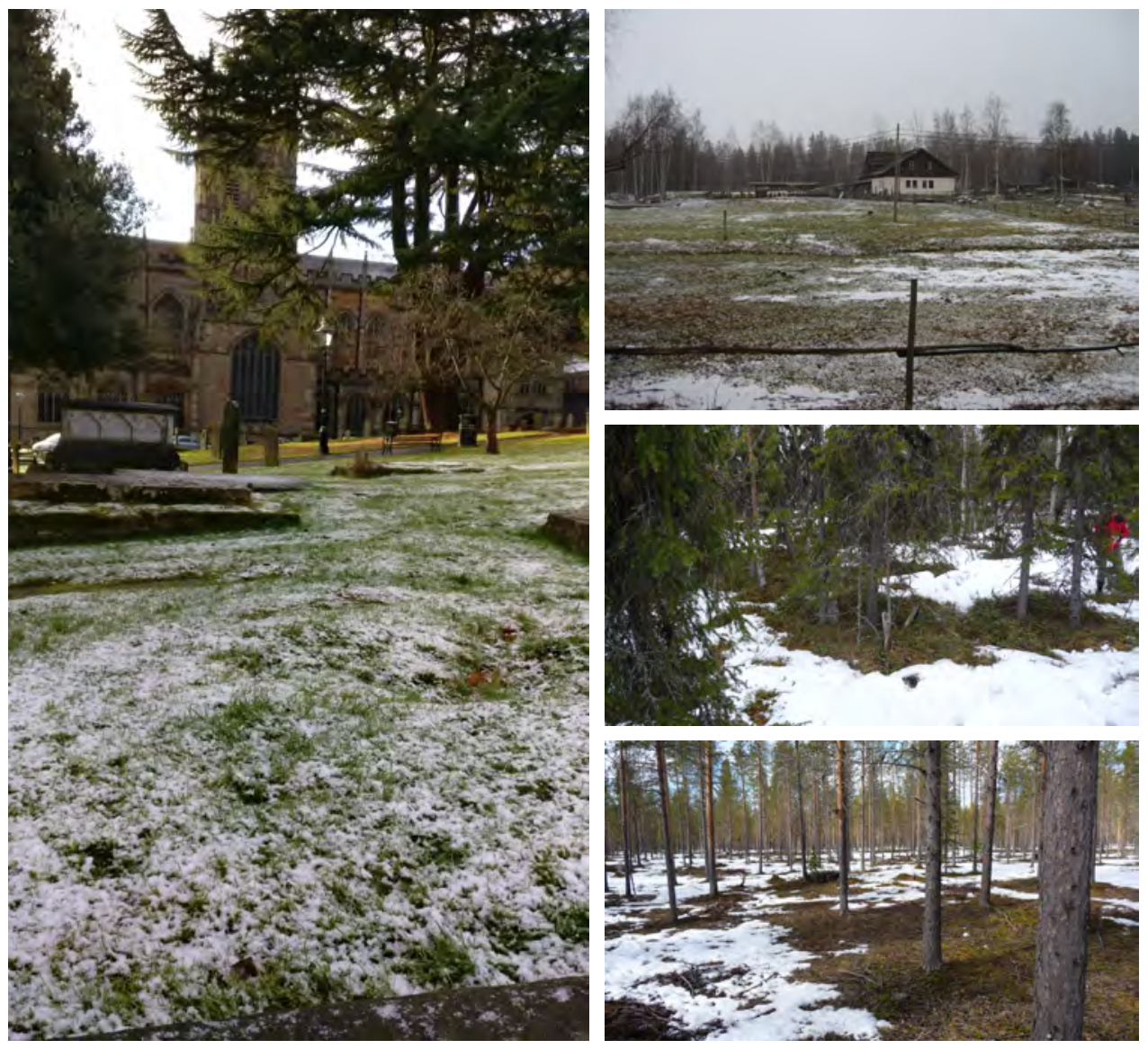

Figure 7 New snow layers are often thin and uneven (photo on the left and top right). Snow cover is especially variable during the melting season when smalland large-scale melting patterns mix and some areas are completely snow-free and others are still almost fully snow-covered (two photos on the right, middle and bottom). Photos: NS.

common in very rough areas where snow tends to accumulate in sheltered spots or near obstacles during windy weather, but even on grass unevenness can be seen (examples in Fig. 7, left and top right). When snow melts, the first snowfree patches are often the thaw circles which form around obstacles such as tree trunks and stones (seen in the top left in Fig. 8). Snow melts faster also on sunny slopes. Melting continues unevenly until snow can be seen only in some sheltered cold spots or in places where larger amounts of snow have accumulated. This can 


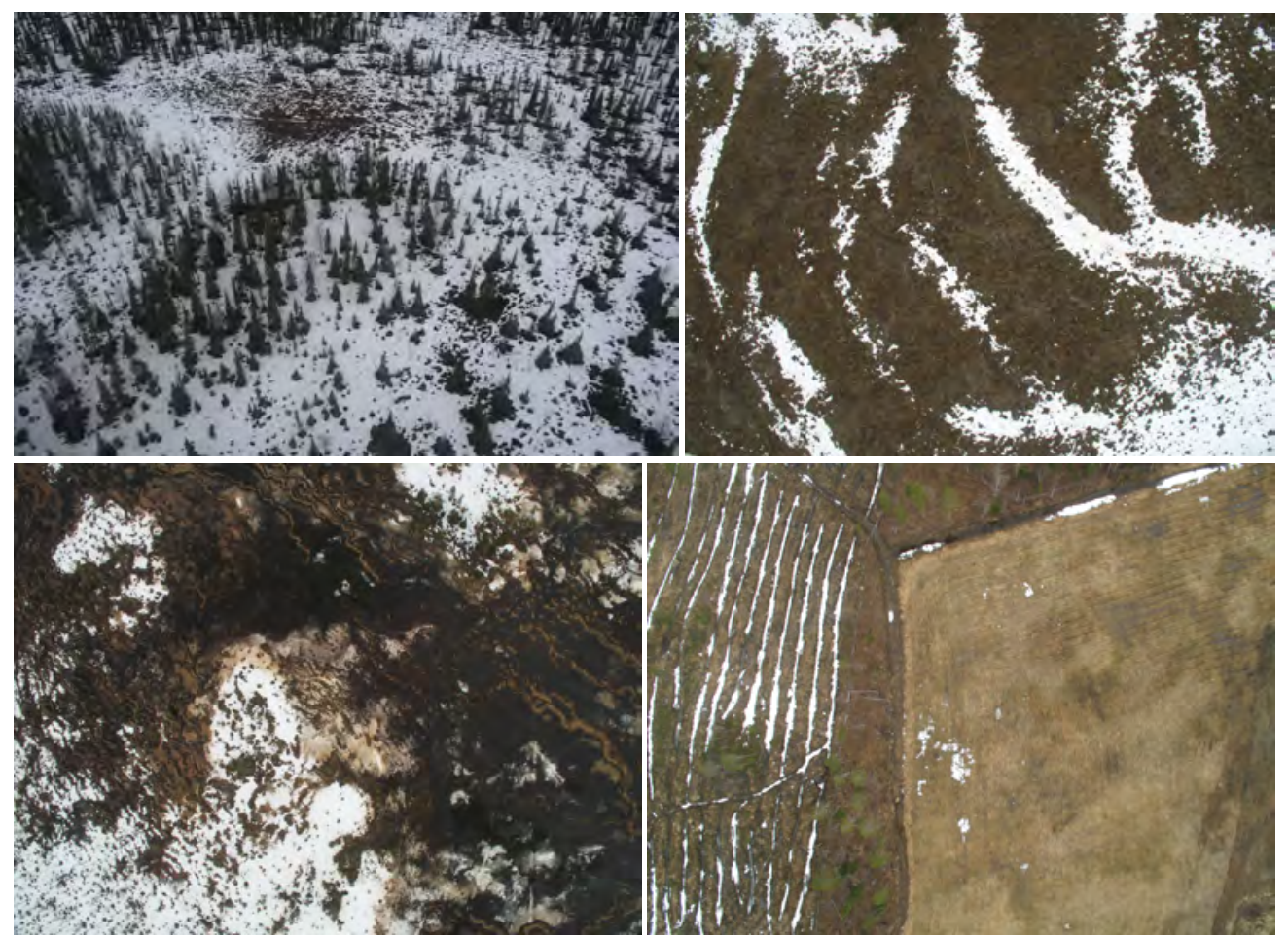

Figure 8 Melting patterns seen from a helicopter. Note the melt patches around the tree trunks on the top left photo and melting water covered bog on the bottom left. Snow in ditches is the reason for the striping in the bottom right photo. Photos: FMI except top left NS.

be seen quite well in the bottom right photo in Fig. 8, where snow in ditches is seen as white stripes. During the melting, meltwater can cause local flooding and sometimes, especially in wetlands near lakes and rivers, a mixture of snow and water can cover large areas (example in Fig. 8).

Another reason for the variability is the snow on trees. Examples are shown in the photos in Fig. 9. This phenomenon is often short in duration because temperature changes and wind can clear the trees soon after the snowfall, but at least some snow may stay on trees even days or weeks. Snow on trees can have a significant role in the snow detection when evergreen canopy is covered by snow, but it also has a role in deciduous forests when the snow sticks on the tree trunks and branches.

Much of the variability is on the surface itself but parts of the variability are more or less related to the observing technology (viewing angles, resolution). In 

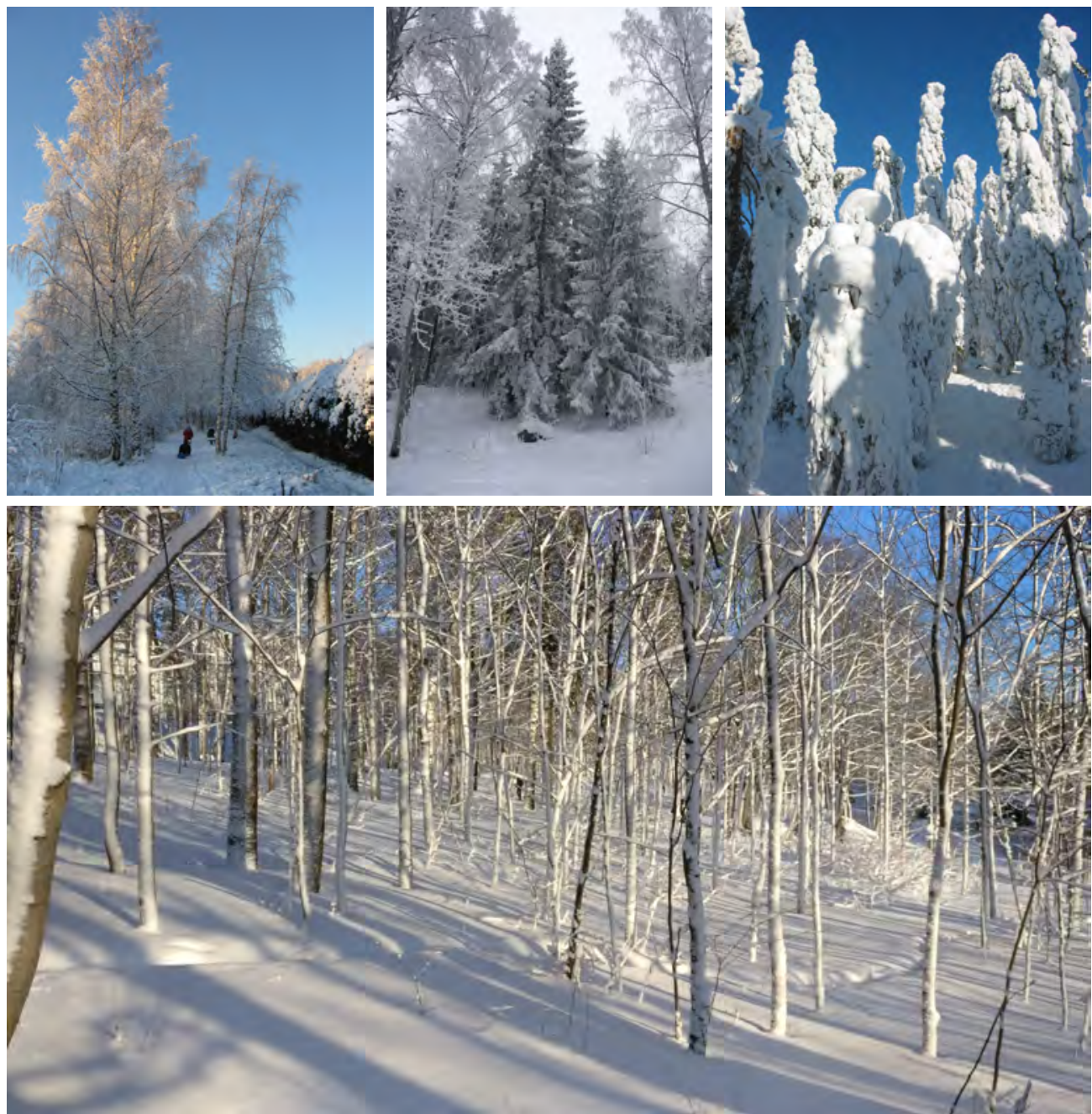

Figure 9 Snow on trees. In the top right and middle, evergreen trees, in the top left and bottom, deciduous trees. In the top right, so-called tykky which forms in special conditions covers fir trees almost completely. Example of snow stuck on the tree trunks in the photo below. Photos: top right Pirkko Pylkkö, others NS. 


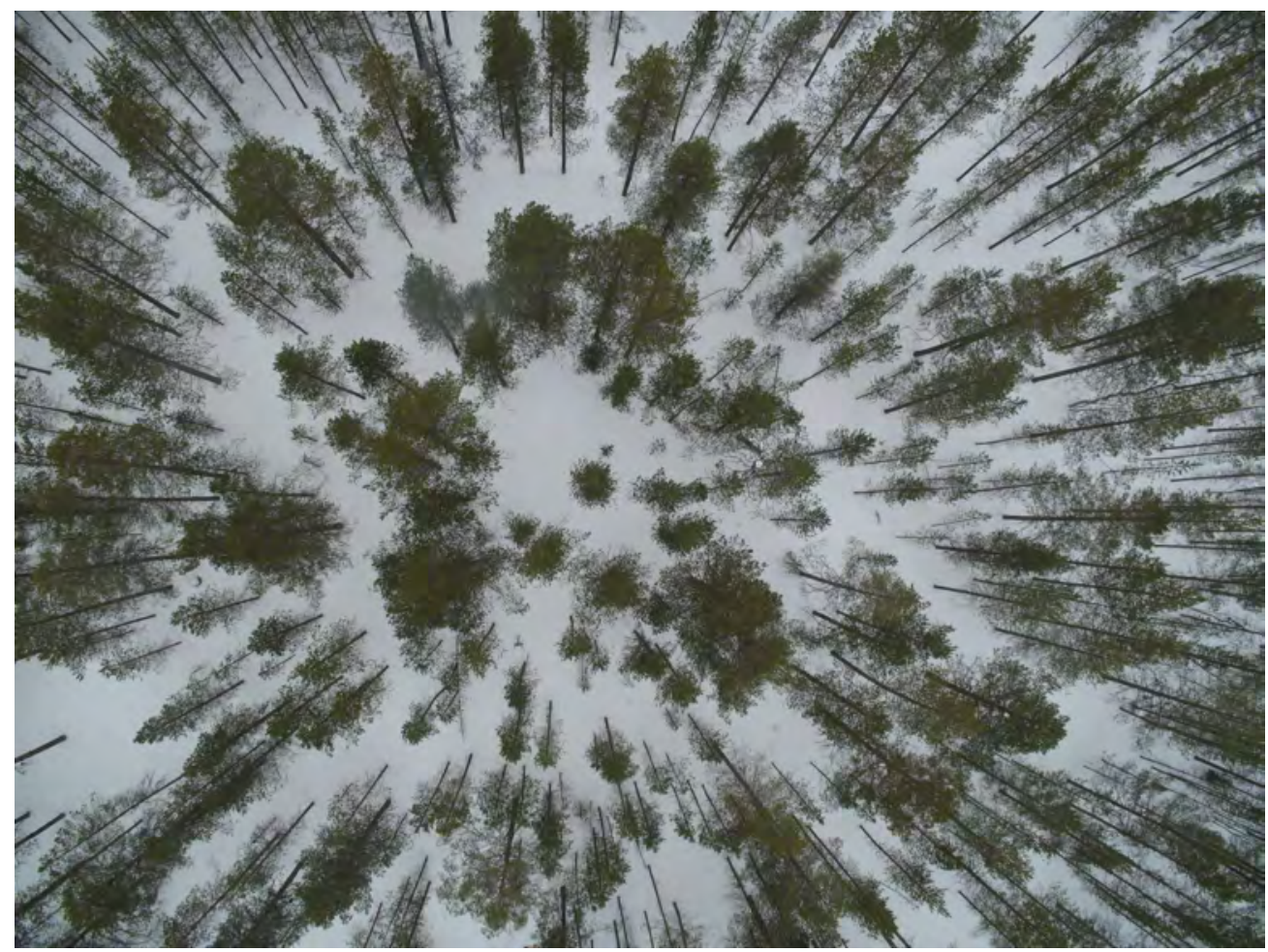

Figure 10 The viewing angle changes the view from satellites. In nadir, trees cover only the small area under the tree, but when seen from angles near the horizon, the surface area obscured by one or more trees is much larger. The area directly under the tree is not visible in nadir, but not covered when seen from a higher angle. Photo: FMI.

addition, there are large-scale features, which limit the use of optical remote sensing (clouds, darkness). Even though satellites detect the surface from high altitudes (Metop about $817 \mathrm{~km}$ and MSG about $35786 \mathrm{~km}$ ), the viewing angle can be quite high near the edge of the swath (polar satellites) or near the edge of the detection disk (geostationary satellites). One characteristic difference between geostationary and polar satellites is that the former always see a certain location from the same angle while the latter observe the surface from a different angle every time. The significance of the viewing angles is illustrated by the photo in Fig. 10 where the trees near nadir cover only a small area directly under the tree while the trees away from nadir cover bigger area behind the tree but the area just under the tree is visible. At very low angles, there may be many trees between the camera (or radiometer) and the surface. 

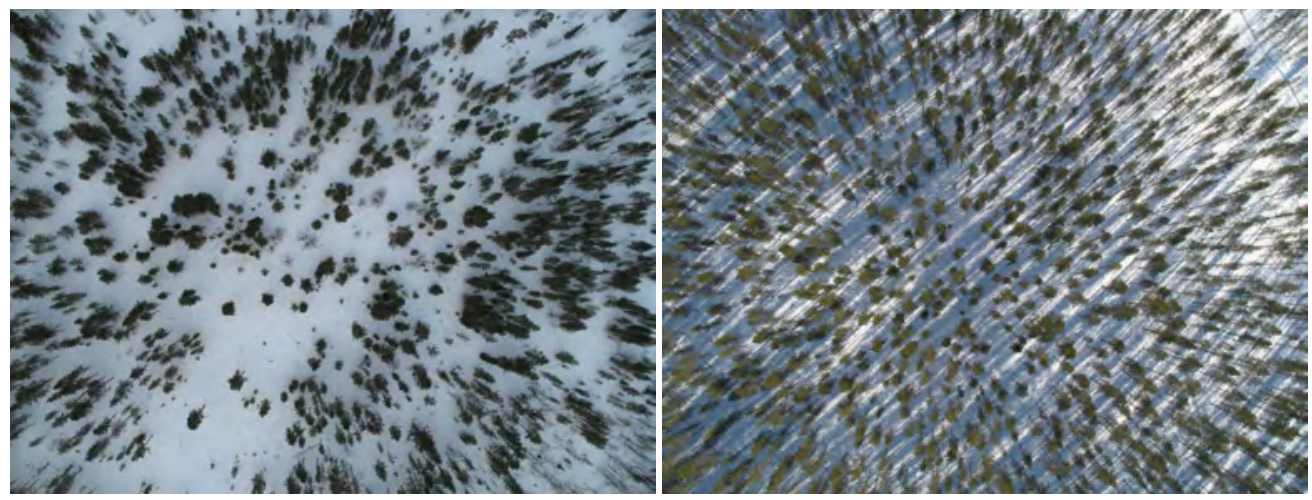

Figure 11 Photo on the left shows that in cloudy conditions snow cover between trees is evenly grey or white. The darkening effect between trees in dense spots is also visible. However, in clear sky conditions which are required for optical satellite snow detection, shadows of the trees create highly variable lighting over the snow cover (photo on the right). Photos: FMI.

Satellite instruments using optical and IR channels for snow detection require clear sky conditions. As shown in the photo in Fig. 5, clouds cover the surface and prevent snow detection. Sometimes thin cloud layers are transparent and snow detection may be possible, but this may be difficult to achieve by automatic algorithms. On the other hand, cloud-free conditions during the day mean that there are shadows. Especially in high latitudes where the sun is near the horizon during the snow season, shadows can cover much of the surface as seen in Fig. 11.

The use of the optical instruments requires that the surface is illuminated. This is a serious problem during the winter when long nights make the snow detection difficult or impossible in snow-covered polar regions (see Fig. 12) even in cloud-free conditions. There are some instruments (e.g., VIIRS onboard SuomiNPP and JPSS satellites) with special day/night channel, which may have potential for nighttime snow detection together with other channels used for removing fog and clouds. At the moment, such channels are not planned for EUMETSAT satellites. 


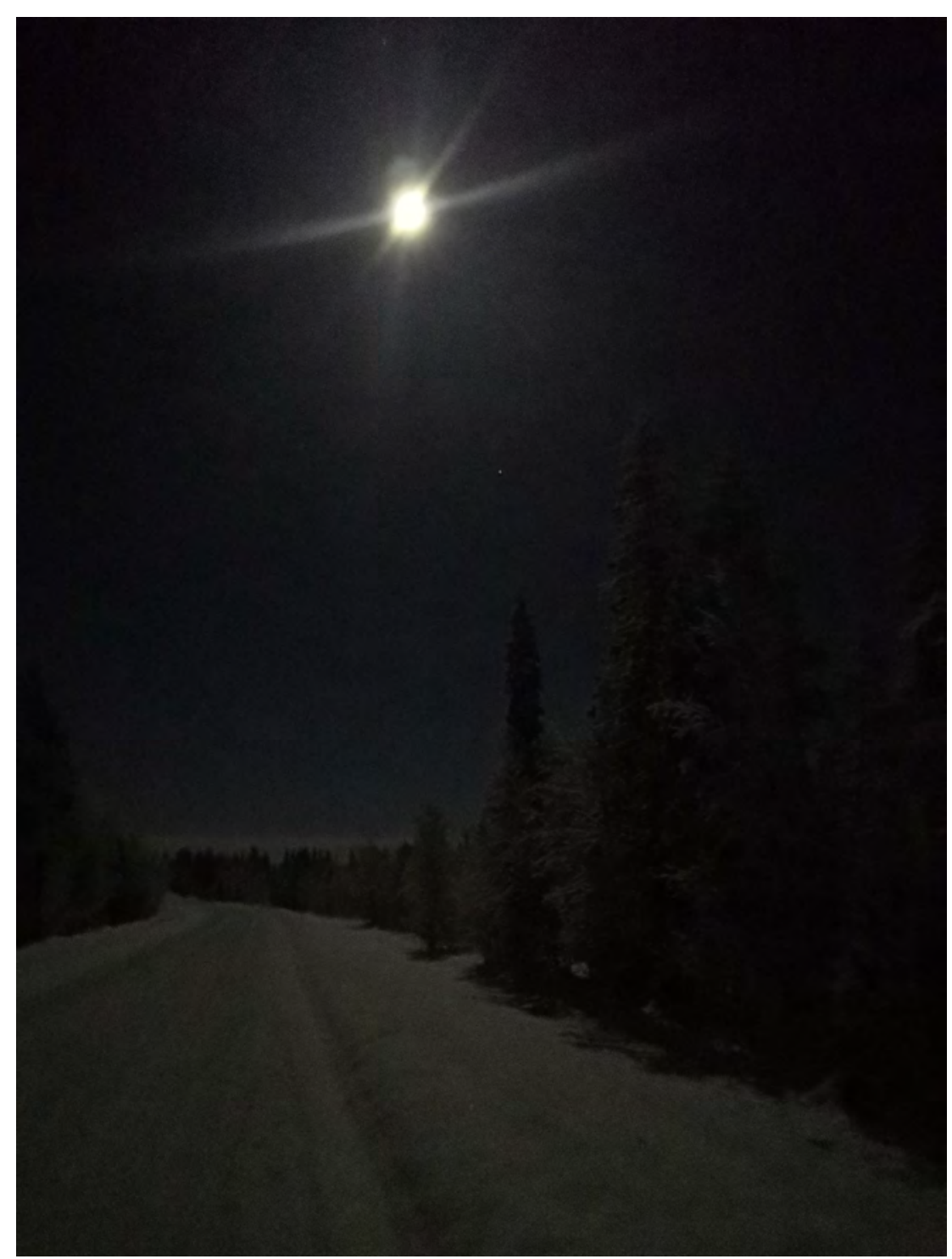

Figure 12 Moon shining during the polar night in Muonio, Finland. Snow-covered surface is visible, but the moonlight is not bright enough for the instruments used in the algorithms presented in this work. In the future, satellite snow algorithms may employ day-night band data provided by some instruments, such as VIIRS. Photo: Merikki Lappi. 


\section{ALGORITHMS}

\subsection{EMPIRICAL APPROACH}

The H31 and H32 snow products have been developed for meteorological applications, especially NWP. The main principles considered during the development were:

directness Snow cover classification is done first without any kind of preceding cloud masking which could introduce additional limitations and even errors to the snow detection algorithm. The algorithm aims at finding snowcovered and snow-free pixels, other pixels are set as unclassified.

accuracy Snow cover classification aims at accuracy instead of coverage. While in many other applications, large coverage is preferred, this approach is preferred by the NWP community (C. Fortelius and L. Rontu, personal communication at FMI).

single-source data Only satellite data from a single instrument will be used. Limited use of static data (such as land cover classification) and other products based on the same instrument and processed in the same system (such as LSA SAF LST) is possible.

In the Introduction, some of the features and phenomena which make the satellite snow detection a rather complicated task were described. The complexity of the snow cover suggests that there are no simple analytical methods for snow detection which work in all areas and in all snow cover conditions. Thus, an empirical approach may be more appropriate and better suited for satellite snow detection. However, the empirical approach requires much more work at the start of the development process, because there must be observations which are the basis of the algorithm.

The empirical approach means that the product is not based solely in such concepts as NDSI or similar simplified ways to distinguish snow-covered and snowfree surfaces or clouds, as there are lots of borderline cases, which may not be classified correctly by such methods.

As described in Papers I and II, the development of both algorithms was started by creating a subjectively classified data set using the data from the instrument for which the algorithm will be developed. These development data sets were created by manually classifying a large number of pixels in satellite images to different classes and then collecting all available data from those pixels (radiances, brightness temperatures, land use, sun and satellite angles etc). This development data set can then be analyzed in many ways to find out the best ways to detect snow and 
snow-free pixels. The development data sets created consist of a large number of manually classified pixels. The MSG/SEVIRI data set has about 509,000 and the Metop/AVHRR dataset about 609,000 classified pixels which cover different land cover types, different snow conditions and different cloud-covered pixels.

\subsection{PROCESSING CHAIN}

A generalized flow chart of the $\mathrm{H} 31$ and $\mathrm{H} 32$ snow product generation is presented in Fig. 13. As the aim was to develop a daily snow detection product, the product generation was split into two phases. The first phase (SC1) is the snow detection in a single satellite image. In the case of H31, this single image product is generated every 15 minutes for the full MSG/SEVIRI disk. Every day there will be 96 single image snow products covering the same area. In the H32 product, the single image product is generated every three minutes for each Product Dissemination Unit (PDU). During one day, there are 480 such images, which cover practically the whole surface of the Earth.

The second phase (SC2) consists of the necessary operations needed to combine single image products into one daily snow extent product. For the H31, this means counting the different classifications in each pixel in all 96 images and then deciding the final daily classification for each pixel. This is a straightforward process, which is described shortly in Table 3 in Paper I.

For the H32, the process required for the generation of the global daily product is slightly more complicated because every PDU snow product covers a different part of the globe. The daily product is created by reprojecting each PDU product pixel from oldest to youngest to the $0.01 \times 0.01$ degree lat-lon grid and then applying some smoothing based on $3 \times 3$ pixels around each pixel in the lat-lon grid (see details in Table 4 in Paper II).

Production in two phases has the additional benefit of flexibility which was not anticipated at first. Even though the original requirement described in the project documentation is to produce daily products in predefined grids (satellite grid for H31 and global lat-lon grid for H32), intermediate SC1 products can be used to generate additional or tailored products for specific users. For example, the intermediate H32 SC1 product can be used to produce "snow barrels" i.e. $10 \times 10$ pixel distributions which may be better suited for NWP data assimilation, but the feasibility studies are still underway.

Both H31 and H32 are produced in the LSA SAF processing environment. Products are distributed via EUMETCast and are also available from the LSA SAF website in HDF5 format. 


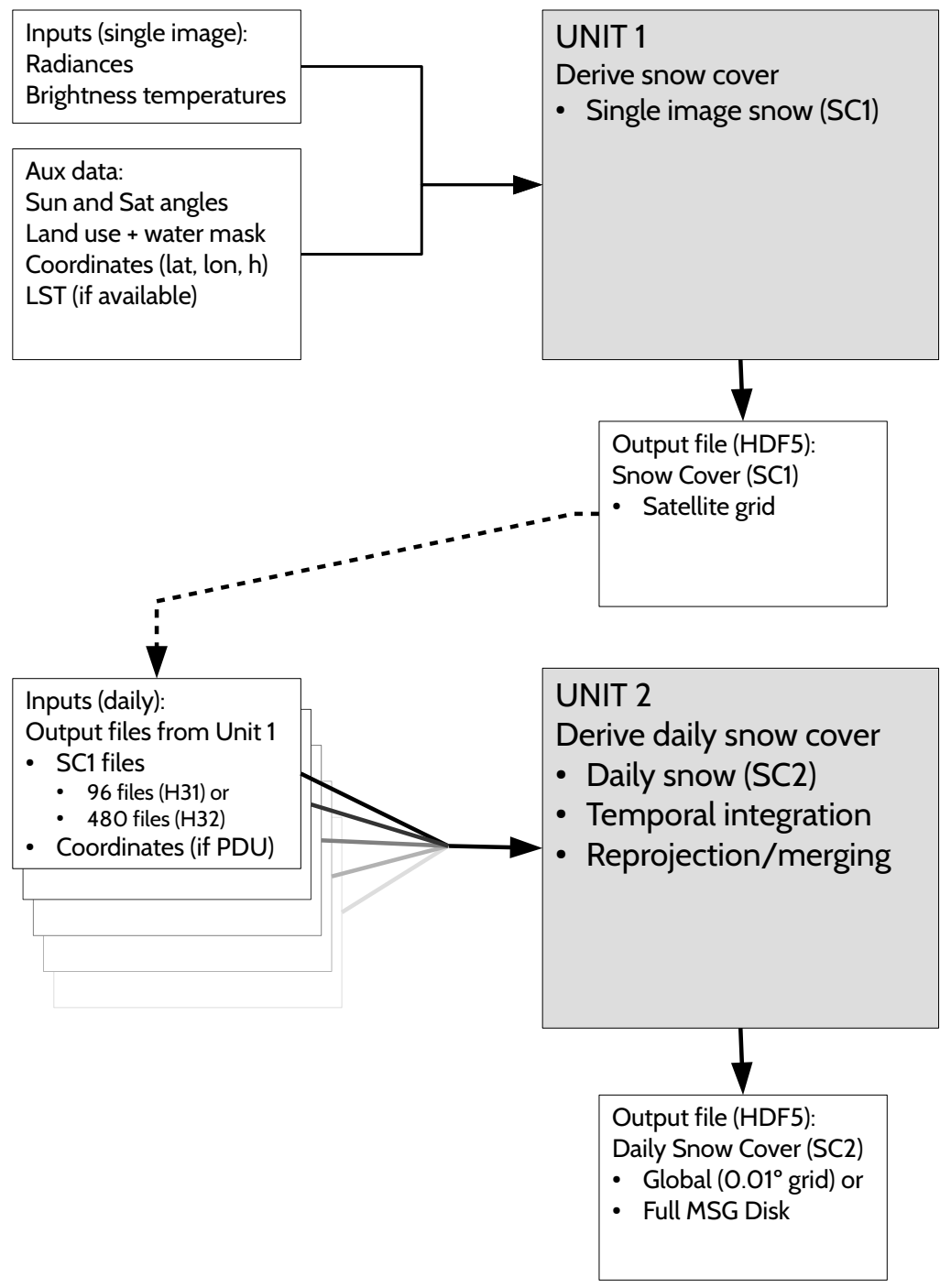

Figure 13 Simplified flow chart of the processing of the H31 (MSG/SEVIRI) and H32 (Metop/AVHRR) snow products. In both versions, single image snow products (SC1, mainly for internal use) are produced when new images are available (every 3 minutes for H32 and every 15 minutes for H31). At the end of the day, single image products are merged and daily snow cover files (SC2) are produced, distributed and archived. 


\subsection{ALGORITHM DEVELOPMENT}

In the LSA SAF production system, radiances and brightness temperatures of different channels are readily available. When the algorithm development started, the development data was collected from these files without converting the data to reflectances. Because practically all of the classification rules are based on channel ratios or ratios of channel differences, this perhaps poor choice was not fatal and the algorithm development was successful. Later, when the H32 algorithm was modified for testing purposes to use the AVHRR Global Area Coverage (GAC) data, reflectances were converted to radiances and the modified algorithm could be used successfully.

The development data sets were analyzed and visualized so that classification rules could be developed. Fig. 14 from Paper I, shows one way to present the collected data. The data can be presented as 2D and 3D plots of channel ratios, channel differences or any other combination of collected data so that methods

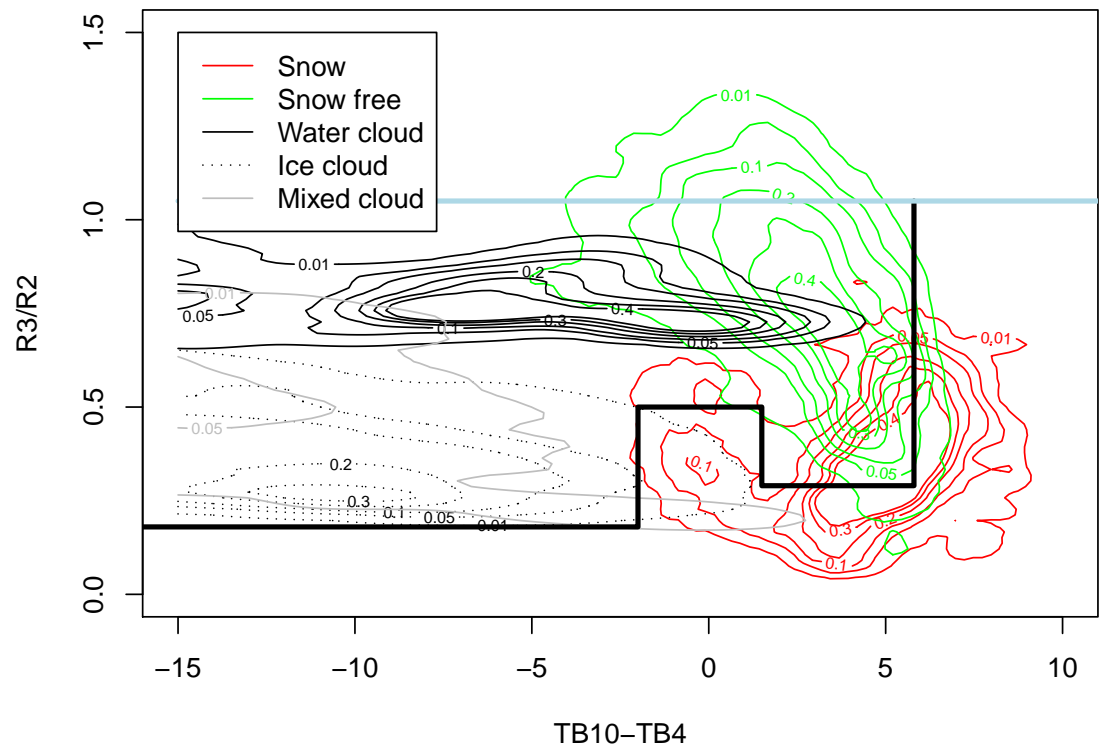

Figure 14 Example of the probability densities of the scatterplots based on the development dataset for MSG/SEVIRI (radiance ratio $R_{3} / R_{2}$ vs brightness temperature difference $\left.\Delta T_{B}=T_{B 10}-T_{B 4}(\mathrm{~K})\right)$. The thick black and blue lines show thresholds for SNOW (black) and NO SNOW (blue), based on the rules used in the MSG/SEVIRI algorithm. SNOW: rules (R9)-(R12) and NO SNOW: rule (R14) as described in Paper I. (Excerpt of Figure 1 in Paper I). 
separating different classifications can be found. The example in Fig. 14 shows a 2D probability density plot of the brightness temperature difference of the SEVIRI channels 10 and 4 and radiance ratio of the channels 3 and 2 (see Table 1).

Use of the MSG/SEVIRI channels 2 and 3 is based on the differences of the spectral properties of snow and clouds on these channels in a similar way as in NDSI. Similarly, the brightness temperature difference of channels 10 and 4 helps in separation of snow and clouds. As can be seen in the figure, different classifications have some overlap, but different clouds, snow free surface and snow covered surface typically have different distributions in this plot. The black and blue lines in the figure present some of the classification rules relevant to this density plot. Other rules are needed to improve the classifications in overlapping cases.

During the development, different algorithm candidates were used to create snow cover images which were then compared to RGB images or sometimes to other satellite products to find out any kind of misclassifications. In some cases, Google Streetview images were used to see the surface features present in the area. Based on the results, the algorithm candidate was modified so that the classifications could be corrected or, in some cases, completely removed. The stable and final SC1-phase algorithm versions consist of 21 and 23 rules for the MSG/SEVIRI and Metop/AVHRR products, respectively.

During the development of the SC1 algorithms, the development of the daily algorithm was also started. The algorithm used to merge single image SC1 products to create the daily H31 MSG/SEVIRI product consists of 7 rules. For the daily H32 Metop/AVHRR product, the SC1 products must first be reprojected to a global grid and then smoothed using an algorithm consisting of 12 rules.

The complete snow extent algorithm consisting of the single image and daily parts for the H SAF MSG/SEVIRI H31 product is presented in Paper I and for H SAF Metop/AVHRR H32 in Paper II. They are also described in the official product documentation available on the LSA SAF and H SAF websites.

Examples of the H31 and H32 products for March 22, 2019, are shown in Figs. 15 and 16, respectively. 
MSG/SEVIRI snow cover 22.3.2019

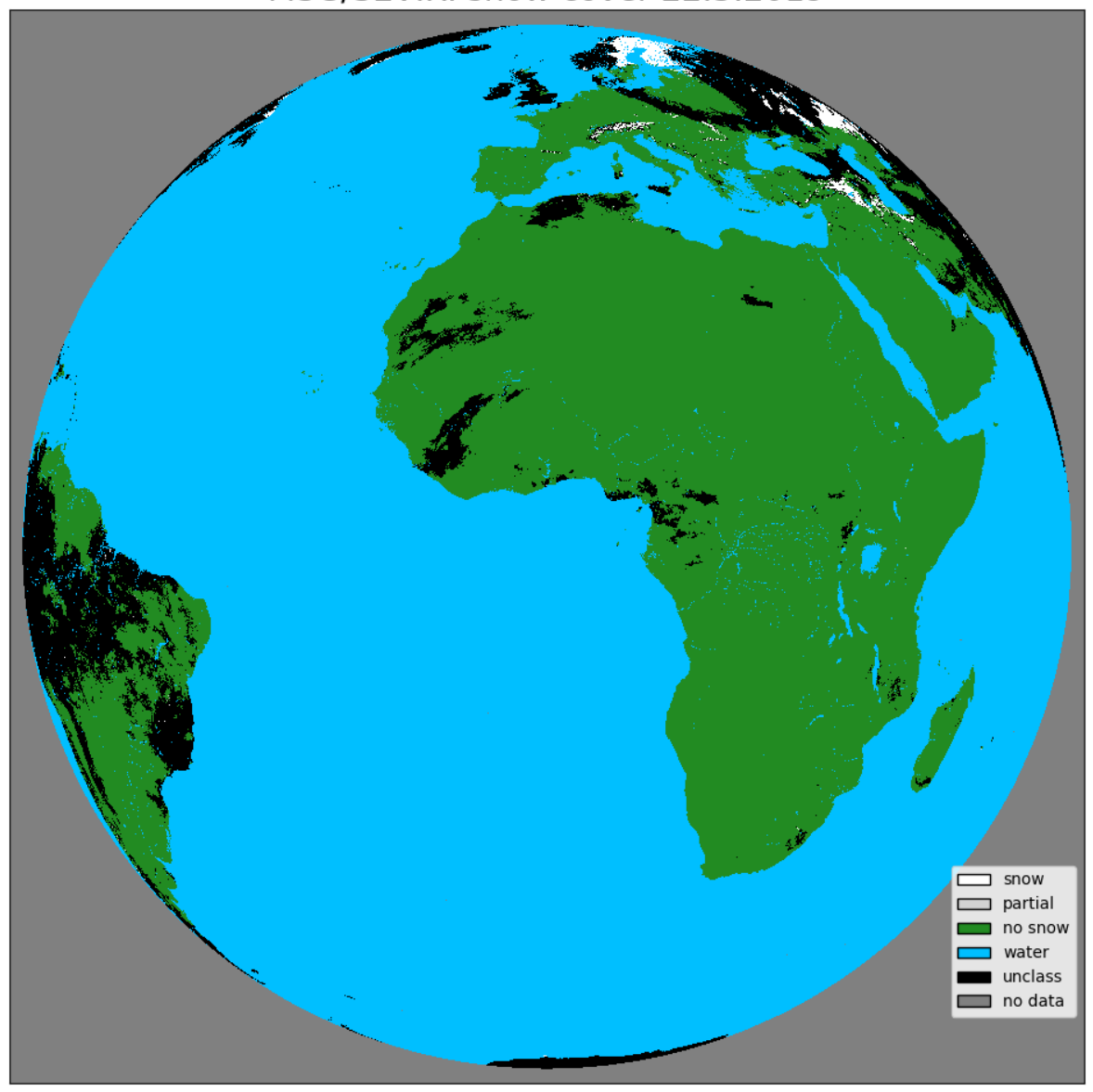

Figure 15 Example of the daily H31 product for March 22, 2019. 


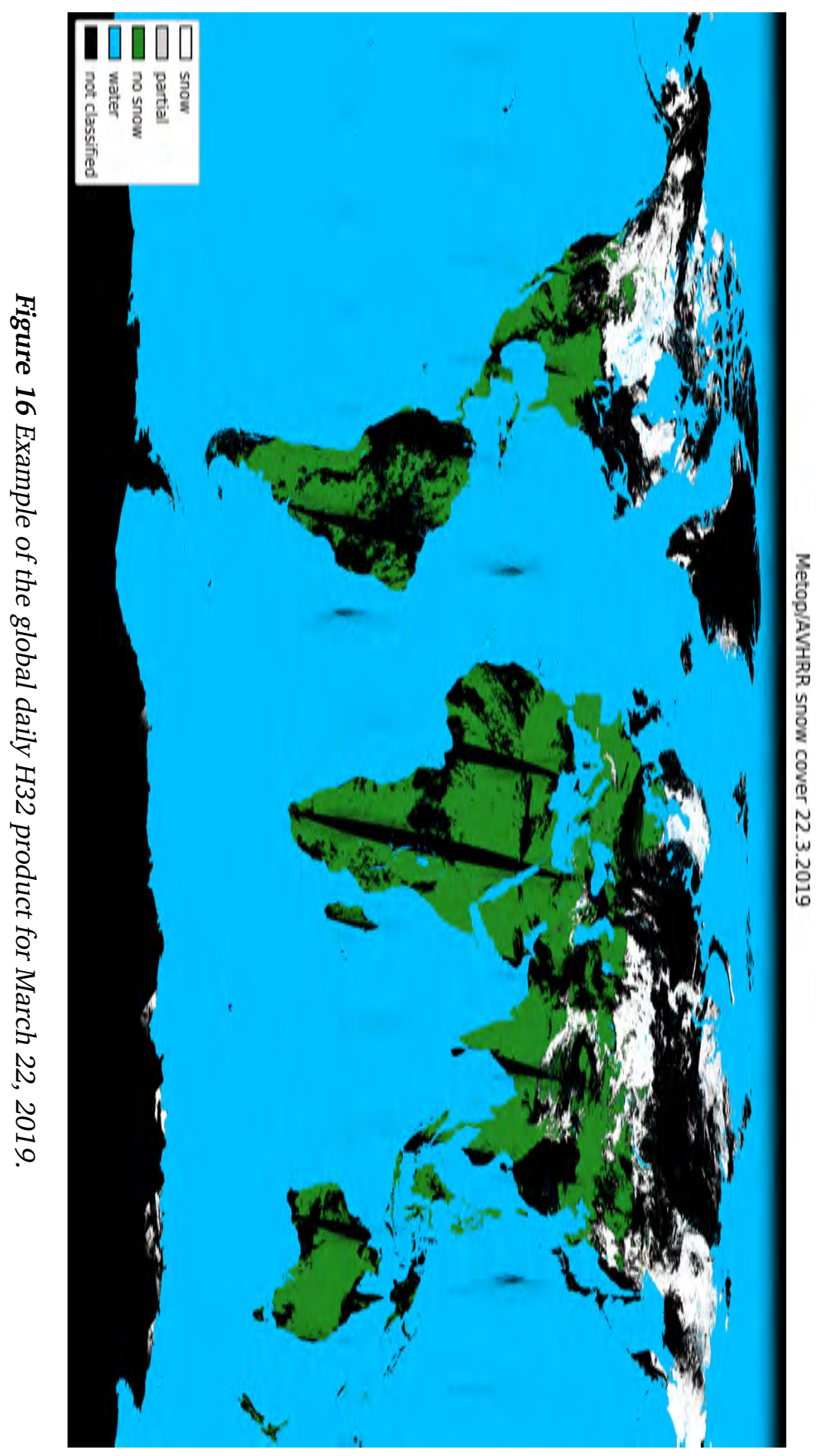




\section{VALIDATION}

\subsection{OBSERVATION SOURCES}

Validation is an essential part of the development of operational products. Validation is needed to confirm that the product is valuable, provides reliable information and meets the requirements for operational use. The major challenge in the validation of any snow-coverage product is the lack of easily available observations of the snow coverage, especially in areas where snow cover is not continuous. For further development and better validation, observations of the snow (or lack of snow) on canopy would be valuable, but such observations are even more difficult to obtain.

The best option for any satellite product validation would be high-quality in situ observations. Thus, for satellite snow extent or fractional snow cover products, observations of the snow coverage (percentage of the snow-covered surface or similar) would be the best choice. Unfortunately, such datasets are not available operationally i.e., in high temporal resolutions (preferably at least daily) and from large areas. Such observations would be invaluable when the edge of the snowcovered area is searched.

There are at least two possible solutions for this lack of observations. One can use observations from the synoptic weather stations which do not measure snow coverage, but usually provide at least snow depth observations and sometimes the state of the ground observations which are rough estimates of the snow coverage. The other option could be a measuring campaign, where some methods for measuring or estimating snow coverage can be used.

One validation option would be the use of other satellite snow products, but this option is not completely satisfactory. Even when the product under validation matches the baseline product closely, there is no way of knowing which of the products is more correct in areas where the products differ. This method was used in Paper I. Also the use of weather model snow analysis has been considered (see also the Paper IV). If in the future satellite snow products will be used in the weather model analysis, this may not be a suitable data source for validation as the validation data is not completely independent of the satellite product.

During this work, many ideas for snow coverage measurements were considered, tried and rejected for different reasons. Some of the ideas tried in practise were:

knotted string In this method, a $100 \mathrm{~m}$ string has markings at $1 \mathrm{~m}$ intervals (knots). The measuring team pulls the string in a straight line and counts snow-covered and snow-free points. This may be repeated several times in 
slightly different spots to improve the number of observations in each site. These counts must then be converted to coverage estimates. The method is rather expensive (labour costs) and time-consuming.

drones Aearial images from drones provide high spatial resolution $(<1 \mathrm{~m})$ data about snow coverage, but analysis of the snow coverage requires either lots of manpower or a high-quality snow detection algorithm for the drone photos. Collecting daily drone imagery from large areas is also challenging.

moving car One way to gather snow coverage observations is a car-based observation team. An observer can estimate the average snow coverage from a moving car at small intervals (e.g. 30 seconds) and save the estimated value using an automated system which saves the GPS coordinates, time of each observation and perhaps photos for later checking of the estimates. This method needs a two-person team of driver and observer and has some biases which may be difficult to avoid or correct. The snow cover near the roads is never natural (snow ploughed from the road, faster melting) and especially in forests, it is difficult to estimate the snow coverage far away from the road. However, this method has some potential because it can provide a large number of observations from relatively large areas. With some development and improvements, this method could produce additional regional validation data.

social media Photos in social media have been used successfully as meteorological observations (Hyvärinen and Saltikoff 2010). There are tools which can be used for fast selection and classification of suitable images, but there are many issues which may make the use of social media photos cumbersome such as privacy and copyright requirements or location and timing inaccuracies.

crowdsourcing Weather (including snow) observations could be collected using mobile applications. E.g. the FMI Weather app includes this capability, but currently, snow coverage is not one of the observation types supported. The reliability of crowdsourced observations is also uncertain because the observers are usually untrained and sometimes even malicious.

The best coverage for validation can be achieved by using weather station observations as described in section $3 \mathrm{~b}$ (Surface observations for validation) in Paper II. In short, the surface observations of snow depth and the state of the ground are converted to binary form (snow/no snow) and partial coverage is handled separately by converting partial values to snow-free or full snow cover. Partial snow cover cases can also be excluded from the validation. All three options were tested and the results presented in Paper II. 


\subsection{VALIDATION MEASURES}

The validation measures are calculated using the counts of cases on the contingency table shown in Table 2. Following the terminology of Jolliffe and Stephenson (2012), cases where the satellite detected snow are either Hits, $a$, when the satellite correctly detected snow, or False Alarms, $b$, when surface observation does not report snow. Similarly, cases where the satellite detected snow-free surface are either Correct Rejections, $d$, or Misses, $c$, when surface observation shows the presence of snow.

However, the snow cover has a strong seasonal cycle, and during the northern summer, there are relatively few snow observations compared to no-snow observations, which means that $d$ is much larger than the other values. The validation of snow products is complicated, because in the cases where one category dominates, the most common validation measures degenerate to trivial values.

A quite comprehensive list of validation measures is presented in Hogan and Mason (2012). The validation measures used and their behaviour when $d$ dominates are described below (and in Paper II).

One of the most commonly used validation measures Proportion Correct

$$
\mathrm{PC}=\frac{a+d}{a+b+c+d},
$$

tends to 1 if $d$ dominates. For other measures, this might not be as self-evident, but can be seen when the measures are shown as the function of two conditional probabilities Hit rate, $(H)$

$$
H=\frac{a}{a+c},
$$

and False Alarm Rate $(F)$

$$
F=\frac{b}{b+d},
$$

Table 2 Contingency table of the comparison between two categorical snow analyses. The symbols a-d represent the number of cases in each category.

\begin{tabular}{ccc} 
& \multicolumn{2}{c}{ Analysis 2 (baseline) } \\
\cline { 2 - 3 } Analysis 1 & Snow & No snow \\
\hline Snow & $a$ (Hit) & $b$ (False Alarm) \\
No snow & $c$ (Miss) & $d$ (Correct Rejection)
\end{tabular}


and the base rate $(s)$

$$
s=\frac{a+c}{a+b+c+d} .
$$

In the perfect analysis, $H$ should be 1 and $F$ should be 0 .

Now PC is

$$
\mathrm{PC}=(1-F)(1-s)+H s,
$$

and dominating $d$ implies $s \rightarrow 0$ and $F \rightarrow 0$, so PC tends to one using this notation also, as it should.

Slightly counter-intuitively, the often-used replacement for PC, Critical Success Index, which ignores Correct Rejections and is therefore used in cases when $d$ dominates, also degenerates. Its definition is

$$
\mathrm{CSI}=\frac{a}{a+b+c}=\frac{H}{1+F(1-s) / s},
$$

and when there are very few snow observations $(s \rightarrow 0)$, CSI will tend to zero. Also the Heidke Skill Score (the PC corrected for random hits)

$$
\mathrm{HSS}=\frac{2(a d-b c)}{(a+c)(c+d)+(a+b)(b+d)},
$$

will tend to zero. On the other hand, the False Alarm Ratio (FAR)

$$
\mathrm{FAR}=\frac{b}{a+b}=\left[1+\left(\frac{s}{1-s}\right) \frac{H}{F}\right]^{-1}
$$

will tend to one, while in the perfect analysis it should be 0 .

BIAS is used quite commonly in validation. It is defined as

$$
\text { BIAS }=\frac{a+b}{a+c}=\frac{(1-s) F}{s}+H,
$$

which in the perfect analysis should be 1 . It is not affected by dominating $d$.

A measure that does not degenerate is the Symmetric Extremal Dependence Index (SEDI)

$$
\mathrm{SEDI}=\frac{\ln F-\ln H+\ln (1-H)-\ln (1-F)}{\ln F+\ln H+\ln (1-H)+\ln (1-F)}
$$

that in the perfect analysis should be 1 . The SEDI can be used to assess whether there is a real drop in quality of the snow product in summer or is it because of the characteristics of the validation measures used. If either $F$ or $H$ is zero or unity, SEDI is not defined. When either $F$ or $H$ was zero, a very small number $(0.0001)$ was added to the numerator and denominator in the calculation of $H$ and $F$. This was done purely for visualization purposes so that all cases would be plotted in Figs. 17 and 18. 


\subsection{VALIDATION RESULTS}

In Paper II (Figs. 5-7), validation results are presented only for the Metop/AVHRR product, but the same validation procedure was also applied to the MSG/SEVIRI product from 2013 onwards. Before that, there were no easily available snow observations in the FMI observations database. The results of the validation are presented in Figs. 17 and 18 for the validation option where partial snow is converted to snow-free.

Subplots of both figures present time series of different validation measures. On the top left, the daily number of snow pixels is shown in light blue. When one correct classification dominates, even a small number of misclassifications can cause unexpected behaviour and emphasize misclassifications unnecessarily. For this reason, daily values are colour-coded: dark green data points mark the days where $d \leq 20(a+b+c)$ i.e., the proportion of correct snow-free observations is not too large, light green marks the days when $d>20(a+b+c)$ and orange the days where $d$ dominates $(d>200(a+b+c))$. In practice, this erratic behaviour happens during the northern summer when seasonal snow cover in the well-lit regions is at its minimum.

Even a single misclassification caused by, for example, a thunderstorm, certain surface features or even unrepresentative surface observations, can change the results significantly even when practically all other classifications are correct. This can be seen quite well in PC and $F$, which show that the results are nearly perfect in these days even though more sophisticated measures, such as the HSS may show much more variability. When the winter begins in the Northern Hemisphere, the snow-covered area becomes larger and the number of Hits, $a$, grow and Correct Rejections, $d$, decrease, the validation measures stabilize and improve greatly and stay at a high level most of the winter and spring.

Even though misclassifications are relatively rare, during the northern summer they do show in some of the validation measures. Both products (H31 and H32) provide excellent results during the northern winter and spring when the snow cover has the highest potential impact on weather, but the results are still very good even during the summer considering that SEDI is still reasonably high.

These surface observation-based validation results strongly suggest that the empirical approach used in the MSG/SEVIRI and Metop/AVHRR snow extent products can produce reliable snow coverage data, especially during the northern winter and spring. 
Global, MSG/SEVIRI, partial = no snow
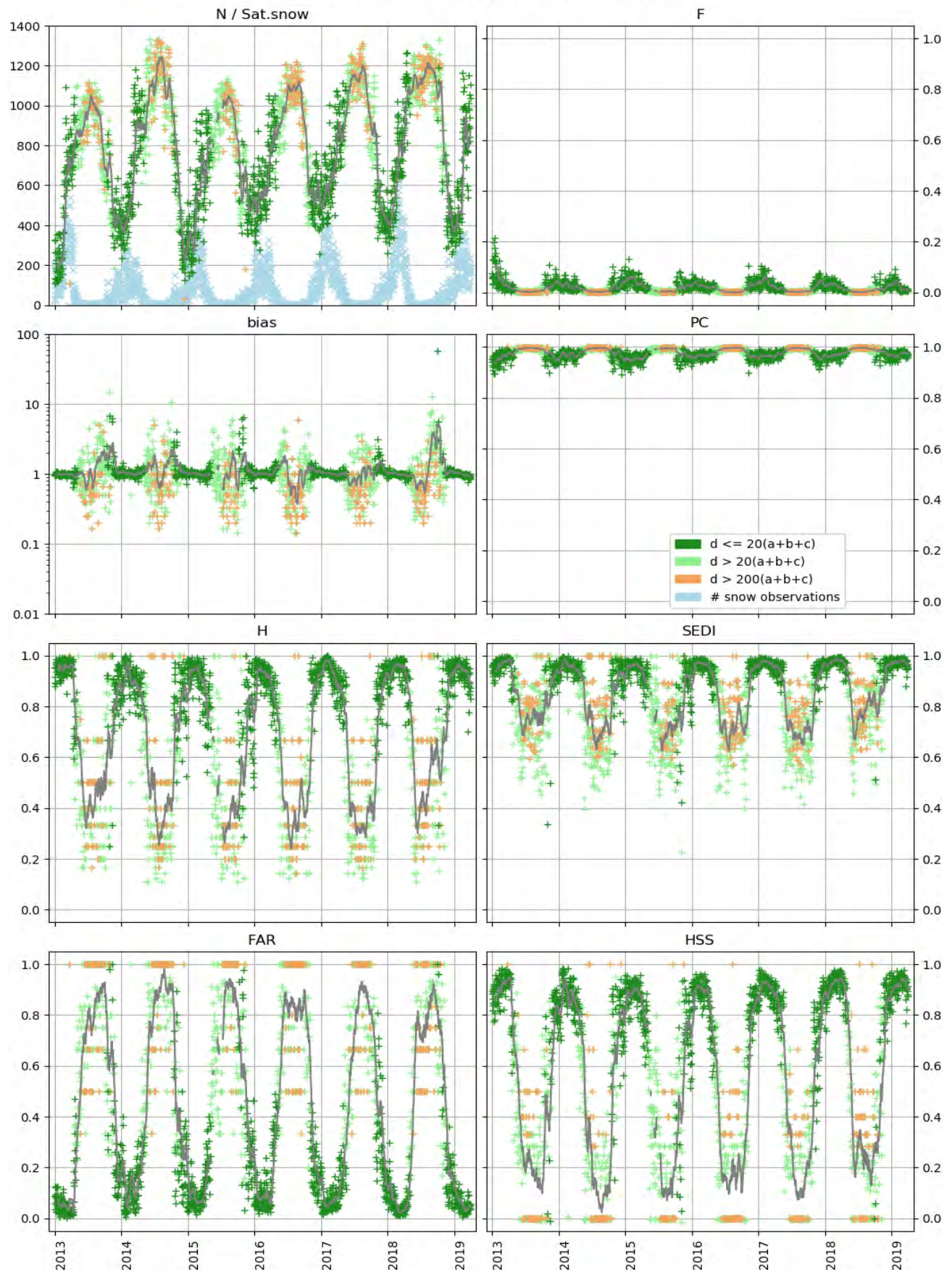

Figure 17 MSG/SEVIRI (H31) validation measure time series, partial classifications converted to snow-free. Each day is colour-coded to indicate whether the proportion of correct snow-free observations is so large that most of the validation measures degenerate (indicated by light green and in the most extreme cases by orange). Light blue marks the number of satellite snow observations per day. 
Global, Metop/AVHRR, partial $=$ no snow
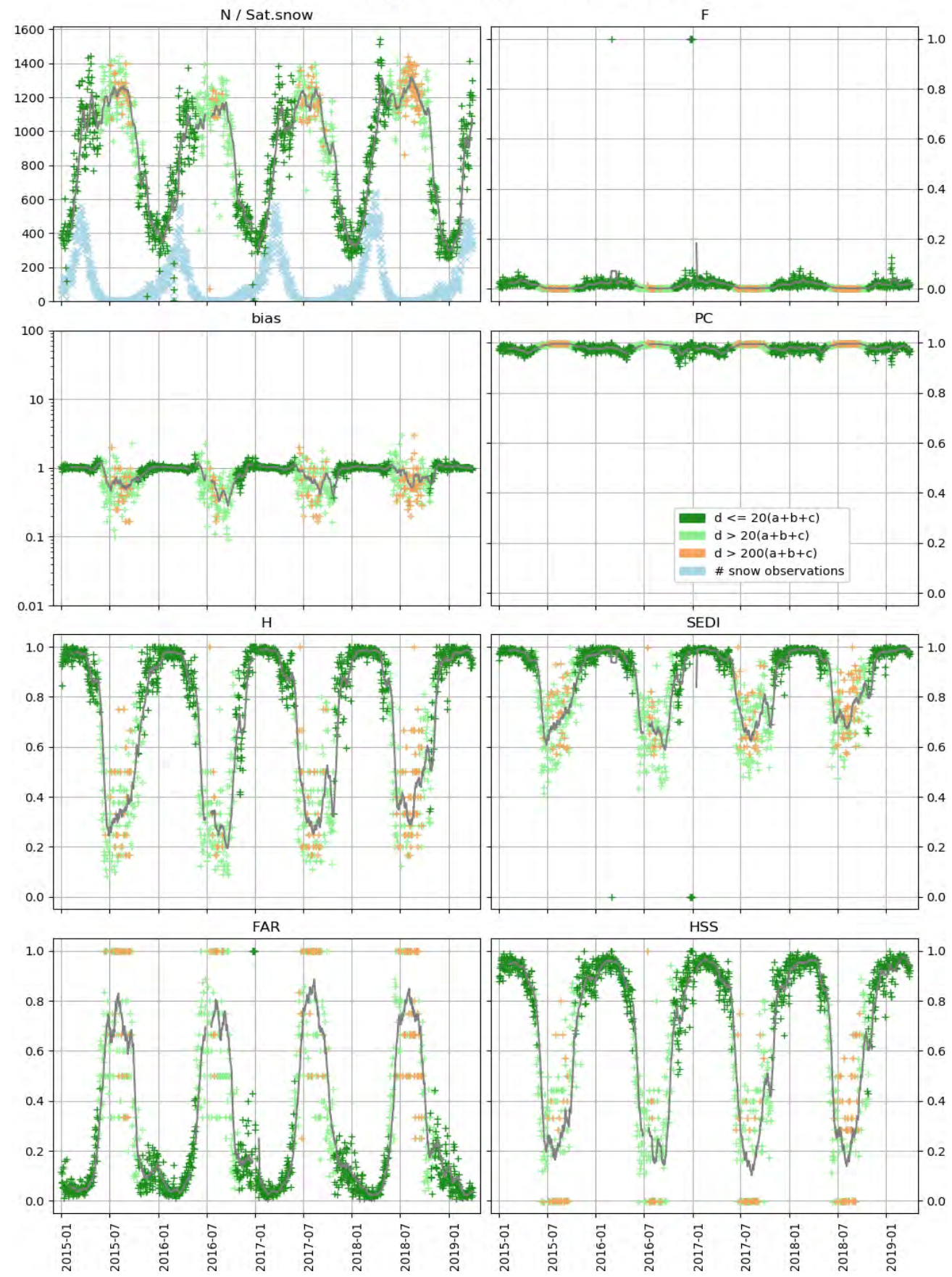

Figure 18 Metop/AVHRR (H32) validation measure time series, partial classifications converted to snow-free. Each day is colour-coded to indicate whether the proportion of correct snow-free observations is so large that most of the validation measures degenerate (indicated by light green and in the most extreme cases by orange). Light blue marks the number of satellite snow observations per day. 


\section{FUTURE}

Snow extent products, such as the ones presented in this work (Papers I and II), may be well suited for NWP data assimilation even though snow extent products do not provide direct data about SWE or snow depth. Neither of the snow products presented in this work have been assimilated in the operational NWP, but there are at least two ongoing projects which aim for operational snow data assimilation. In the Met Office, the work is nearing operational status (Pullen et al. 2019). At FMI, a variant of the Metop/AVHRR H32 product is in the assimilation trial phase, where so-called "snow barrels" have been used to create artificial snow observations which are then going into the assimilation system along with the weather station observations.

The MSG/SEVIRI and Metop/AVHRR algorithms are developed for EUMETSAT satellites and they are only used operationally to process data from EUMETSAToperated satellites (MSG and Metop). The SEVIRI instrument is only onboard MSG satellites, but different versions of the AVHRR instrument have been used also on NOAA operated satellites. Currently, the Metop/AVHRR algorithm relies on the availability of the channel $3 \mathrm{~A}$, which is only available on AVHRR/3, first onboard NOAA-15 launched in 1998. The current algorithm has been successfully modified to use reflectance data based on AVHRR GAC data. The current operational algorithm or the modified reflectance-based version could be used to process all AVHRR/3 data, but processing scenes without channel 3A requires more work.

The next generation of EUMETSAT satellites will supersede the current MSG and Metop satellites in the early 2020s. The MSG series satellites will be replaced by the Meteosat Third Generation (MTG) with the Flexible Combined Imager (FCI), which has 16 channels (SEVIRI has 12 channels) and better resolution (1 $\mathrm{km}$ instead of $3 \mathrm{~km}$ at nadir). The Metop satellites and the AVHRR instrument onboard them will be superseded by Meteorological Operational Satellite - Second Generation (Metop-SG) with the new Meteorological Imager (METimage) which is a considerable improvement (20 channels) on rather outdated AVHRR ( 6 channels, 5 in simultaneous use). It also has better resolution (500 m instead of $1 \mathrm{~km}$ at nadir).

A similar empirical approach will be used to develop snow extent products for these new satellites. The first MTG/FCI launch is planned for 2021 and Metop-SG/METimage launches from 2022 onwards.

High-quality in situ snow coverage observations would be valuable in satellite snow product development. New ways to measure snow coverage either in campaigns or operationally would benefit the development of satellite snow products. 


\section{CONCLUSIONS}

Snow is one of the key components of the global climate system. It has a strong influence on energy transfer, temperatures and many ecological features, but it also has a large impact on societies when it comes to water security, energy production and traffic. Snow cover changes are an important part of the climate change.

In NWP, Satellite-based snow products can improve snow analysis and this may help to improve weather forecasts at least on the local level. Dedicated snow products for meteorological applications are valuable in NWP.

The main contributions of this thesis are:

- The empirical approach has been used for satellite snow product development. This approach takes into account the natural variability of the surface features such as vegetation and the snow itself.

- Two snow detection algorithms and products based on them have been developed. Both products have reached operational status and are freely available.

- Both products have been validated using reliable surface observations. Validation results show that both products estimate the snow cover extent accurately. The surface observation-based validation period for the MSG/SEVIRI product is over 6 years and for the Metop/AVHRR over 4 years.

- Preferences of the NWP community have been considered and taken into account in the product development. The target is reliable snow detection where accuracy is preferred to coverage, i.e., it is better to avoid misclassifications than unclassified pixels.

Especially important for the future of these and similar products is that there are people and organizations which use the products. When the operational satellite products aim for NWP applications, there are two relatively time-consuming phases. Both operational product development and changes in NWP systems require careful testing before changes can be made in the operational system. It is, therefore, very positive that both snow products have found interested users. The MSG/SEVIRI product has been tested actively at Met Office and it seems likely that operational use in NWP analysis will begin during 2020. The polar Metop/AVHRR product reached operational status 2018 and there are now ongoing trials at FMI where the feasibility of the Metop/AVHRR product is studied. For these trials, a new product version based on the intermediate version (SC1) of the Metop/AVHRR product has been provided. 
No product is perfect. There are always misclassifications which should be removed by algorithm improvements. Algorithm improvements may allow classification of the cloud-free pixels which are not classified by the current algorithm. Especially, partial snow cover at the edges of the snow-covered area needs more attention. For that, more and better surface observations of the snow coverage are needed.

New satellites and more powerful computers may allow the development of better snow detection algorithms. Development data sets must still be collected by hand, but machine learning and other artificial intelligence methods may benefit the algorithm development.

Validation will always be an integral part of the product development and for that good coverage of reliable high-quality surface observations are essential. New methods for measuring snow coverage are needed urgently.

While the focus of this work is in the development of operational snow detection products for operational applications, the scientific side of this work is not negligible. Paper I has been cited 26 times at the time of writing and Paper III, which describes LSA SAF and its products, has been cited 115 times.

Even though this work is only a part of a larger picture, the empirical approach to satellite snow detection has potential for future applications.

\section{ACKNOWLEDGEMENTS}

I acknowledge the use of imagery from the NASA Worldview application (https://worldview.earthdata.nasa.gov), part of the NASA Earth Observing System Data and Information System (EOSDIS). 


\section{REFERENCES}

Anttila, K., T. Manninen, T. Karjalainen, P. Lahtinen, A. Riihelä and N. Siljamo (2014). 'The temporal and spatial variability in submeter scale surface roughness of seasonal snow in Sodankylä Finnish Lapland in 2009-2010'. J. Geophys. Res. Atmos. 119: pp. 9236-9252. DOI: 10.1002/2014JD021597.

Baldridge, A., S. Hook, C. Grove and G. Rivera (2009). 'The ASTER spectral library version 2.0'. Remote Sens. Environ. 113:4, pp. 711-715. DOI: 10 . 1016 / j . rse.2008.11.007.

Chen, C., T. Lakhankar, P. Romanov, S. Helfrich, A. Powell and R. Khanbilvardi (2012). 'Validation of NOAA-Interactive Multisensor Snow and Ice Mapping System (IMS) by Comparison with Ground-Based Measurements over Continental United States'. Remote Sens. 4:5, pp. 1134-1145. DOI: 10 . 3390 / rs4051134.

Crowther, T. W., H. B. Glick, K. R. Covey, C. Bettigole, D. S. Maynard, S. M. Thomas, J. R. Smith, G. Hintler, M. C. Duguid, G. Amatulli, M.-N. Tuanmu, W. Jetz, C. Salas, C. Stam, D. Piotto, R. Tavani, S. Green, G. Bruce, S. J. Williams, S. K. Wiser, M. O. Huber, G. M. Hengeveld, G.-J. Nabuurs, E. Tikhonova, P. Borchardt, C.-F. Li, L. W. Powrie, M. Fischer, A. Hemp, J. Homeier, P. Cho, A. C. Vibrans, P. M. Umunay, S. L. Piao, C. W. Rowe, M. S. Ashton, P. R. Crane and M. A. Bradford (2015). 'Mapping tree density at a global scale'. Nature 525:7568, pp. 201-205. ISSN: 1476-4687. DOI: 10.1038/nature14967.

Dybbroe, A., K. Karlsson and A. Thoss (2005). 'NWCSAF AVHRR Cloud Detection and Analysis Using Dynamic Thresholds and Radiative Transfer Modeling. Part I: Algorithm Description'. J. Appl. Meteor. 44:1, pp. 39-54. DOI: 10 . 1175 / JAM-2189. 1.

EUMETSAT (2020). Utilising specialist expertise from the Member States, Satellite Application Facilities (SAFs) are dedicated centres of excellence for processing satellite data. They form an integral part of the distributed EUMETSAT Application Ground Segment. URL: https : //www . eumetsat . int/website/home/ Satellites/GroundSegment/Safs/ (visited on 02/06/2020).

Hall, D. K. and G. A. Riggs (2011). 'Normalized-Difference Snow Index (NDSI)'. In: Encyclopedia of Snow, Ice and Glaciers. Ed. by V. P. Singh, P. Singh and U. K. Haritashya. Dordrecht: Springer Netherlands, pp. 779-780. ISBN: 978-90-4812642-2. DOI: 10.1007/978-90-481-2642-2_376.

Härer, S., M. Bernhardt, M. Siebers and K. Schulz (2018). 'On the need for a timeand location-dependent estimation of the NDSI threshold value for reducing existing uncertainties in snow cover maps at different scales'. The Cryosphere 12:5, pp. 1629-1642. DOI: 10.5194/tc-12-1629-2018. 
Helfrich, S. R., D. McNamara, B. H. Ramsay, T. Baldwin and T. Kasheta (2007). 'Enhancements to, and forthcoming developments in the Interactive Multisensor Snow and Ice Mapping System (IMS)'. Hydrological Processes 21: pp. 15761586. DOI: $10.1002 /$ hyp. 6720.

Hogan, R. J. and I. B. Mason (2012). 'Deterministic forecast of binary data'. In: Forecast Verification: A Practitioners Guide in Atmospheric Science. Ed. by I. T. Jolliffe and D. B. Stephenson. 2nd. Wiley, pp. 31-59.

Hori, M., K. Sugiura, K. Kobayashi, T. Aoki, T. Tanikawa, K. Kuchiki, M. Niwano and H. Enomoto (2017). 'A 38-year (1978-2015) Northern Hemisphere daily snow cover extent product derived using consistent objective criteria from satellite-borne optical sensors'. Remote Sens. Environ. 191: pp. 402-418. DOI: $10.1016 / j$.rse.2017.01.023.

Hüsler, F., T. Jonas, S. Wunderle and S. Albrecht (June 2012). 'Validation of a modified snow cover retrieval algorithm from historical 1-km AVHRR data over the European Alps'. Remote Sens. Environ. 121: pp. 497-515. DOI: 10 . 1016/j . rse. 2012.02.018.

Hyvärinen, O. (2011). 'Categorical Meteorological Products: Evaluation and Analysis'. PhD thesis. University of Helsinki. URL: http : / / urn . fi/URN : ISBN : 978-951-697-752-5.

Hyvärinen, O., K. Eerola, N. Siljamo and J. Koskinen (2009). 'Comparison of snow cover from satellite and numerical weather prediction models in Northern Hemisphere and northern Europe'. J. Appl. Meteor. Climatol. 48:6, pp. 11991216. DOI: $10.1175 / 2008$ JAMC2069.1.

Hyvärinen, O. and E. Saltikoff (2010). 'Social Media as a Source of Meteorological Observations'. Mon. Weather Rev. 138:8, pp. 3175-3184. DOI: 10.1175/ 2010MWR3270.1.

Jolliffe, I. T. and D. B. Stephenson, eds. (2012). Forecast Verification: A Practitioners Guide in Atmospheric Science. 2nd. Wiley, p. 274.

Key, J. R., R. Mahoney, Y. Liu, P. Romanov, M. Tschudi, I. Appel, J. Maslanik, D. Baldwin, X. Wang and P. Meade (2013). 'Snow and ice products from Suomi NPP VIIRS'. J. Geophys. Res. Atmos. 118: pp. 12816-12830. DOI: 10 . $1002 /$ 2013JD020459.

Leppänen, L. (2019). 'Measurements and modelling of seasonal snow characteristics for interpreting passive microwave observations'. PhD thesis. University of Helsinki. URL: http : //urn . fi/URN : ISBN : 978-952-336-091-4.

'Let it snow' (Oct. 2018). Nat. Clim. Change 8: DoI: 10 . 1038 / s41558-018$0332-5$.

Li, X., R. T. Pinker, M. M. Wonsick and Y. Ma (2007). 'Toward improved satellite estimates of short-wave radiative fluxes - Focus on cloud detection over 
snow: 1. Methodology'. J. Geophys. Res. 112: p. D07208. DOI: 10 . 1029 / 2005JD006698.

Manninen, T. and E. Jääskeläinen (Jan. 2018). 'The effect of boreal forest canopy on snow covered terrain broadband albedo'. Geophysica 53:1, pp. 9-29.

Manninen, T., L. Korhonen, P. Voipio, P. Lahtinen and P. Stenberg (Dec. 2009). 'Leaf Area Index (LAI) Estimation of Boreal Forest Using Wide Optics Airborne Winter Photos'. Remote Sensing 1:4, pp. 1380-1394. ISSN: 2072-4292. DOI: $10.3390 /$ rs 1041380 .

- (Jan. 2012). 'Airborne Estimation of Boreal Forest LAI in Winter Conditions: A Test Using Summer and Winter Ground Truth'. IEEE Trans. Geosci. Remote Sens. 50: pp. 68-74. DOI: 10.1109/TGRS . 2011.2173939.

Manninen, T. and J.-L. Roujean (2014). SNORTEX, Snow Reflectance Transition Experiment. Tech. rep. Reports 2014:7. Finnish Meteorological Institute.

Metsämäki, S., O.-P. Mattila, J. Pulliainen, K. Niemi, K. Luojus and K. Böttcher (2012). 'An optical reflectance model-based method for fractional snow cover mapping applicable to continental scale'. Remote Sens. Environ. 123: pp. 508521. DOI: $10.1016 /$ j.rse. 2012.04.010.

Miller, S. D., J. D. Hawkins, J. Kent, F. J. Turk, T. F. Lee, A. P. Kuciauskas, K. Richardson, R. Wade and C. Hoffman (Apr. 2006). 'NexSat: Previewing NPOESS/VIIRS Imagery Capabilities’. Bull. Amer. Meteor. Soc. 87:4, pp. 433-446. DoI: 10 . 1175/BAMS-87-4-433.

Miller, S. D., T. F. Lee and R. L. Fennimore (July 2005). 'Satellite-Based Imagery Techniques for Daytime Cloud/Snow Delineation from MODIS'. J. Appl. Meteor. 44:7, pp. 987-997. DOI: 10.1175/JAM2252.1.

Niittynen, P., R. K. Heikkinen and M. Luoto (Oct. 2018). 'Snow cover is a neglected driver of Arctic biodiversity loss'. Nat. Clim. Change 8: DOI: 10 . 1038/s41558018-0311-x.

Notarnicola, C., M. Duguay, N. Moelg, T. Schellenberger, A. Tetzlaff, R. Monsorno, A. Costa, C. Steurer and M. Zebisch (2013a). 'Snow Cover Maps from MODIS Images at 250 m Resolution, Part 1: Algorithm Description'. Remote Sens. 5:1, pp. 110-126. DOI: $10.3390 /$ rs5010110.

- (2013b). 'Snow Cover Maps from MODIS Images at $250 \mathrm{~m}$ Resolution, Part 2: Validation'. Remote Sens. 5:4, pp. 1568-1587. DoI: 10.3390/rs5041568.

Pullen, S., C. Charlton-Perez, B. Gomez and C. Harris (2019). Development of snow depth data assimilation for the Met Office UK forecasting system. Satellite inspired hydrology in an uncertain future: a H SAF and HEPEX workshop, Reading, UK, 25-28 November, 2019. URL: https: //events . ecmwf . int/event/130/contributions/800/attachments/359/646/HSAF HEPEX-WS-Pullen.pdf. 
Pullen, S., C. Jones and G. Rooney (2010). 'Using Satellite-Derived Snow Cover Data to Implement a Snow Analysis in the Met Office Global NWP Model'. $J$. Appl. Meteor. Climatol. 50: pp. 958-973. Dor: 10.1175/2010JAMC2527.1.

Ramsay, B. (1998). 'Interactive Multisensor Snow and Ice Mapping System (IMS)'. Hydrological Processes 5:12, pp. 1537-1546. DOI: 10 . 1002 / (SICI ) 1099 $1085(199808 / 09) 12: 10 / 11<1537:$ :AID-HYP679>3 . 0 . CO;2-A.

Riggs, G. A., D. K. Hall and M. O. Roman (2015). VIIRS Snow Cover Algorithm Theoretical Basis Document. Tech. rep. NASA Goddard Space Flight Center.

Riggs, G. A., D. K. Hall and M. O. Román (2017). 'Overview of NASA's MODIS and Visible Infrared Imaging Radiometer Suite (VIIRS) snow-cover Earth System Data Records'. Earth Syst. Sci. Data 9:2, pp. 765-777. DOI: 10.5194/essd9-765-2017.

Romanov, P., D. Tarpley, G. Gutman and T. Carroll (2003). 'Mapping and monitoring of the snow cover fraction over North America'. J. Geophys. Res. 108:D16. DOI: $10.1029 / 2002$ JD003142.

Selkowitz, D. J. and R. R. Forster (2015). 'An Automated Approach for Mapping Persistent Ice and Snow Cover over High Latitude Regions'. Remote Sens. DoI: $10.3390 /$ rs 8010016 .

Siljamo, N. and O. Hyvärinen (June 2011). 'New Geostationary Satellite-Based Snow-Cover Algorithm'. J. Appl. Meteor. Climatol. 50:6, pp. 1275-1290. DoI: 10. 1175/2010JAMC2568. 1.

Siljamo, N., O. Hyvärinen, A. Riihelä and M. Suomalainen (2020). 'Metop/AVHRR snow detection method for meteorological applications'. J. Appl. Meteor. Climatol. Submitted February 2020.

Solberg, R., $\varnothing$. Trier, L.-A. Breivik, Ø. Godøy, M. Killie, L. M. Andreassen, J. Hausberg and O. Olsen (Jan. 2009). 'CryoClim-A New System for Cryospheric Climate Monitoring'. Proceedings, 33rd International Symposium on Remote Sensing of Environment, ISRSE 2009.

Takala, M., J. Pulliainen, S. J. Metsamaki and J. T. Koskinen (2009). 'Detection of Snowmelt Using Spaceborne Microwave Radiometer Data in Eurasia From 1979 to 2007'. IEEE Trans. Geosci. Remote Sens. 47:9, pp. 2996-3007.

Takala, M., K. Luojus, J. Pulliainen, C. Derksen, J. Lemmetyinen, J.-P. Kärnä, J. Koskinen and B. Bojkov (2011). 'Estimating northern hemisphere snow water equivalent for climate research through assimilation of space-borne radiometer data and ground-based measurements'. Remote Sens. Environ. 115:12, pp. 3517-3529. ISSN: 0034-4257. DOI: 10 . 1016 / j . rse . 2011. 08.014.

Trigo, I. F., C. C. Dacamara, P. Viterbo, J.-L. Roujean, F. Olesen, C. Barroso, F. Camacho-de-Coca, D. Carrer, S. C. Freitas, J. Garcia-Haro, B. Geiger, F. Gellens- 
Meulenberghs, N. Ghilain, J. Meliá, L. Pessanha, N. Siljamo and A. Arboleda (2011). 'The Satellite Application Facility for Land Surface Analysis'. Int. J. Remote Sens. 32:10, pp. 2725-2744. DOI: 10.1080/01431161003743199.

Walters, D., A. J. Baran, I. Boutle, M. Brooks, P. Earnshaw, J. Edwards, K. Furtado, P. Hill, A. Lock, J. Manners, C. Morcrette, J. Mulcahy, C. Sanchez, C. Smith, R. Stratton, W. Tennant, L. Tomassini, K. Van Weverberg, S. Vosper, M. Willett, J. Browse, A. Bushell, K. Carslaw, M. Dalvi, R. Essery, N. Gedney, S. Hardiman, B. Johnson, C. Johnson, A. Jones, C. Jones, G. Mann, S. Milton, H. Rumbold, A. Sellar, M. Ujiie, M. Whitall, K. Williams and M. Zerroukat (2019). 'The Met Office Unified Model Global Atmosphere 7.0/7.1 and JULES Global Land 7.0 configurations'. Geoscientific Model Development 12:5, pp. 1909-1963. DOI: 10.5194/gmd-12-1909-2019.

Wang, G., L. Jiang, S. Wu, J. Shi, S. Hao and X. Liu (2017). 'Fractional Snow Cover Mapping from FY-2 VISSR Imagery of China'. Remote Sensing 9:10. ISSN: 20724292. DOI: $10.3390 /$ rs 9100983.

WMO (2015). WMO Technical Regulations, The Manual on Codes. Vol. I.2, updated 2017, No. 306. World Meteorological Organization.

Wunderle, S., T. Gross and F. Hüsler (2016). 'Snow Extent Variability in Lesotho Derived from MODIS Data (2000-2014)'. Remote Sens. 8:6. DOI: 10 . 3390 / rs8060448.

Wunderle, S., K. Naegeli, C. Neuhaus, M. Stengel, R. Hollmann and A. Wiesmann (2019). Towards a Global Time Series (1981-2020) of Snow Extent based on AVHRR GAC Data - First Results of ESA CCI Snow Project. ESA 2019 Living Planet Symposium, Milan, Italy. 

(C) 2011 American Meteorological Society,

Reprinted with permission from American Meteorological Society 2020

N. Siljamo and O. Hyvärinen (June 2011). 'New Geostationary SatelliteBased Snow-Cover Algorithm'. J. Appl. Meteor. Climatol. 50:6, pp. 1275-1290. DOI: $10.1175 / 2010$ JAMC2568.1 



\title{
New Geostationary Satellite-Based Snow-Cover Algorithm
}

\author{
NiILO SilJAmo AND OTto HyväRINEN \\ Finnish Meteorological Institute, Helsinki, Finland \\ (Manuscript received 28 May 2010, in final form 7 December 2010)
}

\begin{abstract}
Snow cover plays an important role in the climate system by changing the energy and mass transfer between the atmosphere and the surface. Reliable observations of the snow cover are difficult to obtain without satellites. This paper introduces a new algorithm for satellite-based snow-cover detection that is in operational use for Meteosat in the European Organisation for the Exploitation of Meteorological Satellites Satellite Application Facility on Land Surface Analysis (LSA SAF). The new version of the product is compared with the old version and the NOAA/National Environmental Satellite, Data, and Information Service Interactive Multisensor Snow and Ice Mapping System (IMS) snow-cover product. The new version of the LSA SAF snow-cover product improves the accuracy of snow detection and is comparable to the IMS product in cloud-free conditions.
\end{abstract}

\section{Introduction}

With the growing number of satellite platforms and improvements in the processing and transmission of digital data obtained from them, it has become possible to obtain frequent snow-cover information in near-real time through a variety of different sources. Retrieving snow products from satellite data is still a challenging task. Topography, heterogeneity in snow distribution, the effects of slope, aspect, land use, wind, and other factors in the accumulation and melting periods of snow make it difficult to retrieve snow products from satellite data.

At present, the most useful satellite orbits for snow detection at high latitudes are the near-polar orbit [used by, e.g., the National Oceanic and Atmospheric Administration, the Earth Observing System (EOS), Meteorological Operation (MetOp), the future National Polar-orbiting Operational Environmental Satellite System (NPOESS) Preparatory Project (NPP), and the future Joint Polar Satellite System (JPSS) satellites] and the geostationary orbit [e.g., Meteosat, Geostationary Operational Environmental Satellite (GOES), and Feng Yun 2 (FY-2)]. Both orbits have their strengths and weaknesses. In high latitudes, where snow is most often present, the instruments on board geostationary satellites have low viewing

Corresponding author address: Finnish Meteorological Institute, Erik Palménin aukio 1, P.O. Box 503, FI-00101 Helsinki, Finland. E-mail: niilo.siljamo@fmi.fi angles, resulting in poor spatial resolution, whereas high spatial resolution is an advantage of polar-orbiting satellites. Instruments on board geostationary satellites also have a constrained view of the earth, while polar-orbiting satellites offer a global view. On the other hand, geostationary satellites offer excellent temporal resolution compared to polar-orbiting satellites. While polar-orbiting satellites can produce $1-4$ daily images from a specified region in high latitudes, geostationary instruments produce images for a specified region every $15 \mathrm{~min}$. Satellites in a highly elliptical Molniya orbit (Kidder and Vonder Haar 1990) would offer geostationary-like observations with a better viewing angle for high latitudes, but such satellites for meteorological use are only in the planning stages (e.g., Riisholgaard 2004).

This paper introduces a new geostationary snowcover product for Spinning Enhanced Visible and Infrared Imager (SEVIRI) on board the second generation of Meteosat (MSG) satellites. SEVIRI has 11 channels in visual and IR areas of the radiomagnetic spectrum and represents the state of the art in geostationary imager instruments until the arrival of the next generation of geostationary satellites and their instruments [e.g., Advanced Baseline Imager on board GOES-R (Schmit et al. 2005)]. In practice, visual and IR channels can be used only to detect the existence of snow, not the depth or the water equivalence of snow. This existence of snow is usually disseminated in binary form for each pixel, but fractional subpixel information can also be obtained in 
some circumstances [e.g., Matikainen et al. (2002) or Metsämäki et al. (2005)]. Operational binary snow detection schemes based on visual and IR channels have been constructed for both polar and geostationary satellites. For polar-orbiting satellites there is a global snow analysis scheme based on Moderate Resolution Imaging Spectroradiometer (MODIS) on board EOS/Terra and EOS/Aqua (Miller et al. 2005). Even though snow is classified as part of many Advanced Very High Resolution Radiometer (AVHRR) processing schemes (e.g., Dybbroe et al. 2005), it seems that no snow analysis based on AVHRR data is in widespread use. Both AVHRR and MODIS will be superseded by the Visible/ Infrared Imager/Radiometer Suite (VIIRS) on board the future NPP and JPSS satellites with similar channels for snow detection as MODIS (Miller et al. 2006).

For the geostationary instruments, there are systems for GOES, Meteosat, and FY-2. Romanov et al. (2000) used both geostationary GOES data and Special Sensor Microwave Imager (SSM/I) information from polar-orbiting Defense Meteorological Satellites Program (DMSP) satellites to construct the snow product. The systems using only GOES data for snow detection are presented by Romanov and Tarpley (2003) and Li et al. (2007). For Meteosat, de Wildt et al. (2007) used single SEVIRI images and temporal differences between images to produce snow-cover maps. Through the "GEONETCast" network (Moura 2006), the products obtained by the Visible and Infrared Spin Scan Radiometer (VISSR) of FY-2 satellite series (Dong and Zhang 2004), including the Snow Fraction Product, are disseminated to the global community, but to the authors' best knowledge, no detailed information about the algorithm has been published in English.

The major weakness of algorithms that use a combination of visual and IR channels for snow detection is that they can be used only during daytime and in cloudfree conditions. The high temporal resolution of the instruments on board a geostationary satellite helps to mitigate this to some extent, as it is much more likely that, for a certain area during one day, at least some of the images are cloud free. Some regions, however, can remain cloud covered for days. Active and passive microwave methods would be better suited for cloud-covered areas, but the spatial resolution of the passive microwave instruments [e.g., Advanced Microwave Scanning Radiometer for EOS (AMSR-E)] is poor when compared with optical channels, and passive microwave methods work only for dry snow conditions (Ulaby et al. 1986). Active microwave instruments, in practice synthetic aperture radar (SAR) (on board, e.g., Radarsat), have better spatial resolution, but unfortunately their swath width is comparatively narrow and daily observations of snow cannot be obtained (Koskinen et al. 1997). The use of SAR images in operational setting has been hindered by their relative high cost and the difficulties of acquiring them in a timely manner. It is hoped that this will change in the future. In addition, no microwave instruments are currently on board geostationary satellites, but the possibilities of geostationary microwave instruments are being studied actively.

The best way to validate the satellite-derived snow cover would be to compare it with high-quality in situ measurements, but such data are almost impossible to collect on a large scale because of the serious limitations in the way the weather stations report the snow-cover measurements. The presence of snow is not always reported in many stations, and the absence of snow is not usually reported at all. Automation of the observations does not help, either. Commonly used automatic weather stations do not provide reliable observations for thin (less than $2.5 \mathrm{~cm}$ ) snow layers. Moreover, in comparison to satellitebased snow analyses, the weather station network is also quite sparse. Hyvärinen et al. (2009) compared several snow analyses based on both in situ observations and satellite data, and the National Oceanic and Atmospheric Administration/National Environmental Satellite, Data, and Information Service (NOAA/NESDIS) Interactive Multisensor Snow and Ice Mapping System (IMS) analysis (Helfrich et al. 2007) gave a consistent snow analysis with high resolution. In the absence of a reliable reference, and because of its spatial coverage, the NOAA/NESDIS IMS analysis is a good candidate for a verification dataset. Moreover, IMS is a vital part of the European Centre for Medium-Range Weather Forecasts (ECMWF) snow analysis (Drusch et al. 2004), so there is strong motivation to compare the developed snow product with it.

The main sources for the NOAA/NESDIS IMS product are visible and infrared spectral data from different polar and geostationary satellites and, to a lesser extent, microwave products from polar-orbiting satellites. However, the IMS algorithm is not fully automatic. The combination of data from different sources into one analysis is done subjectively by analysts at NOAA/NESDIS.

In this article, first the two versions of the Satellite Application Facility (SAF) on Land Surface Analysis (LSA) snow-cover (SC) algorithm are introduced. Then the NOAA/NESDIS IMS product is used as a baseline to which both LSA SC products are compared in Europe.

\section{LSA SAF snow algorithm}

The European Organisation for the Exploitation of Meteorological Satellites (EUMETSAT) has several dedicated programs for processing satellite data. Each of these SAFs provides products and services on an operational basis. The main purpose of the LSA SAF is to increase the benefits from MSG and EUMETSAT Polar 
System (EPS) data concerning land, land-atmosphere interactions, and biophysical applications by developing techniques, products, and algorithms that will allow data from the EUMETSAT satellites to be used more effectively. A major user of LSA SAF products is numerical weather prediction (NWP), both for validation and for use as a model input.

EUMETSAT's LSA SAF has been producing the daily snow-cover product with a baseline algorithm for the areas covered by the MSG/SEVIRI instrument since 2005. The snow detection algorithm produces the snowcover product over the MSG/SEVIRI image area, which is divided into four different geographical regions (Europe, North Africa, South Africa, and South America), as is the case for all LSA SAF products. A product using polarorbiting MetOp satellite data is currently under development. The daily products are distributed to users through the EUMETCast system. The daily products are archived and are available on the LSA SAF Web site (http:// landsaf.meteo.pt). The single-image snow-cover product is currently not available for public. At present, the daily products are not reprocessed when the algorithms are changed. Thus, potential users should be aware of the differences in the product versions.

The first version of the LSA SAF snow-cover algorithm was developed by the Swedish Meteorological and Hydrological Institute (SMHI). Development of the snow-cover product was transferred to the Finnish Meteorological Institute (FMI) in 2005.

The version 1 of the snow-cover algorithm determined whether a satellite ground pixel is fully or partially snow covered, through the use of different signatures of snow, ice, and clouds on the reflectance of shortwave IR channels (SEVIRI 1.6 and $3.9 \mu \mathrm{m}$ ). Since the separation between cloud and surface ice-snow is a crucial procedure for cloud detection, the above-mentioned thresholding procedure has been included in the SAF on Support to Nowcasting and Very Short Range Forecasting (NWC SAF) software (Derrien and LeGléau 2005). The cloudmask product was analyzed and the pixels classified every 15 min. Cloudy pixels were reclassified as unclassified, cloud-free pixels as snow free, and snow-contaminated pixels as snow covered. Thus, version 1 of the SEVIRI snow-cover algorithm relied on the cloud mask, derived from the NWC SAF package, for a first pixel classification, before performing snow spatial smoothing and temporal integration of the previous 24-h satellite scenes. Unfortunately, the accuracy of the snow detection was limited in the version of the NWC SAF software used at that time. Only one-third of cloud-free synoptic surface observation stations (SYNOP; see World Meteorological Organization 1995) stations with snow were correctly classified as snow (Derrien and LeGléau 2005).
A new version 2 of the LSA SAF snow-cover product was therefore developed at the FMI. This version was developed specifically for snow detection; that is, it is not a by-product of a cloud-mask product. Different variants of this algorithm version have been used to generate the LSA SAF snow-cover product pre-operationally since summer 2007 and operationally since April 2009. The differences between version 2 algorithm variants are minor or related to changes in the input files.

The mandate of LSA SAF is to produce the snow product for non-mountainous areas. However, mountain areas are processed in the LSA SAF system and the data are available in the product files, but there are no requirements for the product quality and therefore mountains are excluded in this study.

\section{a. Algorithm development}

The spectral properties of snow observed in nature vary considerably (Dozier et al. 2009; Salminen et al. 2009; Wiscombe and Warren 1980a,b). The grain size of snow changes over time and space, the wetness of snow changes, and the reflecting properties change when the surface is viewed from different angles and in different solar illumination conditions. In addition, the effects of vegetation - such as grass, fields, and different forestsare highly variable, even in winter. This natural variability makes it difficult to develop a general classification algorithm for the snow cover. Finally, the atmosphere should be taken into account when surface and laboratory measurements are compared to satellite measurements. Thus most operational algorithms are at least partly empirical, based on the statistics of samples collected from different surface types.

Development of the new version of the snow-cover classification algorithm was started by subjective classification of selected areas in representative MSG/SEVIRI images. Starting from 32 images for 12 days ranging from November 2006 to September 2007, but concentrating on 28 March 2007 (13 images), samples of snow-covered and snow-free areas, different cloud types, and areas where the surface type could be seen through clouds were selected. The day 28 March 2007 was an exceptionally cloudfree day in northern Europe, which enabled the collection of data from early morning to late evening. Particular attention was paid to finding days when there was snow in southern Europe. Although the snow-cover product is calculated for African and South American regions, they are mostly snow-free and data samples from those areas were not sought for statistical analysis. However, the product seems to be reasonably reliable also in these areas.

The actual extent of snow cover was determined subjectively using different SEVIRI red-green-blue (RGB) combinations, ground observations, and MODIS images. 
Over one-half million MSG/SEVIRI pixels were classified to form a dataset for algorithm development. However, the samples were collected in large batches, and because the snow properties in most pixels were spatially correlated with those of their neighbors, the effective number of independent pixels is much smaller. Even so, this increases variations in the surface properties and in the satellite and sun angles.

Based on the dataset that was collected, the differences in various classes were investigated using the different channels. The classification of different surface types using information from channels around $0.6,0.8$, and $1.6 \mu \mathrm{m}$ is the basis for all snow and cloud classification schemes (Hall et al. 2002; Dybbroe et al. 2005; Derrien and LeGléau 2005). As to discriminating between surface and clouds, the capabilities of channels around 1.6 and $3.9 \mu \mathrm{m}$ to discriminate low clouds and snow have been reported widely (Matson 1991; Kidder and Wu 1984). Thus, using the radiance ratio of SEVIRI channels $2(0.8 \mu \mathrm{m})$ and 3 $(1.6 \mu \mathrm{m})$ and the brightness temperature difference of channels $10(12.0 \mu \mathrm{m})$ and $4(3.9 \mu \mathrm{m})$ (Fig. 1a) clouds can be distinguished from a cloud-free surface. Moreover, the radiance ratio of SEVIRI channels 2 and 3 and the sun azimuth angle (Fig. 1b) difference between snow and snow free seem to be promising. These ratios are very similar to the normalized difference snow index (NDSI) used by de Wildt et al. (2007).

The driving philosophy behind the LSA SAF snowcover algorithm is to avoid mistakes, even if this approach produces relatively more unclassified pixels. The LSA SAF snow-cover algorithm does not try to identify cloudfree regions for classification before the snow-cover tests. Instead, it has rules for presence of snow and snow-free surface, and other pixels are left as unclassified whether they are cloudy, too dark, or just too difficult to classify reliably. Rules themselves are based on channel differences and channel ratios that are very similar to other published algorithms, as is shown above.

\section{b. Algorithm implementation}

The LSA SAF snow-cover algorithm is a thresholding method based on the different properties of the snowcovered and snow-free surfaces and clouds. The LSA SAF snow cover is a daily product, produced in two separate phases. Phase 1 is the SC1 snow-cover product based on one cycle of SEVIRI images (every $15 \mathrm{~min}$ ). All of the available SC1 products are used to produce the daily LSA SAF snow-cover product (SC2). This phase produces 96 snow-cover maps each day if all time slots are available. Product resolution is full SEVIRI resolution in each of the four regions used in LSA SAF.

In this study, the mountain definition of the SAF on Support to Operational Hydrology and Water Management (a)

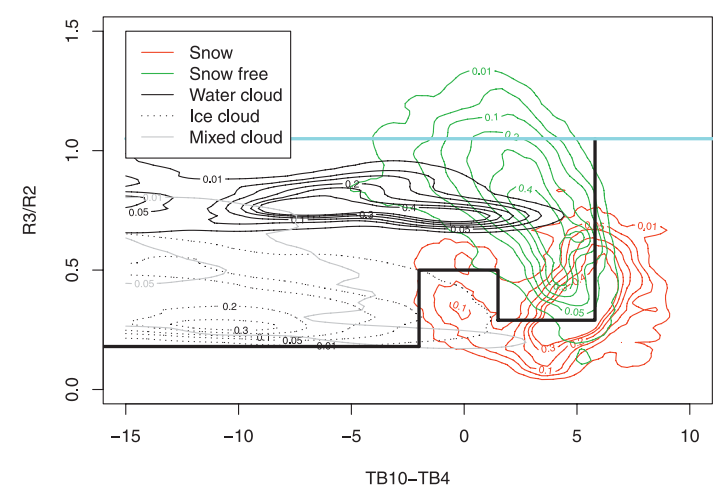

(b)

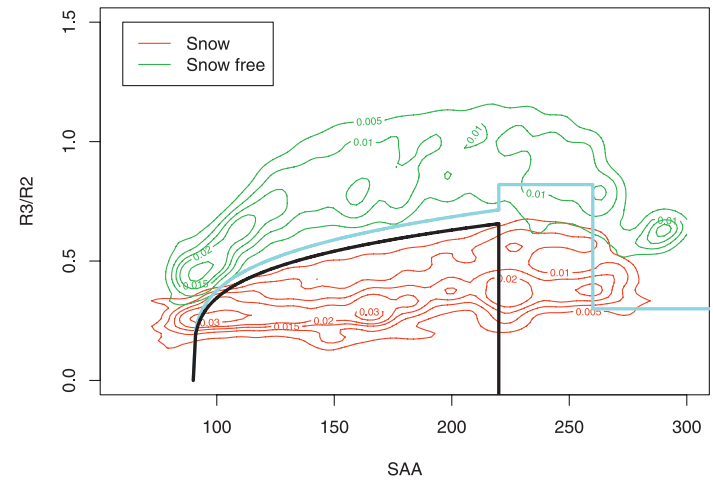

FIG. 1. Examples of the densities of the scatterplots from the development dataset. The thick lines show thresholds for SNOW (black) and NO SNOW (blue), based on the rules in Table 2: (a) SNOW: rules (R9)-(R12) and NO SNOW: rule (R14); (b) SNOW: rule (R5) and NO SNOW: rules (R6)-(R8). For definitions of the variables, see Table 1 .

(H-SAF) was followed, because the similar mountain snow product is part of the H-SAF. The area was defined to be mountainous if the mean altitude exceeded $2000 \mathrm{~m}$ or the mean altitude exceeded $700 \mathrm{~m}$ and the standard deviation of the slope was greater than $2^{\circ}$ in a $10 \mathrm{~km} \times 10 \mathrm{~km}$ area (Lahtinen et al. 2009). This area is shown in Fig. 2a.

The algorithm utilizes the top-of-atmosphere radiances of 6 SEVIRI channels $(0.6,0.8,1.6,3.9,10.8$, and $12.0 \mu \mathrm{m})$ and brightness temperatures of three channels $(3.9,10.8$, and $12.0 \mu \mathrm{m})$, sun and satellite zenith and azimuth angles, the International Geosphere-Biosphere Programme (IGBP) land-cover type by the U.S. Geological Survey (USGS), and the land surface temperature (LST) classification produced by the LSA SAF (Table 1). Our plan is to start using the Global Land Cover 2000 Project (GLC2000) (Bartholomé and Belward 2005) landcover data in the future versions of the algorithm. 
(a)
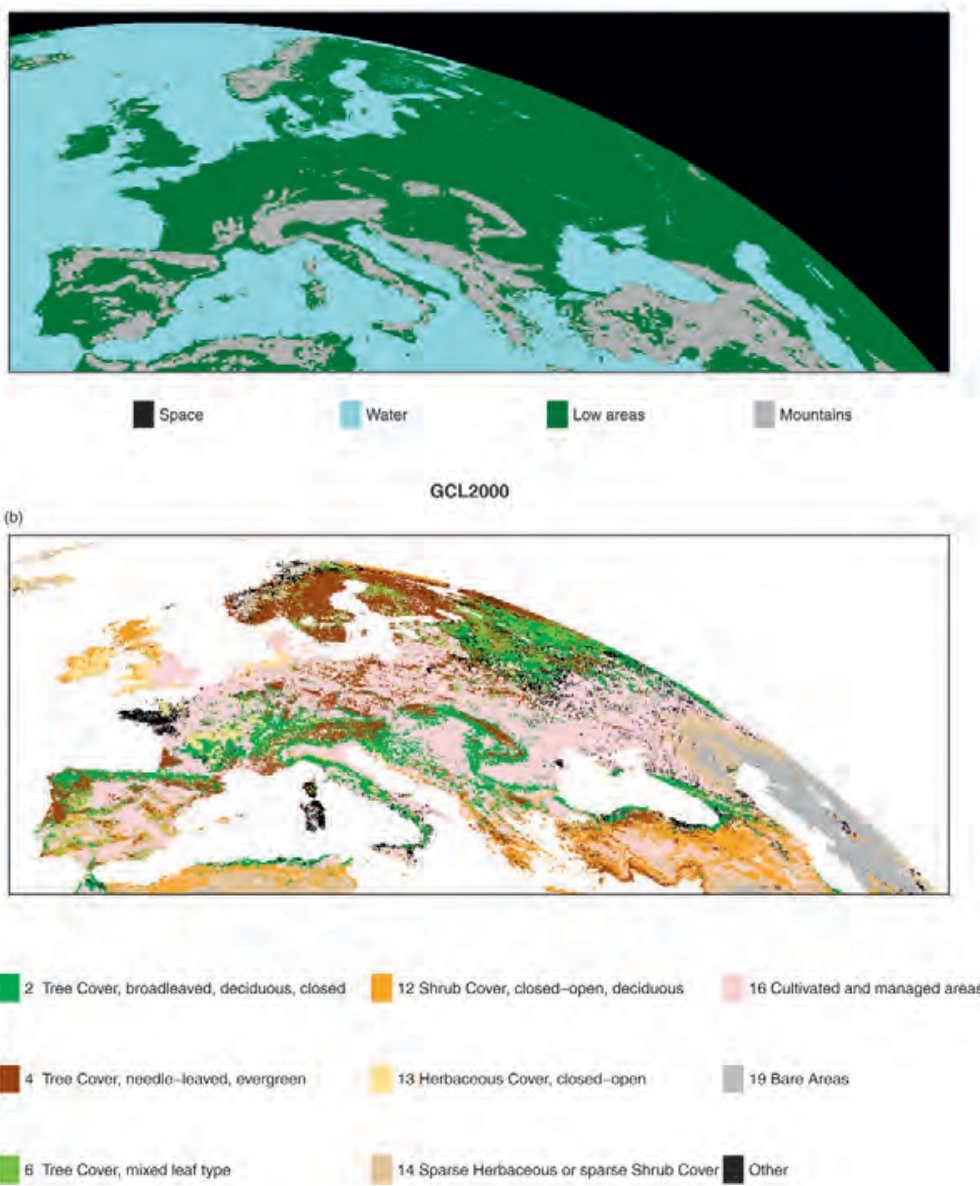

FIG. 2. (a) The height of the terrain in the study area. The snow product is only valid in the low areas. (b) The land-cover classification for the study area according to the GLC2000 Project. Only land-cover classes covering more than $5 \%$ of the area under study are shown. The class numbers are according to the original GLC2000 classes.

It is quite straightforward to estimate whether the surface is totally snow free or totally snow covered, but it is difficult to define when to change from a snow-free to a snow-covered surface. Even a thin layer of snow should be defined as snow covered, because it changes the albedo and radiative properties of the surface. This is quite often the case when there is a new layer of snow. During the melting season, snow cover can be very variable; the surface is a patchwork of snow-covered and snow-free areas of different shapes and sizes. Trees are also a challenge for definition, because the trees can be snow covered or snow free even if the surface is fully covered.

Most of the snow-covered, snow-free, and cloud-covered pixels are fairly easy to detect. Some of the rules are used to classify these pixels. The difficulties occur near the edges of snow and clouds, and also in poorly lit areas. To reduce errors, classification is avoided when there is uncertainty about the surface status. Near the clouds, this means that the unclassified pixel type is preferred. Near the edge between snow-covered and snow-free surfaces some rules will find partially snow-covered pixels although most of these are still classified as snow covered or in some cases left unclassified.

In the beginning of the snow detection, the algorithm sets all pixels as unclassified. Then the tests of Table 2 are applied one by one in the order shown. Finally, each pixel is classified to one of the snow-cover (or snow free) classes or it remains unclassified. Some of the rules are 
TABLE 1. List of the inputs for the LSA SAF SC1 snow-cover algorithm.

\begin{tabular}{lll}
\hline \hline Input type & Code & Description \\
\hline Satellite channels & $R_{1}$ & Radiance in channel 1 $(0.6 \mu \mathrm{m})$ \\
& $R_{2}$ & Radiance in channel 2 $(0.8 \mu \mathrm{m})$ \\
& $R_{3}$ & Radiance in channel 3 $(1.6 \mu \mathrm{m})$ \\
& $R_{4}$ & Radiance in channel 4 $(3.9 \mu \mathrm{m})$ \\
& $R_{9}$ & Radiance in channel 9 $(10.8 \mu \mathrm{m})$ \\
& $R_{10}$ & Radiance in channel 10 $(12.0 \mu \mathrm{m})$ \\
& $T_{\mathrm{B} 4}$ & Brightness temperature in \\
& & channel 4 $(3.9 \mu \mathrm{m})$ \\
& $T_{\mathrm{B} 9}$ & Brightness temperature in \\
& & channel 9 $(10.8 \mu \mathrm{m})$ \\
& $T_{\mathrm{B} 10}$ & Brightness temperature in \\
& & channel 10 $(12.0 \mu \mathrm{m})$ \\
Angles & SAA & Sun azimuth angle \\
& SZA & Sun zenith angle \\
& VAA & Satellite azimuth angle \\
& VZA & Satellite zenith angle \\
Other & LC & Land-cover type \\
& LST & LSA SAF land surface \\
& & temperature $\left({ }^{\circ} \mathrm{C}\right)$ \\
\hline
\end{tabular}

overlapping, and many rules may apply to the same pixel. The relative importance of these rules is currently being analyzed and the decision-making process improved so that the number of misclassified pixels can be reduced and, possibly, the detection of partially snow-covered pixels, which are often near the edge of the snow-covered area, can be improved.
Cloud cover is the most common reason for not classifying a pixel. A pixel is also unclassified if it is too dark or in an area where the satellite elevation angle is too low [i.e., rules (R15)-(R17)]. There are also rules that remove obvious misclassifications, such as pixels where the land surface is too warm to contain snow [rules (R18), (R19) and (R21)]. These rules must come after all other rules.

Most of the cloudy and cloud-free areas can be separated using the brightness temperature difference between channels 10 and 4 and the radiance ratio of channels 3 and 2 , although there is some overlap (Fig. 1a). As opposed to cloud detection, the aim is to find cloud-free pixels and thus to avoid such erroneous classifications where cloudy and possibly cloud-contaminated pixels are defined as snow covered. Classification rules (R1)-(R3) and (R9)(R12) are based on this figure. Rule (R4) is used to find cloudy areas based on a $3 \mathrm{D}$ view of three radiance ratios of channels 1 to 3 .

Classification rules (R5)-(R8) are based on the information from Fig. 1b. The radiance ratio of channels 3 and 2 against the sun azimuth angle differentiates between snow and snow-free pixels very well. The reason for this is the strong relation of the reflective properties of the surface to the bidirectional reflectance distribution function (BRDF), which is different for snow (Peltoniemi et al. 2005a) and different vegetation types (Peltoniemi et al. 2005b). Currently, these rules are defined conservatively to avoid misclassifications, but new rules to classify currently unclassified pixels are being investigated.

TABLE 2. List of classification rules of the LSA SAF SC1 snow-cover algorithm. These rules are applied one by one. If the condition is true, the snow-cover status is set to the defined value. The final snow-cover status is the value set after all the rules have been checked. Here, $\Delta T_{B}=T_{\mathrm{B} 10}-T_{\mathrm{B} 4}$; for other definitions see Table 1 . Logical AND is marked by $\wedge$, and logical OR is marked by $\vee$.

\begin{tabular}{|c|c|c|}
\hline$\Delta T_{B} \geq 0 \wedge R_{3} / R_{2}<0.6 \Rightarrow$ & PARTIAL & (R1) \\
\hline$\Delta T_{B} \geq 2.5 \Rightarrow$ & PARTIAL & (R2) \\
\hline$\Delta T_{B} \leq-2.5 \wedge R_{3} / R_{2}<0.90 \Rightarrow$ & UNCLASS & (R3) \\
\hline$R_{3} / R_{2}<0.96 \wedge R_{3} / R_{2} \geq 0.62 \wedge R_{3} / R_{1}<1.22 \wedge R_{3} / R_{1} \geq 0.77$ & & (R4) \\
\hline$\wedge R_{2} / R_{1}<1.49 \wedge R_{2} / R_{1} \geq 1.15 \Rightarrow$ & UNCLASS & \\
\hline$\Delta T_{B} \geq 1.5 \wedge \mathrm{SAA}<220 \wedge \mathrm{SAA}>700\left(R_{3} / R_{2}\right)^{4}+90 \Rightarrow$ & SNOW & (R5) \\
\hline$\Delta T_{B} \geq 1.5 \wedge \mathrm{SAA}<220 \wedge \mathrm{SAA}<500\left(R_{3} / R_{2}\right)^{4}+90 \wedge \mathrm{SAA}>5.0 \Rightarrow$ & NO SNOW & (R6) \\
\hline$\Delta T_{B} \geq 1.5 \wedge \mathrm{SAA}<220 \wedge R_{3} / R_{2} \geq 0.82 \Rightarrow$ & NO SNOW & (R7) \\
\hline$\Delta T_{B} \geq 1.5 \wedge \mathrm{SAA} \geq 260 \wedge R_{3} / R_{2} \geq 0.30 \Rightarrow$ & NO SNOW & (R8) \\
\hline$R_{3} / R_{2}<0.18 \Rightarrow$ & SNOW & (R9) \\
\hline$\Delta T_{B} \geq-2.0 \wedge \Delta T_{B} \leq 1.5 \wedge R_{3} / R_{2}<0.5 \Rightarrow$ & SNOW & (R10) \\
\hline$\Delta T_{B} \geq-2.0 \wedge \_\Delta T_{B} \leq 20.0 \wedge R_{3} / R_{2}<0.290 \Rightarrow$ & SNOW & (R11) \\
\hline$\Delta T_{B} \geq 5.8 \Rightarrow$ & SNOW & (R12) \\
\hline$R_{3} / R_{1} \geq 1.50 \wedge \Delta T_{B}>-25 \Rightarrow$ & NO SNOW & (R13) \\
\hline$R_{3} / R_{2} \geq 1.05 \wedge \Delta T_{B}>-15 \Rightarrow$ & NO SNOW & (R14) \\
\hline $\mathrm{SZA}>80.0 \Rightarrow$ & UNCLASS & (R15) \\
\hline $\mathrm{VZA}>85.0 \Rightarrow$ & UNCLASS & (R16) \\
\hline $\mathrm{SZA}>70.0 \wedge(\mathrm{SAA}<90.0 \vee \mathrm{SAA}>270.0) \Rightarrow$ & UNCLASS & (R17) \\
\hline$\left(T_{\mathrm{B} 9}+T_{\mathrm{B} 10}\right) / 2 \geq 278.0 \wedge(\mathrm{SNOW} \vee \mathrm{PARTIAL}) \wedge(\mathrm{LC}$ is not forest $) \Rightarrow$ & NO SNOW & (R18) \\
\hline $\begin{array}{l}\text { Date between June and October } \wedge\left(T_{\mathrm{B} 9}+T_{\mathrm{B} 10}\right) / 2 \geq 278.0 \wedge \\
(\mathrm{SNOW} \vee \mathrm{PARTIAL}) \wedge(\mathrm{LC} \text { is forest })) \Rightarrow\end{array}$ & NO SNOW & (R19) \\
\hline Any one of $R_{1}, R_{2}, R_{3}, R_{4}, R_{9}$, or $R_{10}<0.001 \Rightarrow$ & UNCLASS & $(\mathrm{R} 20)$ \\
\hline $\mathrm{LST} \geq 3.0 \Rightarrow$ & NO SNOW & (R21) \\
\hline
\end{tabular}


TABLE 3. List of the rules for the daily product: $N$ is the total number of classified observations during the day for each pixel; $S$ $P$, and $F$ are the numbers of snow-covered, partially snow-covered, and snow-free observations, respectively. These rules are used one after the other from the top, and the final daily classification is the classification in effect after the last rule. Logical AND is marked by $\wedge$, and logical OR is marked by $\vee$.

\begin{tabular}{lll}
\hline \hline Set default value $\Rightarrow$ & UNCLASS & (D1) \\
$S>N / 4 \wedge S>5 \wedge F<3 \Rightarrow$ & SNOW & (D2) \\
$F>N / 3 \wedge F>3 \Rightarrow$ & NOSNOW & (D3) \\
$P>N / 3 \wedge P>3 \wedge F=0 \wedge$ & PARTIAL & (D4) \\
$S>1 \wedge S \leq 4 \Rightarrow$ & \\
$P>N / 3 \wedge P>3 \wedge F>1 \wedge F \leq 6 \wedge$ & PARTIAL \\
$\quad S>1 \wedge S \leq 6 \Rightarrow$ & & (D5) \\
$P>N / 3 \wedge P>3 \wedge F=0 \wedge S>4 \Rightarrow$ & SNOW \\
$P>N / 3 \wedge P>3 \wedge F>0 \wedge S=0 \Rightarrow$ & NOSNOW & (D6) \\
\hline
\end{tabular}

Once per day, the daily snow-cover (SC2) product is calculated using the SC1 products for the day. Again the system classifies each pixel as snow free, partially snow covered, or totally snow covered. For the daily LSA SAF snow-cover product, all of the snow-cover maps produced every $15 \mathrm{~min}$ are combined. The algorithm counts the number of different classifications for each pixel and then determines the final daily classification if there have been reasonable amount of cloud-free observations during the day. The actual rules are presented in Table 3.

The class of partial snow is used if the pixel is classified as snow free and snow covered during the same day or if it is probable that snow does not cover the whole pixel. This class is not yet well defined, because only a very limited number of reliable surface observations could be used to estimate the accuracy of this classification. In the future, this class may be replaced by the snow-covered area (SCA) product.

The last phase of the product generation is quality flagging. Surface type such as forests, solar illumination conditions such as night, sun glint, high terrain, and quality flags are set. Currently all classified pixels (i.e., snow, partial snow, or snow free) are set as high quality, but this will change when an improved quality flagging will be introduced.

\section{Validation data and methods}

\section{a. Use of IMS as the reference analysis}

The NOAA/NESDIS IMS analyses are available as gridded data in American Standard Code for Information Interchange (ASCII) format on the Internet. The higherresolution version of $4 \mathrm{~km}(6144 \times 6144$ grid $)$ was used in this study. IMS products are disseminated in a polar stereographic projection; they were reprojected to same projection as the LSA SAF SC. This projection is not an area-preserving projection, and pixels correspond to
TABLE 4. Contingency table of the comparison between two categorical snow analyses. The symbols $a-d$ represent the different number of pixels observed to occur in each category.

\begin{tabular}{lll}
\hline \hline & \multicolumn{2}{c}{ Analysis 2 (baseline) } \\
\cline { 2 - 3 } Analysis 1 & Snow & \multicolumn{1}{c}{ No snow } \\
\hline Snow & $a$ (hit) & $b$ (false alarm) \\
No snow & $c$ (miss) & $d$ (correct rejection) \\
\hline
\end{tabular}

areas of different sizes. However, as it is the projection in which the LSA SAF SC is disseminated, it was the natural projection for the comparison.

\section{b. Validation measures}

The results of a comparison between two products can be shown in a $2 \times 2$ contingency table (Table 4). Hits $a$ is the number of cases in which both analyses reported snow, correct rejections $d$ is the number of cases in which neither of the analyses reported snow, false alarms $b$ is the number of cases in which only the LSA SAF SC, the analysis under investigation, reported snow, and misses $c$ is the number of cases in which only the baseline analysis, IMS, reported snow. The measures used are summarized in the appendix.

In this study, attention should be paid to the number of correct rejections. In Europe, almost all snow melts in summer, as is shown below. Then the number of correct rejections, $d$, is several magnitudes greater than $a, b$, or $c$ and proportion correct (PC) tends to 1. After some manipulation, it is easily shown for Heidke skill score (HSS) that

$$
\lim _{d \rightarrow \infty} \operatorname{HSS}=\frac{2 a}{2 a+b+c}
$$

which is the critical success index (CSI) where a double weight has been given to hits $a$ [in, e.g., the clustering community where the CSI is known as the Jaccard index or coefficient, this is known as the Sorensen's similarity coefficient (Kaufman and Rousseeuw 1990)]. Thus, in this study, HSS and the CSI are closely related, and the decision was made to concentrate on the HSS. Further, if $b$ is less than $a$ and $c$, HSS and CSI obtain values similar to hit rate $(H)$.

\section{c. Validation strategy}

Because of clouds or inadequate solar illumination, not all pixels can be classified by LSA SAF SC, and the number of pixels classified varied from day to day. No attempt was made to mitigate this; LSA SAF SC was compared to IMS only for pixels classified by LSA SAF SC.

The data of this study can be thought of as a threedimensional grid consisting of two-dimensional maps and time. Each data point has one of the four possible values 
shown in Table 4. First, the data points were merged for all dimensions, resulting in one contingency table. Second, the values on each map were merged, resulting in one contingency table for each map; the results can be shown as time series.

Third, the values in the time dimension were merged, producing a map where each pixel has a contingency table of its own. This makes it possible to assess the spatial performance of the algorithm. It is reasonable to suppose that snow behaves differently over different terrain types. Whereas the IGBP land cover was used for the development and the operational run of the algorithm, the GLC2000 land cover was used for the validation work (Fig. 2b). The GLC2000 was chosen because, first, it was more up to date than the IGBP and, second, it was an independent data source, which is useful in validation.

The effect of land cover was investigated subjectively first by examining the maps showing the distribution of measures and then objectively, in quantitative fashion. Using a verification measure (e.g., PC or HSS), it was calculated whether certain areas (e.g., needle-leaved evergreen forest) were more probable to have values higher or lower than the median value. The median, instead of the mean, was used, because the distribution of values is far from Gaussian. This ratio of probabilities can be approximated by the ratio of pixels with values higher and lower than the median value $\tilde{X}$ of the whole map:

$$
\frac{P(X>\tilde{X})}{P(X<\tilde{X})}=\frac{\frac{\text { No. pixels }>\tilde{X}}{\text { No. pixels }}}{\frac{\text { No. pixels }<\tilde{X}}{\text { No. pixels }}}=\frac{\text { No. pixels }>\tilde{X}}{\text { No. pixels }<\tilde{X}} .
$$

Values around the unity mean that there is no notable difference in the ratio of high and low values, and the verification measure is not dependent on the characteristics of the area. A ratio less (greater) than 1 suggests that the lower (higher) values are more likely for the area. Confidence intervals were computed with bootstrapping using the method outlined in Hamill (1999). This method assumes that there is a high correlation between spatial observations (grid points) but no correlation between days (grids). However, our data may not be in line with the latter assumption, and so the true confidence intervals may be somewhat greater.

\section{Validation results}

The algorithm was tested using data from Europe for the period of January 2007 to December 2009. From January 2007 to July 2007, version 1 was operational, and after that, version 2, so operational version 2 processed more than 4 times as many images as operational version
1. For the comparison between algorithms to be meaningful some days should be processed with both algorithms. So, in spring 2007, 25 days were processed with version 2 , but some of these images were used for development of the algorithm and, all in all, there are 20 days that were not used for the algorithm development and that were processed by both versions of the software.

So that the results concerning the differences between algorithm versions would be less ambiguous, it would be necessary to reprocess all of the days from January 2007 to July 2007 with version 2, but unfortunately this would require substantial work beyond our current resources.

\section{a. Visual inspection of products for one day}

For subjective evaluation, false-color RGB combinations provide a useful tool. The image is constructed from three grayscale images of satellite channels, each with different characteristics, and the colors can be given a physical interpretation. Different false-color RGB combinations can be constructed that emphasize different phenomena. Here the main aim was to emphasize snow and the RGB combination of SEVIRI channels VIS0.6, IR1.6, and inverted IR10.8 was used. This combination clearly separates snow from low clouds, usually made of water droplets, but is not as good in separating snow from high clouds that are usually made of ice particles. The colors in the image have a physical interpretation: the snow-free surface reflects better in IR1.6 (the green component) than in VIS0.6 (the red component) and is relatively warm (the blue component is small, because values are inverted), and therefore it shows greenish in the RGB image. Relatively warm low clouds made of water droplets reflect well both in VIS0.6 and IR1.6, which make their color much lighter yellowish; colder water clouds more white-yellowish. Snow on surface reflects well in VIS0.6, but very little in IR1.6, and are rather cold (the blue component is larger), making snow purple. Ice clouds are of lighter shades of purple because their reflectance in VIS0.6 and IR1.6 is similar to snow on the ground, while they are usually much colder than the surface (the blue component is larger).

The RGB composite of SEVIRI images at 1200 UTC 26 January 2007 and LSA SAF SC (version 2) and IMS products for the same day are shown in Fig. 3. The day was relatively cloud free, with snow even in southern Europe. The poor illumination of northern regions can also be seen. The IMS snow-cover analysis (Fig. 3b) classifies all of the pixels, but several snow edges seem too smooth and unphysical (e.g., in the area north of the Black Sea, 1 in Fig. 3b). The LSA SAF snow-cover algorithm (Fig. 3c) has used all of the images available during the day and thus covers more surface than the 1200 UTC image (Fig. $3 a)$. The area left unclassified, mostly because of clouds, is 
(a)

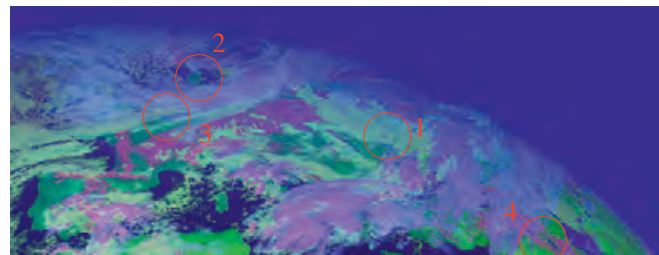

(b)

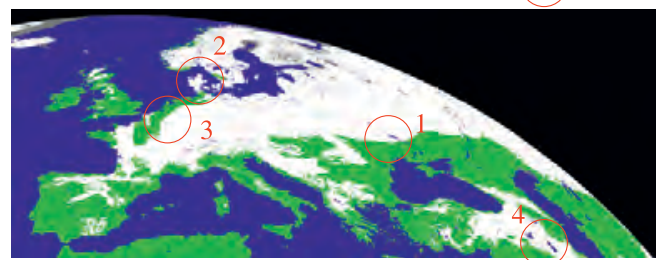

(c)

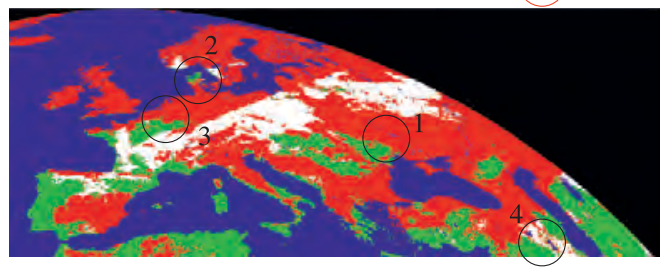

FIG. 3. (a) The RGB combination of SEVIRI channels VIS0.6, IR1.6, and IR10.8, (b) the NOAA/NESDIS IMS snow product, and (c) the LSA SAF snow-cover product for 26 Jan 2007. In both satellite products, snow is white and snow-free areas are green, sea areas are blue, and unclassified areas are red. In the RGB combination, snow is purple, snow-free areas are green, sea areas are dark blue, water clouds are yellow, and ice clouds range from light purple to light blue. The numbers in (b) refer to the discussion in the text

quite large, but the snow analysis in cloud-free areas shows some interesting differences between the products. Denmark is snow covered in the IMS but snow free in LSA SAF SC, and the satellite image suggests the latter (2 in Fig. 3b). The edge of the snow-covered area in France ( 3 in Fig. 3b) is different in the products and LSA SAF SC again agrees better with the satellite image. The third example can be seen in southern Turkey (4 in Fig. 3b), where the IMS shows a large snow-covered area. In the LSA SAF SC, the snow-covered area is much smaller and much more patchy, which seems to be in good agreement with satellite images, although this area is classified as mountainous region and is thus outside the scope of LSA SAF SC.

\section{b. Results merged to one contingency table}

All data of different versions of LSA SAF SC were merged, resulting in one contingency table for version 1 , test cases, and an operational run of version 2 (Table 5). From the IMS product it can be calculated that there are about half million land surface pixels that can be classified. Both version 1 and version 2 leave a substantial amount of pixels unclassified, about $25 \%$ and $40 \%$, respectively, because of clouds or inadequate solar illumination. In addition, some pixels, mainly at the cloud and snow edges, are not classified because the pixels do not match any of the rules used. Version 2 is more conservative as to what pixels to classify than version 1 , as version 2 avoids classification in conditions where misclassifications are probable.

In Europe, most of surface is snow free most of the time, and thus correct rejections occurred for about $90 \%$ of the pixels in all of the images. In spring 2007, version 2 had less misses than version 1 , which yielded more hits in version 2 than in version 1 , but the differences in false alarms and in correct rejections were negligible. For version 2, the differences between false alarms and misses were also rather small in spring 2007 and in the operational run, but there were more hits and fewer correct rejections in spring 2007 because the operational run includes summers when very little snow was present.

In spring 2007, all measures had better values for the test cases of version 2 than for version 1 . The operational

TABLE 5. Aggregated results from January 2007 to December 2009. From January 2007 to July 2007, version 1 was operational but some days were run with version 2. After July 2007, version 2 was run operationally.

\begin{tabular}{lccc}
\hline \hline & \multicolumn{2}{c}{ Spring 2007 } & $\begin{array}{c}\text { Summer 2007-09 } \\
\text { Version 2 (operational) }\end{array}$ \\
\cline { 2 - 4 } & Version 1 & Version 2 (test cases) & $6898843(3.9 \%)$ \\
Hit $a$ & $2202274(4.4 \%)$ & $564022(8.5 \%)$ & $686785(0.4 \%)$ \\
False alarm $b$ & $344737(0.7 \%)$ & $29952(0.5 \%)$ & $1553271(0.9 \%)$ \\
Miss $c$ & $2546168(5.1 \%)$ & $72760(1.1 \%)$ & $169307675(94.9 \%)$ \\
Correct rejection $d$ & $45116671(89.9 \%)$ & $5976827(90.0 \%)$ & 0.897 \\
Bias & 0.536 & 0.933 & 0.004 \\
$F$ & 0.008 & 0.005 & 0.816 \\
$H$ & 0.464 & 0.886 & 0.091 \\
FAR & 0.135 & 0.050 & 0.987 \\
PC & 0.942 & 0.985 & 0.854 \\
HSS & 0.576 & 0.908 & 842 \\
Images & 190 & 42 & $39 \%$ \\
Unclassified pixels & $24 \%$ & $54 \%$ & \\
\hline
\end{tabular}


version 2 had slightly lower values than test cases, but this is understandable, as test cases covered only a limited time span and some days were used in development of the algorithm; this means that some overfitting may have occurred.

All versions detected less snow than IMS as the bias was less than 1 in all versions and was the least in version 1 (bias $\approx 0.5$ in version 1 and bias $\approx 0.9$ in version 2 ). When IMS detected snow, it was detected by version 1 only half of the time $(H \approx 0.5)$, while version 2 detected $80 \%(H \approx 0.8)$. But when LSA SAF SC detected snow, usually it was also detected by IMS, only around $10 \%$ of this snow was not detected by IMS [in both versions, the false-alarm ratio $(\mathrm{FAR}) \approx 0.1$, and this amounted to less than $1 \%$ of snow-free areas in IMS [in both versions, the false-alarm rate $(F)<0.01]$.

Using $\mathrm{PC}$ as a measure, both version 2 and version 1 agree well with IMS $(\mathrm{PC}>0.9)$. High $\mathrm{PC}$ values are derived from correct rejections, which dominate the other components and PC can be considered somewhat overoptimistic in depicting the skill of LSA SAF SC. Skill scores yield more realistic results. And indeed, the difference between IMS and LSA SAF SC is more pronounced in $\mathrm{HSS}$, where $\mathrm{HSS} \approx 0.6$ for version 1 and $\mathrm{HSS} \approx 0.9$ for version 2 .

\section{c. Results for days when both versions were available}

In Table 5, the results for version 2 in spring 2007 included days that where used for the algorithm development. Here the focus is on 20 days that were not used to develop the algorithm, but for which both version 1 and version 2 were run. During these days, three different areas can be distinguished: an area were both algorithms where run (BOTH), an area where only version 1 was run (OLDONLY), and an area where only version 2 was run (NEWONLY). However, the amount of pixels in NEWONLY is only about $3 \%$ of pixels in BOTH and was not investigated further. But the amount of pixels in OLDONLY is still about $40 \%$ of the pixels in BOTH and meaningful comparisons can be made. For these days a contingency table was calculated, from which further measures can be calculated.

In the first test, the daily results of version 1 in $\mathrm{BOTH}$ were compared to those of version 1 in OLDONLY. The values for different measures $(H, \mathrm{FAR}, \mathrm{PC}$, and HSS, only PC, and HSS are shown) of version 1 in BOTH were subtracted from the values of version 1 in OLDONLY (Fig. 4a). If results of different areas are not significantly different, the differences should be around zero. But this is not the case, version 1 yielded better results in BOTH than in OLDONLY. This can be interpreted so that OLDONLY is harder to classify than BOTH and version 2 has made a good choice in refusing to classify that area.
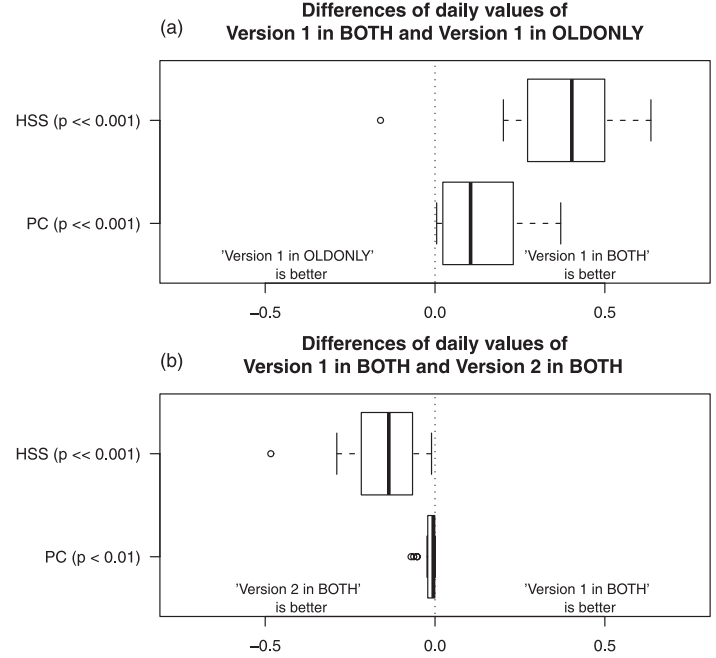

FIG. 4. Twenty-day run of version 1 and version 2. Daily results (using PC and HSS) of version 1 in the area where both version 1 and version 2 were calculated (version 1 in BOTH) are compared with (a) version 1 in the area where version 2 was not calculated (version 1 in OLDONLY) and (b) version 2 for the common area (version 2 in BOTH). The differences are shown as box-and-whisker plots. (The median is shown as a thick line. The hinges show the first and third quartile. The whiskers extend to a data point no more than 1.5 times the interquartile range (IQR) from the median, while data points still farther from the median are plotted.) The $p$ value is calculated for a two-sided $t$ test that the mean of differences is equal to zero.

In the second test, version 1 in BOTH was compared with version 2 in BOTH (Fig. 4b). In this case, version 2 yielded better values than version 1 . So even if version 1 had not classified difficult areas of OLDONLY, it would still give inferior results to version 2 .

The results were statistically significant at the $95 \%$ level with the exception of the second test for FAR, but even then results were significant at the $90 \%$ level.

\section{d. Seasonal variability of results}

The results as time series, when a contingency table is calculated from each image, give a detailed view of the seasonal variability of snow. The amount of snow varies, as the dataset includes three winters and three summers. The maximum extent of snow is in February (Fig. 5a); the snow starts to melt in mid-March and has melted almost completely by the end of May. The remaining snow is found on mountaintops and glaciers, which are mostly outside the scope of LSA SAF SC. New snow starts to accumulate in November. The surface area that is classified varies both because of the varying cloud cover and also with the season, as during the winter the zenith angle can be too high to enable classification for all day in 


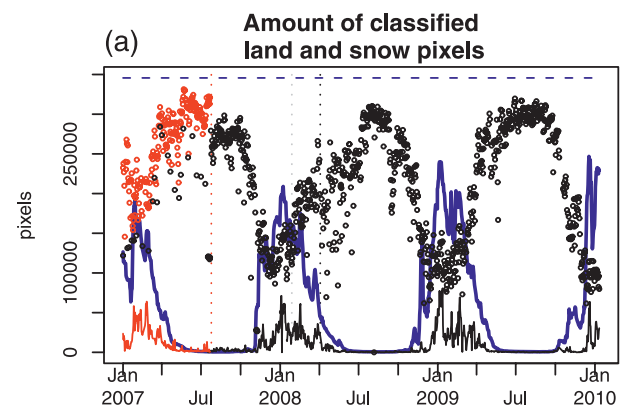

(b)

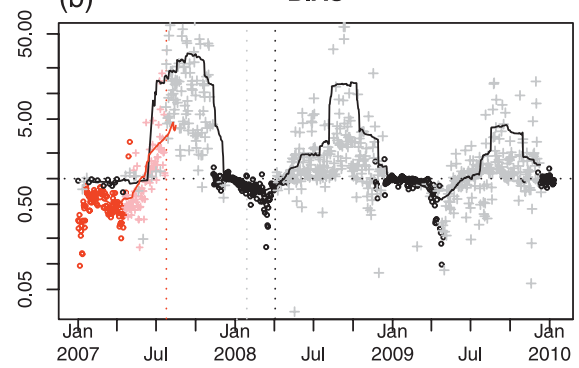

(c)

FAR

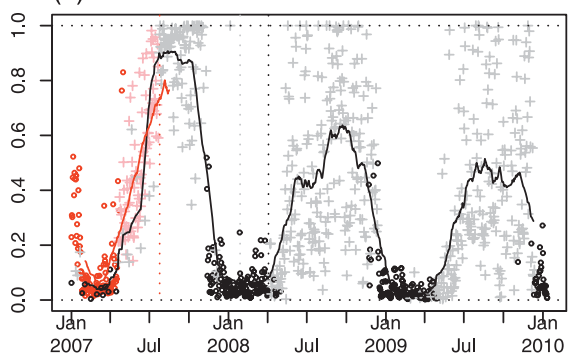

(e)

PC

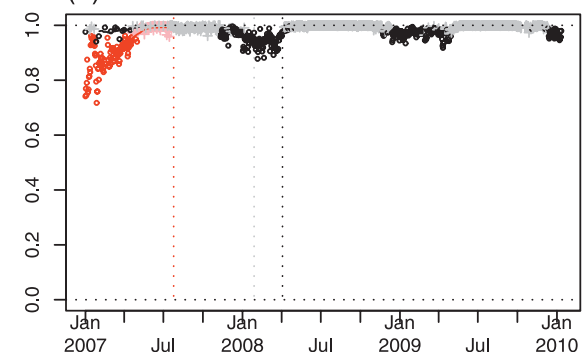

(d)

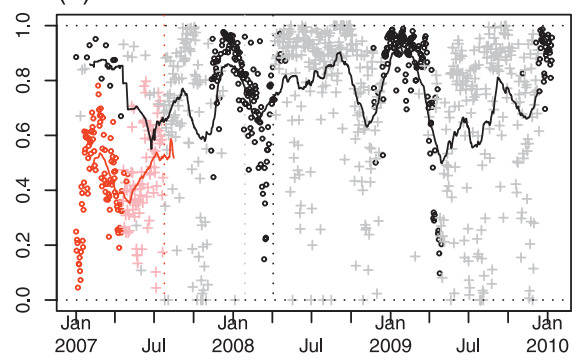

HSS

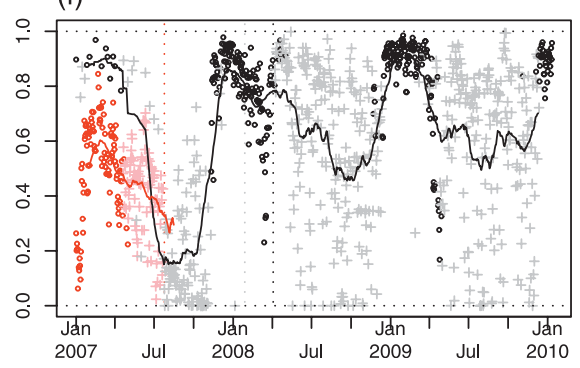

FIG. 5. (a) Amount of cloud-free land pixels (blue dashed line, IMS; red circle, version 1; black circle, version 2), and amount of snow-covered pixels (blue line, IMS; red line, version 1; black line, version 2). (b) Bias, (c) FAR, (d) $H$, (e) PC, and (f) HSS for version 1 (red circle) and version 2 (black circle) when compared with the IMS product. When the correct rejections exceed the other classes by more than 20 times, version 1 is shown in pink and version 2 in gray crosses. Vertical dotted lines show the transition from version 1 to version 2.02 (red), version 2.05 (gray), and version 2.10 (black). Curves show the two-month moving average of the data.

northern regions. In addition, the results should be given less emphasis when the absolute amount of snow is very small in summer, as the results vary greatly owing to even slight differences in snow cover between products. Therefore, days when there are more than 20 times more correct rejections than other classes are depicted with a different color in the rest of the plots in Fig. 5.

When a considerable amount of snow is present, version 1 constantly detects less snow than IMS, and bias is constantly less than one (Fig. 5b). The difference between version 2 and IMS is not as pronounced, but even so LSA SAF SC is inclined to detect less snow. In summer, when the absolute amount of snow is very small, bias may vary erratically and can be considerably more than or less than one. During winter 2007, test cases of version 2 had consistently better values than test cases of version 1 , but the difference disappeared as spring progressed.

The amount of snow detected by LSAF SAF SC when IMS detected none was slight in both versions and $F$ was near zero throughout the test period (not shown). In winter, most of the snow detected by LSAF SAF SC was also present in IMS; FAR started out with low values in winter, but the values increased as the snow melted (Fig. 5c). In summer, FAR can reach unity, meaning that none of the snow detected in LSAF SAF SC is present in IMS. Especially in summer 2007, this coincides with bias $>1$, 
but FAR can be quite high when bias $\approx 1$. In such a case, the snow would be in completely different areas even if the amounts of snow were comparative. In the summer of 2007, FAR rose to near unity for a considerable period, which was corrected by introducing special rules for summer. The difference between the test cases of version 2 and version 1 is not clearly visible.

On average, LSAF SAF SC detected about $80 \%$ of the snow detected by IMS $(H \approx 0.8)$, but the amount varies and can be near unity or even zero (Fig. 5d). The seasonal variability in $H$ was not as apparent as it was for FAR. In spring 2007, version 2 consistently had better values than version 1 .

According to PC (Fig. 5e), version 2 and IMS did not differ to any large extent and the differences all but disappeared during summer. Version 1 had lower values during winter but comparable values in summer. During other winters, the operational PC dropped lower than in the test cases but was still higher than version 1 .

During the winter HSS agreed with PC that version 2 was not very far from the IMS snow cover, even if the values were somewhat lower (Fig. 5f), but as the snow melted the skill substantially diminishes because not much skill is needed to say that no snow is present during summer. CSI yielded similar results, only with slightly lower values than HSS (not shown). The pattern of HSS was also very similar to that of $\mathrm{H}$, but the HSS values were lower in summer. There was a period of very low values in the second half of 2007 . Version 1 gave lower values for HSS than version 2 during winter, but after the snow started to melt the difference was no longer as evident. It is encouraging that there is no evident difference between the test cases in spring 2007 and the operational run afterward.

\section{e. Spatial variability of results}

During the operational period when only version 2 was available, LSA SAF SC differed from IMS at the very edge of the satellite view, as PC had low values there (Fig. 6a). Otherwise, the spatial distribution of PC had very high values for most of the area. Additionally, HSS had low values in the areas where the snow cover was mostly transitory (Fig. 6b). When the snow cover was present for only a couple of days, a constant analysis of no snow would still yield good grades for PC, but would not show much skill and would yield low grades for HSS. LSA SAF SC detected more snow mainly in southern Europe, where bias $<1$, and less in the north (Fig. 6c). However, there were areas where HSS and bias could not be calculated, as when no snow was detected by either products (or both products detected snow in all cases) and only correct rejections (or hits) had nonzero values, in which case HSS and bias had zero in the denominator. Areas where HSS or bias could not be computed are ignored in the rest of the analysis.

\section{f. Spatial results for different land-cover classes}

The spatial performance of version 2 over different terrain types was investigated using only land classes covering more than $5 \%$ of the area under study. Thus only 8 out of the 22 classes of GLC2000 were used, but they covered more than $95 \%$ of the area. The largest terrain types were cultivated and managed areas (43\%) and different forest types ( $27 \%$ of the area). For each class, ratios of probabilities of HSS and PC were calculated (Fig. 7). Our intuition was that most problematic areas would be forests, as forests block the snow surface from being visible and the shadows of the trees decrease the reflectance observed above the forest canopy (Salminen et al. 2009). And, indeed, for both HSS and PC, the ratios for tree-covered areas were less than unity; meaning those areas are more likely to have smaller values than the median of the values. For the other vegetation types, the results were not as clear. For shrub and herbaceous areas, HSS suggested low values whereas PC suggested no difference or high values. Sparse shrub and herbaceous areas gave little indication of to high values, but the ratios are seldom unity. Mostly smooth areas (cultivated and managed areas and bare area) were more likely to get higher, better values. However, most ratios were not very far from unity, and most of the time they were only about twice as likely to get values higher or lower than median values. Still, these results encourage taking terrain types more into account in further development of the algorithm. Furthermore, performing the same experiment using the IGBP land-cover classification produced similar results (not shown), so the results are fairly robust and not confined to one land-cover classification scheme.

\section{Discussion and conclusions}

This article introduces the LSA SAF snow-cover product and also continues the validation work started in Hyvärinen et al. (2009), where no snow product was deemed to present the truth. In this study the NOAA/ NESDIS IMS product was chosen as the reference for verification measures. Version 2 of LSA SAF classified fewer surfaces than version 1 but had higher values of the validation measures in those areas, thereby increasing the usability of the product for NWP, where the accuracy of the data is much more relevant than large areal coverage.

Because of the lack of snow in southern Europe, there were large areas where many verification measures had zero in the denominator and were thus undefined. How to handle these areas in a more principled way would be an interesting topic for future study. A more 
(a)

Spatial distribution of PC in Version 2 (2007-2009)

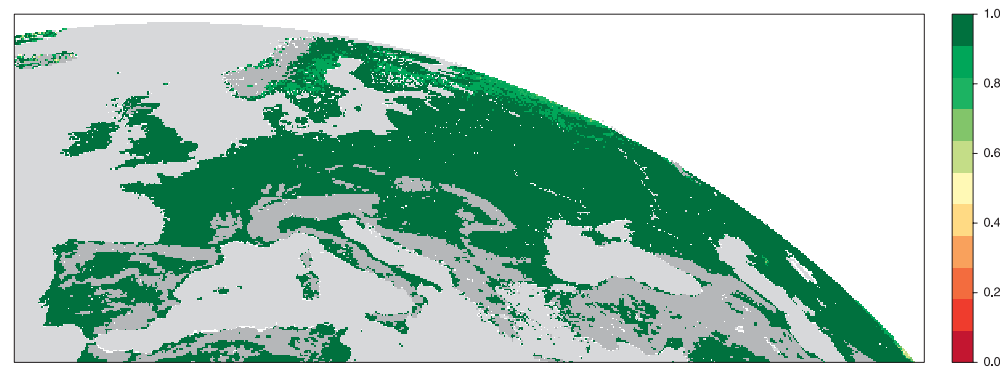

(b)

Spatial distribution of HSS in Version 2 (2007-2009)

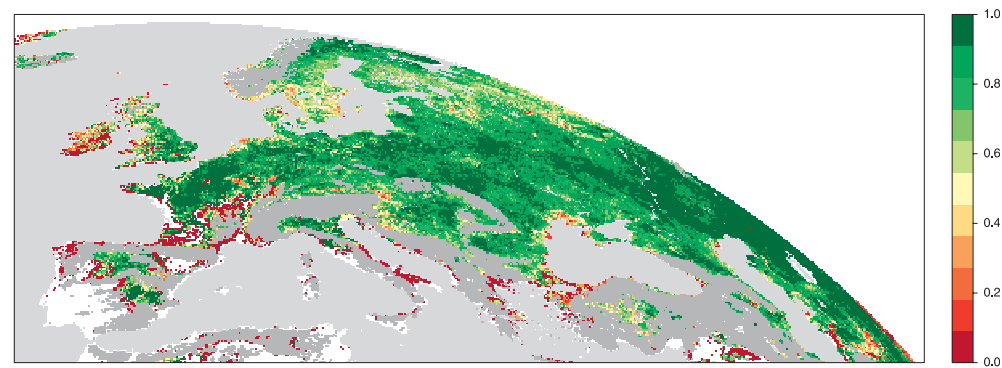

(c)

Spatial distribution of BIAS in Version 2 (2007-2009)

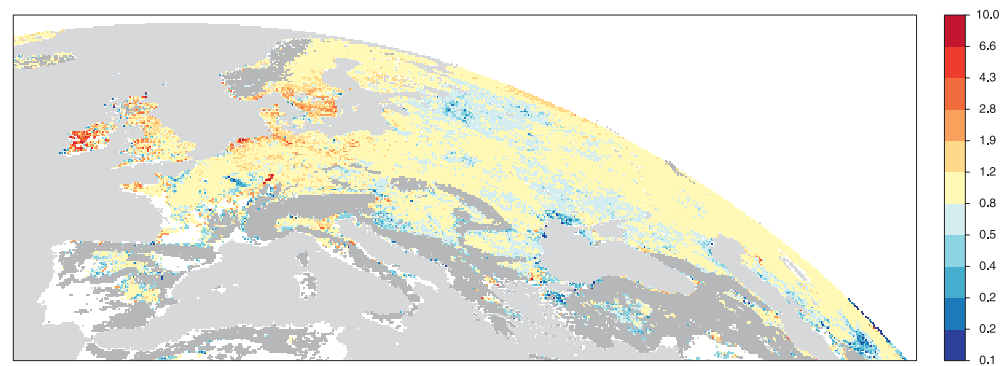

FIG. 6. Spatial distribution of (a) PC, (b) HSS, and (c) Bias in version 2 from July 2007 to December 2009. HSS and bias cannot be computed in areas where the denominator is zero.

Bayesian-oriented analysis might be able to give scores for these areas using some a priori distribution of values that would then be adjusted on the basis of observations. Another approach would be to assign some predefined value to these areas. This has been discussed for similar measures, but in a different context, by Batagelj and Bren (1995).

Both version 2 and the NOAA/NESDIS IMS product presented a reasonable and realistic snow-cover analysis, particularly during the winter season. The disagreement between products was at its largest outside the winter season and in areas where the snow cover was mostly transitory. Especially when there is great temporal variability in the snow cover, it may no longer be feasible to use NOAA/NESDIS IMS as the ground truth for verification measures, as it is hard to say whether NOAA/ NESDIS IMS really presents the truth. For example, on 12 October 2007, there was a snow-covered belt across Scandinavia that was not detected by the IMS product, but which the LSA SAF snow-cover algorithm detected correctly. This correct detection was of course penalized 


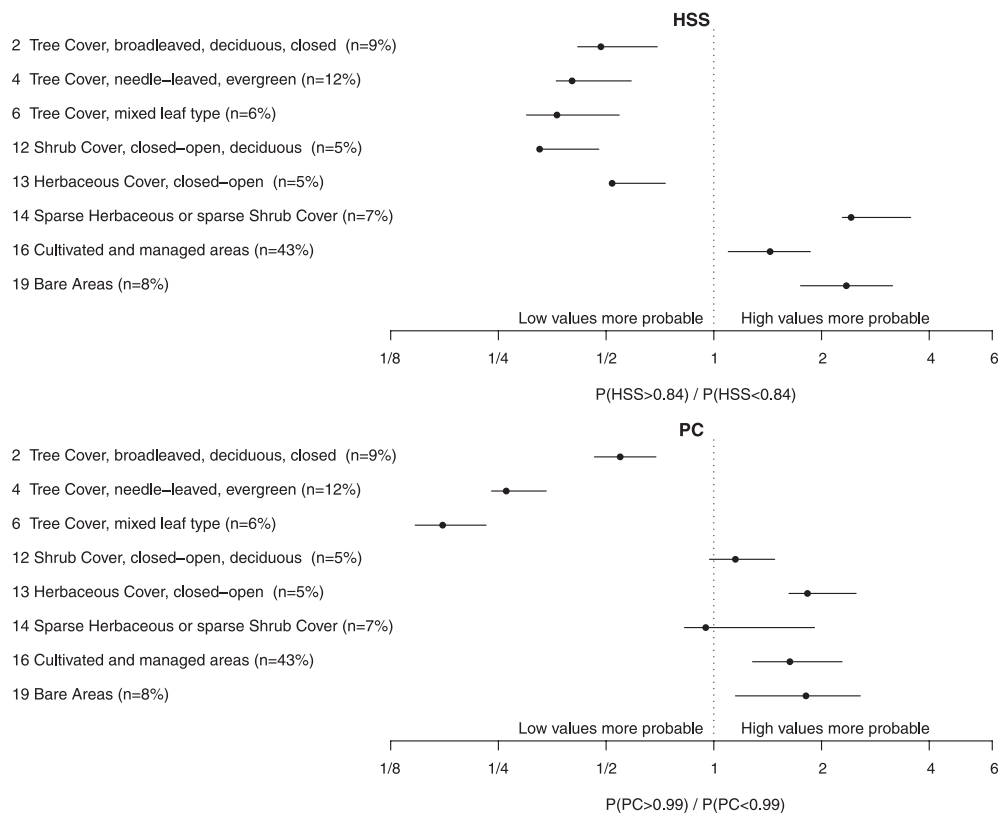

FIG. 7. The probability of high and low values of HSS and PC as a function of land cover. Only GLC2000 classes covering more than $5 \%$ of the study area were used. The class numbers are according to the original GLC2000 classes.

when compared with IMS. Further validation must rely on surface observations. Automatic snow observations have given less than satisfactory results, but advances in ground-based observations are taking place. For example, a digital camera attached to a measuring tower could provide an adequate estimate of the fractional snow cover (M. Takala 2010, personal communication). In addition to operational observations, measurement campaigns, such as Snow Reflectance Transition Experiment (SNORTEX; Roujean et al. 2009), offer valuable support for the validation of products. The feasibility of a method to measure fractional snow cover is being studied, but the results are not yet available.

The different versions of the algorithm gave somewhat surprising results, as our simple version 2 performed better than version 1 based on the state-of-the-art algorithm presented by NWC SAF. The surprising outcome can be explained by the tendency of version 2 to refuse to classify hard-to-classify areas. This comes at a price, as our algorithm classifies less surface area. For NWP, however, this withholding of some data is not a serious problem. On average, the background field gives a good estimate of the actual snow cover, and therefore gaps in the observations are generally not a serious obstacle. Biased or otherwise misleading snow observations would be a much worse problem.
Future plans for the algorithm development are concentrating on improvements in the individual classification rules, fractional snow-cover analysis, and a version of the algorithm for the AVHRR instrument available on polar-orbiting satellites such as MetOp.

Acknowledgments. This work was financially supported by the Land SAF project, cofunded by EUMETSAT. The first algorithm version was developed by the SMHI. We are grateful to Dr. Sylvain Joffre, Dr. Terhikki Manninen, Dr. David M. Schultz, and Ms. Elena Saltikoff for reading the early versions of this paper and for their many valuable comments. We also thank Dr. Carl Fortelius, Dr. Laura Rontu, and Mr. Kalle Eerola for the discussions we had about the needs of numerical weather prediction.

\section{APPENDIX}

\section{Validation Measures}

There is an extensive literature on different measures calculated from Table 4. Many of them have been named many times and the terminology can be confusing. Overviews of the measures and their history can be found in, for example, Jolliffe and Stephenson (2003) and Wilks (2006). 
This paper follows the terminology of Jolliffe and Stephenson (2003). The basic descriptive measure is the bias:

$$
\text { bias }=\frac{a+b}{a+c}
$$

the ratio of the number of snow pixels in the test analysis to the number of snow pixels in the baseline analysis. The best value for bias is 1 ; less than 1 means underestimation and more than 1 means overestimation.

The contingency table gives the joint distribution of analyses. From this distribution the following conditional distributions are constructed for use as performance measures:

The hit rate $H$ or probability of detection (POD) is

$$
H=\frac{a}{a+c},
$$

and in the perfect analysis this should be 1 . The falsealarm rate $F$ is

$$
F=\frac{b}{b+d}
$$

and in the perfect analysis this should be 0 . The falsealarm ratio (FAR) is

$$
\mathrm{FAR}=\frac{b}{a+b}
$$

and in the perfect analysis this should be 0 .

An intuitive measure of accuracy is proportion correct:

$$
\mathrm{PC}=\frac{a+d}{a+b+c+d},
$$

the fraction of items classified the same way in both analyses. The best value for PC is 1 and the worst is 0 . PC alone is insufficient, in particular when one of the categories dominates. A refinement often used is the critical success index:

$$
\mathrm{CSI}=\frac{a}{a+b+c}
$$

which ignores correct rejections. Like PC, its best value is 1 and the worst is 0 .

Skill scores measure the relative skill by comparing the results with the reference. The reference often used is the random hits, which in this study would be snow correctly detected as snow by chance in the absence of skill. When the reference is the random hits, from $\mathrm{PC}$ we can devise the Heidke skill score:

$$
\mathrm{HSS}=\frac{2(a d-b c)}{(a+c)(c+d)+(a+b)(b+d)},
$$

its best value being 1 and its worst being -1 .

\section{REFERENCES}

Bartholomé, E., and A. Belward, 2005: GLC2000: A new approach to global land cover mapping from earth observation data. Int. J. Remote Sens., 26, 1959-1977.

Batagelj, V., and M. Bren, 1995: Comparing resemblance measures. J. Classif., 12, 73-90.

Derrien, M., and H. LeGléau, 2005: MSG/SEVIRI cloud mask and type from SAFNWC. Int. J. Remote Sens., 26, 4707-4732.

de Wildt, M. R., G. Siez, and A. Gruen, 2007: Operational snow mapping using multitemporal Meteosat SEVIRI imagery. Remote Sens. Environ., 109, 29-41.

Dong, C., and W. Zhang, 2004: China's current and future meteorological satellites systems. Proc. 2004 EUMETSAT Meteorological Satellite Conf., Prague, Czech Republic, EUMETSAT, $17-24$.

Dozier, J., R. O. Green, A. W. Nolin, and T. H. Painter, 2009: Interpretation of snow properties from imaging spectrometry. Remote Sens. Environ., 113 (Suppl.), S25-S37, doi:10.1016/ j.rse.2007.07.029.

Drusch, M., D. Vasiljevic, and P. Viterbo, 2004: ECMWF's global snow analysis: Assessment and revision based on satellite observations. J. Appl. Meteor., 43, 1282-1294.

Dybbroe, A., K. Karlsson, and A. Thoss, 2005: NWCSAF AVHRR cloud detection and analysis using dynamic thresholds and radiative transfer modeling. Part I: Algorithm description. J. Appl. Meteor., 44, 39-54.

Hall, D., G. Riggs, V. Salomonson, N. DiGirolamo, and K. Bayr, 2002 MODIS snow products. Remote Sens. Environ., 83, 181-194.

Hamill, T., 1999: Hypothesis tests for evaluating numerical precipitation forecasts. Wea. Forecasting, 14, 155-167.

Helfrich, S. R., D. McNamara, B. H. Ramsay, T. Baldwin, and T. Kasheta, 2007: Enhancements to, and forthcoming developments in the Interactive Multisensor Snow and Ice Mapping System (IMS). Hydrol. Processes, 21, 1576-1586.

Hyvärinen, O., K. Eerola, N. Siljamo, and J. Koskinen, 2009: Comparison of snow cover from satellite and numerical weather prediction models in Northern Hemisphere and northern Europe. J. Appl. Meteor. Climatol., 48, 1199-1216.

Jolliffe, I. T., and D. B. Stephenson, Eds., 2003: Forecast Verification A Practitioner's Guide in Atmospheric Science. John Wiley and Sons, $240 \mathrm{pp}$.

Kaufman, L., and P. J. Rousseeuw, 1990: Finding Groups in Data: An Introduction to Cluster Analysis. Wiley-Interscience, 368 pp.

Kidder, S. Q., and H.-T. Wu, 1984: Dramatic contrast between low clouds and snow cover in daytime $3.7 \mu \mathrm{m}$ imagery. Mon. Wea. Rev., 112, 2345-2346.

— Molniya orbits for meteorological observation of middle and high latitudes. J. Atmos. Oceanic Technol., 7, 517-522.

Koskinen, J. T., J. T. Pulliainen, and M. T. Hallikainen, 1997: The use of ERS-1 SAR data in snow melt monitoring. IEEE Trans. Geosci. Remote Sens., 35, 601-610.

Lahtinen, P., A. Ertürk, J. Pulliainen, and J. Koskinen, 2009: Merging flat/forest and mountainous snow products for extended European area. Proc. 2009 IEEE Int. Geoscience and 
Remote Sensing Symp., Vol. II, Cape Town, South Africa, IEEE, 563-566.

Li, X., R. T. Pinker, M. M. Wonsick, and Y. Ma, 2007: Toward improved satellite estimates of short-wave radiative fluxes-Focus on cloud detection over snow: 1. Methodology. J. Geophys. Res., 112, D07208, doi:10.1029/2005JD006698.

Matikainen, L., R. Kuittinen, and J. Vepsäläinen, 2002: Estimating drainage area-based snow cover percentages from NOAA/ AVHRR images. Int. J. Remote Sens., 23, 2971-2988.

Matson, M., 1991: NOAA satellite snow cover data. Global Planet. Change, 4, 213-218.

Metsämäki, S., S. Anttila, M. Huttunen, and J. Vepsäläinen, 2005: A feasible method for fractional snow cover mapping in boreal zone based on a reflectance model. Remote Sens. Environ., 95, 77-95.

Miller, S. D., T. F. Lee, and R. L. Fennimore, 2005: Satellite-based imagery techniques for daytime cloud/snow delineation from MODIS. J. Appl. Meteor., 44, 987-997.

— , and Coauthors, 2006: NexSat: Previewing NPOESS/VIIRS imagery capabilities. Bull. Amer. Meteor. Soc., 87, 433-446.

Moura, A., 2006: WMO's contribution to GEOSS and GEONetcast. WMO Bull., 55, 256-260.

Peltoniemi, J. I., S. Kaasalainen, J. Näränen, L. Matikainen, and J. Piironen, 2005a: Measurement of directional and spectral signatures of light reflectance by snow. IEEE Trans. Geosci. Remote Sens., 43, 2294-2304.

, — - — M. Rautiainen, P. Stenberg, H. Smolander, S. Smolander, and P. Voipio, 2005b: BRDF measurement of understory vegetation in pine forests: Dwarf shrubs, lichen, and moss. Remote Sens. Environ., 94, 343-354.

Riisholgaard, L. P., 2004: The case for launching a meteorological imager in a Molniya orbit. Proc. Seventh Int. Winds Workshop, Helsinki, Finland, EUMETSAT, 323-330.
Romanov, P., and D. Tarpley, 2003: Automated monitoring of snow cover over South America using GOES Imager data. Int. J. Remote Sens., 24, 1119-1125.

_ , G. Gutman, and I. Csiszar, 2000: Automated monitoring of snow cover over North America with multispectral satellite data. J. Appl. Meteor., 39, 1866-1880.

Roujean, J.-L., and Coauthors, 2009: SNORTEX (Snow Reflectance Transition Experiment): Remote sensing measurement of the dynamic properties of the boreal snow-forest in support to climate and weather forecast: Report of IOP-2008. Proc. 2009 IEEE Int. Geoscience and Remote Sensing Symp., Vol. II, Cape Town, South Africa, IEEE, 859-862.

Salminen, M., J. Pulliainen, S. Metsämäki, A. Kontu, and H. Suokanerva, 2009: The behaviour of snow and snow-free surface reflectance in boreal forests: Implications to the performance of snow covered area monitoring. Remote Sens. Environ., 113, 907-918.

Schmit, T., M. Gunshor, W. Menzel, J. G. J. Li, and A. Bachmeier, 2005: Introducing the next-generation advanced baseline imager on GOES-R. Bull. Amer. Meteor. Soc., 86, 1079-1096.

Ulaby, F. T., R. K. Moore, and A. K. Fung, 1986: From Theory to Applications. Vol. III, Microwave Remote Sensing, Active and Passive, Addison Wesley, $1097 \mathrm{pp}$.

Wilks, D. S., 2006: Statistical Methods in the Atmospheric Sciences. 2nd ed. Academic Press, 648 pp.

Wiscombe, W. J., and S. G. Warren, 1980a: Model for the spectral albedo of snow. I: Pure snow. J. Atmos. Sci., 37, 2712-2733. , and $-1980 \mathrm{~b}$ : Model for the spectral albedo of snow. II: Snow containing atmospheric aerosols. J. Atmos. Sci., 37, 2734-2745.

World Meteorological Organization, 1995: Manual on codes. Volume I.1, No. 306, 229 pp. 
N. Siljamo, O. Hyvärinen, A. Riihelä and M. Suomalainen (2020). 'Metop/AVHRR snow detection method for meteorological applications'. J. Appl. Meteor. Climatol. Submitted February 2020 



\title{
Metop/AVHRR snow detection method for meteorological applications
}

\author{
Nillo Siljamo* and Otto Hyvärinen and Aku RiIhelä \\ Finnish Meteorological Institute, Helsinki, Finland \\ MarkKu SuOmalainen \\ Center of Ubiquitous Computing, Faculty of Information Technology and Electrical Engineering, \\ University of Oulu, Finland.
}

\begin{abstract}
Snow cover plays a significant role in the weather and climate system by affecting the energy and mass transfer between the surface and the atmosphere. It has also far-reaching effects on ecosystems of the snow-covered areas. Therefore, global snow cover observations in a timely manner are needed. Satellite-based instruments can be utilized to produce snow cover information suitable for these needs. Highly variable surface and snow cover features suggest that operational snow extent algorithms may benefit from at least partly empirical approach, based on carefully analyzed training data. Here a new two-phase snow cover algorithm utilizing data from the Advanced Very High Resolution Radiometer (AVHRR) onboard the Metop satellites of the European Organisation for the Exploitation of Meteorological Satellites (EUMETSAT) is introduced and evaluated. This algorithm is used to produce the Metop/AVHRR H32 snow extent product for the Satellite Application Facility on Support to Operational Hydrology and Water Management (H SAF). The algorithm aims at direct detection of snow-covered and snow-free pixels without preceding cloud-masking. Pixels which can not be classified reliably to snow or snow-free, due to clouds or other reasons, are set as unclassified. This reduces the coverage but increases the accuracy of the algorithm. More than four years of snow depth and state of the ground observations from weather stations were used to validate the product. Validation results show that the algorithm produces high-quality snow coverage data which may be suitable, e.g., for numerical weather prediction, hydrological modelling and other applications.
\end{abstract}

\section{Introduction}

Snow has far-reaching effects on climate and ecosystems. In weather forecasting and climate research, the effects of snow have been widely considered, but a recent study by Niittynen et al. (2018) reiterates that snow may have a strong impact on ecosystems as well. Snow is also an important factor in hydrology, as discussed by Thirel et al. (2012), who emphasized the role of forests in snow products. Pullen et al. (2010) discuss the importance of snow data in weather models and forecasting.

Current remote sensing satellites used for snow detection are either in polar or geostationary orbits, which have their advantages and disadvantages. Most of the seasonal snow is in high latitudes, which are poorly covered by geostationary satellites. Whereas instruments aboard geostationary satellites provide excellent temporal resolution, polar satellite instruments have a better spatial resolution and a better polar coverage, making them often a better option in snow detection. However, due to their orbital characteristics, only a few observations per day may be available, making them more susceptible to, for example, cloudiness preventing surface observation. Other challenges, such as topography, surface properties, weather

\footnotetext{
*Corresponding author: Niilo Siljamo, niilo.siljamo@fmi.fi
}

and snow cover evolution are present in the satellite snow product development for both orbit types.

This paper introduces a new global two-phase snow cover algorithm and product for Advanced Very High Resolution Radiometer (AVHRR) onboard the first generation Metop satellites. This product is a part of the product portfolio of the Satellite Application Facility (SAF) on Support to Operational Hydrology and Water Management (H SAF). Earlier product and algorithm for SEVIRI onboard the Meteosat Second Generation (MSG) satellites provides snow data on limited geographical coverage on MSG/SEVIRI disk, mainly Europe and Africa (Siljamo and Hyvärinen 2011). This new product for Metop/AVHRR provides truly global coverage and a better spatial resolution in polar regions.

The AVHRR onboard polar-orbiting satellites is a wellknown imager instrument with a long history in remote sensing. The visual and IR ranges of the electromagnetic spectrum are covered by 6 channels ( 5 in simultaneous use). Snow extent is usually provided either in binary (snow/no snow) or fractional (percentage) format. The product presented in this paper resembles binary products, with an additional class for a partial snow cover.

There are, of course, many previous snow extent or coverage algorithms and products based on those algorithms. Many AVHRR processing packages include a snow prod- 
uct (e.g., Dybbroe et al. 2005). Hüsler et al. (2012) suggest another method for snow detection over the European Alps using AVHRR. There are well-known global snow analysis products for the more recent Moderate Resolution Imaging Spectroradiometer (MODIS) instrument (e.g., Miller et al. 2005). Notarnicola et al. (2013a,b) present another MODIS snow detection algorithm and validation results with a resolution of $250 \mathrm{~m}$. In the paper by Hori et al. (2017), an algorithm using both AVHRR and MODIS and product covering Northern Hemisphere for years 19782015 is described, along with validation results. The CryoClim project provides cryospheric products using various satellite instruments, including MODIS-based snow cover extent (Solberg et al. 2009).

Even though the AVHRR and MODIS instruments are perhaps the most well-known and most used polar-orbiting instruments for meteorological and hydrological applications, other instruments could be utilized. For example, Selkowitz and Forster (2015) present a method for automatic mapping of persistent ice and snow for Landsat TM and ETM+.

The Aqua and Terra satellites, which have the MODIS instrument onboard, are nearing the end of their lifetime. Their successor, Visible/Infrared Imager/Radiometer Suite (VIIRS) onboard the National Polar-orbiting Partnership (NPP) and the Joint Polar Satellite System (JPSS) satellites, is an instruments with similar channels and snow detection capabilities as MODIS (Miller et al. 2006). Key et al. (2013) describe snow and ice products for the SuomiNPP/VIIRS. Riggs et al. (2017) describe both MODIS and VIIRS snow cover products.

Likewise, in the early 2020s, the Metop satellites with the AVHRR instrument on-board will be superseded by the next generation of EUMETSAT polar satellites (Metop$\mathrm{SG}$ ) with the new Meteorological Imager (METimage). A similar snow product as the one presented here will be developed for the METimage instrument.

In the geostationary orbit, there are several satellites (such as GOES, Meteosat, FY-2, Himawari) and instruments which could be used to provide snow products for different regions. GOES data is used for snow fraction detection (Romanov et al. 2003) and to detect snow and clouds (Li et al. 2007). For MSG/SEVIRI there are several snow extent products, such as H SAF H31 based on the algorithm presented in Siljamo and Hyvärinen (2011). A fractional snow cover product obtained by the FY-2 Visible and Infrared Spin Scan Radiometer (VISSR) instrument is described by Wang et al. (2017).

Instead of relying on one instrument or satellite, the $\mathrm{Na}$ tional Oceanic and Atmospheric Administration/National Environmental Satellite, Data, and Information Service (NOAA/NESDIS) Interactive Multisensor Snow and Ice Mapping System (IMS) (Helfrich et al. 2007; Ramsay 1998) provides high-resolution multisensor snow product. Rather than being fully automatic, the production employs human analysts who merge data from different sources. Validation results for IMS are presented, for example, by Chen et al. (2012).

The pros and cons of different snow products have been studied by many authors. Frei et al. (2012) compare three different snow products (AMSR-E, IMS, MODIS) and discuss the differences of products and future directions in their applications. The merits of the normalized-difference snow index (NDSI) are discussed by Härer et al. (2018) who show that at local scale improvements are needed. A review by The European Cooperation in Science and Technology (COST) Action ES1404 "HarmoSnow" summarizes different approaches used for snow data assimilation in different fields, such as numerical weather prediction (NWP) and hydrology (Helmert et al. 2018).

While optical instruments employing visual and IR bands provide high-quality high-resolution data, they have weaknesses. The most important weakness of using optical channels for snow detection is the requirement of cloudfree conditions. Also, during nights the optical instruments have only limited applicability. The high temporal resolution of the instruments on the geostationary orbit helps to mitigate this in mid-latitudes, as it is more probable that there are cloud-free moments during the day, but for polar orbiters, night and cloud cover are a serious hindrance. There are regions which can be cloud-covered for several days and vast areas may be too dark for snow detection for several weeks during the polar night. However, on favorable conditions, instruments on polar satellites provide excellent spatial resolution.

Active and passive microwave instruments (radars and radiometers) have advantages in cloud-covered and night conditions. Unfortunately, these methods have also associated restrictions, such as lower resolution (microwave radiometers) or very narrow swath widths (radars). The GlobSnow project (Metsämäki et al. 2015) provides both snow extent and Snow Water Equivalent (SWE) products for long time periods, but operational near-real time data does not seem to be available. Many SWE products need ancillary data such as snow depth observations in the product generation. Such dependence on ancillary data is a limiting factor, for example, in NWP, where independent data is required or preferred.

Even the best satellite-based snow products are useless if the users do not have any indication of the reliability and accuracy of the product. Ideally, satellite snow extent products are validated using daily in-situ snow coverage measurements with fine resolution of at least $10 \%$. However, such measurements are not available on operational basis. Regional or local measurement campaigns do not allow continuous global validation.

Fortunately, synoptic weather stations provide in-situ snow depths and the state of the ground observations which can be used for satellite snow product validation. While the weather station network provides global coverage in 
general, there are regions where the network is sparse. When using weather station data for satellite product validation, the representativeness of the observations should be considered. At the moment, weather station observations seem to be the best in-situ option for large scale operational validation of snow products.

There are still limitations in the way the weather stations report snow cover measurements. Many stations report the snow observations only when snow is present, others do not provide snow measurements at all. Therefore, a missing snow observation can not be interpreted as lack of snow at the station. Automatic weather stations can measure snow depth, but many commonly used snow depth instruments do not provide reliable snow depth observations of thin (less than $2.5 \mathrm{~cm}$ ) snow layers.

This lack of snow coverage observations has stimulated creativity and new innovative methods for snow product validation have been described by many authors. For example, Salvatori et al. (2011) suggest the use of fixed webcam photographs for estimation of snow coverage. Piazzi et al. (2019) discuss the use of high-resolution Sentinel2 imagery to validate medium resolution snow products (H SAF H10 and H12). They also evaluate the consistency of Sentinel-2 observations based on in-situ observations and webcam photographs. Even though webcams and high-resolution imagery can be used for validation, both methods are better suited for regional validation or case studies. Hyvärinen and Saltikoff (2010) study the possibilities to use social media as a source of observations.

The new snow detection algorithm for Metop/AVHRR presented in this paper is used to produce the first daily operational global snow extent product (H SAF H32) for EUMETSAT. Earlier, an operational snow extent algorithm for MSG/SEVIRI and the corresponding product (currently known as H SAF H31) with limited coverage was published (Siljamo and Hyvärinen 2011). Both products aim specifically to fill the needs of NWP and hydrological modelling as discussed later in the paper. Extensive trials of MSG/SEVIRI H31 snow extent product in snow analysis have been performed at the Met Office successfully (Pullen et al. 2018, 2019). Similar work based on Metop/AVHRR H32 snow extent has been started at FMI.

During a re-organization of the snow products in the SAFs, the development of the H31 and H32 snow extent products was transferred to $\mathrm{HSAF}$, but the processing and production of these snow products remain in the Satellite Application Facility on Land Surface Analysis (LSA $\mathrm{SAF}$ ). The LSA SAF, in general, is described in Trigo et al. (2011). Both the MSG/SEVIRI H31 snow product and the new Metop/AVHHRR H32 snow product based on the algorithm presented in this paper are available via LSA SAF website. The data is publicly available, but data retrieval requires registration for the LSA SAF website. Single product example files can be retrieved from product description pages.
The algorithm version presented in this paper uses the preprocessed data available in the LSA SAF production system, but the use of the algorithm is not limited to the LSA SAF system, as it can be modified to use other AVHRR data sources and similar auxiliary data.

Even though the algorithm was developed for operational use, it could be used to process archived data to produce snow extent data sets covering longer time spans which are needed in reanalysis and similar applications.

\section{Development of the Metop/AVHRR snow extent al- gorithm}

The natural high variability of snow reflectance, caused by the subpixel variability of the surface, makes the development of a general snow extent algorithm challenging. The resolution of the weather satellite instruments (about $1 \mathrm{~km}$ for Metop/AVHRR) is rather coarse considering the existing variability at scales smaller than satellite resolution (e.g., Cortés et al. 2014; Dozier et al. 2009; Salminen et al. 2009; Wiscombe and Warren 1980a,b). While snow cover itself may vary considerably inside one satellite pixel, there are also other surface features which must be taken in account.

Vegetation type and density have a significant impact on snow detection. The vegetation can vary from sparse and small (e.g., deserts) to thick and large (dense evergreen forests). There may be small scale topography and water bodies of different sizes and shapes. Another source of variability is the snow on the canopy, which can vary from thin sprinkled snow to thick crown-covering snow causing damage to the trees. Finally, the snow cover itself can be thin and patchy (melting season, new snow) or thick enough to cover small surface features.

While the properties of snow, vegetation and surface features cause a significant part of the variability, one must account for the viewing angle which can have large effect. In nadir, trees may cover the surface below, but at the edge of the satellite scene the large viewing angle means that the obscuring effect of the canopy is considerably larger. In dense forests, there may be several trees between the surface and the satellite. However, deciduous forests are far less affected because the leaf canopy is absent during the snow-covered season.

Another challenge caused by trees and other large objects on the surface are shadows. In high latitudes, where the sun elevation is low during the snow season, shadows can cover large parts of the surface, especially in forests. The fraction of the shadowed surface is not constant and is related to the sun elevation and the type and size of the objects causing the shadows. Also, the effects of the atmosphere and clouds should be taken into account.

Considering all sources of variability in landscape and snow cover inside one satellite pixel, along with the technical limitations of the satellite imagery, development of 
a purely physics-based snow detection algorithm would be challenging. A further difficulty is caused by the unavailability of detailed satellite pixel-based information regarding these surface features. Thus, the development of an operational snow extent algorithm will benefit from a partly empirical approach based on a high-quality data set of carefully analyzed satellite images.

Moreover, for an operational product, it is better to use an algorithm where the decisions can be backtracked to a single rule. This restricts using currently popular black box image classification algorithms, such as deep learning.

The snow cover extent algorithm developed for the $\mathrm{H}$ SAF Metop/AVHRR snow extent is a sequence of classifiers. The classifiers operate on hand-crafted features, e.g., algebraic combinations of results from two channels, which are chosen based on the reflection properties of AVHRR channel wavelengths from various land and cloud classes. These features are crafted such that a simple threshold on a feature can be used to identify a class. These combinations of features and thresholds are called rules, which are based on an empirical manually classified data set representing different surface properties as seen from the satellite.

As the aim was to develop a global daily snow extent product, the algorithm had to be divided in two phases (see Fig. 1). The first phase classifies single AVHRR images and creates intermediate single image snow extent product (SC1) on the satellite grid. After the last satellite scene of the day is processed, phase 2 reads all the SC1 products of that day in acquisition time order from the oldest to the newest. These SC1 snow products are then reprojected and merged into the global $0.01 \times 0.01$ degree grid. The data in this grid is then tuned and smoothed to create the final daily snow extent product (SC2).

\section{a. The physical basis of snow detection}

The differences in reflectances of different soil and cloud types can be used for classification of pixels. Typical solar reflectance spectra of soil, vegetation, and different snow types are shown in Fig. 2, along with an example of the water cloud reflectance spectrum. An example of snow detection based on reflective and absorbing bands is the Normalized Difference Snow Index (NDSI). Similarly, socalled 'red edge' (Horler et al. 1983) which refers to rapid change region in the reflectance spectrum of vegetation can be used for vegetation detection.

For more accurate detection, the ratios between AVHRR channels were used. Fig. 3a shows the ratio of radiances from AVHRR channels 3 and 2 for various surface types, and similarly Fig. $3 \mathrm{~b}$ for AVHRR channels 3 and 1. The ratio of channels 3 and 2 discriminates snow pixels from snow-free land and cloud pixels, while the ratio of channels 3 and 1 is better at discriminating snow-free land from other classes. From these figures it can be observed that snow and snow-free regions are quite well separated along the axis representing the ratios - thus, these ratios serve well as features for classifying the pixels. Many such ratios, based on the reflection physics shown in Fig. 2, were researched to find the conditions that make up the final list of rules of the algorithm.

\section{b. Algorithm development principles}

During the development of the earlier MSG/SEVIRI snow extent algorithm Siljamo and Hyvärinen (2011) the driving philosophy was to avoid incorrect classifications, even if it leads to a smaller number of classified pixels and a larger number of unclassified pixels. This approach was discussed with and recommended by the NWP experts (C. Fortelius and L. Rontu, personal communication) at the Finnish Meteorological Institute (FMI).

There is slightly different emphasis between NWP and hydrological modelling. In hydrological modelling, thin snow layers $(\sim 1 \mathrm{~cm}$ or less) are often irrelevant as the water content in them is insignificant. However, in weather models, the presence of a thin snow layer, which alters the radiative properties of the surface, is often important.

Further discussions with the members of the NWP community using different weather models in different institutions enhanced the view that the main points of the snow product targeting the meteorological community and especially NWP are:

directness The number of preliminary steps before actual snow detection should be as small as possible. As the aim is to detect snow and snow-free pixels, there is no reason to use cloud masking as a preliminary step as it does not add value, while cloud masking could introduce errors.

accuracy Accuracy is preferred to coverage. While in many other applications, large coverage is preferred, in NWP missing data is easier to handle than misclassifications.

single-source data Only satellite data from a single instrument will be used. Limited use of static data (such as land cover classification) and other products based on the same instrument and processed in the same system (such as LSA SAF LST) is possible.

availability The NWP community prefers operational products as there is at least some certainty of data availability in the future.

These points form the current development philosophy behind the new Metop/AVHRR snow cover algorithm. The new Metop/AVHRR algorithm does not use third-party or other independent cloud masking, does not try to force classification of all pixels, is based on only Metop/AVHRR data and has reached operational status. 


\section{c. Data sources for the algorithm}

The inputs used in the algorithm are presented in Table 1 . The algorithm utilizes the top-of-atmosphere radiances of three AVHRR channels (1,2 and 3A) and brightness temperatures of two channels (4 and 5). This data is preprocessed in the LSA SAF processing system and then delivered for further processing in Product Dissemination Units (PDU).

In addition to the radiances and brightness temperatures, there is preprocessed auxiliary data in the LSA SAF production system, such as pixel coordinates, elevation, sun and satellite angles, land cover type and water mask (see online documentation available in the LSA SAF website for details). To separate forests and open areas, the algorithm employs the International Geosphere-Biosphere Programme (IGBP) land-cover type (Loveland and Belward 1997) by the U.S. Geological Survey (USGS), which is also preprocessed and readily available in the operational LSA SAF production system (see Table 2). Other land cover datasets could be used as well. Land surface temperature (LST) provided by the LSA SAF production system is employed to remove some misclassifications.

\section{d. The iterative algorithm development}

Development of the algorithm began with subjective classification of selected areas in representative Metop/AVHRR images to create a development data set. Selected areas were classified to eight different classes (snow, snow-free, ice clouds, water clouds, mixed clouds, transparent clouds covering snow or snow-free surface, and water). Clouds were classified to several groups from snow detection perspective to help in the algorithm development. For this, 69 false colour RGB images were used from December 2007 to March 2010 to classify approximately 610000 pixels. This subjectively classified dataset was used as a basis for the algorithm development.

The algorithm consists of rules based on channel differences and ratios, which aim to differentiate snow-covered and snow-free surfaces when possible. Any pixel which does not match one of the rules is left as unclassified. This group includes pixels where classification is too difficult or impossible for any reason, such as darkness (sun elevation angle), probable cloud cover, and difficulties deciding whether to classify pixels as snow-free or snow-covered. As the algorithm aims to detect snow and snow-free surfaces, it is often not possible to determine the exact reason why a certain pixel is not classified.

Based on the subjectively classified data set, the first set of empirical classification rules was created. The development environment provided tools for comparison of different channels, analysis of the behaviour of different classification rules and general analysis of relative importance of different rules. Once the initial set of classification rules was prepared, different satellite images from October
2014 to June 2015 were used to identify misclassifications and challenging cases around the world. Classification rules were updated to correct misclassifications and to find ways to extend the classification to initially unclassified areas.

In this development phase, nearly all of the land surface of the Earth on select days (e.g., all images of February 19 and March 26, 2015) was analyzed to find any suspicious classifications. External data sources, such as Google aerial and street view images, were used to get a better understanding of local conditions (e.g., surface type, vegetation). In addition, MODIS images were used to estimate the current surface status subjectively. The rules were adjusted, in many cases so that challenging pixels were excluded from classification.

This first candidate for the final SC1 algorithm allowed development of the algorithm for the second phase (SC2) which reprojects and merges the results of the $\mathrm{SC} 1$ algorithm to a global daily product in required lat-lon grid. The $\mathrm{SC} 1$ products are processed in order from the oldest to the newest based on the acquisition time. Pixels in the SC1 product are reprojected to the nearest pixel in the global grid and the current classification in that pixel is updated either from default value (unclassified) or the previously set classification value (snow, no snow, partial snow). In practice, there are still small gaps and single-pixel misclassifications in the product after initial merging. Therefore, final smoothing based on $3 \times 3$ pixels around each pixel is used to generate the final product.

This global product candidate was checked visually against other data to find potential misclassifications, which were then studied in more detail using the SC1 product and external sources. Some rules in the algorithm were slightly adjusted.

\section{e. The final algorithm}

The final rules in the $\mathrm{SC} 1$ product, along with certain special conditions, are presented in Tables 3 and 4. As this product is targeting only land surfaces, a water mask provided by the LSA SAF production system is used. The notes column in Table 4 shortly describes the physical interpretation for each rule. The rules used in the generation of the daily product are presented in Table 5.

After the algorithm was implemented in the LSA SAF production system and the product generation started, up to date snow cover data was available from the LSA SAF system for testing purposes. For further validation, a longer time period was required. For that, LSA SAF processed Metop/AVHRR data since January 1, 2015. After successful internal validation, the product reached operational status in early 2018. 


\section{Validation strategy and data}

Quantitative product validation using surface observations was the final phase of the product development. This phase aims to confirm that the system produces valuable and reliable information, so that the product can be accepted for operational use. For this paper, the original internal 22 month validation period was extended to cover the period from January 2015 to March 2019 (51 months) to give more insight into the product and its properties.

\section{a. Visual inspection of products}

In the Fig. 4, an example of the product for April 10, 2017 is presented. At that time, Northern snow cover is melting, but there is still snow in the northern parts of Eurasia and America. Snow is also present in the mountain ranges and other high elevation areas. Even though the snow cover is quite well detected, the limitations of an optical algorithm are obvious as cloud cover creates patches of unclassified land. Darkness is the reason for the unclassified area especially in the Antarctic. There are also some unclassified stripes crossing the equator, which are not covered by daytime satellite swaths. More product examples are presented in Figs. S1-S10 in the online supplementary material.

For an initial subjective evaluation, false-colour RGB images from Metop/AVHRR and other satellite instruments, such as MODIS, were used to estimate the quality of the snow product. Visual inspection of several examples did not reveal any obvious problems, although there were slight differences in the details. Fig. 5 shows parts of Europe in April 15, 2018, in false colour (channels 3/6/7) MODIS RGB image, reprojected false-colour Metop/AVHRR (channels 1/2/3A) and reprojected H32 snow product for the same day. The limitations of the satellite algorithm reduce the number of classified pixels especially in difficult conditions, but the speed of automatic snow detection balances this in practical applications where fast and reliable products are essential, such as NWP.

\section{b. Surface observations for validation}

The synoptic weather station observations were retrieved from the FMI observations database. It has an adequate global coverage and provides easy and fast access to the observations. For validation, stations which had over 20 snow depth or state of the ground observations between January 1, 2015, and October 31, 2016 were selected. Snow depth, state of the ground and $2 \mathrm{~m}$ air temperature observations were retrieved from January 2015 to March 2019 from 4240 stations. Fig. 6 shows the locations of the selected weather stations. Although there are considerable gaps in the global coverage, the regions of seasonal snow are quite well covered.
The state of the ground measurements (as defined in WMO 2015) are not widely available from weather stations, mainly because they are manual observations and an increasing number of weather stations have been converted to automatic operations. However, when this measurement is available, it is well suited for snow extent product validation. Although it does not provide exact information about snow coverage, it provides an estimate (snow-free, less than half, over half, completely snow-covered) which is better than estimated on/off snow coverage based on point observations of snow depth.

The total number of individual observations retrieved from the database was about 68 million. However, some of the stations reported snow cover data only intermittently while many others provided hourly data. For validation, all observations from each station were merged to a single set of daily observations. The highest snow depth of the day or the largest coverage value of the state of the ground was selected as the daily observation of each station. After this, there were about 6.2 million daily observations of snow cover or air temperature from these stations. Of these observations, about 4.1 million included either snow depth or state of the ground observations or both and the rest were only temperature measurements.

As a part of the processing of observations, both snow depth and state of the ground observations were converted to three classes: snow, partial snow and no snow. Both measurement types have different challenges which had to be taken into account in the conversion.

Quite often there is no state of the ground observations. Snow depth is often reported only when snow is present. This makes the snow depth a practically useless indicator of a snow-free surface, because a missing snow depth measurement can be either from a snow-free station or more often from a station which does not measure or report snow depth at all.

There are also different practices of reporting snow depth. Some stations report snow depth in meters, others in centimetres. Some stations use zero or negative values to indicate no snow, others use similar values for partial snow. The state of the ground values are more straightforward to use, but the definitions itself required interpretation.

The state of the ground code values 0-9 ("without snow or measurable ice cover") are used as no snow observations, code values $11,12,15$ and 16 are used as partial snow cover and values 10,13, 14 and 17-19 ("with snow or measurable ice cover") represent snow-covered surface. Snow depth values are classified as snow if snow depth is greater than zero and snow free if snow depth is less than zero. Sometimes there are special values which indicate partial snow cover and these have been converted accordingly. Zero values are converted to partial snow cover as the value should be used to report that there is no snow at the measuring point but there is still some snow at the vicinity. Currently, 
there is some uncertainty as sometimes zero snow depth is used to report no snow.

Then, a list of daily observations in each station was created. Because the selected validation measures need binary data (no snow/snow), different options for treatment of partial snow cover values were tested both in the satellite product and surface observations: converting partial snow to snow-free (hereafter, "no snow"), converting partial snow to full snow cover ("snow") and excluding partial snow ("off").

The daily observations were then converted to a single value which represents the snow coverage at each station. If both snow depth and state of the ground values were available but conflicting, the observation was marked as such and excluded from validation. Two consistent observations or the only observation (snow depth or state of the ground) was used as the daily value for the station and included in the validation data set (about 4.1 million daily observations).

In many cases, clouds or inadequate solar illumination prevent proper classification of the satellite pixels and therefore the number of classified pixels varies from day to day. No attempt was made to mitigate this and thus, if the pixel is not classified as snow-free, partially snowcovered or snow-covered by the algorithm, it is not used in the validation.

\section{c. Validation Measures}

For validation of the snow product with surface observations, the common validation measures computed from $2 \times 2$ contingency table (Table 6 ) were used. Then, following the terminology of Hogan and Mason (2012), cases where the satellite detected snow are either Hits, $a$, when the satellite correctly detected snow, or False Alarms, $b$, when surface observation contradicts it. Similarly, cases where the satellite detected snow free surface are either Correct Rejections, $d$, or Misses, $c$, when surface observation shows the presence of snow.

However, the snow cover has a clear seasonal cycle, and during summer there are relatively few snow observations compared to no-snow observations $(d \gg a+b+c)$. This complicates the validation of snow product because most common validation measures degenerate to trivial values when the number of cases in one category is very small compared with the other.

It is easy to see that the commonly used measure Proportion Correct

$$
\mathrm{PC}=\frac{a+d}{a+b+c+d},
$$

tends to 1 if $d$ dominates. For other measures this might be not as self-evident, but can be seen when the measures are shown as the function of two conditional probabilities
Hit rate, $(H)$

$$
H=\frac{a}{a+c},
$$

and False Alarm Rate $(F)$

$$
F=\frac{b}{b+d}
$$

and the base rate $(s)$

$$
s=\frac{a+c}{a+b+c+d} .
$$

In the perfect analysis, $H$ should be 1 and $F$ should be 0 . Now PC is

$$
\mathrm{PC}=(1-F)(1-s)+H s,
$$

and dominating $d$ implies $s \rightarrow 0$ and $F \rightarrow 0$, so PC tends to 1 as it should.

Slightly counter-intuitively, the often-used replacement for PC, Critical Success Index, which ignores Correct Rejections and therefore used in cases when $d$ dominates, also degenerates. Its definition is

$$
\mathrm{CSI}=\frac{a}{a+b+c}=\frac{H}{1+F(1-s) / s},
$$

and when there are very few snow observations $(s \rightarrow 0)$, CSI will tend to zero. Also the Heidke Skill Score (the PC corrected for random hits)

$$
\mathrm{HSS}=\frac{2(a d-b c)}{(a+c)(c+d)+(a+b)(b+d)},
$$

will tend to zero. On the other hand, the False Alarm Ratio (FAR)

$$
\mathrm{FAR}=\frac{b}{a+b}=\left[1+\left(\frac{s}{1-s}\right) \frac{H}{F}\right]^{-1}
$$

will tend to one, while in the perfect analysis it should be 0 .

A measure that does not degenerate is the Symmetric Extremal Dependence Index (SEDI)

$$
\mathrm{SEDI}=\frac{\ln F-\ln H+\ln (1-H)-\ln (1-F)}{\ln F+\ln H+\ln (1-H)+\ln (1-F)}
$$

that in the perfect analysis should be 1 . The SEDI can be used to assess whether there is a real drop in quality of the snow product in summer or if it's due to the characteristics of the validation measures used. If either $F$ or $H$ is zero or unity, SEDI is not defined. When either $F$ or $H$ was zero, a very small number $(0.0001)$ was added to the numerator and denominator in the calculation of $H$ and $F$. This was done purely for visualization purposes so that all cases would be plotted in Figures below. 


\section{Validation Results}

In the Fig. 7, pixel counts of each class are presented. There are days with some missing SC1 images and days without any data which can be seen in the figure as spikes and vertical stripes. In general, there are a significant number of pixels which can be classified as snow-covered or snow-free.

The validation results for the full validation period (January 2015 to March 2019) are presented in Table 7 for three different sets of stations. All stations are used in the global set of stations while Europe excludes stations outside Europe. The third set of stations, variable, includes station which have reported both snow-free and snow-covered observations during the validation period, i.e., these stations are probably in areas where snow is present occasionally.

Overall, the validation results are very good (HSS > 0.90 and SEDI $>0.95$ for global validation). Thus, the Metop/AVHRR snow extent algorithm is shown to produce realistic estimates of the snow cover. Full validation period hit rate $(H)$ and false alarm rate $F$ are very good as well as PC, HSS and CSI, which all suggest that there are no large scale systematic difficulties in the algorithm. Especially SEDI suggests that the algorithm produces good results during the summer which could be rather challenging period due to small number of snow-covered pixels.

As expected, there are differences when the results of different treatments of partial snow are compared. Table 7 suggests that either excluding partial snow or converting these pixels to no snow produce the best scores, whereas conversion of partial to full snow cover deteriorates the validation score. This implicates that partial snow cover is both difficult to measure realistically and to classify automatically. However, it seems that areas which are partially snow-covered have more similarities with a snowfree surface than a snow-covered surface.

Further analysis of partial snow cover both in the algorithm and in the observations would benefit from more detailed observations, such as high-resolution imagery and observations of the temporal development of the snow cover. Unfortunately, such observations are not widely available. Also, more detailed analysis of the excluded cases of conflicting snow depth and the state of the ground observations in the weather stations could improve the understanding of the weather station observations.

The results do not differ significantly when different regions are compared. They may be slightly better in the variable region which includes only those stations which recorded both snow-covered and snow-free observations. This may imply that the algorithm does perform very well in the areas which have seasonal snow.

The daily validation measures were calculated to create time series which are presented in Figs. 8, 9 and 10. These three figures differ in the way partial snow cover is treated. In Fig. 8, partial snow cover observation and product classi- fications are all converted to snow-free ("no snow"). Fig. 9 shows the results when partial snow is converted to full snow cover ("snow") and Fig. 10 show the results when partial snow is excluded from validation ("off").

In the panels of all three figures different validation measures are presented. On the top left panel, also the number of snow pixels each day is presented. Each time series uses the same colour-coding where the dark green data points mark the days where $d<=20 *(a+b+c)$, i.e., the proportion of correct snow free observations is not too large, light green the day when $d>20 *(a+b+c)$ and orange the days when $d>200 *(a+b+c)$. This colour-coding is used to emphasize that many validation measures can be misleading when the distribution of correct observations is strongly skewed.

These strongly skewed distributions are common during the northern summer when seasonal snow cover in the well-lit regions is at its minimum. During summer, a small number of misclassifications caused by, for example, thunderstorms, peculiar surface features or unrepresentative surface observations, can change the results significantly even when practically all other classifications are correct. This can be seen quite well in the PC and F, which are nearly perfect during the summers even though more sophisticated measures (HSS and SEDI) show high dispersion of values. At the beginning of the winter, when the snow covered area grows and the number of Hits, $a$, grow and Correct Rejections, $d$, decrease, the validation measures improve greatly and stay at a high level most of the winter and spring.

The relatively rare misclassifications during the northern summer do show in some of the validation measures, but in general, the algorithm produces very good results throughout the year and excellent results during the northern winter and spring when snow cover has the largest impact on weather.

\section{Discussion \\ a. H32 and other products}

Many optical snow detection algorithms rely on detecting cloud-free regions before the actual snow cover classification. The approach used in the algorithm presented in this paper bypasses cloud detection and associated potential misclassifications by trying to find directly snowcovered and snow-free pixels. When that fails, the pixel is considered unclassified without any further analysis for the reason.

The strengths and weaknesses of different satellite snow extent products can be compared. Although multi-source products (such as IMS) provide much better coverage, the quality and accuracy of multi-source products is often difficult to analyze, especially if the source of the snow cover estimate in each pixel cannot be traced. Single source products (such as H31 and H32) do have more data gaps, but 
when available the accuracy is well defined and consistent across the coverage area. This is beneficial for users who prefer consistent and predictable behaviour of the product, such as NWP and reanalysis.

The accuracy of the algorithm presented here should be compared with the accuracy of other snow extent products available. Literature-based accuracy estimates of some operational snow extent products are presented in Table 8. Similar table has been presented earlier by Surer et al. (2014). The accuracy of the present product is comparable with accuracy other products. For most products, as for the present algorithm, the PC and the $H$ are usually over $90 \%$, and $F$ less than $10 \%$. However, as can be seen in Figs. 810 , trying to compress the quality of a product in one number, or even a set of numbers, can be a difficult as the values of verification metrics vary with the season, terrain type, illumination conditions and other physical properties of the surface. A more detailed comparison at the pixel or a gridpoint level would be most useful, but that is a task for another article. Even more useful, but also a very demanding, task would be to assimilate different products in NWP and see which product improves the forecasts most.

Another factor to keep in mind is the level of human interference in the product generation. A fully automatic product provides consistency and speed. An experienced human analyst may improve the product quality but with added uncertainty of the product behaviour and error statistics, especially in areas which are not prioritized in the analysis. As manual analysis of the snow cover is timeconsuming, it is unlikely that human analysis can be extended to full global coverage in operational products.

\section{b. Validation}

Validation with snow depth and the state of the ground observations from surface weather stations shows good agreement with the Metop/AVHRR H32 snow product especially during winter and spring. Thus, the Metop/AVHRR snow extent product can provide new and reliable data about snow extent. Similar benefits can be achieved with the previously published MSG/SEVIRI snow extent product with better temporal resolution which helps to reduce the limitations caused by cloud cover and short day length. However, the resolution of the MSG/SEVIRI product in the northern parts of Europe is limited. The Metop/AVHRR product provides global coverage and much better resolution in polar regions. However, cloud cover and availability of daylight may prevent snow detection.

All data used during the development work was gathered prior to 2016. The days studied extensively during the development were not excluded from validation. However, the data from 2016 onward was used for validation only. The validation metrics, based on surface observations as the ground truth, shown in Figs. 8-10 remain consistent throughout the whole validation period of 2015-2019. This clears concerns of overfitting, which could result from limited temporal variance of the development data.

\section{c. Artificial observations}

Because the lack of snow cover is not always reported, the idea of using artificial snow-free surface observations based on temperature was tried. Unfortunately, cold temperatures are quite common even when the surface is snowfree. For that reason, generation of artificial surface observations in the trial runs was limited to cases where the daily minimum and maximum temperatures are high enough to ensure the surface is truly snow-free $\left(T_{\min }>5^{\circ} \mathrm{C}\right.$ and $T_{\max }>10^{\circ} \mathrm{C}$ ).

Validation measures were recalculated based on this artificial secondary data set, but the results were essentially identical (differences less than one per cent) with the results based on actual snow cover observations. Thus, the idea of artificial snow-free surface observations was rejected and only actual snow measurements were used in this study. However, the use of generated artificial snow observations based on other measurements could be beneficial in filling the gaps in snow observations and might be worth a further study.

\section{d. Future}

The current operational algorithm version would benefit from further analysis of the relative importance of individual classification rules. Some rules may need adjusting or may be redundant in the current form. Nearly all seasonal snow is in the Northern Hemisphere, but snow in the Southern Hemisphere should get more attention in further snow product development.

Continuous availability of near-real time products, including snow products, is important for the NWP community. While current $\mathrm{H}$ SAF $\mathrm{H} 32$ and $\mathrm{H} 31$ products will be generated until the end of the MSG and Metop programs, new products based on the same development principles are expected to be available for the next generation of EUMETSAT weather satellites (Meteosat Third Generation (MTG) and Metop-SG). While the same development philosophy will be used, new tools such as machine learning may be used as an aid to speed up the development work. Even though black-box models, such as neural networks, are popular at the moment, they may not be the best idea for production due to the difficulty of backtracking solutions. However, machine learning tools providing visualizable solutions, such as random forests or support vector machines (Bishop 2006), may be useful in future snow cover algorithm development. 


\section{Conclusions}

In this article, a new Metop/AVHRR based snow extent algorithm and product are introduced. The algorithm is used operationally to produce daily global H SAF Metop/AVHRR H32 snow extent product. The algorithm applies the same approach of avoiding preliminary cloud masking before actual snow cover recognition which was used successfully earlier in the former LSA SAF, current H SAF MSG/SEVIRI H31 snow extent product. The algorithm aims to be as independent as possible of any external data sets, algorithms and products.

Validation results based on snow depth and the state of the ground observations in weather stations are very good (HSS >0.90, SEDI > 0.95) and suggest that the algorithm produces realistic estimates of snow cover especially during the northern winter and spring. Together with the H SAF MSG/SEVIRI snow extent product which employs a similar algorithm (Siljamo and Hyvärinen 2011), these two products provide excellent snow coverage data of the world and especially Europe.

Data availability statement. The $\mathrm{H}$ SAF Metop/AVHRR snow extent product described in this study is produced in the LSA SAF processing system and is freely available online via LSA SAF web site (https://landsaf.ipma.pt/en/), which requires registration for data access. One example file is available from the product description page without registration. Dataset used is Metop/AVHRR global daily snow extent (H32), subset used: January 2015 - March 2019.

In this study, synoptic weather station observations as archived for internal use in the FMI were used, but, in general, weather station data is publicly available both freely and for a fee. One such free dataset is published by Unidata/University Corporation for Atmospheric Research (2003): Historical Unidata Internet Data Distribution (IDD) Global Observational Data, doi:10.5065/9235WJ24.

Acknowledgments. This work was financially supported by the H SAF project, co-funded by EUMETSAT. We are grateful to Drs. Terhikki Manninen, Elena Saltikoff and Kati Anttila for their valuable comments during the writing of this paper. We also thank Drs Carl Fortelius, Laura Rontu and Kalle Eerola from the FMI and Dr Samantha Pullen from the Met Office for the discussions we had about the needs of numerical weather prediction during the development of our snow extent products and Ari Aaltonen for his help in the data retrieval from the FMI data archives. We acknowledge the use of imagery from the NASA Worldview application (https://worldview.earthdata.nasa.gov), part of the NASA Earth Observing System Data and Information System (EOSDIS).

\section{References}

Baldridge, A., S. Hook, C. Grove, and G. Rivera, 2009: The ASTER spectral library version 2.0. Remote Sens. Environ., 113 (4), 711-715, doi:10.1016/j.rse.2008.11.007.

Bishop, C. M., 2006: Pattern recognition and machine learning. Springer.

Brubaker, K. L., R. T. Pinker, and E. Deviatova, 2005: Evaluation and comparison of MODIS and IMS snow-cover estimates for the continental united states using station data. J. Hydrometeor., 6 (6), 1002-1017, doi:10.1175/JHM447.1.

Chen, C., T. Lakhankar, P. Romanov, S. Helfrich, A. Powell, and R. Khanbilvardi, 2012: Validation of NOAA-Interactive Multisensor Snow and Ice Mapping System (IMS) by Comparison with GroundBased Measurements over Continental United States. Remote Sens., 4 (5), 1134-1145, doi:10.3390/rs4051134.

Cortés, G., M. Girotto, and S. A. Margulis, 2014: Analysis of subpixel snow and ice extent over the extratropical Andes using spectral unmixing of historical Landsat imagery. Remote Sens. Environ., 141, 64-78, doi:10.1016/j.rse.2013.10.023.

Dozier, J., R. O. Green, A. W. Nolin, and T. H. Painter, 2009: Interpretation of snow properties from imaging spectrometry. Remote Sens. Environ., doi:10.1016/j.rse.2007.07.029.

Dybbroe, A., K. Karlsson, and A. Thoss, 2005: NWCSAF AVHRR Cloud Detection and Analysis Using Dynamic Thresholds and Radiative Transfer Modeling. Part I: Algorithm Description. J. Appl. Meteor., 44 (1), 39-54, doi:10.1175/JAM-2189.1.

Frei, A., M. Tedesco, S. Lee, J. Foster, D. K. Hall, R. Kelly, and D. A. Robinson, 2012: A review of global satellite-derived snow products. Adv. Space Res., 50, 1007-1029, doi:10.1016/j.asr.2011.12.021.

Hall, D. K., and G. A. Riggs, 2007: Accuracy assessment of the MODIS snow products. Hydrological Processes, 21 (12), 1534-1547, doi: 10.1002/hyp.6715.

Härer, S., M. Bernhardt, M. Siebers, and K. Schulz, 2018: On the need for a time- and location-dependent estimation of the NDSI threshold value for reducing existing uncertainties in snow cover maps at different scales. The Cryosphere, 12 (5), 1629-1642, doi: 10.5194/tc-12-1629-2018.

Helfrich, S. R., D. McNamara, B. H. Ramsay, T. Baldwin, and T. Kasheta, 2007: Enhancements to, and forthcoming developments in the Interactive Multisensor Snow and Ice Mapping System (IMS). Hydrological Processes, 21, 1576-1586, doi:10.1002/hyp.6720.

Helmert, J., and Coauthors, 2018: Review of Snow Data Assimilation Methods for Hydrological, Land Surface, Meteorological and Climate Models: Results from a COST HarmoSnow Survey. Geosciences, 8 (12), doi:10.3390/geosciences8120489, URL https://www.mdpi.com/2076-3263/8/12/489.

Hogan, R. J., and I. B. Mason, 2012: Deterministic forecast of binary data. Forecast Verification: A Practitioners Guide in Atmospheric Science, I. T. Jolliffe, and D. B. Stephenson, Eds., 2nd ed., Wiley, 31-59.

Hori, M., K. Sugiura, K. Kobayashi, T. Aoki, T. Tanikawa, K. Kuchiki, M. Niwano, and H. Enomoto, 2017: A 38-year(1978-2015) Northern Hemisphere daily snow cover extent product derived using consistent objective criteria from satellite-borne optical sensors. Remote Sens. Environ., 191, 402-418, doi:10.1016/j.rse.2017.01.023. 
Horler, D. N. H., M. Dockray, and J. Barber, 1983: The red edge of plant leaf reflectance. Int. J. Remote Sens., 4 (2), 273-288, doi: $10.1080 / 01431168308948546$.

Hüsler, F., T. Jonas, S. Wunderle, and S. Albrecht, 2012: Validation of a modified snow cover retrieval algorithm from historical 1-km AVHRR data over the European Alps. Remote Sens. Environ., 121, 497-515, doi:10.1016/j.rse.2012.02.018.

Hyvärinen, O., and E. Saltikoff, 2010: Social Media as a Source of Meteorological Observations. Mon. Weather Rev., 138 (8), 31753184, doi:10.1175/2010MWR3270.1.

Key, J. R., and Coauthors, 2013: Snow and ice products from Suomi NPP VIIRS. J. Geophys. Res. Atmos., 118, 12816-12830, doi:10. 1002/2013JD020459.

Li, X., R. T. Pinker, M. M. Wonsick, and Y. Ma, 2007: Toward improved satellite estimates of short-wave radiative fluxes - Focus on cloud detection over snow: 1. Methodology. J. Geophys. Res., 112, D07 208, doi:10.1029/2005JD006698.

Loveland, T. R., and A. S. Belward, 1997: The IGBP-DIS global 1km land cover data set, DISCover: First results. Int. J. Remote Sens., 18 (15), 3289-3295, doi:10.1080/014311697217099.

Metsämäki, S., and Coauthors, 2015: Introduction to GlobSnow snow extent products with considerations for accuracy assessment. Remote Sens. Environ., 156, 96-108, doi:10.1016/j.rse.2014.09.018.

Miller, S. D., T. F. Lee, and R. L. Fennimore, 2005: Satellite-Based Imagery Techniques for Daytime Cloud/Snow Delineation from MODIS. J. Appl. Meteor., 44 (7), 987-997, doi:10.1175/JAM2252.1.

Miller, S. D., and Coauthors, 2006: NexSat: Previewing NPOESS/VIIRS Imagery Capabilities. Bull. Amer. Meteor. Soc., 87 (4), 433-446, doi:10.1175/BAMS-87-4-433.

Niittynen, P., R. K. Heikkinen, and M. Luoto, 2018: Snow cover is a neglected driver of Arctic biodiversity loss. Nat. Clim. Change, $\mathbf{8}$, doi:10.1038/s41558-018-0311-x.

Notarnicola, C., and Coauthors, 2013a: Snow Cover Maps from MODIS Images at $250 \mathrm{~m}$ Resolution, Part 1: Algorithm Description. Remote Sens., 5 (1), 110-126, doi:10.3390/rs5010110.

Notarnicola, C., and Coauthors, 2013b: Snow Cover Maps from MODIS Images at $250 \mathrm{~m}$ Resolution, Part 2: Validation. Remote Sens., 5 (4), 1568-1587, doi:10.3390/rs5041568.

Piazzi, G., and Coauthors, 2019: Cross-country assessment of h-saf snow products by sentinel-2 imagery validated against in-situ observations and webcam photography. Geosciences, 9 (3), doi:10. 3390/geosciences9030129, URL https://www.mdpi.com/2076-3263/ $9 / 3 / 129$.

Pullen, S., C. Charlton-Perez, B. Gomez, and C. Harris, 2019: Snow data assimilation developments at the Met Office. ISWG, URL http://cimss.ssec.wisc.edu/iswg/meetings/2019/presentations/ WEDNESDAY/0930_Pullen.pdf, 3rd International Surface Working Group (ISWG) Workshop, Montreal, Canada, 15-17 July, 2019.

Pullen, S., B. Gomez, C. Charlton-Perez, R. Renshaw, and B. Candy, 2018: Land surface data assimilation at the Met Office and developments in snow depth analysis. LSA SAF, URL https://landsaf. ipma.pt/en/newsmedia/workshops/, 8th LSA SAF Workshop, Joint ISWG/LSA SAF Workshop, Lisbon, Portugal, 26-28th June 2018.

Pullen, S., C. Jones, and G. Rooney, 2010: Using Satellite-Derived Snow Cover Data to Implement a Snow Analysis in the Met Office
Global NWP Model. J. Appl. Meteor. Climatol., 50, 958-973, doi: 10.1175/2010JAMC2527.1.

Ramsay, B., 1998: Interactive Multisensor Snow and Ice Mapping System (IMS). Hydrological Processes, 5 (12), 15371546, doi:10.1002/(SICI) 1099-1085(199808/09)12:10/11<1537:: AID-HYP679>3.0.CO;2-A

Riggs, G. A., D. K. Hall, and M. O. Román, 2017: Overview of NASA’s MODIS and Visible Infrared Imaging Radiometer Suite (VIIRS) snow-cover Earth System Data Records. Earth Syst. Sci. Data, 9 (2), 765-777, doi:10.5194/essd-9-765-2017.

Romanov, P., D. Tarpley, G. Gutman, and T. Carroll, 2003: Mapping and monitoring of the snow cover fraction over North America. $J$. Geophys. Res., 108 (D16), doi:10.1029/2002JD003142.

Salminen, M., J. Pulliainen, S. Metsämäki, A. Kontu, and H. Suokanerva, 2009: The behaviour of snow and snow-free surface reflectance in boreal forests: Implications to the performance of snow covered area monitoring. Remote Sens. Environ., 113 (5), 907-918, doi: 10.1016/j.rse.2008.12.008.

Salvatori, R., and Coauthors, 2011: Snow cover monitoring with images from digital camera system. Italian Journal of Remote Sensing, $\mathbf{4 3}$ (2), 137-145, doi:10.5721/ItJRS201143211.

Selkowitz, D. J., and R. R. Forster, 2015: An Automated Approach for Mapping Persistent Ice and Snow Cover over High Latitude Regions. Remote Sens., doi:10.3390/rs8010016.

Siljamo, N., and O. Hyvärinen, 2011: New Geostationary SatelliteBased Snow-Cover Algorithm. J. Appl. Meteor. Climatol., 50 (6), 1275-1290, doi:10.1175/2010JAMC2568.1.

Solberg, R., Ø. Trier, L.-A. Breivik, Ø. Godøy, M. Killie, L. M. Andreassen, J. Hausberg, and O. Olsen, 2009: CryoClim-A New System for Cryospheric Climate Monitoring. Proceedings, 33rd International Symposium on Remote Sensing of Environment, ISRSE 2009.

Surer, S., J. Parajka, and Z. Akyurek, 2014: Validation of the operational msg-seviri snow cover product over austria. Hydrol. Earth Syst. Sci., 18 (2), 763-774, doi:10.5194/hess-18-763-2014, URL https://www. hydrol-earth-syst-sci.net/18/763/2014/.

Thapa, S., P. K. Chhetri, and A. G. Klein, 2019: Cross-comparison between MODIS and VIIRS snow cover products for the 2016 hydrological year. Climate, 7 (4), 57, doi:10.3390/cli7040057.

Thirel, G., and Coauthors, 2012: Assessing the quality of a real-time Snow Cover Area product for hydrological applications. Remote Sens. Environ., 127, 271-287, doi:10.1016/j.rse.2012.09.006.

Trigo, I. F., and Coauthors, 2011: The Satellite Application Facility for Land Surface Analysis. Int. J. Remote Sens., 32 (10), 2725-2744, doi:10.1080/01431161003743199.

Unidata/University Corporation for Atmospheric Research, 2003: Historical Unidata Internet Data Distribution (IDD) Global Observational Data. Research Data Archive at the National Center for Atmospheric Research, Computational and Information Systems Laboratory, Boulder CO, doi:10.5065/9235-WJ24.

Wang, G., L. Jiang, S. Wu, J. Shi, S. Hao, and X. Liu, 2017: Fractional Snow Cover Mapping from FY-2 VISSR Imagery of China. Remote Sensing, 9 (10), doi:10.3390/rs9100983.

Wiscombe, W. J., and S. G. Warren, 1980a: Model for the spectral albedo of snow, Pt. 1, Pure snow. J. Atmos. Sci., 37 (12), 2712-2733, doi:10.1175/1520-0469(1980)037<2712:AMFTSA>2.0.CO;2. 
Wiscombe, W. J., and S. G. Warren, 1980b: Model for the spectral albedo of snow, Pt. 2, Snow containing atmospheric aerosols. J. Atmos. Sci., 37 (12), 2734-2745, doi:10.1175/1520-0469(1980)037<2734: AMFTSA $>2.0 . \mathrm{CO} ; 2$.

WMO, 2015: WMO Technical Regulations, The Manual on Codes, Vol. I.2, updated 2017, No. 306. World Meteorological Organization. 
TABLE 1. List of the inputs for the H SAF Metop/AVHRR (H32) snow extent algorithm.

\begin{tabular}{lll}
\hline \hline Input type & code & description \\
\hline Satellite & $R_{1}$ & Radiance in Ch 1 $(0.58-0.68 \mu \mathrm{m})$ \\
channels & $R_{2}$ & Radiance in Ch 2 $(0.725-1.00 \mu \mathrm{m})$ \\
& $R_{3}$ & Radiance in Ch 3A $(1.58-1.63 \mu \mathrm{m})$ \\
& $R_{4}$ & Radiance in Ch $4(10.30-11.30 \mu \mathrm{m})$ \\
& $R_{5}$ & Radiance in Ch 5 $(11.50-12.50 \mu \mathrm{m})$ \\
& $T_{B 4}$ & Brightness temperature in Ch 4 $(10.30-11.30 \mu \mathrm{m})$ \\
& $T_{B 5}$ & Brightness temperature in Ch 5 $(11.50-12.50 \mu \mathrm{m})$ \\
Angles & SAA & Sun azimuth angle \\
& SZA & Sun zenith angle \\
& VAA & Satellite azimuth angle \\
& VZA & Satellite zenith angle \\
Other & LC & Land cover type \\
& LST & LSA SAF land surface temperature (in Celsius) \\
& $\Delta T_{B}$ & $T_{B 4}-T_{B 5}$ \\
\hline
\end{tabular}

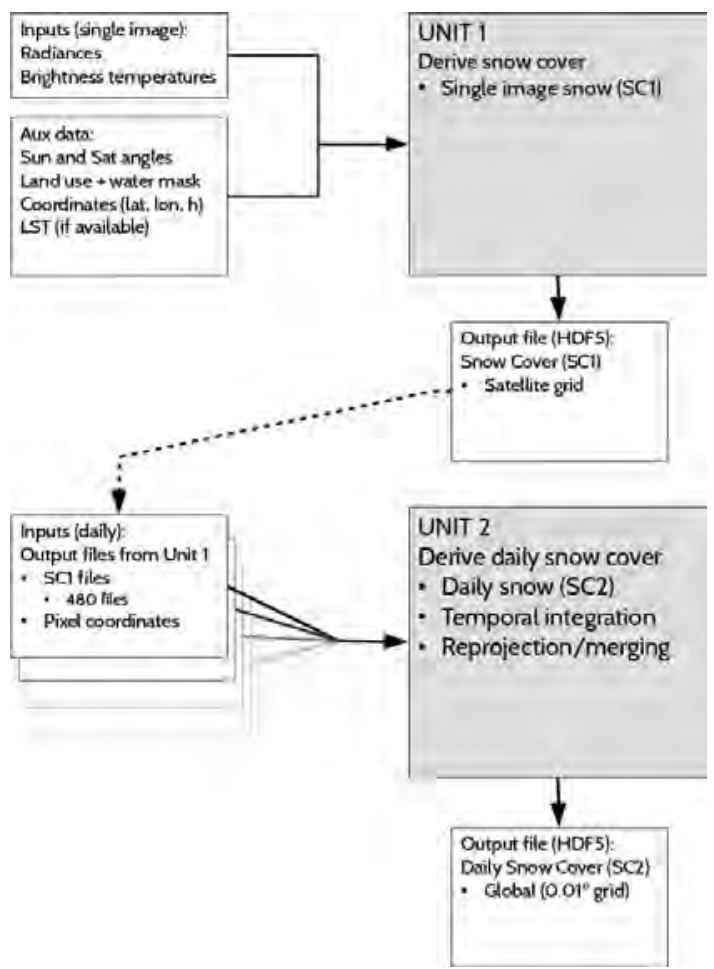

FIG. 1. General flow chart of the Metop/AVHRR snow extent algorithm. The algorithm has two separate phases. Unit 1 processes single satellite scene (in this case one PDU) and produces intermediate SC1 snow product. After the last scene of the day has been received and processes, Unit 2 merges all SC1 snow products to the global grid in acquisition order. After smoothing based on $3 \times 3$ pixel around each pixel, the final daily snow product $(\mathrm{SC} 2)$ is generated. 


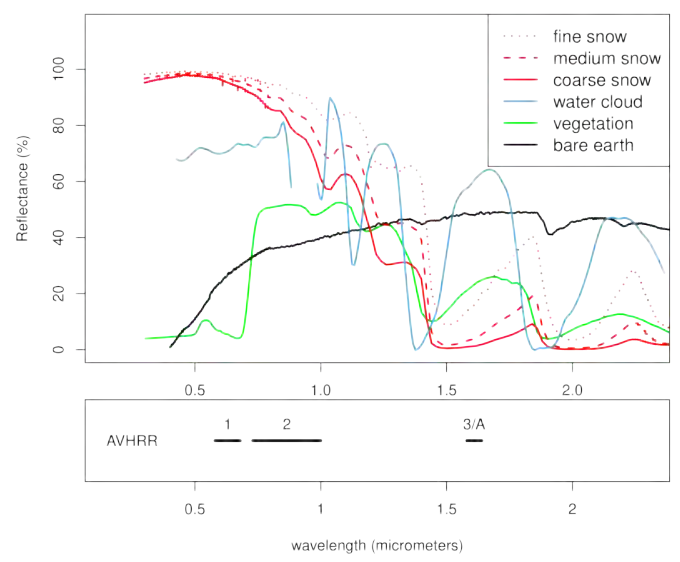

FIG. 2. The qualitative comparison of different ground types and the water cloud reflectances with the solar AVHRR channels. The reflectances of ground types are based on Baldridge et al. (2009) and the reflectance of a water cloud is based on an arbitrary image taken on 12 June 2010 02:08 UTC near Barbourville, Kentucky, United States using the hyperspectral Hyperion instrument onboard the Earth Observing-1 (EO-1) satellite. The effective particle size of fine snow is $24 \mu \mathrm{m}$, the medium snow $82 \mu \mathrm{m}$, and the coarse snow $178 \mu \mathrm{m}$. Note that because ground type and cloud reflectances are based on different sources, only qualitative comparison is possible.
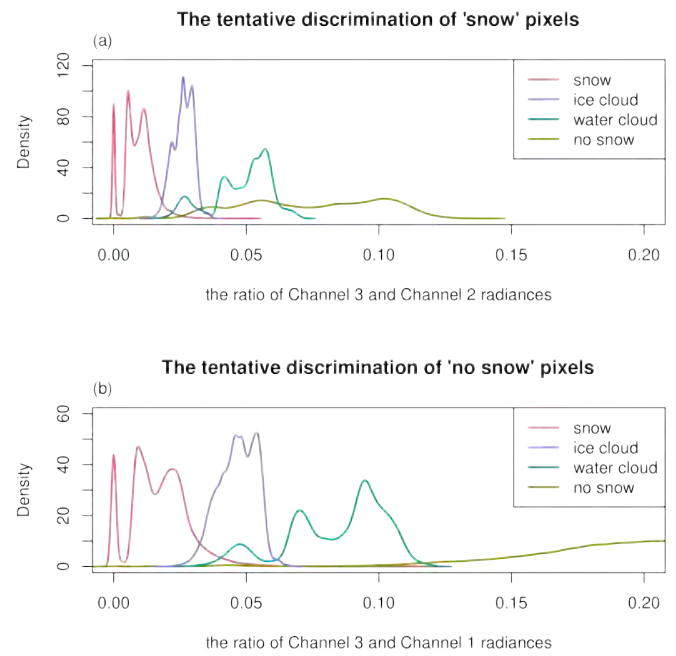

FIG. 3. The tentative discrimination of (a) "snow" and (b) "no snow" pixels using only the ratios of the solar channels of the AVHRR instrument. The densities of two land classes "snow" and "no snow", and two cloud classes "ice cloud" and "water cloud" are estimated using the subjective classification data set. 
Metop/AVHRR snow cover 10.4.2017

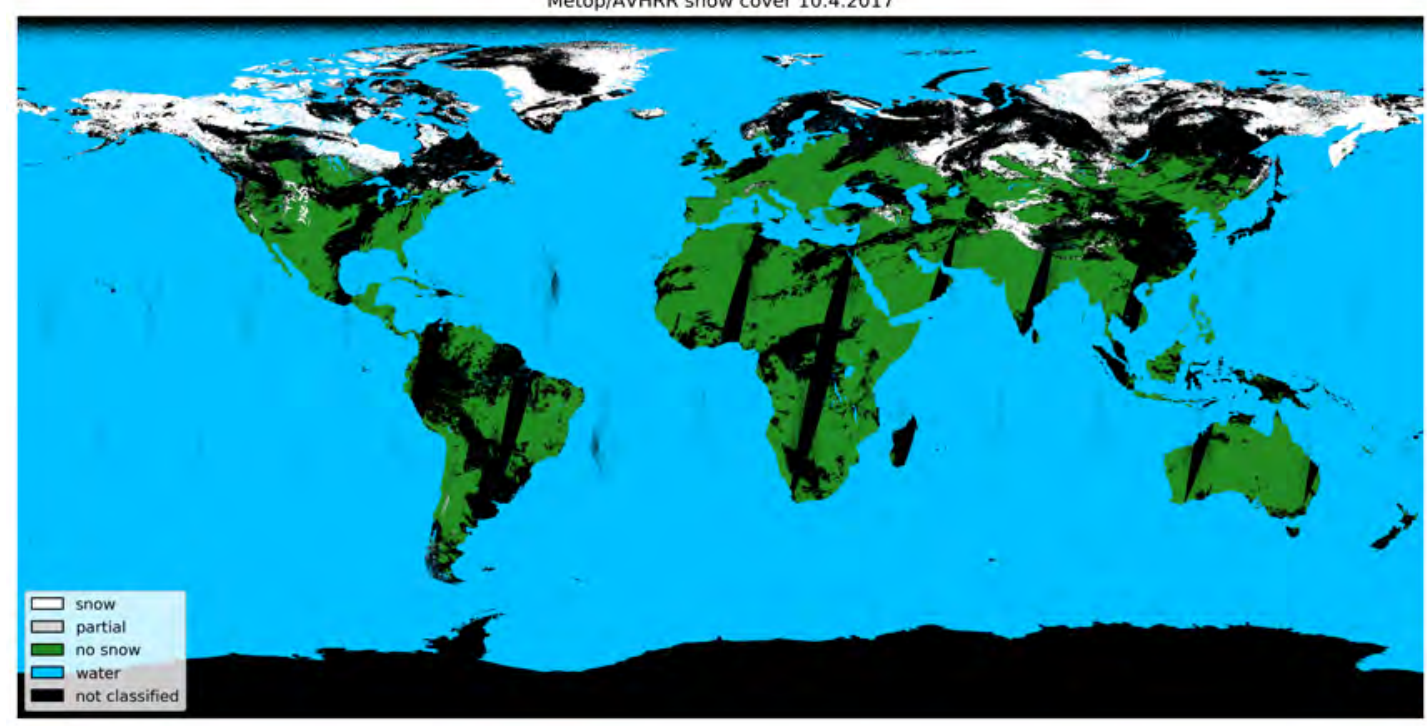

Fig. 4. An example of the H SAF H32 snow extent product April 10, 2017. The algorithm catches the general features of the snow cover well, but the limitations of an optical algorithm can be seen as black irregular patches in cloud covered areas. Unclassified areas near the poles are caused by low sun elevation and, in the Antarctic, by polar night. There are also some unclassified stripes across the equator where the daytime satellite swaths do not cover all of the surface. 

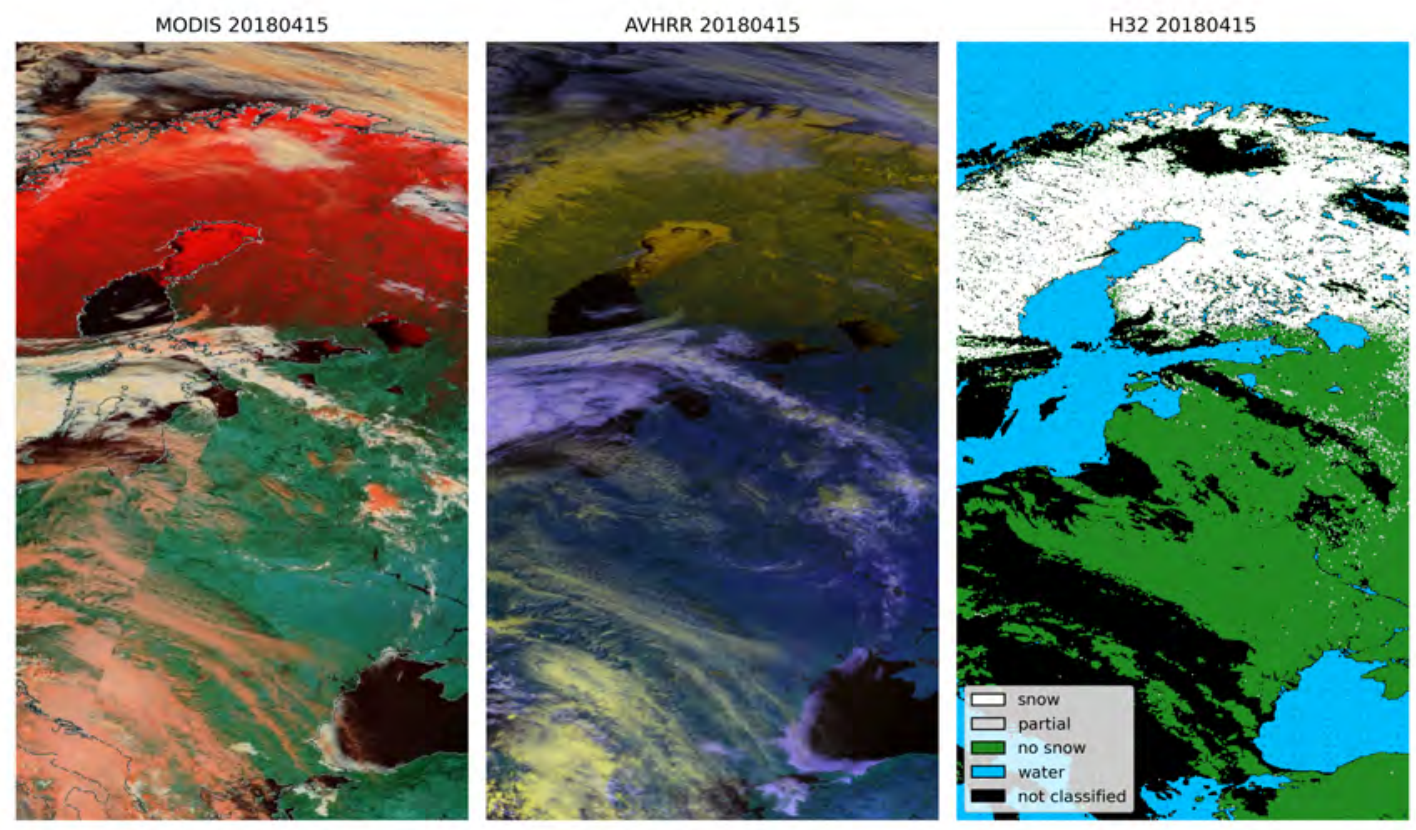

FIG. 5. A false-colour MODIS RGB (channels 3/6/7), reprojected false-colour Metop/AVHRR RGB (channels $1 / 2 / 3 \mathrm{~A}$ ) and reprojected H SAF H32 snow extent April 15, 2018. The MODIS image (by NASA Worldview) shows that there is snow (dark red). There are also different clouds (white or pink) in the area. Metop/AVHRR shows snow in dark yellowish shades and clouds as light blue or light yellow. The general features of the snow cover are detected, but there are potential misclassifications, especially in regions where snow is presumably melting. 
TABle 2. IGBP DISCover Data Set Land Cover Classification System

\begin{tabular}{ll}
\hline \hline Class & Class name \\
\hline 1 & Evergreen Needleleaf Forests \\
2 & Evergreen Broadleaf Forests \\
3 & Deciduous Needleleaf Forests \\
4 & Deciduous Broadleaf Forests \\
5 & Mixed Forests \\
6 & Closed Shrublands \\
7 & Open Shrublands \\
8 & Woody Savannas \\
9 & Savannas \\
10 & Grasslands \\
11 & Permanent Wetlands \\
12 & Cropland \\
13 & Urban and Built-up \\
14 & Cropland/Natural Vegetation Mosaics \\
15 & Snow and Ice \\
16 & Barren \\
17 & Water Bodies \\
\hline
\end{tabular}

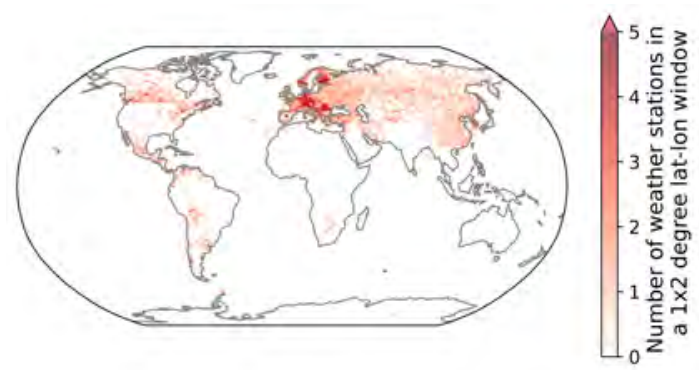

FIG. 6. The number of weather stations used in the validation in $1 \times 2$ degree grid cells. 
TABLE 3. List of special conditions in the algorithm rules. Special condition is true, when the condition in the middle is true.

\begin{tabular}{lll}
\hline \hline Name & When true & Notes \\
\hline slc & $\mathrm{LC}=2,5-12,14$ & IGBP, see Table 2 \\
creg0 & lat $<-60$ or lat $>60$ & High latitudes \\
creg1 & lat $<-45$ or lat $>58$ or & Southern mid-latitudes \\
& $($ lat $>45$ and $($ lon $<-30$ or lon $>30))$ & Mid-latitude non-Europe \\
cMid & $\mathrm{h} \geq 1500$ and (lat $<-35$ or lat $>35)$ & Mid- or High Latitude highlands \\
cMo & $\mathrm{h} \geq 3000$ & Mountains \\
creg4 & month $=1-5$ and $($ lat $<-35$ or lat $>60$ or & \\
& $($ lat $>35$ and $($ lon $<-30$ or lon $>30)))$ & \\
creg & creg0 or creg1 or cMid or cMo & \\
Scold & $((c r e g 0$ or creg1 or cMid) and month $=1-5)$ or cMo & \\
tropic & $\mathrm{h} \leq 3000$ and lat $<20$ and lat $>-20$ & \\
moderate & $\mathrm{h} \leq 2500$ and lat $<40$ and lat $>-40$ & \\
for & $\mathrm{LC}=1-6,8,14$ & forest by IGBP, see Table 2 \\
nonfor & $\mathrm{LC}=7,9-13,15-$ & non-forest by IGBP, see Table 2 \\
\hline
\end{tabular}

TABLE 4. List of classification rules in the $\mathrm{SC} 1$ algorithm. If the condition is true, the snow cover status is set to Value $(\mathrm{SN}=\mathrm{snow}, \mathrm{NS}=\mathrm{no}$ snow, $\mathrm{PS}=$ partial snow, $\mathrm{WA}=$ water, $\mathrm{UC}=$ unclassified). These rules are applied sequentially from the top in the order presented and the final snow cover classification is the value in effect after last rule. For definitions see Tables 1 and 3 . Logical AND is marked by $\wedge$ and logical OR by $\vee$.

\begin{tabular}{|c|c|c|c|}
\hline Rule condition & Value & Rule & Notes \\
\hline set default value & $\mathrm{UC}$ & & \\
\hline \multicolumn{4}{|l|}{ nonfor $\wedge R_{2} / R_{1}<\left(-0.2 T_{B 5}+57\right) \wedge R_{3} / R_{1}<0.002 T_{B 5}-0.45 \wedge$} \\
\hline$T_{B 5}<272.6 \wedge R_{2} / R_{1}>-0.05 T_{B 5}+15.5$ & PS & $\mathrm{R} 1$ & Cold surface, relatively bright \\
\hline$T_{B 4}>290$ & NS & $\mathrm{R} 2$ & Too warm for snow \\
\hline nonfor $\wedge R_{3} / R_{1}>0.134$ & NS & $\mathrm{R} 3$ & Open, NIR vs VIS too high for snow \\
\hline $\left.\operatorname{creg} \wedge \operatorname{nonfor} \wedge R_{2} / R_{3}>\left(-2 T_{B 4}+585\right) \wedge T_{B 4}<277\right)$ & SN & $\mathrm{R} 4$ & Cold, snow possible, $R_{2} / R_{3}$ indicate snow \\
\hline Scold $\wedge$ nonfor $\wedge R_{2} / R_{3}>\left(-2 T_{B 4}+574\right) \wedge T_{B 4}>256.5 \wedge T_{B 4}<269.7$ & SN & R5 & Amends R4 in problem cases \\
\hline Scold $\wedge$ for $\wedge R_{2} / R_{1}>\left(-0.1 T_{B 5}+29.5\right) \wedge R_{2} / R_{1}<2.86 \wedge T_{B 5}<280$ & PS & R6 & Cold forest, 'red edge' less distinct for snow-free \\
\hline$R_{3} / R_{1}<0.045 \wedge T_{B 4}>280$ & NS & $\mathrm{R} 7$ & Warm, reflectance indicate snow, set no snow \\
\hline $\operatorname{creg} 4 \wedge\left(R_{3}-R_{2}\right) /\left(R_{3}+R_{2}\right)<-0.975 \wedge T_{B 4}<279 \wedge T_{B 4}>240$ & SN & $\mathrm{R} 8$ & Low $R_{3} / R_{2}$ with cold surf. No coldest clouds \\
\hline for $\wedge R_{3} / R_{1}>0.135$ & NS & $\mathrm{R} 9$ & Forest, distinct 'red edge', snow highly unlikely \\
\hline $\operatorname{creg} \wedge R_{2} / R_{3}>120 \wedge T_{B 4}<276$ & SN & $\mathrm{R} 10$ & Similar to R8 \\
\hline creg $\wedge$ for $\wedge R_{2} / R_{3}>72 \wedge T_{B 4}>253$ & SN & $\mathrm{R} 11$ & North Forest, no 'red edge', warm for ice clouds \\
\hline Scold $\wedge$ for $\wedge R_{2} / R_{3}>45 \wedge T_{B 4}>263$ & SN & $\mathrm{R} 12$ & North Forest, no 'red edge', warm for ice clouds \\
\hline \multicolumn{4}{|l|}{ Scold $\wedge\left(\left(R_{2} / R_{3}>120 \wedge T_{B 4}<254\right) \vee\left(R_{2} / R_{3}>220 \wedge T_{B 4}<280\right) \vee\right.$} \\
\hline$\left.\left(R_{2} / R_{3}>50 \wedge T_{B 4}>267 \wedge T_{B 4}<276 \wedge \Delta T_{B}<1.5\right)\right)$ & SN & $\mathrm{R} 13$ & Snow, filter out clouds \\
\hline$\left(T_{B 5}>280 \wedge R_{2} / R_{1}>2\right)$ & NS & $\mathrm{R} 14$ & Clear 'red edge', warm. Snow very unlikely \\
\hline$T_{B 4}<242 \wedge R_{2} / R_{3}<68.8$ & UC & $\mathrm{R} 15$ & Very cold surface with an indistinct $R_{2} / R_{3}$ \\
\hline$\Delta T_{B}>4 \wedge R_{3} / R_{1}>0.09 \wedge R_{3} / R_{1}<0.11$ & $\mathrm{UC}$ & $\mathrm{R} 16$ & Remove misclassifications \\
\hline $\mathrm{VZA}>60$ & $\mathrm{UC}$ & $\mathrm{R} 17$ & Viewing geometry is too challenging \\
\hline $\mathrm{SZA}>80$ & $\mathrm{UC}$ & $\mathrm{R} 18$ & Illumination geometry is too challenging \\
\hline tropic $\wedge \operatorname{slc} \wedge(S N \vee P S)$ & $\mathrm{UC}$ & R19 & No snow near-equatorial lowlands \\
\hline moderate $\wedge\left(T_{B 4}+T_{B 5}\right) / 2<253 \wedge(\mathrm{SN} \vee \mathrm{PS})$ & UC & $\mathrm{R} 20$ & Unreliable cold snow surface \\
\hline $\mathrm{LST}>=293.15 \wedge(\mathrm{SN} \vee \mathrm{PS})$ & NS & $\mathrm{R} 21$ & Trust LST over snow retrieval \\
\hline \multicolumn{4}{|l|}{$(\mathrm{SN} \vee \mathrm{PS}) \wedge$} \\
\hline$R_{1}<1.2 / \cos ^{2}(\mathrm{SZA}) \wedge R_{2}<1.2 / \cos ^{2}(\mathrm{SZA}) \wedge R_{3}<0.02 / \cos ^{2}(\mathrm{SZA})$ & $\mathrm{UC}$ & $\mathrm{R} 22$ & Unclassify too dark snow pixels \\
\hline If water pixel in water mask & WA & $\mathrm{R} 23$ & No retrieval over water \\
\hline
\end{tabular}


TABLE 5. List of the smoothing rules used in the generation of the daily ( $\mathrm{SC} 2)$ product. The number of classifications in $3 \times 3$ grid around a pixel are counted and the values are used to define the final classification in each pixel. F, W, U, S, P, and N are the numbers of; non-processed, water, unclassified, snow-covered, partially snow-covered, and snow-free pixels, respectively. These rules are used one after the other from the top, and the final daily classification is the classification in effect after the last rule. Logical AND is marked by $\wedge$ and $\operatorname{logical}$ OR by $\vee$.

\begin{tabular}{|c|c|c|}
\hline Rule condition & Value set & Rule \\
\hline set default value & original value & D1 \\
\hline$U+F>4$ & $\mathrm{UC}$ & D2 \\
\hline$S+P<2 \wedge N<2 \wedge U>2$ & $\mathrm{UC}$ & D3 \\
\hline$W>3 \wedge S+N+P+U=0$ & WA & D4 \\
\hline \multicolumn{3}{|l|}{$W+F \leq 3 \wedge$} \\
\hline$S+P=0 \wedge N>2 \wedge W+F=0$ & NS & D5 \\
\hline$S+P>3 \wedge N=0$ & SN & D6 \\
\hline$S+P=0 \wedge N>2$ & NS & D7 \\
\hline$S+P>3 \wedge N>2$ & PS & D8 \\
\hline
\end{tabular}

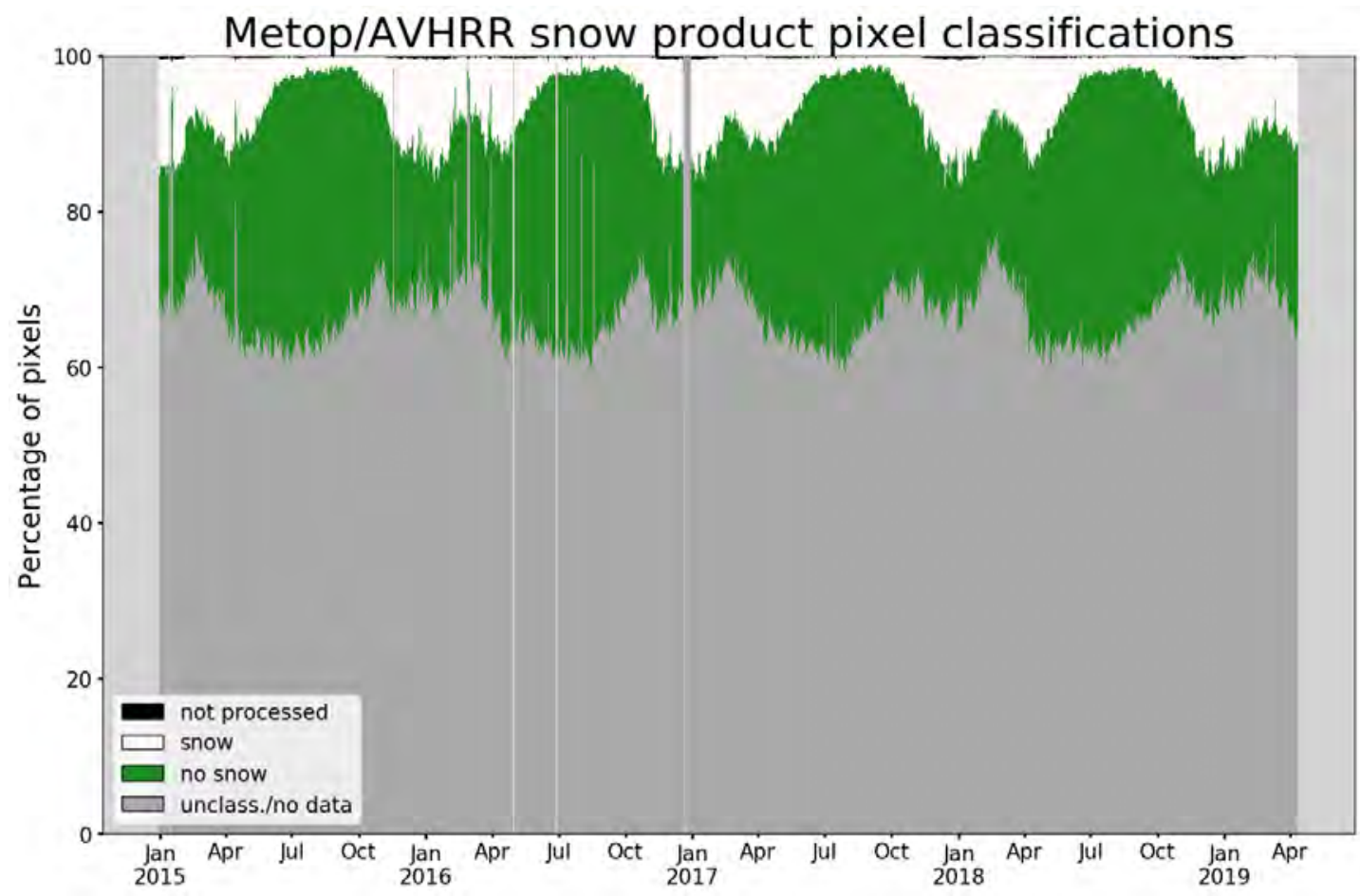

Fig. 7. Daily classification distributions in the Metop/AVHRR snow extent product from January 2015 to April 2019. Main cause for vertical stripes and spikes is missing input data on those days. Seasonal snow of the large northern continents dominate the global snow extent. 
Global, Metop/AVHRR, partial $=$ no snow
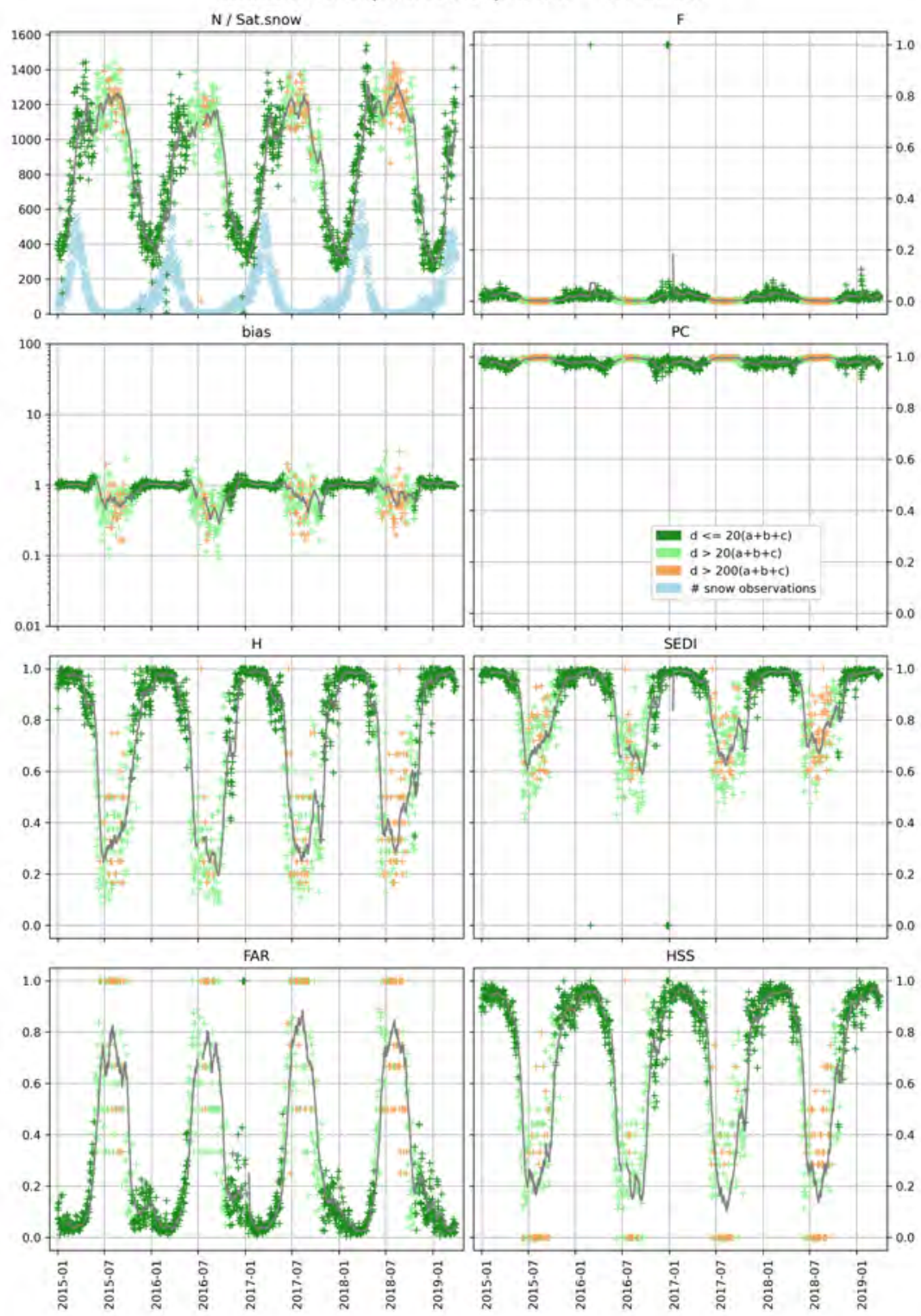

FIG. 8. Metop validation measure time series, partial classifications converted to snow-free. Each day is colour coded to indicate whether the proportion of correct snow-free observations is so large that most of the validation measures degenerate (indicated by light green and in the most extreme cases by orange). Most of the snow observations are from the northern seasonal snow region which dominates in the time series. The results are excellent during the northern winter. 
Global, Metop/AVHRR, partial $=$ snow

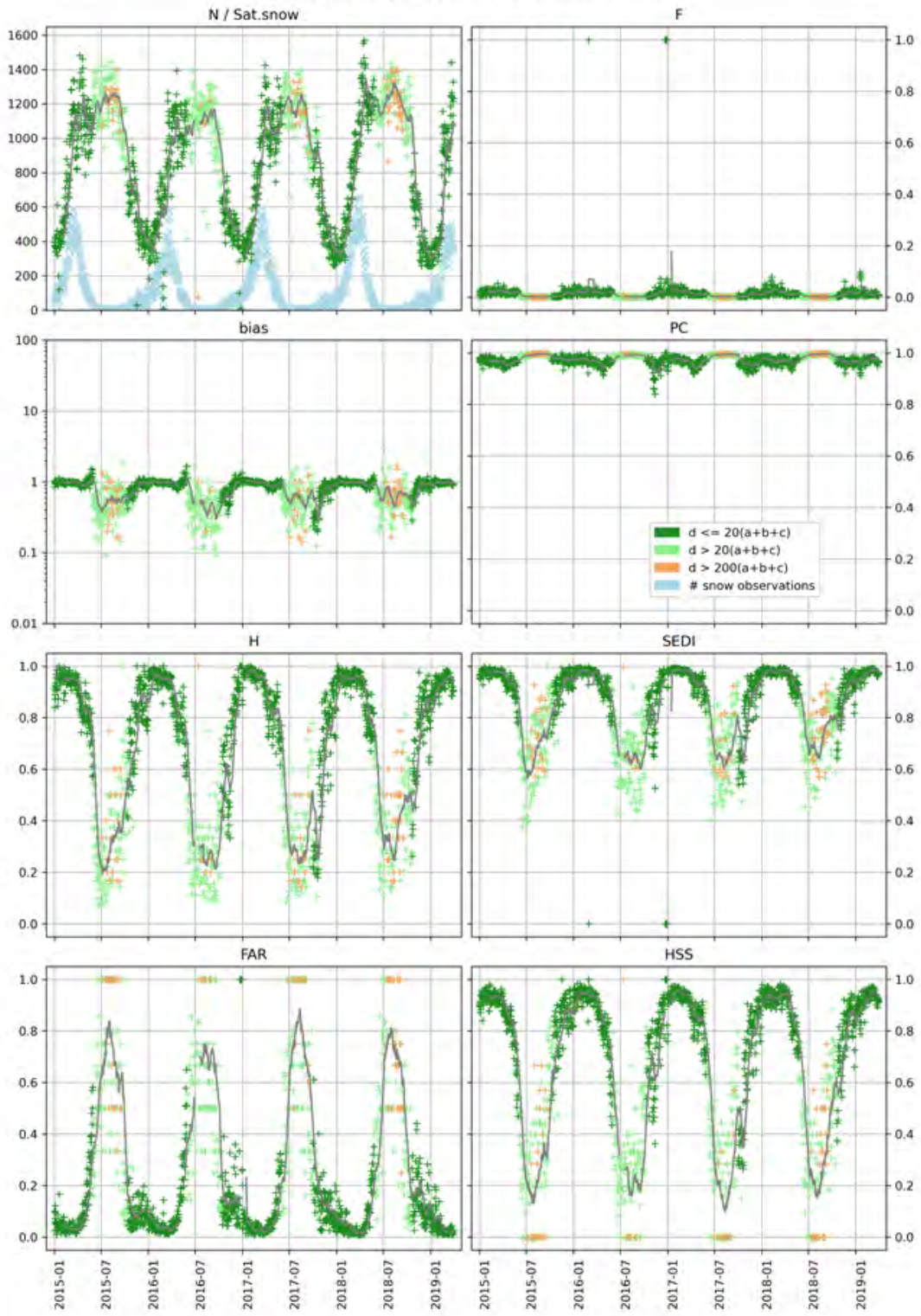

FIG. 9. As in Fig. 8, but partial classifications converted to full snow cover. 
Global, Metop/AVHRR, partial $=$ off

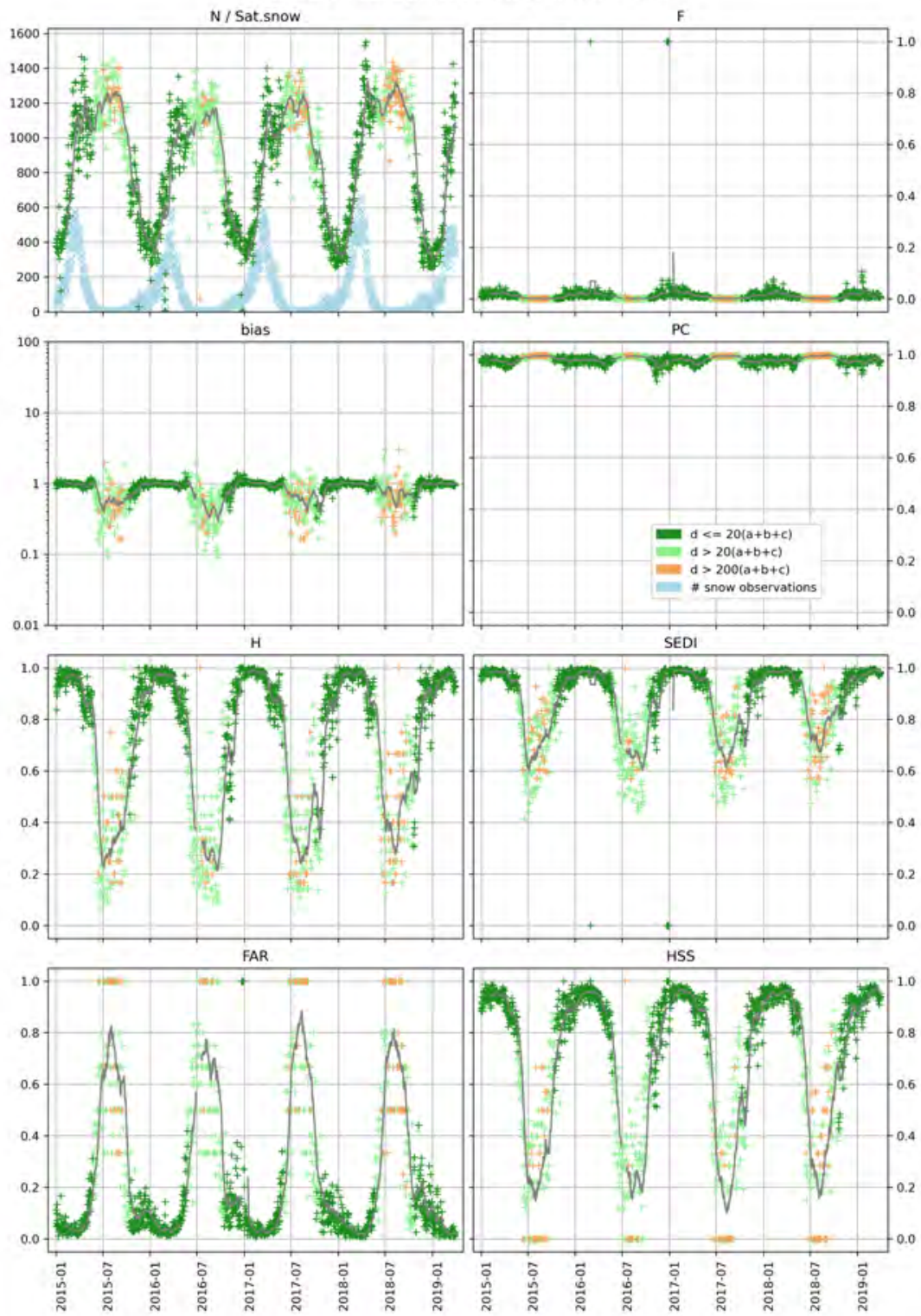

Fig. 10. As in Fig. 8, but partial classifications excluded. 
TABLE 6. Contingency table of the comparison between two categorical snow analyses. The symbols $a$ - $d$ represent the number of cases in each group.

\begin{tabular}{ccc} 
& \multicolumn{2}{c}{ Analysis 2 (baseline) } \\
\cline { 2 - 3 } Analysis 1 & Snow & No snow \\
\hline Snow & $a$ (Hit) & $b$ (False Alarm) \\
No snow & $c$ (Miss) & $d$ (Correct Rejection)
\end{tabular}


TABLE 7. Global validation results for the period from January 2015 to March 2019. Global, Europe and Variable regions and all three partial snow treatments presented. Differences between versions are rather small, even though treating partial snow as snow seem to be slightly worse than other two options. $N$ is the number of cases, other validation measures are defined in Section 3c.

\begin{tabular}{lrrrrrrrrr}
\hline \hline & \multicolumn{3}{c}{ Global (4240 stations) } & \multicolumn{4}{c}{ Europe (2021 stations) } & \multicolumn{3}{c}{ Variable (2286 stations) } \\
Partial & no snow & snow & off & no snow & snow & off & no snow & snow & off \\
\hline$N$ & 1327910 & 1337570 & 1328561 & 727098 & 729781 & 725434 & 948663 & 955943 & 949833 \\
BIAS & 0.989 & 0.929 & 0.964 & 1.009 & 0.913 & 0.962 & 1.031 & 0.954 & 0.990 \\
$H$ & 0.928 & 0.884 & 0.920 & 0.933 & 0.857 & 0.913 & 0.974 & 0.918 & 0.958 \\
$F$ & 0.009 & 0.008 & 0.007 & 0.005 & 0.005 & 0.004 & 0.006 & 0.005 & 0.004 \\
FAR & 0.062 & 0.049 & 0.045 & 0.076 & 0.062 & 0.051 & 0.055 & 0.038 & 0.032 \\
PC & 0.983 & 0.977 & 0.983 & 0.991 & 0.985 & 0.991 & 0.992 & 0.987 & 0.992 \\
CSI & 0.875 & 0.845 & 0.882 & 0.866 & 0.811 & 0.870 & 0.921 & 0.886 & 0.929 \\
HSS & 0.924 & 0.903 & 0.928 & 0.923 & 0.888 & 0.925 & 0.955 & 0.932 & 0.959 \\
SEDI & 0.978 & 0.963 & 0.976 & 0.981 & 0.957 & 0.977 & 0.993 & 0.977 & 0.989 \\
\hline
\end{tabular}

TABLE 8. Some operational snow products available currently with published accuracy estimates. (Disk = Geostationary satellite detection disk, $\mathrm{NH}=$ Northern Hemisphere $)$.

\begin{tabular}{|c|c|c|c|c|c|c|}
\hline Product & Data Source & $\begin{array}{l}\text { Start } \\
\text { year }\end{array}$ & Resolution & $\begin{array}{l}\text { Time } \\
\text { res. }\end{array}$ & Coverage & Reference/Accuracy \\
\hline H SAF H32 & Metop (AVHRR) & 2015 & $0.01^{\circ}$ & Daily & Global & Described in this paper \\
\hline H SAF H31 & MSG (SEVIRI) & 2008 & $3 \mathrm{~km}$ (nadir) & Daily & Disk & $\begin{array}{l}\text { The PC against IMS about } 99 \% \text { calcu- } \\
\text { lated over the whole year, but some- } \\
\text { what lower during the NH winter only. } \\
\text { The } H \approx 80 \% \text { and } F<10 \% \text {. (Siljamo } \\
\text { and Hyvärinen 2011). }\end{array}$ \\
\hline $\begin{array}{l}\text { VIIRS } \\
\text { snow products }\end{array}$ & $\begin{array}{l}\text { Suomi-NPP } \\
\text { NOAA-20 }\end{array}$ & 2012 & $375 \mathrm{~m} / 0.05^{\circ}$ & Daily & Global & $\begin{array}{l}\text { Comparable to MODIS, but VIIRS has } \\
\text { the potential to map snow cover area } \\
\text { more accurately (Riggs et al. 2017; } \\
\text { Thapa et al. 2019) }\end{array}$ \\
\hline $\begin{array}{l}\text { MODIS } \\
\text { snow products }\end{array}$ & $\begin{array}{l}\text { Terra (MODIS) } \\
\text { Aqua (MODIS) }\end{array}$ & 2000 & $500 \mathrm{~m} / 0.05^{\circ}$ & $\begin{array}{l}\text { Daily } \\
\text { 8-day } \\
\text { monthly }\end{array}$ & Global & $\begin{array}{l}\text { The PC against in-situ snow observa- } \\
\text { tions in Collection } 5 \text { about } 93 \% \text {, but } \\
\text { lower accuracy is found in forested } \\
\text { areas and complex terrain and when } \\
\text { snow is thin and ephemeral. Very high } \\
\text { PC, up to } 99 \% \text {, may be found in crop- } \\
\text { lands and agricultural areas (Hall and } \\
\text { Riggs 2007). Note that Collection } 6 \\
\text { has been published. (Riggs et al. 2017) }\end{array}$ \\
\hline $\begin{array}{l}\text { NOAA/NESDIS } \\
\text { IMS }\end{array}$ & Multisource & 1998 & $4 \mathrm{~km}$ & $\begin{array}{l}\text { Daily } \\
\text { 8-day }\end{array}$ & NH & $\begin{array}{l}\text { Described in Helfrich et al. (2007); } \\
\text { Ramsay (1998). The PC against in- } \\
\text { situ snow observations } 80-90 \%, H \\
\approx 95 \% \text {, and } F 0-20 \% \text { during the } \\
\text { NH winter, but values vary with sea- } \\
\text { son (Brubaker et al. 2005; Chen et al. } \\
2012 \text { ). }\end{array}$ \\
\hline
\end{tabular}


Article published in International Journal of Remote Sensing May 2011 (C) Taylor \& Francis, reprinted with permission available online:

http://www.tandfonline.com/10.1080/01431161003743199

I. F. Trigo, C. C. Dacamara, P. Viterbo, J.-L. Roujean, F. Olesen, C. Barroso, F. Camacho-de-Coca, D. Carrer, S. C. Freitas, J. Garcia-Haro, B. Geiger, F. GellensMeulenberghs, N. Ghilain, J. Meliá, L. Pessanha, N. Siljamo and A. Arboleda (2011). 'The Satellite Application Facility for Land Surface Analysis'. Int. J. Remote Sens. 32:10, pp. 2725-2744. DOI: 10.1080/01431161003743199 



\title{
The Satellite Application Facility for Land Surface Analysis
}

\author{
ISABEL F. TRIGO*†t, CARLOS C. DACAMARA \\ JEAN-LOUIS ROUJEAN§, FOLKE OLESENII, CARLA BARROSO $\dagger$, \\ FERNANDO CAMACHO-DE-COCA|, DOMINIQUE CARRER§, \\ SANDRA C. FREITAS $\dagger$, JAVIER GARCÍA-HARO|, BERNHARD GEIGER§, \\ FRANÇOISE GELLENS-MEULENBERGHSa, NICOLAS GHILAINa, \\ JOAQUÍN MELIÁ|, LUIS PESSANHA†, NIILO SILJAMO¥ and \\ ALIRIO ARBOLEDAם \\ $\dagger$ Instituto de Meteorologia, Lisbon, Portugal \\ IInstituto Dom Luiz, Lisbon, Portugal \\ $\S \mathrm{CNRM/GAME,} \mathrm{Météo-France/CNRS,} \mathrm{Toulouse,} \mathrm{France}$ \\ IFForschungszentrum Karlsruhe, Institut für Meteorologie und Klimaforschung, \\ Karlsruhe, Germany \\ |Departament de Termodinàmica, Universitat de Valencia, Valencia, Spain \\ aDepartment of Research and Development, Royal Meteorological Institute, \\ Brussels, Belgium \\ $¥$ Finnish Meteorological Institute, Earth Observation, Helsinki, Finland
}

(Received 10 December 2008; in final form 19 February 2010)

\begin{abstract}
Information on land surface properties finds applications in a range of areas related to weather forecasting, environmental research, hazard management and climate monitoring. Remotely sensed observations yield the only means of supplying land surface information with adequate time sampling and a wide spatial coverage. The aim of the Satellite Application Facility for Land Surface Analysis (Land-SAF) is to take full advantage of remotely sensed data to support land, land-atmosphere and biosphere applications, with emphasis on the development and implementation of algorithms that allow operational use of data from European Organization for the Exploitation of Meteorological Satellites (EUMETSAT) sensors. This article provides an overview of the Land-SAF, with brief descriptions of algorithms and validation results. The set of parameters currently estimated and disseminated by the Land-SAF consists of three main groups: (i) the surface radiation budget, including albedo, land surface temperature, and downward short- and longwave fluxes; (ii) the surface water budget (snow cover and evapotranspiration); and (iii) vegetation and wild-fire parameters.
\end{abstract}

\section{Introduction}

The Satellite Application Facility for Land Surface Analysis (Land-SAF) is part of the SAF network, a set of specialized development and processing centres serving the European Organization for the Exploitation of Meteorological Satellites (EUMETSAT) Application Ground Segment (Schmetz et al. 2002). The SAF network complements the product-oriented activities at the EUMETSAT Central

*Corresponding author. Email: Isabel.Trigo@meteo.pt 
Facility in Darmstadt. The main purpose of the Land-SAF is to take full advantage of remotely sensed data, particularly those available from EUMETSAT sensors, to measure land surface variables, which will find applications primarily in meteorology.

The Land-SAF makes use of two main satellite systems: the geostationary series, Meteosat Second Generation (MSG), and the EUMETSAT Polar System (EPS). With respect to the previous generation of European geostationary satellites, the spin-stabilized MSG has an imaging-repeat cycle of $15 \mathrm{~min}$ (against $30 \mathrm{~min}$ on the previous system), which provides more timely information. The EPS is Europe's first polar orbiting operational meteorological satellite and the European contribution to a joint polar system with the US. EUMETSAT will have the operational responsibility for the 'morning orbit' with Meteorological-Operational (MetOp) satellites, the first of which was launched successfully on 19 October 2006.

The Spinning Enhanced Visible and Infrared Imager (SEVIRI) radiometer, onboard MSG, has unique spectral characteristics and accuracy, with a $3 \mathrm{~km}$ resolution (sampling distance) at nadir (1 km for the high-resolution visible channel), and 12 spectral channels (table 1; Schmetz et al. 2002). Its combination with the Advanced Very High Resolution Radiometer (AVHRR) onboard MetOp permits global coverage of the land surface, with AVHRR complementing SEVIRI at high latitudes.

The Land-SAF (figure 1) started its 5-year development phase in September 1999, and its initial operations in January 2005. During the current phase of the project, from March 2007 to February 2012, the Land-SAF consortium is pursuing the consolidation of its operational and user support activities. Emphasis is on the validation and upgrading of algorithms based on the changing needs of the users and full exploitation of the capabilities of EUMETSAT sensors. The Land-SAF has been especially designed to serve the needs of the meteorological community, particularly Numerical Weather Prediction (NWP). The products retrieved from Meteosat and EPS satellites can be grouped into (i) Surface Radiation Budget parameters, which include downward long- (DSLF) and shortwave (DSSF) surface fluxes, albedo (AL), land surface temperature (LST), and emissivity (EM); and (ii) Biogeophysical parameters, such as snow cover (SC), soil moisture and evapotranspiration (ET), and vegetation products (table 2). The growing number of users in agricultural and

Table 1. Characteristics of the Spinning Enhanced Visible and Infrared Imager (SEVIRI) onboard Meteosat Second Generation (www.eumetsat.int).

\begin{tabular}{lcll}
\hline Channel & Central wavelength $(\mu \mathrm{m})$ & \multicolumn{1}{c}{ Dynamic range } & \multicolumn{1}{c}{ Radiometric noise } \\
\hline VIS0.6 & 0.635 & $533 \mathrm{~W} \mathrm{~m}^{-2} \mathrm{sr}^{-1} \mu \mathrm{m}^{-1}$ & $\mathrm{~S} / \mathrm{N} 10$ at $1 \%$ albedo \\
VIS0.8 & 0.81 & $357 \mathrm{~W} \mathrm{~m}^{-2} \mathrm{sr}^{-1} \mu \mathrm{m}^{-1}$ & S/N 7 at $1 \%$ albedo \\
NIR1.6 & 1.64 & $75 \mathrm{~W} \mathrm{~m}^{-2} \mathrm{sr}^{-1} \mu \mathrm{m}^{-1}$ & $\mathrm{~S} / \mathrm{N} 3$ at $1 \%$ albedo \\
IR3.9 & 3.92 & $335 \mathrm{~K}$ & $0.35 \mathrm{~K}$ at $300 \mathrm{~K}$ \\
WV6.2 & 6.25 & $300 \mathrm{~K}$ & $0.75 \mathrm{~K}$ at $250 \mathrm{~K}$ \\
WV7.3 & 7.35 & $300 \mathrm{~K}$ & $0.75 \mathrm{~K}$ at $250 \mathrm{~K}$ \\
IR8.7 & 8.70 & $300 \mathrm{~K}$ & $0.28 \mathrm{~K}$ at $300 \mathrm{~K}$ \\
IR9.7 & 9.66 & $310 \mathrm{~K}$ & $1.50 \mathrm{~K}$ at $255 \mathrm{~K}$ \\
IR10.8 & 10.80 & $335 \mathrm{~K}$ & $0.25 \mathrm{~K}$ at $300 \mathrm{~K}$ \\
IR12.0 & 12.00 & $335 \mathrm{~K}$ & $0.37 \mathrm{~K}$ at $300 \mathrm{~K}$ \\
IR13.4 & 13.40 & $300 \mathrm{~K}$ & $1.80 \mathrm{~K}$ at $270 \mathrm{~K}$ \\
HRV & Broadband (about $0.4-1.1)$ & $460 \mathrm{~W} \mathrm{~m}^{-2} \mathrm{sr}^{-1} \mu \mathrm{m}^{-1}$ & S/N 1.2 at $0.3 \%$ albedo \\
\hline
\end{tabular}

$\mathrm{S} / \mathrm{N}$, Signal-to-noise ratio. 


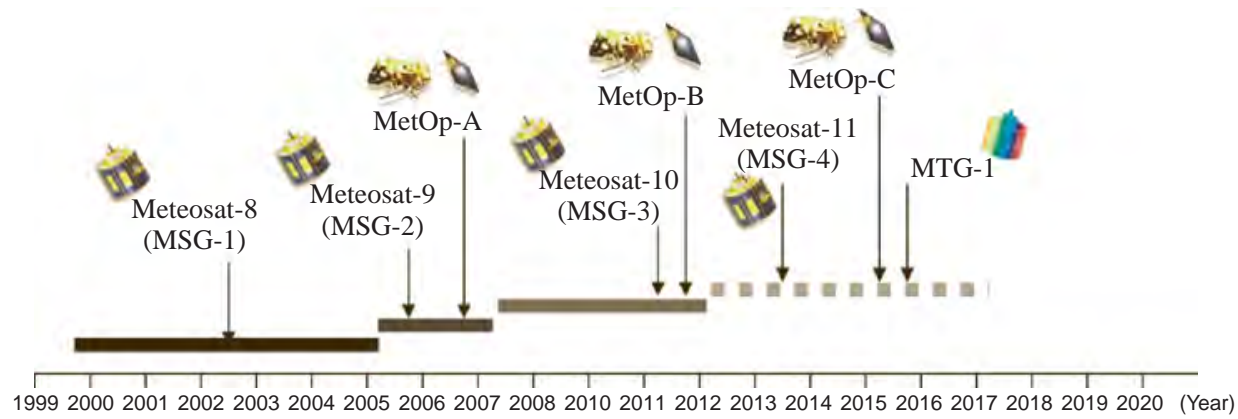

Figure 1. Project phases: (i) 5-year development period (September 1999 to December 2004); (ii) initial operations phase (January 2005 to February 2007); and (iii) the continuous development and operations phase, which began in March 2007. The schedule for EUMETSAT satellite launches is also indicated.

forestry applications, land use, and the broader topics of climate, environment monitoring and atmospheric chemistry, have supported the extension of biogeophysical parameters to wild-fire-related products. The Land-SAF generates land surface variables on a pixel-by-pixel basis, which are provided to users in the satellite nominal resolution, for most of the products. An indication of the expected accuracy of each retrieved value is also given, either in the form of quality flags or as an estimated error range (i.e. estimates of product inaccuracy taking into account known algorithm uncertainties and propagation of input errors).

User requirements evolve with the availability of improved or new data sources, and the rise of potential applications for new products. Programmes promoted by the World Meteorological Organization (WMO) or by the European Commission (EC) and European Space Agency (ESA), such as the Global Monitoring for Environment and Security (GMES), have established guidelines for the monitoring of climate and environment, stressing the need for global, long-term, high quality and reliable products. The life cycle of EUMETSAT satellites, and the participation of LandSAF consortium members in the geoland project (a prototype for the land component of GMES), put the Land-SAF in a privileged position as a product/service provider for those programmes. Finally, the proactive relationship with the user community is expected to be reinforced through cooperation with users regarding validation activities, and through promotion of workshops to discuss the adequacy of the Land-SAF list of products, and their respective characteristics (workshop proceedings, with examples of product application, are available at http://landsaf.meteo.pt/ workshops.jsp).

\section{Surface radiation budget}

\subsection{Products and algorithms}

Surface radiation budget-related parameters have been estimated from SEVIRI/ MSG, archived and disseminated on a regular basis since March 2005. Estimations using AVHRR/MetOp and merging of polar orbiting and geostationary satellite data are now foreseen for 2009. Polar orbiters will improve spatial coverage at high latitudes, as well as the angular sampling for a better estimation of surface albedo. Land surface albedo (AL) is the fraction of incoming solar energy reflected at the 


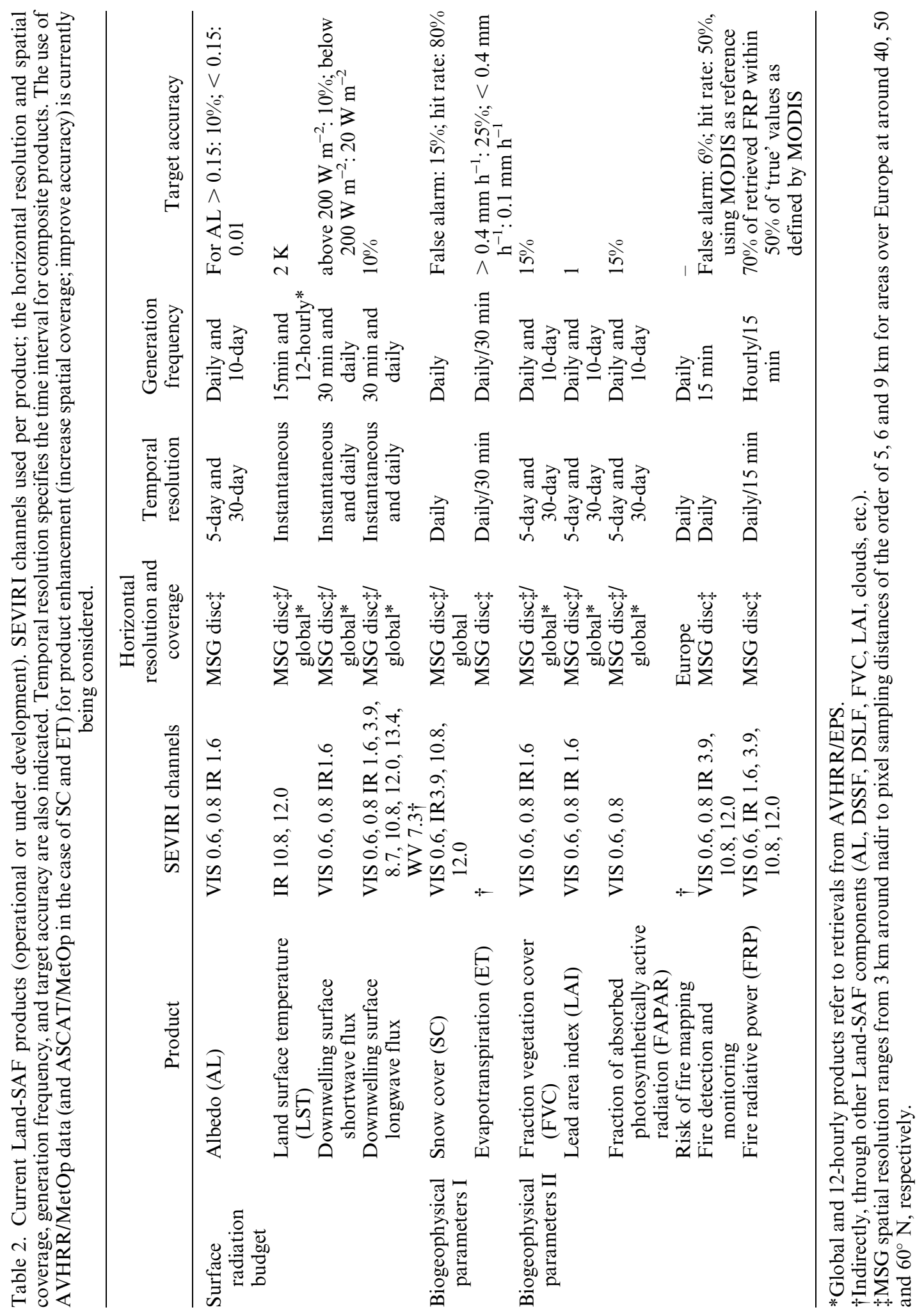


surface. It indirectly quantifies the fraction of the energy that is absorbed and transformed into surface sensible and latent heat fluxes. Owing to strong feedback effects, the knowledge of albedo is important for determining weather conditions in the atmospheric boundary layer (Dickinson 1983). The Land-SAF AL product (Geiger et al. 2008a) is based on the three shortwave channels at 0.6, 0.8 and 1.6 $\mu \mathrm{m}$. In the first step of the AL processing chain, cloud-free reflectance observations of each time-slot are corrected for atmospheric effects using the simplified radiative transfer code SMAC (Rahman and Dedieu 1994). A linear kernel-driven bidirectional reflectance distribution function (BRDF) model (Roujean et al. 1992) is then inverted against daily time series of top-of-canopy reflectance values. The integration of the BRDF model provides spectral AL values that are then converted into broadband estimates corresponding to visible (e.g. figure 2(a)), near-infrared, and total (e.g. figure $2(b))$ shortwave ranges. These are available as directional-hemispherical ('black-sky') and bi-hemispherical ('white-sky') quantities (Geiger et al. 2008a). Two temporal AL products are considered: one with an effective temporal scale of 5 days, updated on a daily basis, and a 30-day composite, updated every 10 days. The temporal resolution associated with the former reduces the sensitivity to uncorrected atmospheric effects (e.g. residual cloudiness), while still being able to detect shortterm variations of the surface properties, such as recent snowfall or burnt areas. Median values of error estimates for the 5-day AL are of the order of 0.005, while the 90th centile is around 0.010. Nevertheless, the reliability of AL retrievals (both 5-day and 30-day products) may be degraded ( $i$ ) over regions with persistent cloud cover, as is often the case in tropical areas during the rainy season; (ii) over areas with very high aerosol loads, since the current version of the AL algorithm relies on aerosol climatological data for the atmospheric correction; and (iii) over pixels with recent snowfall or snow melt. Users may easily identify such cases, associated with larger error ranges and degraded quality flags.

The monthly composite AL samples (sub-)seasonal time-scales. The Land-SAF Team is currently working on an improved version of the 30-day AL composite, which makes use of observations provided by SEVIRI/MSG (for multiple illumination angles) and AVHRR/MetOp (for different viewing geometries). The
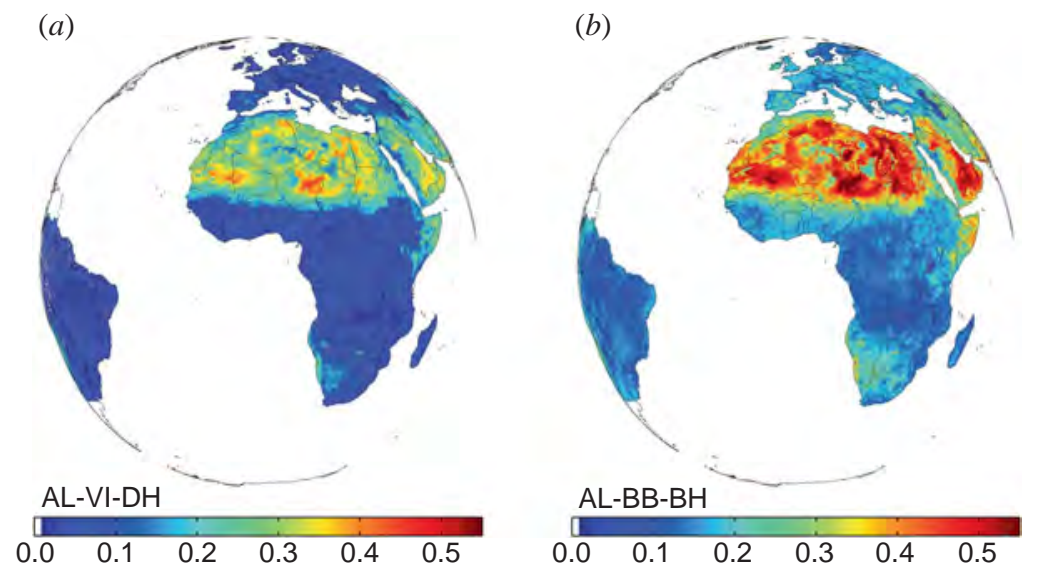

Figure 2. Albedo estimated for 10 July 2006: $(a)$ visible (range 0.4-0.7 $\mu \mathrm{m}$ ) black sky; and $(b)$ total shortwave (range $0.4-4 \mu \mathrm{m}$ ) white sky albedo. 
combination of data sets from geostationary and polar systems is indeed challenging because it requires some harmonized effort relative to the data preprocessing (cloud and aerosol removal). The expected improvements in BRDF quality with a better angular resolution will be operated typically at $3 \mathrm{~km}$ spatial resolution. This value corresponds to a compromise as it represents the SEVIRI subsatellite footprint and an average resolution for AVHRR between nadir $(1 \mathrm{~km})$ and off-nadir $(6 \mathrm{~km})$.

Land surface temperature (LST), or directional radiometric temperature of the surface, provides the best approximation to the thermodynamic temperature based on a radiance measurements (Norman and Becker 1995). It should be kept in mind, however, that directional effects are important for heterogeneous and non-isothermal surfaces, such as a satellite pixels over land (Barroso et al. 2005, Trigo et al. 2008a). There, thermodynamic temperature would be better represented by the hemispherical radiometric temperature (Norman and Becker 1995). Currently, the Land-SAF LST (figure $3(a)$ ) is obtained by correcting top-of-atmosphere (TOA) radiances for the atmospheric attenuation along the path and the reflection of downward radiance. The LST algorithm is based on a generalized split window, following the formulation first proposed by Wan and Dozier (1996) to derive LST from the AVHRR and Moderate Resolution Imaging Spectroradiometer (MODIS), adapted to SEVIRI data (Trigo et al. 2008a). Surface temperature is estimated as a linear function of clear-sky, TOA brightness temperatures for the split-window channels $10.8 \mu \mathrm{m}$ and $12.0 \mu \mathrm{m}$, where regression coefficients depend explicitly on land surface emissivity for each channel, and implicitly on atmospheric water vapour content and satellite viewing angle. Channel and broadband emissivity is estimated as a weighted average of that of bare ground and vegetation elements within each pixel (Peres and DaCamara 2005, Trigo et al. 2008b), using the fraction of vegetation cover (FVC), another Land-SAF product described below. The uncertainty of LST retrievals (figure $3(b)$ ) takes into account the inaccuracy inherent in the generalized split-windows method and the propagation of errors in the input variables (Freitas et al. 2010). The field presented in figure 3(b) depicts well the regions with lower LST accuracy (error ranges above $3 \mathrm{~K}$ ), namely: $(i)$ arid areas where the uncertainty in surface emissivity is generally high, and

(a)

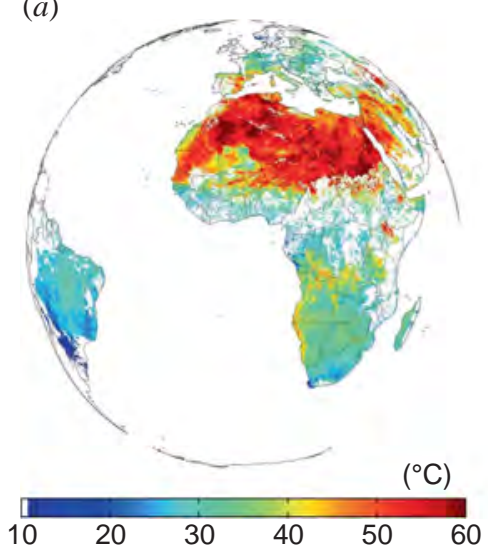

(b)

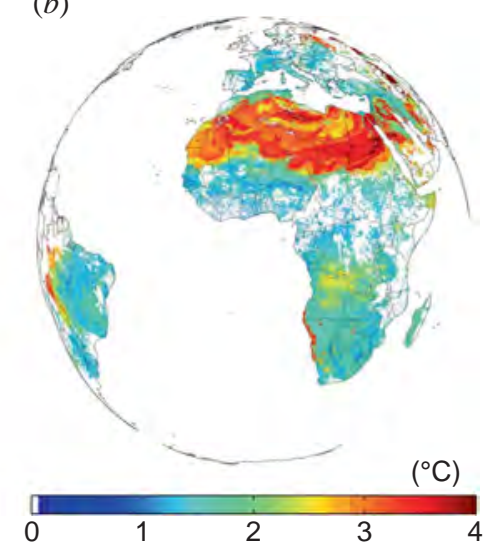

Figure 3. (a) Land surface temperatures (LSTs) estimated for 10 July 2006, 12 UTC and (b) the uncertainty of the LST retrievals. White areas over continents correspond to cloudy pixels, where LST was not retrieved. 
where the extreme high brightness temperatures tend to further enhance LST error ranges; and (ii) regions near the border of the MSG disc, where large optical paths associated with high viewing angles lead to large LST uncertainties, particularly in the presence of moist atmospheres.

Information on cloud cover is obtained using the Nowcasting and Very Short Range Forecasting Satellite Application Facility (SAFNWC) software (http:// www.nwcsaf.org/HD/Main.jsp). Dynamic information on the atmospheric pressure and total column water vapour comes from the European Centre for Medium-range Weather Forecasts (ECMWF) NWP model. Cloud data (identification and cloud type classification) are used in the processing of all Land-SAF products, either to flag non-processed pixels (e.g. BRDF, LST) or to be used for the estimation of atmospheric absorption/emission within the visible (VIS)/infrared(IR) domain needed for the estimation of the respective downward fluxes at the surface.

The downwelling surface short- and longwave radiation fluxes (DSSF and DSLF) refer to the radiative energy flux in the wavelength intervals $0.3-4.0 \mu \mathrm{m}$ and $4-100 \mu \mathrm{m}$, respectively. Both DSSF and DSLF products are calculated for every second slot of MSG input data at intervals of $30 \mathrm{~min}$. The estimates are derived for the instantaneous acquisition time of each image line. Satellite-derived estimates of radiation fluxes are valuable tools to validate results from assimilation systems and climate models (Allan et al. 2004, Harries et al. 2005, Bony et al. 2006) or off-line forcing of land surface models (Dirmeyer et al. 2006).

The shortwave component, DSSF (figure 4(a)), essentially depends on the solar zenith angle, cloud cover and, to a lesser extent, atmospheric absorption and surface albedo. The methodology for the retrieval of DSSF implemented in the Land-SAF system (Geiger et al. 2008b) relies on the approach developed within the framework of the Ocean and Sea Ice (OSI) SAF (Brisson et al. 1999). The distinguishing features of the Land-SAF product are the spatial and temporal resolution, the source of ancillary input data, and the use of three shortwave SEVIRI channels $(0.6,0.8$ and $1.6 \mu \mathrm{m})$. DSSF is strongly anti-correlated with observed TOA reflectances; bright clouds (i.e. high TOA reflectances) correspond to low solar radiation reaching the surface. Estimated TOA albedo serves as the most important input information for a simple
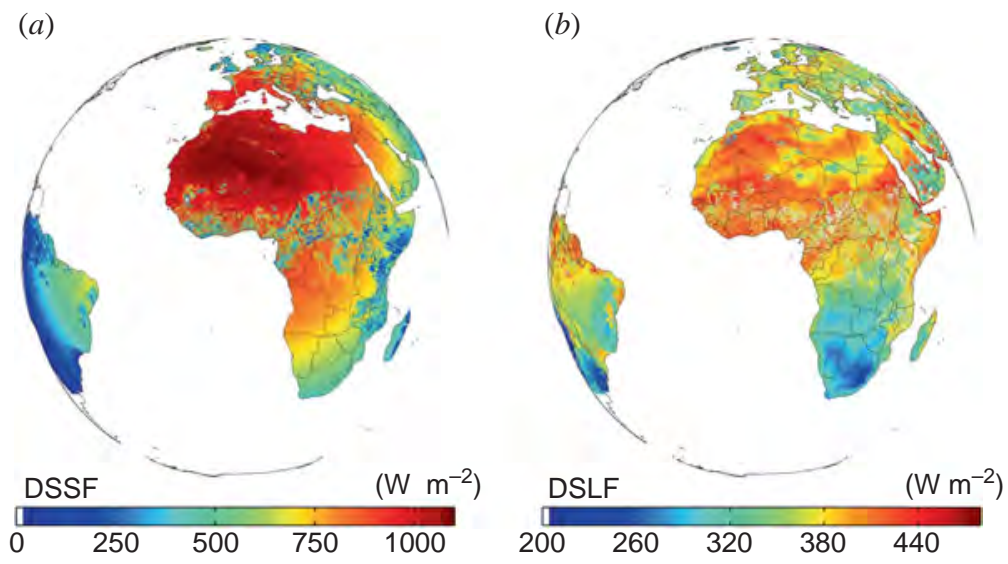

Figure 4. (a) Shortwave and (b) longwave downwelling fluxes at the surface ( $\mathrm{W} \mathrm{m}^{-2}$ ), estimated for 10 July 2006, 12 UTC. 
physical parameterization of the radiation transfer in the cloud-atmosphere-surface system. In clear-sky conditions DSSF is estimated directly by a parameterization for the effective transmittance of the atmosphere as a function of the concentration of atmospheric constituents (Frouin et al. 1989). For cloudy situations, DSSF estimates rely on a simplified physical description of the radiation transfer in the cloud-atmosphere-surface system (Gautier et al. 1980, Brisson et al. 1999). Important elements of this scheme are cloud transmittance, cloud albedo, and atmospheric transmittance between the surface and clouds. Estimates for the cloud properties are derived from TOA albedo (Geiger et al. 2008b), determined from the satellite measurements by applying a broadband conversion relationship (Clerbaux et al. 2005) and an angular dependence model (Manalo-Smith et al. 1998).

The estimation of DSLF (figure 4(b)) combines remotely sensed information on clouds and atmospheric fields (temperature and humidity) provided by NWP models. In the Land-SAF approach, DSLF makes use of bulk parameterization schemes merging formulations derived for clear-sky conditions (e.g. Prata 1996), with schemes developed for cloudy skies (e.g. Josey et al. 2003). DSLF retrievals benefit from the signature of clouds and different cloud types on IR and VIS channels, complemented with information on atmosphere water content and near-surface air temperature available from NWP fields, also used to estimate atmospheric transmittance in the DSSF algorithm. It is worth noting that NWP fields, obtained from ECMWF 12- to 24-h forecasts, include information from atmospheric sounders and other observations, and thus correspond to the best knowledge of atmospheric profiles for each time slot.

\subsection{Validation of radiative parameters}

The validation strategy for Land-SAF products focuses on three main aspects: $(i)$ comparison with similar parameters retrieved from different sensors; (ii) comparison with in-situ measurements; and (iii) sensitivity studies and assessment of the impact of input errors on the quality of the Land-SAF products. The latter are the basis for the estimation of the product error range for each retrieved value, which is disseminated to users (see, for example, figure 3(b)). Validation of surface radiative fluxes makes use of the Baseline Surface Radiation Network (BSRN) (http://www.bsrn.awi.de), a project of the World Climate Research Programme (WCRP) and the Global Energy and Water Experiment (GEWEX) aimed at detecting important changes in the Earth's radiation field (Ohmura et al. 1998). BSRN radiation measurements include surface downwelling short- and longwave fluxes and more rarely upwelling fluxes. As a result of a strict quality control, BSRN data have been widely used to validate radiation schemes in climate modelling and to check the calibration of satellitederived radiometric products. To overcome the scarcity of LST ground measurements within the area covered by Meteosat, the Land-SAF Team carried out exploratory studies to find suitable LST validation sites and one LST ground-truth station has already been set up in Évora (Southern Portugal), in operation since August 2005 (Kabsch et al. 2008). Recently, two other sites have been set up in Africa, in Namibia and Senegal, respectively.

As an example, figure 5 presents results from different methodologies involved in the validation of Land-SAF radiation products, including comparison with similar parameters retrieved from MODIS (LST and albedo), and with in situ measurements (DSSF and DSLF). Validation exercises not only provide information on product 

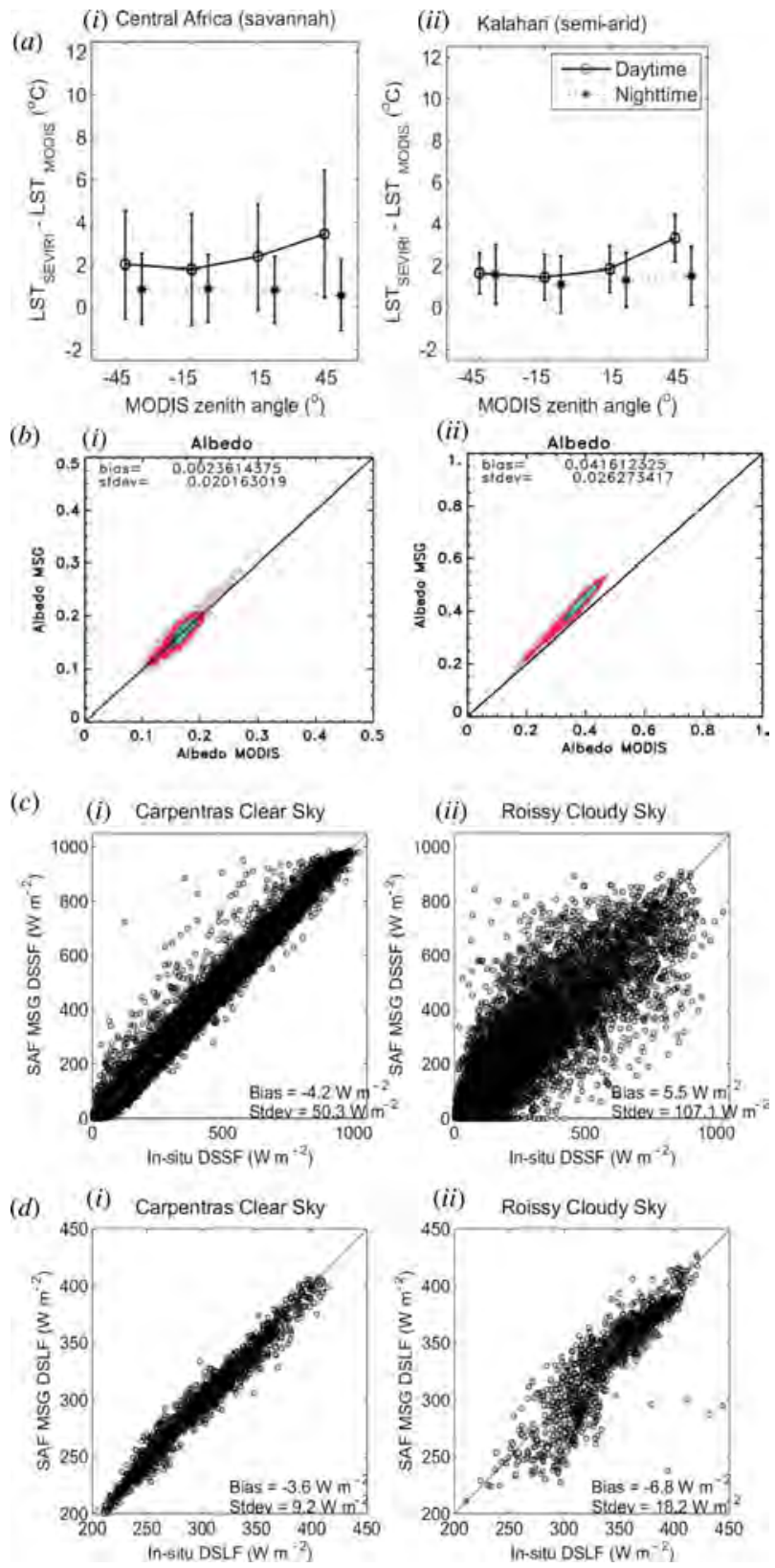

Figure 5. Examples of validation exercises carried out for radiation parameters, including comparison with products from other satellites and in situ observations. (a) Average and standard deviation $\left({ }^{\circ} \mathrm{C}\right)$ differences between SEVIRI and MODIS LST products for two $10^{\circ} \times 10^{\circ}$ boxes in Africa, centred at (i) $10^{\circ} \mathrm{S}, 20^{\circ} \mathrm{E}$ (Central Africa and (ii) $25^{\circ} \mathrm{S}, 20^{\circ} \mathrm{E}$ (Kalahari). The statistics are obtained for the period 25-31 July 2005, for MODIS daytime and night-time passages (see legend), and for the classes of MODIS satellite zenith angle specified on the $x$-axis. (b) Land-SAF broadband bidirectional albedo ( $y$-axis) retrieved $(i)$ over Europe (10-25 June 2006) and (ii) over Northern Africa (12-27 July 2006), plotted against the equivalent MODIS parameter ( $x$-axis); average (bias) and standard deviation (Stdev) of differences are also indicated. (c) Scatterplot of Land-SAF DSSF versus in situ measurements for $(i)$ clearsky cases observed in Carpentras, France and (ii) cloudy conditions observed in Roissy, France. The data were collected between 2006 and 2007. (d) Scatterplot of Land-SAF DSLF versus in situ measurements for same cases as in $(c)$. 
accuracy but also reveal product characteristics and problematic/optimal retrieval conditions. The comparison between Land-SAF (SEVIRI) and MODIS LST (figure 5(a)) shows a clear dependence of discrepancies with viewing angles, for daytime cases. As discussed in detail in Trigo et al. (2008a), these results indicate clearly the directional character of remotely sensed LST, and also suggest that comparison of night-time estimates is more suitable for the detection of biases associated with the algorithm or input data. Overall, SEVIRI LST is higher than MODIS LST, with night-time systematic differences ranging between $0.5^{\circ} \mathrm{C}$ and $1.0^{\circ} \mathrm{C}$. Similarly, Land-SAF SEVIRI AL is routinely compared with MODIS AL (figure $5(b)$ ). The results reveal very good matching between the two parameters. Over northern Africa, characterized by very bright surfaces, the Land-SAF product generates higher broadband albedo values (figure 5(b)(ii)). Such overestimation with respect to MODIS albedo is primarily linked to differences in angular integration of surface reflectances, due either to the use of different BRDF models or diverse angular samplings (more details in Geiger et al. 2008a).

Although not shown, the validation of LST and AL products includes evaluation against in situ measurements. Figures $5(c)$ and $5(d)$ show, also as an example, scatterplots of Land-SAF downward fluxes for DSSF and DSLF, respectively, versus ground observations for two stations in France. The results are presented separately for clear and cloudy-sky conditions, revealing higher discrepancies for the latter, as expected. In general, the radiative fluxes are within the target accuracy (table 2) for most retrieved values. Conditions likely to produce lower quality estimates (e.g. partially clouded pixels, high angle observations) are flagged within the retrieved products. In addition, DSSF (DSLF) may be overestimated (underestimated) under very high aerosol loads, as shown by Slingo et al. (2006).

Product validation is essential for assessing whether user requirements (table 2) are met. The example presented in figure 5 aims to illustrate the ongoing validation of surface radiation parameters, using both in situ observations and data from other satellites. Further detailed results on product performance may be found in the LandSAF validation reports updated regularly (http://landsaf.meteo.pt; see also Geiger et al. 2008a,b, Kabsch et al. 2008, Trigo et al. 2008a,b).

\section{Biogeophysical parameters}

\subsection{Water budget}

In addition to the surface radiation budget, the Land-SAF has been tasked to provide a series of biogeophysical products, essential for modelling and understanding land surface processes. SC and ET constitute the first set, related to the surface water budget.

$\mathrm{SC}$ relies on different signatures of snow, ice and clouds on the reflectance of shortwave IR channels onboard SEVIRI/MSG and AVHRR/MetOp to provide daily fields discriminating snow-free, snow-covered and partially snow-covered pixels over the whole European area. As the separation between cloud and surface ice/snow is also crucial for cloud detection, the SC algorithm is based on a thresholding procedure to distinguish surfaces covered with snow or ice from clouds and snowfree pixels. The resulting SC (http://landsaf.meteo.pt) product has been generated on an operational basis and archived since March 2005. An additional set of quality/ processing flags for each pixel is provided to users, giving information on the uncertainty of the classification (further details may be found in the respective Product User Manual, Land-SAF 2006). Table 3 presents a summary of the Land-SAF SC scores 
Table 3. Land-SAF snow cover product verified against NOAA/NESDIS (Europe; July 2007-February 2009).

\begin{tabular}{ll}
\hline Proportion correct & 0.977 \\
Bias & 0.863 \\
Probability of detection & 0.747 \\
False alarm rate & 0.135 \\
\hline
\end{tabular}

using the National Oceanic and Atmospheric Administration (NOAA)/National Environmental Satellite, Data and Information Service (NESDIS) product as reference. The statistics corresponding to SC retrievals over the European region, between July 2007 and February 2009, show good agreement between the two products. Detection of snow with VIS and IR is generally less reliable for terrains with steep slopes, or over areas with dense forests with snow under the canopy. These cases are flagged in the Land-SAF SC product.

Although SC estimations based on IR and VIS channels provide maps with high spatial resolution, they may be hampered by persistent cloudiness; in this respect, the high temporal sampling of geostationary satellites provides a clear advantage towards polar orbiters. The information from both platforms will be used to produce daily SC maps, which will be particularly useful over the mid- to high latitudes. In regions such as Central and Eastern Europe or Scandinavia, Meteosat viewing geometry makes the detection of snow more difficult because of the high satellite zenith angles, and radiances correspond to coarser spatial resolution pixels (with distances between pixels reaching 6-12 km). There the better spatial resolution provided by MetOp, along with observations closer to nadir, will complement the higher observation frequency of Meteosat. Microwave data are not limited to clear-sky observations, they are also sensitive to snow water equivalent (e.g. Kongoli et al. 2004, Drusch et al. 2004). However, they have coarser resolution (typically $25-50 \mathrm{~km}$, instead of 1-5 km) and may present problems in the detection of thin or wet snow (Kongoli et al. 2004). The accuracy of snow products derived from VIS/IR and from microwave varies considerably with surface and terrain types and atmospheric conditions. Merging the two different sources of data will provide the best means to improve accuracy, extend product availability, and provide information on snow metamorphism (snow ageing, melting, ice). The Land-SAF Team expects to minimize known sources of errors by introducing, for example, topographic and land cover corrections (e.g. forests).

One of the aims of the Land-SAF is the estimation of parameters necessary for a complete description of the energy budget over land surfaces, making use of EUMETSAT. Within this framework, ET, which combines soil and intercepted water evaporation with plant transpiration, is essential to the estimation of surface latent heat flux.

The approach currently followed to derive ET makes use of a soil-vegetation-atmosphere transfer (SVAT) model - a simplified version of the ECMWF TESSEL SVAT scheme - forced by Land-SAF radiation products (DSSF, DSLF and AL) and ECMWF meteorology to estimate ET. Soil moisture will be estimated through Advanced Scatterometer (ASCAT)/MetOp data, through either direct assimilation of TOA radiances or soil moisture retrievals (provided by EUMETSAT). ET depends on many local factors and variables (e.g. vegetation type and state, soil moisture, near surface wind), making its validation particularly difficult. Figure 6 shows a scatterplot of Land-SAF ET estimates against observations taken in Cabauw (The Netherlands), 


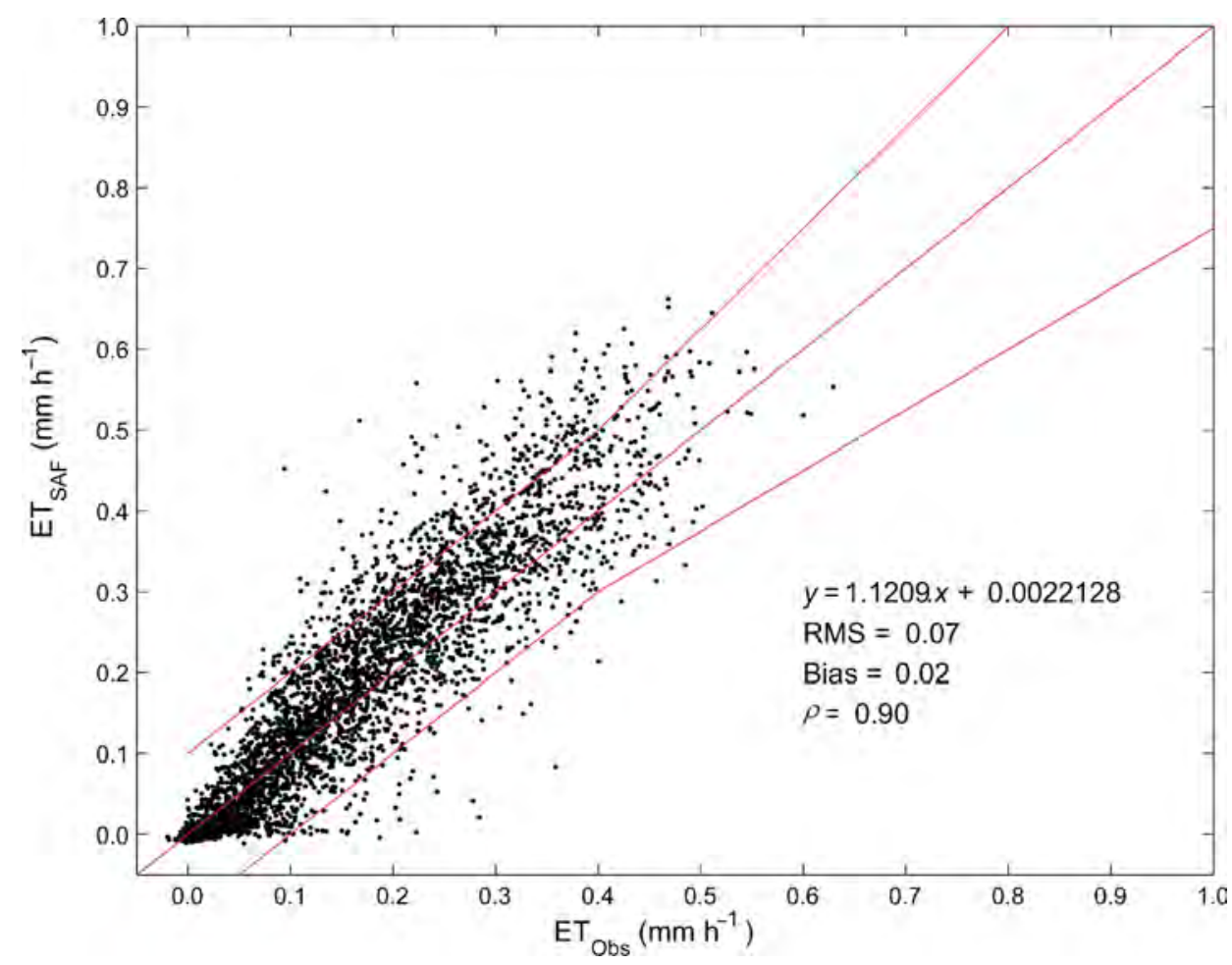

Figure 6. Comparison of 30-min Land-SAF evapotranspiration (ET_SAF) estimates ( $\mathrm{mm} \mathrm{h}^{-1}$ ) with in-situ measurements (ET_Obs) taken in Cabauw (The Netherlands) over the period ranging from 1 March to 31 December 2007.

characterized by grassland (Beljaars and Bosveld 1997). The comparison with observations does not present evident systematic biases. In general, the validation results reveal good agreement between estimations and observations obtained for stations in areas dominated by grasslands (figure 6) and mixed forests (not shown; Land-SAF 2008). So far, validation of ET has been mostly performed for Europe. Flux measurements over Africa and South America are scarcer but a full assessment of Land-SAF ET estimations over those regions is ongoing.

At a later stage, the Land-SAF Team expects to test alternative approaches to the estimation of daily ET by exploiting the spectral and temporal resolution of SEVIRI. Among others, Caparrini et al. (2004) showed that sequential LST data contain useful information on the partitioning of available surface energy into latent and sensible surface heat fluxes. Thus, high frequency (e.g. 15-min) fields of LST may be assimilated into an SVAT model, which can also use other surface radiation parameters as forcing.

\subsection{Vegetation and wild fires}

The second set of biogeophysical parameters comprises vegetation and wild fire indices. Fraction of Vegetation Cover (FVC), Leaf Area Index (LAI), and Fraction of Absorbed Photosynthetically Active Radiation (FAPAR) are currently retrieved from SEVIRI; retrievals based on AVHRR and on merged AVHRR and SEVIRI 

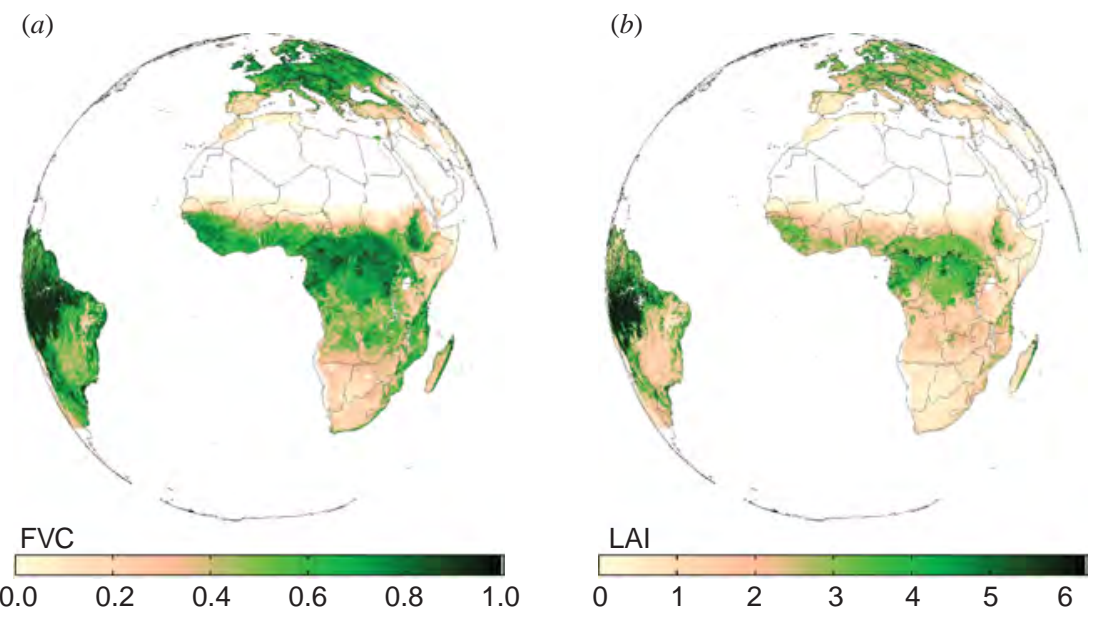

Figure 7. (a) Fraction of Vegetation Cover (FVC) and (b) Leaf Area Index (LAI), corresponding to a 5-day composite, estimated on 10 July 2006.

data will become available later. FVC (figure 7(a)) characterizes the fraction of vegetation on a flat background; LAI (figure $7(b)$ ) is a dimensionless variable $\left(\mathrm{m}^{2}\right.$ $\mathrm{m}^{-2}$ ) defined as one half of the total leaf area per unit ground area, and accounts for the surface of leaves contained in a vertical column normalized by its cross-sectional area; and FAPAR (not shown) represents the fraction of solar energy absorbed by vegetation for photosynthesis. FVC, LAI and FAPAR are relevant parameters for a wide range of land-biosphere applications, from agriculture and forestry to environmental management and land use. FVC determines the partition between soil and vegetation contributions, also used for emissivity estimations. For fully and healthy developed canopies, LAI indicates the amount of green vegetation that absorbs or scatters solar radiation, and is an important parameter in NWP, climate and SVAT models. Finally, FAPAR is an indicator of the health and thereby productivity of vegetation. FAPAR is generally well correlated with LAI, particularly for healthy, fully developed, vegetation canopies.

The algorithms of the vegetation products rely on the use of BRDF parameters (Roujean and Lacaze 2002), which contain specific spectral directional signatures of vegetation reflectances. The normalization of SEVIRI images to a common geometry minimizes surface anisotropy effects, which constitute one of the main drawbacks of using geostationary satellites for vegetation monitoring. While FAPAR is based on simulations of surface reflectances in optimal angular geometries (Roujean and Bréon 1995), FVC is estimated through the application of a spectral mixture analysis methodology, developed taking into account the spectral variability of vegetation in different ecosystems (e.g. Bateson et al. 2000, García-Haro et al. 2005), to VIS and near-IR reflectance values. The algorithm relies on a statistical approach, in which soil and vegetation components are represented by a multimodal probability density function. Finally, LAI is estimated from FVC following the methodology developed by Roujean and Lacaze (2002), which proved to be more effective than traditional techniques based on spectral vegetation indices.

The high rate of acquisition provided by the SEVIRI instrument guarantees the availability of spatially consistent cloud-free data for adequately monitoring both the 
seasonality of vegetation and the long-term trends in the state of vegetation. The spatial and temporal variation of the SEVIRI vegetation products in Southern Africa was validated using data collected by Privette et al. (2002) and Huemmrich et al. (2005) along the International Geosphere Biosphere Programme (IGBP) Kalahari Transect. A representative example of this analysis is presented in figure 8. LAI retrieved from SEVIRI/MSG captures the phenology in this area, from peak-biomass in March-April (towards the end of the wet season), to senescence, peak dry season and minimum foliar biomass in early September, and rapid green-up into the next season. Large product errors are generally found at high latitudes, particularly over Europe during winter, since the inputs are derived under suboptimal conditions. Product limitations at high latitudes are anticipated to be considerably reduced by combining SEVIRI and AVHRR data. Moreover, the quality of FVC, LAI and FAPAR also tends to be degraded for areas with persistent cloud, high aerosol loads, or large viewing angles, as in the case of the AL product. Such degradation is reflected in the product error range, and in extreme cases (e.g. very large input uncertainties, or traces of snow) the estimated values are masked out. In the case of FAPAR, values with estimated uncertainty higher than 0.25 are set to 'not processed' in the final product files. The information on retrieval conditions or on the reasons for ignoring the retrieval is detailed in the product quality flags. Maps of estimated error ranges for FVC, LAI and FAPAR (not shown) generally exhibit high values over high latitudes, particularly during winter, and along the most active areas of the Inter-Tropical Convergence Zone (ITCZ). Uncertainty estimates, based on the propagation of input errors and on the theoretical uncertainty of the algorithm, typically range between 0.04 and 0.15 for FVC, between 0.03 and 0.10 for LAI, and between 0.05 and 0.15 for FAPAR.

Fire-related processes have long been identified as applications with great potential to be derived from SEVIRI/MSG and AVHRR/MetOp (Pereira and Govaerts 2001, Boschetti et al. 2003). These applications include the monitoring of vegetation susceptibility to fire, which is linked to water stress and surface temperature. The merging

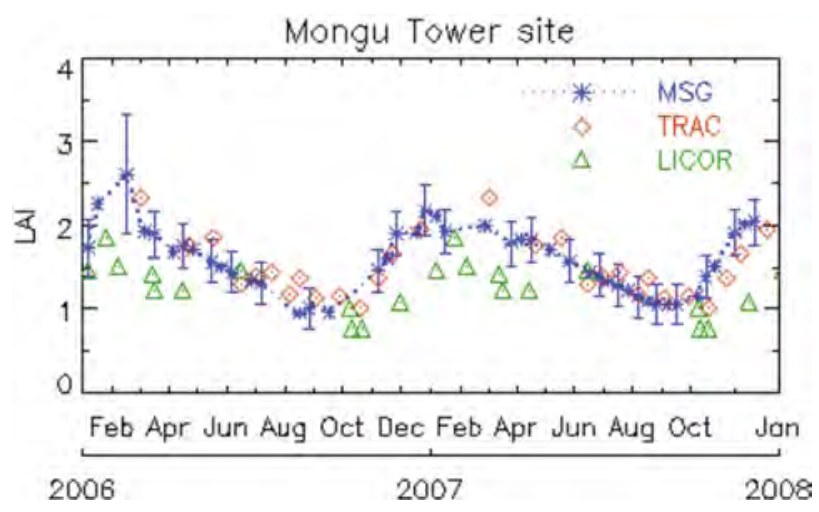

Figure 8. Comparison of Land-SAF LAI product (stars; labelled MSG) retrieved from SEVIRI over a 2-year period (2006-2007) with (non-concomitant) field measurements over the Mongu site in western Zambia (15.438 S, $23.253 \mathrm{E})$. The land-cover type at the site is a Miombo woodland on Kalahari sand (woody savannah). The single time-profile combines all measurements taken with two different instruments and periods: (i) TRAC instrument (Natural Resources Canada, Canada Centre for Remote Sensing, Ontario, Canada) over the year 2000 (diamonds) and (ii) LAI-2000 LICOR instrument (Li-COR Biosciences, Lincoln, NE, USA) over the period 2000-2002 (triangles). 
of such data with meteorological parameters provides indicators of fire risk, fire detection, monitoring and fire scar identification. Following demands from environment monitoring and risk management (e.g. GMES requirements), the Land-SAF is currently exploring $(i)$ the capability of SEVIRI/MSG to detect and monitor active fires, particularly over Africa, leading to the operational generation, archiving and dissemination of the Fire Detection and Monitoring (FD\&M) product; and (ii) signals of vegetation water stress on SEVIRI channels $(0.8,1.6$ and $3.9 \mu \mathrm{m})$, to follow its variability in space and time, and to produce a meaningful danger of fire rating, or Risk of Fire Mapping (RFM), for (Southern) Europe. The latter is still under development; an operational version is currently foreseen for the end of 2010.

Biomass burning is a significant global source of aerosols, greenhouse gases (e.g. carbon dioxide and methane) as well as of nitric and carbon monoxides, methyl bromide and hydrocarbons that lead to acid rain and the photochemical production of tropospheric ozone and destruction of stratospheric ozone, which impact global climate (e.g. Crutzen and Andreae 1990). Other impacts of biomass burning relate to the biogeochemical cycling of nitrogen and carbon compounds, the hydrological cycle, the reflectivity and emissivity of the land, the stability of ecosystems and ecosystem biodiversity (e.g. Dwyer et al. 1999). The radiant energy released per unit time during a vegetation fire is directly related to the amount of biomass burning and combustion gases emitted to the atmosphere (Wooster et al. 2005). As wild fires are generally associated with vegetation combustion at temperatures within the $600-1300 \mathrm{~K}$ range, they exhibit an emission peak in the mid-IR $(3-5 \mu \mathrm{m})$, in accordance with Wien's displacement law. Therefore, the detection of active fires is essentially based on the signature of these events (even with subpixel scales) on the brightness temperature of channel IR3.9. The algorithm used by the Land-SAF for fire detection is based on a series of contextual thresholds, derived empirically for channels IR3.9 and IR10.8, which take into account values of immediate (fire-free) neighbours (Giglio et al. 2003). The Land-SAF currently produces Fire Radiative Power (FRP) at the pixel scale (every 15-min; figure 9), and at a coarser resolution $\left(1^{\circ}\right.$ longitude $\times 1^{\circ}$ latitude; hourly), following the algorithm described in Wooster et al. (2005). The rate of radiant energy emitted by a fire (FRP) is estimated using the Planck function, relating the emitted spectral radiance and the emitter temperature (Wooster et al. 2003).

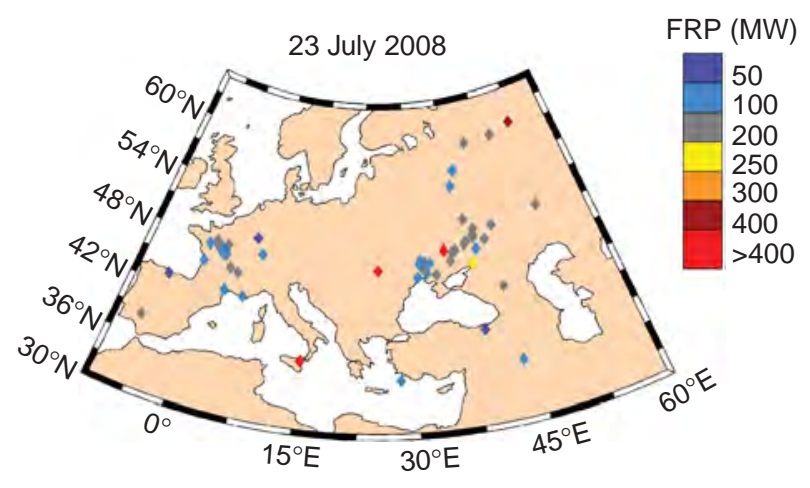

Figure 9. Fire Radiative Power (FRP) corresponding to all fire events detected over Europe on 23 July 2008. The point over Sicily corresponds to the volcano in Mount Etna. 
Validation of the detection of wild-fire events and corresponding radiative power obtained from SEVIRI/MSG is mostly based on comparisons with similar MODIS products. The higher spatial resolution of the MODIS instrument allows the identification of significantly more events (weak or small fires) than SEVIRI; for simultaneous observations SEVIRI misses up to $50-55 \%$ of fires detected by MODIS. In addition, the higher dynamic range of MODIS allows the estimation of higher FRP values than SEVIRI, which saturates at lower temperatures. However, because of its high (15-min) sampling rate, SEVIRI is likely to capture a signal from most fire events, in contrast to MODIS, with only four overpasses per day. SEVIRI is able to observe a significant part of the life-cycle of wild fires, and thus capture most events when they reach their peak intensity. Moreover, the FRP estimations using SEVIRI will be far more representative of the radiative energy released over a day by wild fires than those provided by instruments on polar orbiters, such as MODIS (Govaerts et al. 2008).

\section{Conclusion}

After a 5-year development phase and a 2-year period in pre-operation, the LandSAF Team has a set of consolidated algorithms, used to generate land surface products in an operational mode, which are archived and disseminated in near real time or off-line. These include retrievals of surface radiative components, vegetation parameters and snow cover. Other algorithms are already in an advanced stage of development and foreseen to become operational during the current 5-year phase of the project (2007-2012). All of the products are distributed with quality control information and for some of them with an error range, indicative of the expected accuracy of the retrieved fields, on a pixel-by-pixel basis, supported by sensitivity studies and product validation.

Product validation is an essential component of Land-SAF activities, as the main source of information on the compliance of generated products with user requirements. Only parameters that meet the target accuracy described in table 2 for a significant number of cases are considered operational (i.e. are distributed to users). Furthermore, the results of product validation are one of the drivers for further algorithm development and improvements of the quality of products. Validation activities basically consist of intercomparison of Land-SAF products and similar parameters retrieved from other satellite data (e.g. LST retrieved from AATSR on ENVISAT, LST and AL from MODIS on EOS, vegetation parameters from MERIS on ENVISAT, MODIS on EOS, snow cover from NOAA/NESDIS and MODIS) and with ground-truth sites. Such intercomparison exercises are often carried out in cooperation with existing projects or networks of detailed in situ measurements (e.g. BSRN, GEWEX). Given the lack of LST ground measurements within the Meteosat disc, the Land-SAF Team has set up its own sites, which are particularly dedicated to LST, but that also collect downward surface radiative fluxes and other meteorological data. The first of these stations has been set up in Évora (Southern Portugal), while two others have recently been installed in Namibia and Senegal.

The Land-SAF addresses a wide community, ranging from surface processes modelling (e.g. NWP, seasonal forecasting and climate models) to agriculture and forestry applications (e.g. fire hazards, food production) and hydrology. This community greatly benefits from products generated from a reliable observation system designed to ensure long-term operations. The MSG programme alone is expected to provide observations for at least 12 years (e.g. Schmetz et al. 2002), while Meteosat 
Third Generation is already under preparation. Both Meteosat and MetOp series are important components of the Global Earth Observation System of Systems (GEOSS), a comprehensive, sustained observation system of the Earth. It is the role of the LandSAF, and all SAFs in general, to adapt existing algorithms to forthcoming (EUMETSAT) sensors, guaranteeing the continuation of current products, and to develop applications that fully exploit new remote sensing capabilities.

The Land-SAF products, classified as 'essential' by EUMETSAT, are available on a free and unrestricted basis. The data may be requested and downloaded off-line from the Land-SAF website, while near-real-time users are encouraged to use EUMETCast, which is the primary distribution means for EUMETSAT image data and derived products. Additional information on the Land-SAF is available at http:// landsaf.meteo.pt/, while the EUMETSAT website at www.eumetsat.int provides details on European meteorological satellites and other SAFs.

\section{Acknowledgements}

The Land-SAF project is funded by EUMETSAT. The authors would like to express their gratitude to various people involved in the project team, whose efforts have been essential for the success of the Land-SAF. In situ data are essential for validation purposes; most data used for the validation of radiation fluxes were obtained from BSRN stations; observations of evapotranspiration in Cabauw were kindly provided by F. Bosveld.

\section{References}

Allan, R.P., Ringer, M.A., Pamment, J.A. and Slingo, A., 2004, Simulation of the Earth's radiation budget by the European Centre for Medium-Range Weather Forecasts 40year reanalysis (ERA40). Journal of Geophysical Research, 109, D18107, doi:10.1029/ 2004JD004816

Barroso, C, Trigo, I.F., Olesen, F., DaCamara, C. and Queluz, M.P., 2005, Intercalibration of NOAA and Meteosat window channel brightness temperatures. International Journal of Remote Sensing, 26, pp. 3717-3733.

Bateson, C.A., Asner, G.P. and Wessman, C.A., 2000, Endmember bundles: a new approach to incorporating endmember variability into spectral mixture analysis. IEEE Transactions on Geosciences and Remote Sensing, 38, pp. 1083-1094.

Beljatrs, A.C.M. and Bosveld, F.C., 1997, Cabauw data for the validation of land surface parameterization schemes. Journal of Climate, 10, pp. 1172-1193

Boschetti, L., Brivio, P.A. and Gregoire, J.M., 2003, The use of Meteosat and GMS imagery to detect burned areas in tropical environments. Remote Sensing of Environment, 81, pp. 78-91.

Brisson, A., Le Borgne, P. and Marsouin, A., 1999, Development of Algorithms for Surface Solar Irradiance Retrieval at O\&SI SAF Low and Mid Latitudes (Lannion: MétéoFrance/CMS).

Bony, S., Colman, R., Kattsov, V.M., Allan, R.P., Bretherton, C.S., Dufresne, J.-L., Hall, A., Hallegatte, S., Holland, M.M., Ingram, W., Randall, D.A., Soden, B.J., Tselioudis, G. and WebB, M.J., 2006, How well do we understand and evaluate climate change feedback processes? Journal of Climate, 19, pp. 3445-3482.

Caparrini, F., Castelli, F. and Entekhabi, D., 2004, Estimation of surface moisture control and turbulent transfer by assimilating sequences of radiometric surface temperature measurements. Journal of Hydrometeorology, 5, pp. 145-159.

Clerbaux, N., Bertrand, C., Caprion, D., Depaepe, B., Dewitte, S., Gonzalez, L. and Ipe, A., 2005, Narrowband-to-broadband conversions for SEVIRI. In Proceedings of the 2005 EUMETSAT Meteorological Satellite Conference, Dubrovnik, pp. 351-357, Available 
online at: http://www.eumetsat.int/Home/Main/AboutEUMETSAT/Publications/ index.htm.

Crutzen, P. and Andreae, M.O., 1990, Biomass burning in the tropics: impact on atmospheric chemistry and biogeochemical cycles. Science, 250, pp. 1669-1678.

Dickinson, R.E., 1983, Land surface processes and climate - surface albedos and energy balance. Advances in Geophysics, 25, pp. 305-353.

Dirmeyer, P.A., Gao, X., Zhao, M., Guo, Z., Oki, T. and Hanasaki, N., 2006, GSWP-2: multimodel analysis and implications for our perception of the land surface. Bulletin of the American Meteorological Society, 87, pp. 1381-1397.

Drusch, M., VasiljeVic, D. and Viterbo, P., 2004, ECMWF's global snow analysis: assessment and revision based on satellite observations. Journal of Applied Meteorology, 45, pp. 1282-1294.

Dwyer, E., Pereira, J.M.C., Gregoire, J.P. and DaCamara, C.C, 1999, Characterization of the spatio-temporal patterns of global fire activity using satellite imagery for the period April 1992 to March 1993. Journal of Biogeography, 27, pp. 57-69.

Freitas, S., Trigo, I.F., Bioucas-Dias, J. and Göttsche, F., 2010, Quantifying the uncertainty of land surface temperature retrievals from SEVIRI/Meteosat. IEEE Transactions on Geoscience and Remote Sensing, 48, pp. 523-534.

Frouin, R., Lingner, D.W., Gautier, C., Baker, K.S. and Smith, R.C., 1989, A simple analytical formula to compute clear sky total and photosynthetically available solar irradiance at the ocean surface. Journal of Geophysical Research, 94, pp. 9731-9742.

García-Haro, F.J., Sommer, S. and Kemper, T., 2005, Variable multiple endmember spectral mixture analysis (VMESMA). International Journal of Remote Sensing, 26, pp. 2135-2162.

Gautier, C., Diak, G. and Masse, S., 1980, A simple physical model to estimate incident solar radiation at the surface from GOES satellite data. Journal of Climate and Applied Meteorology, 19, pp. 1005-1012.

Geiger, B., Carrer, D., Franchistéguy, L., Roujean, J.-L. and Meurey, C., 2008a, Land surface albedo derived on a daily basis from Meteosat second generation observations. IEEE Transactions on Geoscience and Remote Sensing, 46, pp. 3841-3856.

Geiger, B., Meurey, C., Lajas, D., Franchistéguy, L., Carrer, D. and Roujean, J.-L., 2008b, Near real-time provision of downwelling shortwave radiation estimates derived from satellite observations. Meteorological Applications, 15, pp. 411-420.

Giglio, L., Descloitres, J., Justice, C.O. and Kaufman, Y.J., 2003, An enhanced contextural fire detection algorithm for MODIS. Remote Sensing of Environment, 87, pp. 273-282.

Govaerts, Y., Wooster, M., Lattanzio, A., Roberts, G., Freeborn, P., Xu, W. and Trigo, I., 2008, The operational MSG/SEVIRI fire radiative power product generated at the Land SAF. In Proceedings of the 2008 EUMETSAT Meteorological Satellite Conference, Darmstadt. Available online at: www.eumetsat.int/Home/Main/AboutEUMETSAT/ Publications/.

Harries, J.E., Russell, J.E., Hanafin, J.A., Brindley, H., Futyan, J., Rufus, J., Kellock, S., Matthews, G., Wrigley, R., Last, A., Mueller, J., Mossavati, R., Ashmall, J., Sawyer, E., Parker, D., Caldwell, M., Allan, P.M., Smith, A., Bates, M.J., Coan, B., Stewart, B.C., Lepine, D.R., Cornwall, L.A., Corney, D.R., Ricketts, M.J., Drummond, D., Smart, D., Cutler, R., Dewitte, S., Clerbaux, N., Gonzalez, L., Ipe, A., Bertrand, C., Joukoff, A., Crommelynck, D., Nelms, N., Llewllyn-Jones, D.T., Butcher, G., Smith, G.L., Szewczyk, Z.P., Mlynczak, P.E., Slingo, A., Allan, R.P. and Ringer, M.A., 2005, The Geostationary Earth Radiation Budget Project. Bulletin of the American Meteorological Society, 86, pp. 945-960.

Huemmrich, K.F., Privette, J.L., Mukelabai, M., Myneni, R.B. and Knyazikhin, Y., 2005, Time-series validation of MODIS land biophysical products in a Kalahari woodland, Africa. International Journal of Remote Sensing, 26, pp. pp. 4381-4398.

Josey, S.A., Pascal, R.W., Taylor, P.K. and Yelland, M.J., 2003, A new formula for determining the atmospheric longwave flux at the ocean surface at mid-high latitudes. Journal of Geophysical Research, 108, 3108, doi:10.1029/2002JC001418. 
Kabsch, E., Olesen, F.S. and Prata, 2008, Initial results of the land surface temperature (LST) validation with the Evora, Portugal ground-truth station measurements. International Journal of Remote Sensing, 29, pp. 5329-5345.

Kongoli, C., Grody, N.C. and Ferraro, R.R., 2004, Interpretation of AMSU microwave measurements for the retrievals of snow water equivalent and snow depth. Journal of Geophysical Research, 109, D24111, doi:10.1029/2004JD004836.

LAND-SAF, 2006, Product User Manual: Snow Cover. SAF/LAND/FMI/PUM/SC/2.5. Available online at: http://landsaf.meteo.pt.

LAND-SAF, 2008, Validation Report: Evapotranspiration. SAF/LAND/RMIB/VR_MET_0.3. Available online at: http://landsaf.meteo.pt.

Manalo-Smith, N., Smith, G.L., Tiwari, S.N. and Staylor, W.F., 1998, Analytic forms of bidirectional reflectance functions for application to Earth radiation budget studies. Journal of Geophysical Research, 103D, pp. 19733-19751.

Norman, J.M. and Becker, F., 1995, Terminology in thermal infrared remote sensing of natural surfaces. Agricultural and Forest Meteorology, 77, pp. 153-166.

Ohmura, A., Dutton, E.G., Forgan, B., Fröhlich, C., Gilgen, H., Hegner, H., Heimo, A., König-Langlo, G., McArthur, B., Müller, G., Philipona, R., Pinker, R., Whitlock, C.H., Dehne, K. and Wild, M., 1998, Baseline Surface Radiation Network (BSRN/WRMC), a new precision radiometry for climate research. Bulletin of the American Meteorological Society, 79, pp. 2115-2136.

Pereira, J.M.C. and Govaerts, Y., 2001, Potential Fire Applications from MSG/SEVIRI Observations. EUMETSAT Programme Development Department, Technical Memorandum No. 7.

Peres, L.F. and DaCamara, C.C., 2005, Emissivity maps to retrieve land-surface temperature from MSG/SEVIRI. IEEE Transactions on Geosciences and Remote Sensing, 43, pp. 1834-1844.

Prata, A.J., 1996, A new long-wave formula for estimating downward clear-sky radiation at the surface. Quarterly Journal of the Royal Meteorological Society, 122, pp. 1121-1151.

Privette, J.L., Myneni, R.B., Knyazikhin, Y., Mukelabai, M., Roberts, G., Tian, Y., Wang, Y. and Leblanc, S.G., 2002, Early spatial and temporal validation of MODIS LAI product in the Southern Africa Kalahari. Remote Sensing of Environment, 83, pp. $232-243$.

Rahman, H. and Dedieu, G., 1994, SMAC: a simplified method for the atmospheric correction of satellite measurements in the solar spectrum. International Journal of Remote Sensing, 15, pp. 123-143.

RouJeAn, J.-L. and BRÉON, F.M., 1995, Estimating PAR absorbed by vegetation from bidirectional reflectance measurements. Remote Sensing of Environment, 51, pp. 375-384.

ROUJEAN, J.-L. and LACAZE, R., 2002, Global mapping of vegetation parameters from POLDER multiangular measurements for studies of surface-atmosphere interactions: a pragmatic method and its validation. Journal of Geophysical Research, 107D, pp. 1-14.

Roujean, J.-L., Leroy, M. and Deschamps, P.-Y., 1992, A bidirectional reflectance model of the Earth's surface for the correction of remote sensing data. Journal of Geophysical Research, 97D, pp. 20455-20468.

Schmetz, J., Pili, P., Tuemkes, S., Just, D., Kerkman, J., Rota, S. and Ratier, A., 2002, An introduction to Meteosat Second Generation (MSG). Bulletin of the American Meteorological Society, 83, pp. 977-992.

Slingo, A., Ackerman, T.P., Allan, R.P., Kassianov, E.I., McFarlane, S.A., Robinson, G.J., Barnard, J.C., Miller, M.A., Harries, J.E., Russell, J.E. and Dewitte, S., 2006, Observations of the impact of a major Saharan dust storm on the atmospheric radiation balance. Geophysical Research Letters, 33, L24817, doi:10.1029/2006GL027869.

Trigo, I.F., Monteiro, I.T., Olesen, F. and Kabsch, E., 2008a, An assessment of remotely sensed land surface temperature. Journal of Geophysical Research, 113, D17108, doi:10.1029/2008JD010035. 
Trigo I.F., Peres, L.F., DaCamara, C.C. and Freitas, S.C., 2008b, Thermal land surface emissivity retrieved from SEVIRI/Meteosat. IEEE Transactions on Geosciences and Remote Sensing, 46, pp. 307-3157.

WAN, Z. and DozIER, J., 1996, A generalized split-window algorithm for retrieving land surface temperature from space. IEEE Transactions on Geosciences and Remote Sensing, 34, pp. 892-905.

Wooster, M.J., Roberts, G., Perry, G. and Kaufman, Y.J., 2005, Retrieval of biomass combustion rates and totals from fire radiative power observations: calibration relationships between biomass consumption and fire radiative energy release. Journal of Geophysical Research, 110, D21111, doi:10.1029/2005JD006318.

Wooster, M.J., Zhukov, B. and Oertel, D., 2003, Fire radiative energy for quantitative study of biomass burning from the BIRD experimental satellite and comparison to MODIS fire products. Remote Sensing of Environment, 86, pp. 83-107. 
(C) 2009 American Meteorological Society,

Reprinted with permission from American Meteorological Society 2020

O. Hyvärinen, K. Eerola, N. Siljamo and J. Koskinen (2009). 'Comparison of snow cover from satellite and numerical weather prediction models in Northern Hemisphere and northern Europe'. J. Appl. Meteor. Climatol. 48:6, pp. 11991216. DOI: $10.1175 / 2008$ JAMC2069.1 



\title{
Comparison of Snow Cover from Satellite and Numerical Weather Prediction Models in the Northern Hemisphere and Northern Europe
}

\author{
Otto Hyvärinen, Kalle Eerola, Nillo Siljamo, And JarkKo Koskinen \\ Finnish Meteorological Institute, Helsinki, Finland
}

(Manuscript received 30 June 2008, in final form 5 November 2008)

\begin{abstract}
Snow cover has a strong effect on the surface and lower atmosphere in NWP models. Because the progress of in situ observations has stalled, satellite-based snow analyses are becoming increasingly important. Currently, there exist several products that operationally map global or continental snow cover. In this study, satellitebased snow cover analyses from NOAA, NASA, and the European Organisation for the Exploitation of Meteorological Satellites (EUMETSAT), and NWP snow analyses from the High-Resolution Limited-Area Model (HIRLAM) and ECMWF, were compared using data from January to June 2006. Because no analyses were independent and since available in situ measurements were already used in the NWP analyses, no independent ground truth was available and only the consistency between analyses could be compared. Snow analyses from NOAA, NASA, and ECMWF were similar, but the analysis from NASA was greatly hampered by clouds. HIRLAM and EUMETSAT deviated most from other analyses. Even though the analysis schemes of HIRLAM and ECMWF were quite similar, the resulting snow analyses were quite dissimilar, because ECMWF used the satellite information of snow cover in the form of NOAA analyses, while HIRLAM used none. The differences are especially prominent in areas around the snow edge where few in situ observations are available. This suggests that NWP snow analyses based only on in situ measurements would greatly benefit from inclusion of satellite-based snow cover information.
\end{abstract}

\section{Introduction}

Snow cover and snow depth are important parameters for numerical weather prediction (NWP) and hydrological models, especially in springtime during the melting period. Essential characteristics include snow water equivalent (SWE), snow depth, and snow covered area. For hydrology, the maximum SWE prior to the onset of spring snowmelt is typically the most important snow characteristic for operational runoff and river discharge forecasts. In NWP models, the snow cover affects the surface albedo and the heat flux between the ground and the atmosphere, and therefore has a strong effect on the lower part of the atmosphere. The variable inside NWP models is typically SWE. However, because the SWE can only be analyzed indirectly from temporally and spatially sparse snow depth and snow cover observations, the accuracy of analysis is limited. Thus there is a pressing need for improved snow analysis in numerical models.

Corresponding author address: Otto Hyvärinen, Finnish Meteorological Institute, P.O. Box 503, FI-00101 Helsinki, Finland.

E-mail: otto.hyvarinen@fmi.fi
In the foreseeable future, there will be no improvements to in situ snow observations, but the satellite technology is advancing rapidly and the progress in snow analysis will be based on the increasing use of satellite products. Snow cover analyses produced from satellite information have much better spatial coverage, and both snow and no-snow observations are readily made. However, methods are often based on visible and near-infrared channels and suffer from cloud cover and limited sunlight during the polar winter. On the other hand, methods based on passive microwave instruments are not limited by clouds but suffer from coarser spatial resolution and they work only for dry snow conditions (Ulaby et al. 1986).

The purpose of the current study was to assess the current situation: What satellite products are available and how consistent are their results with each other and with NWP analyses of snow cover? This study concentrated on satellite analyses with methods based on visible and near-infrared channels, as they are more widely used in NWP than methods-based microwave instruments [e.g., Advanced Microwave Scanning Radiometer for Earth Observing System (EOS) (AMSR-E)]. With

DOI: 10.1175/2008JAMC2069.1 
methods based on visible and near-infrared channels, we are in practice restricted to information about the existence of snow in binary form. However, for many applications, SWE is a more important parameter than the snow cover, and therefore developments in this area will be welcome (e.g., Comiso et al. 2003; Pulliainen 2006). Also, our emphasis is more on operational NWP use than on climatological studies [for more climatological and SWE-oriented comparison, see, e.g., Frei et al. (2005)].

Satellite and NWP snow analyses were compared with each other from January to June 2006, first in the whole Northern Hemisphere and then concentrating on northern Europe. The satellite analyses were from the Interactive Multisensor Snow and Ice Mapping System (IMS) from the National Oceanic and Atmospheric Administration (NOAA), Moderate Resolution Imaging Spectroradiometer (MODIS) snow product from the National Aeronautics and Space Administration (NASA), and the snow cover analysis of the Land Surface Analysis (LSA) Satellite Applications Facility (SAF) from the European Organisation for the Exploitation of Meteorological Satellites (EUMETSAT). The NWP analyses were from the High-Resolution Limited-Area Model (HIRLAM) and European Centre for MediumRange Weather Forecasts (ECMWF). HIRLAM uses only in situ observations for its analysis, while ECMWF uses both in situ and satellite observations (the analysis from NOAA). ECMWF and NASA analyses are global, NOAA covers the Northern Hemisphere, HIRLAM covers northern Europe, and LSA SAF uses the geostationary satellite instrument and is thus constricted by the field of view of the instrument.

Numerous studies of snow analyses or comparisons between analyses and ground truth have been made. Producers of snow analyses have published validation studies; for example, Hall and Riggs (2007) reported that the absolute accuracy [the proportion correct (PC), as defined below, against in situ observations] of the MODIS analysis is around $93 \%$, but varied on the land cover type. Most problems arose from cloud detection over snow and from very thin (less than $1 \mathrm{~cm}$ ) snow. Other studies have compared MODIS snow analyses of in situ observations in, for example, China (Wang et al. 2008) and Europe (Parajka and Blöschl 2006; Sorman et al. 2007) with comparable results. Brubaker et al. (2005) compared MODIS and IMS snow analyses with in situ observations in the United States and reported that IMS underestimates snow in the transition seasons but outperforms MODIS analysis in cloudy areas with new snow and during winter. Drusch et al. (2004) shows how the inclusion of IMS snow improves the ECMWF snow analysis. However, to our knowledge, the present study is novel because comparisons between more than two snow analyses have not been widely performed.

\section{Data}

The snow analyses used in this study are called both products and analyses. The difference between an analysis and a product is a matter of definition. The term product emphasizes that the analysis is made for the general use, while, for example, NWP analyses are more restricted both in distribution and in intended use. For consistency in this study, after the introduction of analyses and products, only the term analysis will be used.

\section{a. MODIS snow product}

The MODIS instrument onboard the Terra and Aqua satellites of the EOS satellite series provides daily observations up to 500-m resolution. The fully automated MODIS snow-mapping algorithm uses satellite reflectances in MODIS bands $4(0.545-0.565 \mu \mathrm{m})$ and 6 $(1.628-1.652 \mu \mathrm{m})$ to calculate the normalized difference snow index (Hall et al. 1995). The MODIS snow products are also equipped with quality assurance information tags that indicate where nominal or abnormal results occurred (Hall et al. 2002).

MODIS snow cover can be accessed in a number of different data products, differing in projection, resolution, and spatial and temporal coverage. The swath and daily tile snow products classify each pixel as snow, snow-free land, cloud, water, or another condition, but daily and 8-day global products also offer information regarding fractional snow cover (Hall et al. 2002). In this study the daily $0.05^{\circ}$ (about $5 \mathrm{~km}$ ) Climate Modeling Grid (CMG) product was used. There are two products, one for Terra [earth science data type (ESDT) MOD10C1] and one for Aqua (ESDT MYD10C1). The products are constantly improved and reprocessed. At the time of the present work, version or collection 4 was the most up-to-date version. Since then, collection 5 has been released and it is recommended that the most current collection is used for studies.

\section{b. IMS}

NOAA has provided operational snow cover maps for the Northern Hemisphere since 1966. The recent Interactive Multisensor Snow and Ice Mapping System was developed to provide daily snow and ice information from the Northern Hemisphere by combining data from various sensor sources. The main sources are visible and infrared spectral data from the Polar and Geostationary Operational Environmental Satellite programs (POES/ GOES) operated by the National Environmental Satellite, Data, and Information Service (NESDIS), Japanese 


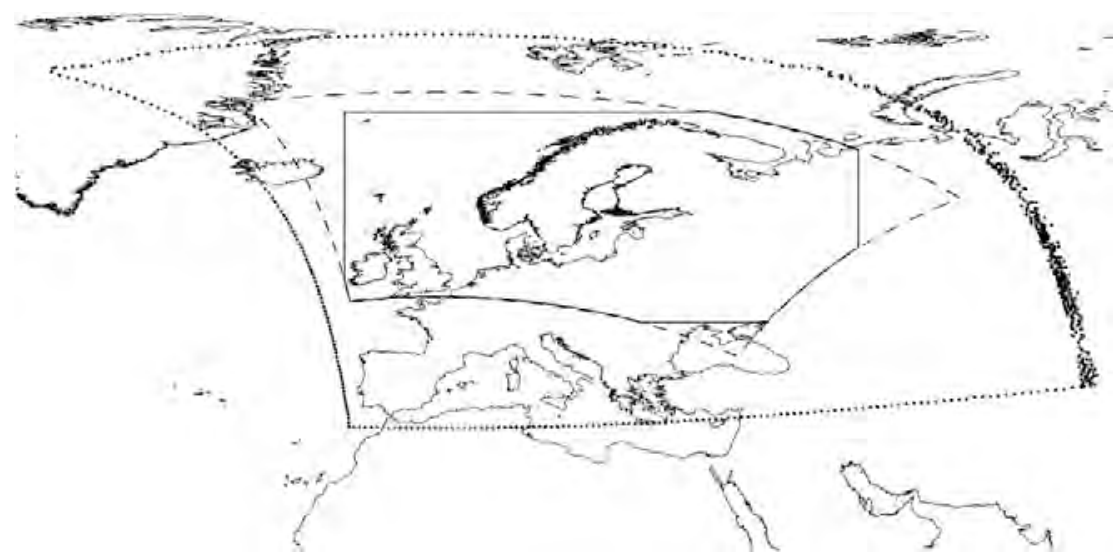

FIG. 1. Areas of LSA SAF analysis (dotted line), HIRLAM analysis (dashed line), and the area for comparison (solid line) over northern Europe.

geostationary satellites [Geostationary Meteorological Satellite (GMS) and lately the Multifunctional Transport Satellite (MTSAT)], and European geostationary satellite (Meteosat). MODIS images, not automatic MODIS snow products, and the microwave products from the Defense Meteorological Satellite Program (DMSP) operated by the U.S. Department of Defense are also used.

The combination of data from different sources for one analysis is done subjectively by analysts at NOAA/ NESDIS. Since there are several other derived snow/ice products of varying accuracy, such as those from the National Ice Center (NIC) and National Centers for Environmental Prediction (NCEP), it is highly desirable for analysts to be able to interactively compare and contrast the products so that a more accurate composite map can be produced (Ramsay 1998). Analysts prefer to use visible imagery for snow-extent mapping. Geostationary data looping is the main source of information, representing an estimated $60 \%$ of snow analysis areas during winter, and $30 \%$ during summer. In summer, polar orbiting satellites' visible channels contribute $65 \%$ of snow areas. Even during winter, microwave-derived snow data represent only $5 \%$ of an analysis (Helfrich et al. 2007).

Currently the IMS produces snow/ice analyses at two resolutions: a lower resolution of $25 \mathrm{~km}(1024 \times 1024$ grid) and a higher resolution of $4 \mathrm{~km}(6144 \times 6144$ grid $)$. Gridded data are available in ASCII format from the Internet. Because IMS products are daily products with a major human element, they cannot be reprocessed in the same manner as MODIS products discussed above.

\section{c. LSA SAF snow cover}

EUMETSAT has several dedicated centers for processing satellite data. Each of the satellite application facilities provides products and services on an operational basis. The main purpose of the Land Surface Analysis Satellite Applications Facility is to increase the benefits from Meteosat second-generation (MSG) and EUMETSAT Polar System (EPS) data related to land, land-atmosphere interactions, and biophysical applications by developing techniques, products, and algorithms that will allow a more effective use of data from the EUMETSAT satellites.

The LSA SAF snow cover is a simple snow presence product, which classifies every land pixel as snow covered, partially snow covered, or snow free if the clouds and lighting conditions allow the classification. The product is aimed at numerical weather prediction and similar applications. The area of analysis is shown in Fig. 1. LSA SAF is primarily concentrated on operational products, and snow analyses are archived but not reprocessed when algorithms are improved. This makes it difficult to use for climatological studies.

During our study period, the LSA SAF snow algorithm was based on the cloud mask of the Nowcasting and Very Short Range Forecasting (NWC) SAF software for Spinning Enhanced Visible and Infrared Imager (SEVIRI) data (Derrien and LeGléau 2005). These cloud masks were generated every $15 \mathrm{~min}$. From cloud masks, only daytime pixels over land classified as cloudy, snow free, or snow covered were used. Images for one day were combined to produce the daily snow cover map over land. This way the impact of short-lived clouds is minimized. The likelihood of finding cloud-free conditions for a certain pixel during one day is better from images generated every 15 min by geostationary MSG satellites than from few images from a polar-orbiting satellite like Terra. 


\section{d. Snow analysis in the HIRLAM model}

HIRLAM is a complete NWP system including hydrostatic primitive equation model and data assimilation. A detailed description of the whole HIRLAM system is given in Undén et al. (2002) and only the snow analysis scheme is described here. The HIRLAM data for this study have been taken from the operational meso-beta (MBE) suite of the Finnish Meteorological Institute. MBE HIRLAM covers the area shown in Fig. 1 with the horizontal resolution of $0.08^{\circ}$.

During our study period the snow analysis in MBE HIRLAM was based on the successive correction method. The first guess for the snow analysis is a shortrange $(6 \mathrm{~h})$ forecast from the previous assimilation cycle that is blended with the climatology. Thus in areas of sparse observations the final snow analysis is close to the short forecast and hence the snow amount is simulated by the melting and accumulation of snow in the forecast model. In addition, the blending guarantees that the final analysis does not drift too far from the climatology even if there is a systematic drift in the forecast model and no observations are available.

The only observation type used in the HIRLAM snow analysis is the snow depth data from synoptic surface (SYNOP) observations (World Meteorological Organization 1995). In the SYNOP observation the snow variable is snow depth, while the corresponding variable in the HIRLAM model is SWE. The analysis is done in snow depth and therefore the HIRLAM first guess must be converted to snow depth. This is done using monthly mean density values of snow. Hence the density of the snow depends only on the time of the year (month) and other properties, like the age of snow, are not taken into account.

The successive correction method corrects the first guess by analyzing the deviation between the first guess and observations. The weights are functions of horizontal and vertical distances between observations and the grid points. In the horizontal, the weights are inversely proportional to the square of the distance. The maximum influence radius is decreased in four iterations from 600 to $100 \mathrm{~km}$. In the vertical, the weights depend inversely on the difference of the gridpoint height and station height, but observations from mountainous areas with height differences of more than $300 \mathrm{~m}$ are not used. The quality control consists of only checking the observations against the first guess and no crosschecking of observations against each other is performed. After the analysis of snow depth, the conversion back to SWE is done in the same way as the conversion to snow depth before the analysis (i.e., using the monthly mean snow density values).

\section{e. Snow analysis in the ECMWF model}

The ECMWF snow analysis is very similar to that of HIRLAM. The successive correction method is used and SYNOP observations are the main source of in situ information. If snow depth observations are not available, the snow accumulation and melting is simulated by using the 6-h forecast from the model. The horizontal and vertical weights are similar to those of HIRLAM. The analysis contains the same steps as HIRLAM: converting the SWE of snowpack to snow depth, analyzing the snow depth, and then converting back to SWE. An important difference is that ECMWF uses IMS snow information (Drusch et al. 2004).

The IMS analysis is used both in creating the first guess and in the analysis. If there is no snow in a first guess grid box, but the area is snow covered in IMS, the snow depth in the first guess is set to $10 \mathrm{~cm}$. During the analysis the IMS data help to analyze the snow edge. Since many SYNOP stations do not report the snow depth of $0 \mathrm{~cm}$ if no snow is present, the snow edge is difficult to analyze using only SYNOP observations. The satellite data are used to create pseudo-observations of $0 \mathrm{~cm}$ of snow in the areas of no snow cover.

For this study, data from the Meteorological Archival and Retrieval System (MARS) at ECMWF were obtained for the Northern Hemisphere with the resolution of $0.225^{\circ}$.

\section{Methods}

In this study we concentrate only on binary snow cover, that is, if the land is snow covered or not. As detailed above, data are disseminated in a variety of projections, but first all data were reprojected to Lambert cylindrical equal-area projection. In this area-preserving projection, comparisons of analyses extending over large geographical areas are meaningful. For the comparisons of ECMWF, IMS, and MODIS analyses in the Northern Hemisphere, analyses were reprojected with a resolution of $25 \mathrm{~km}$. This resolution is close to the original resolution of ECMWF data. For comparisons of HIRLAM, ECWMF, IMS, MODIS, and LSA SAF analyses in northern Europe, analyses were reprojected with a resolution of $5 \mathrm{~km}$, which is close to the original resolution of analyses other than ECMWF. All reprojections were done using the freely available Geospatial Data Abstraction Library (GDAL).

Resamplings were done using the simple nearestneighbor method.

NWP analyses are for SWE, not snow cover. To transform this to snow cover, we simply classified grid boxes with SWE greater than zero as snow covered. 


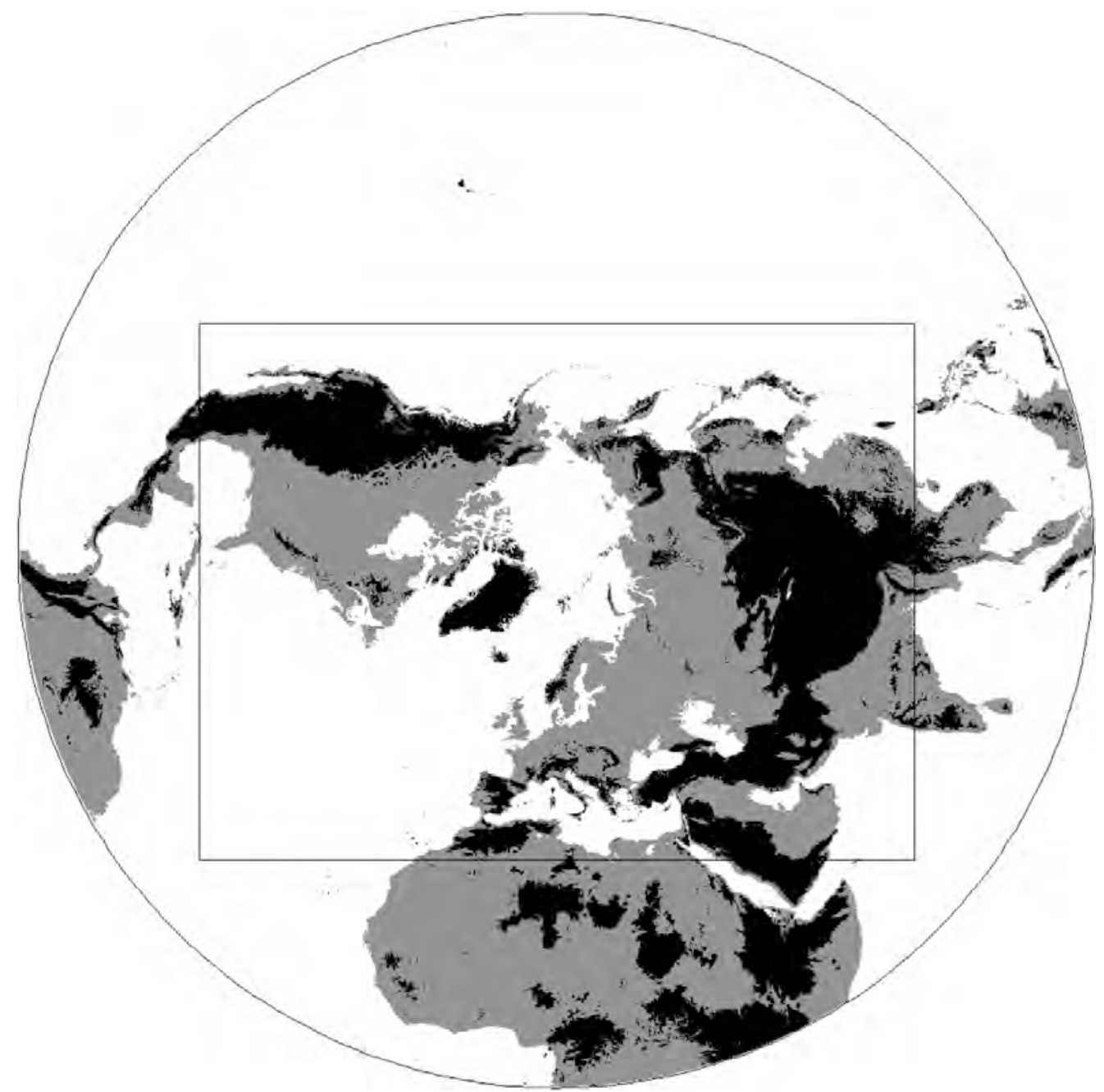

FIG. 2. Land areas classified by height: lowlands (gray) and highlands (black) in the NH, the threshold being $600 \mathrm{~m}$. The black rectangle shows the area shown in Fig. 4. The image is in the polar stereographic projection, but the analysis was done in Lambert cylindrical equal-area projection.

This may result in a little overestimation of snow in comparisons. MODIS analyses have the fractional snow area for each grid point and we classified the fractional snow area greater than $20 \%$ as snow. This may result in a little underestimation of snow in comparisons. In addition, only MODIS grid points more than $50 \%$ cloud free were processed.

Snow behaves differently in mountainous areas and near the sea surface level, and therefore, using the freely available global topography with 30 arc s resolution from the U.S. Geological Survey's (USGS) Center for Earth Resources Observation and Science (EROS)
(GTOPO30), we divided the land areas into two classes: lowlands and highlands with a threshold of $600 \mathrm{~m}$. This threshold is somewhat arbitrary and was selected so that the same threshold could be used in the Northern Hemisphere and northern Europe. In the Northern Hemisphere, lowlands will cover $65 \%$ of land and highlands $35 \%$ (Fig. 2). The area for which the comparison in northern Europe is done is shown in Fig. 1. Here lowlands will cover $95 \%$ of the chosen area and highlands $5 \%$ of the area (Fig. 3).

The treatment of clouds in MODIS and LSA SAF analyses needs to be considered. As the purpose of this 


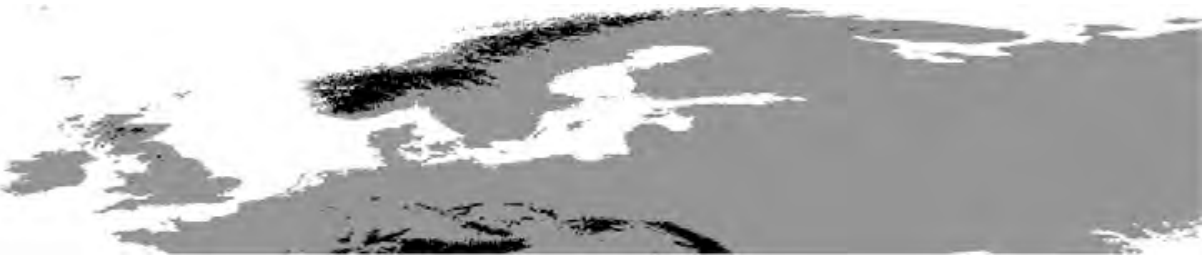

FIG. 3. Land areas classified by height: lowlands (gray) and highlands (black) in northern Europe, the threshold being $600 \mathrm{~m}$.

study was to compare day-to-day analyses, no effort was made to lessen the impact of clouds, by, for example, aggregating cloudy analyses from different days. A simple solution adopted was to compare analyses only in cloud-free areas and ignore the cloudy area.

To further simplify the comparison, only 1200 UTC analyses of ECMWF and HIRLAM and only MODIS Terra snow analyses were used. The amount of snow varies from one analysis time to the next or between Terra and Aqua analyses, but we found the difference to be smaller than the difference between different analyses.

The results of comparison between two analyses can be shown in a $2 \times 2$ contingency table (Table 1 ), where $a$ is the number of cases where both analyses reported snow, $d$ is the number of cases where neither analyses reported snow, $b$ is the number of cases where only the first analysis reported snow, and $c$ is the number of cases where only the second analysis reported snow. There is extensive literature of different measures calculated from this table (e.g., Jolliffe and Stephenson 2003). The basic measure is proportion correct, defined as

$$
\mathrm{PC}=\frac{a+d}{a+b+c+d} .
$$

$\mathrm{PC}$ is the fraction of items classified correctly when one of the analyses represents the truth. The best value for $\mathrm{PC}$ is 1 , and the worst value is 0 . This measure alone is not sufficient, in particular when one of the categories dominates.

Another widely used measure is the Heidke skill score. HSS is PC adjusted to account for the agreement between two analyses due to chance. HSS is defined as

$$
\mathrm{HSS}=\frac{2(a d-b c)}{(a+c)(c+d)+(a+b)(b+d)},
$$

and has the same value regardless of whether analysis 1 or analysis 2 is the truth, because the value does not change if we switch $b$ and $c$. HSS is important for our study, as the amount of the snow varies considerably during our study period and PC can give quite misleading results. HSS has been independently discovered and named many times. For example, in the remote sensing community, it is called kappa (Congalton and Green 1998).

One of the challenges of this study is that there is no independent ground truth. As analyses use the same input data or even directly use other analyses, none of them are independent and none can be said to represent the truth. IMS uses MODIS and SEVIRI data as input and is the basis for ECMWF snow. Although HIRLAM does not use satellite data, it uses the same in situ SYNOP observations as ECMWF. Had it been possible to rerun NWP analyses, independent in situ observations could be done by cross validation (e.g., Wilks 2006) of ground measurements, but rerunning analyses would require resources not at our disposal. This lack of ground truth means we cannot assess the accuracy of, for example, ECMWF compared with IMS, but can only assess the difference of analyses (e.g., the impact of in situ measurements on ECMWF).

We cannot rank the analyses with, for example, HSS, because the ground truth does not exist. Instead of ranking, we can compare the consistency between analyses by calculating HSS for each possible analysis pair. There are however many pairings, and results can be hard to visualize. One way forward is to note that HSS tells how similar analyses are and can be considered as a measure of distance between analyses. This suggests we can use multidimensional scaling (MDS) (e.g., Ripley 1996) to construct a simpler two-dimensional mapping of results. MDS tries to retain the distances between variables, that is, distances between variables in a map should be proportional to the actual distances. These measures of distance, or dissimilarity, do not have to satisfy all

TABLE 1. Contingency table of the comparison between two categorical snow analyses. The variables $a-d$ represent the different number of pixels observed to occur in each category.

\begin{tabular}{lcc}
\hline \hline & \multicolumn{2}{c}{ Analysis 2 } \\
\cline { 2 - 3 } Analysis 1 & Snow & No snow \\
\hline Snow & $a$ & $b$ \\
No snow & $c$ & $d$ \\
\hline
\end{tabular}


(a) IMS

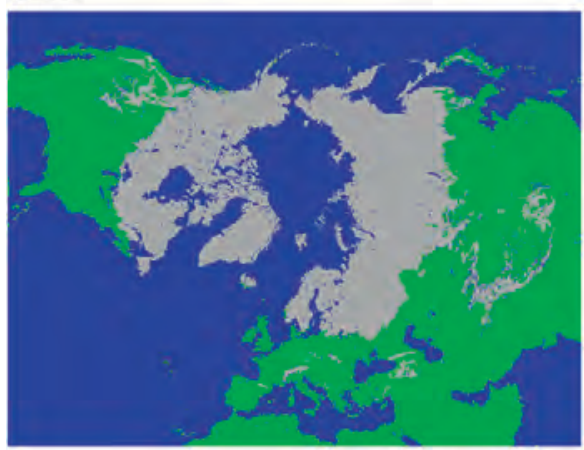

(b) IMS vs. ECMWF

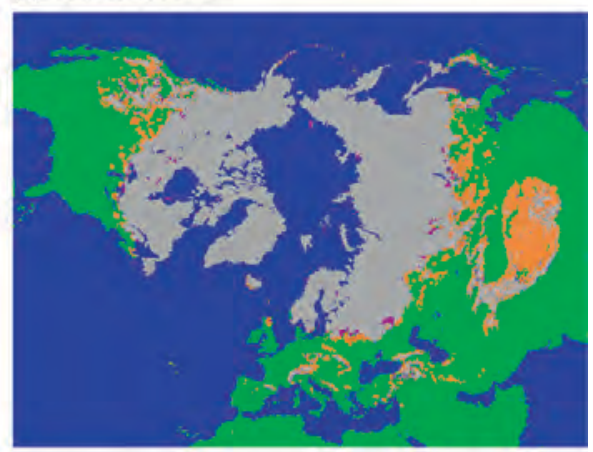

(c) IMS vs. MODIS

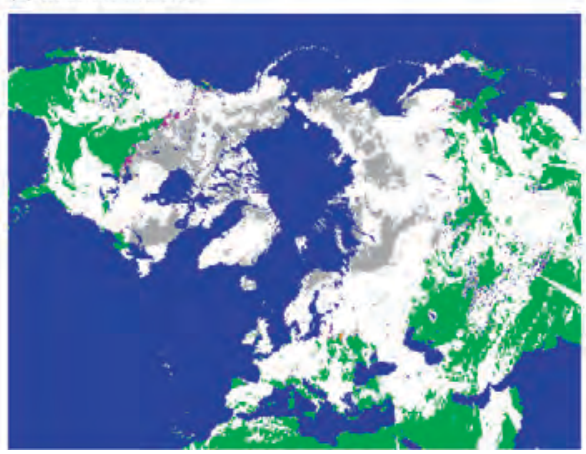

FIG. 4. Comparison between different analyses in day 93, 3 Apr 2006. (a) Actual IMS analysis, (b) comparison between IMS and ECMWF, and (c) comparison between IMS and Terra MODIS. Color codes are gray for snow in both analyses, green for no snow in any analyses, purple for snow only in IMS, and orange for snow only in the other analyses. Clouds and areas of no data are white. The image is in the polar stereographic projection, but the analysis was done in Lambert cylindrical equal-area projection.

requirements for a proper mathematical distance; it is enough for them to be nonnegative symmetric numbers. Often MDS is done using the Euclidean distance or the correlation matrix between variables, but here HSS, or 1 - HSS in practice, is used. As a perfect match has the maximum value HSS $=1,1-$ HSS is nonnegative. In addition, 1 - HSS is symmetric because the score remains the same when the reference and the test datasets are swapped. There are different methods of how to implement MDS, and for this study Sammon mapping (Ripley 1996) was chosen, as it converged most reliably with the best solution in the current dataset.

Finally, days should be aggregated unless one mapping for each day is desired. Using the objective $k$-means algorithm (e.g., Ripley 1996), the test period is partitioned into two clusters. Tests with more than two clusters did not alter the conclusions below, but unnecessarily complicated the analysis. The clustering was done using all components of the HSS matrix as features, so in the Northern Hemisphere there were three features and in northern Europe ten features. In the clustering, no temporal information is used, so clusters need not be continuous in time. After clustering, Sammon mappings are calculated for the mean values of each cluster.

In comparisons below, the following plan is followed: first, images of different analyses for a particular day are presented. As snow cover changed considerably during our study period, simple static images are not enough and time series are needed. Time series of the snow amount in analyses and values of HSS with IMS as a baseline are shown. Finally, HSS matrices and derived Sammon mappings are presented.

\section{Comparison of snow analyses in the Northern Hemisphere}

First we compare the IMS analysis with ECMWF and MODIS analyses in the Northern Hemisphere. An example (Fig. 4) shows a comparison of analyses for day 
(a)

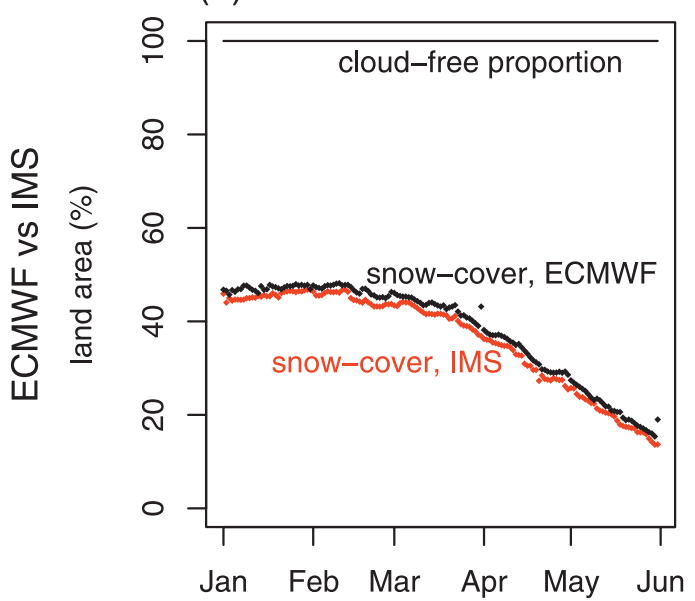

(c)

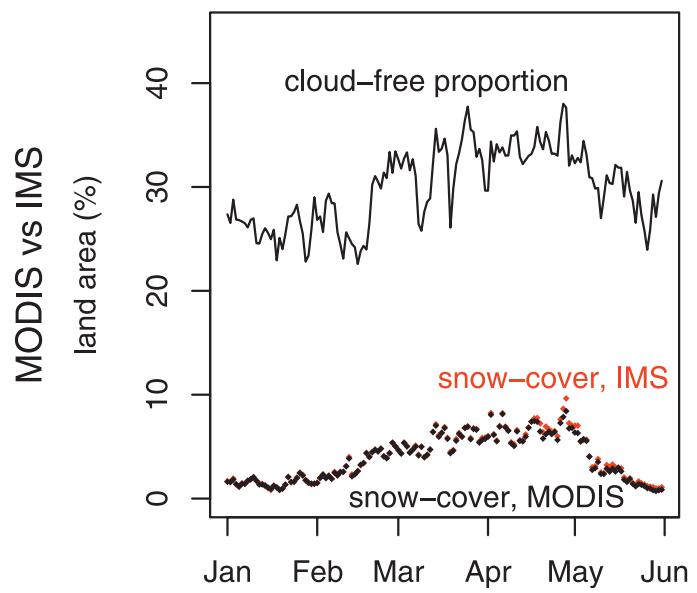

(b)

$\mathrm{h}>600 \mathrm{~m}$

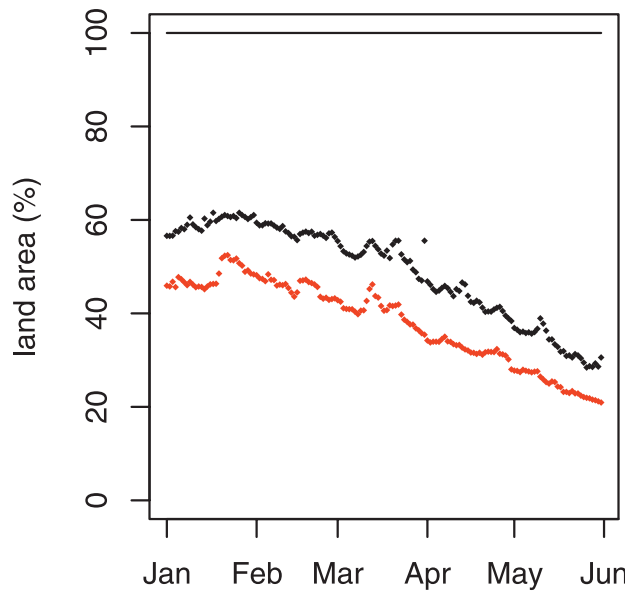

(d)

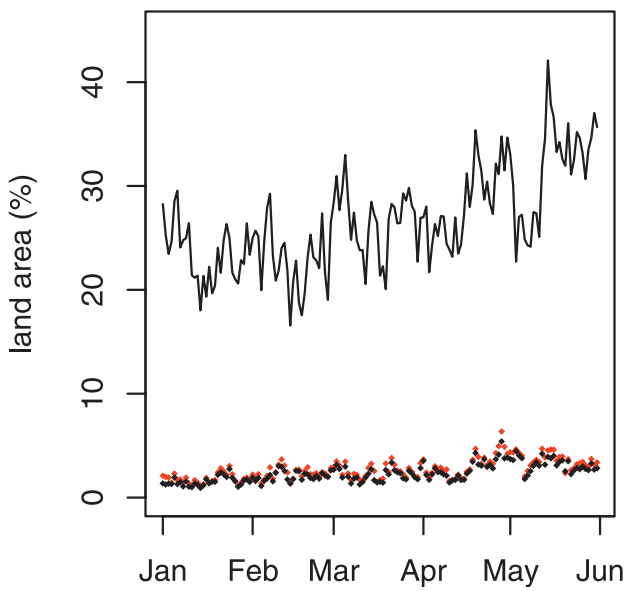

FIG. 5. Percentage of total cloud-free surface (solid line) and snow covered cloud-free surface (dotted line) in analyses for NH. Red dots show the snow covered area in IMS and black dots show the snow covered area in the other analysis in cloud-free proportion to the compared analysis (ECMWF 1200 UTC, MODIS Terra). In the comparison of IMS and ECMWF, the cloudfree proportion remains constant at $100 \%$, but the proportion varies in comparisons with MODIS.

93, 3 April. ECMWF and IMS agreed for the most part (Fig. 4b), though ECMWF had more snow. MODIS appeared quite similar to IMS in cloud-free areas (Fig. 4c), but overall visual comparison was difficult if not impossible, as the area was very much obscured by clouds, even though this day was chosen because it was relatively cloud free.

The change of the percentage of snow-covered areas and cloud-free areas in different analyses and two different height classes, lowlands and highlands, is shown in Fig. 5. The comparison between ECMWF and IMS is straightforward because snow cover is available both for cloudy and cloud-free conditions in ECMWF and there are no clouds in IMS. As expected, the snow started to melt as the spring progressed. In the lowlands, melting started in late February (Fig. 5a). In the highlands, melting started a little earlier, in late January (Fig. 5b), probably because large parts of its area, like the Tibetan Plateau, are rather far south. ECMWF consistently detected more snow than IMS, especially in the highlands. The proportion of snow-covered area detected in IMS is almost the same in the highlands and lowlands, but ECMWF detected more snow in the highlands than in the lowlands. Most of this extra snow is detected in the 
Tibetan Plateau (Fig. 4b). The Tibetan Plateau is a difficult area to analyze (Drusch et al. 2004). It is characterized by intermittent and patchy snow cover, which is problematic for methods based on visible and infrared measurements from satellite. Also, few reliable realtime observations are available.

Because of the clouds, MODIS analyses detected much less surface than ECMWF and IMS analyses (Figs. 5c,d). In addition, MODIS analyses detected even less snow. For example, in the lowlands on 1 January, there was approximately as much snow-free area as snow-covered area in the IMS analysis (Fig. 5a), but there was 15 times more snow-free area than snowcovered area in cloud-free areas of the MODIS analysis (Fig. 5c). And in MODIS analyses of the lowlands, the snow area actually increased until the end of May. Thus the clouds in MODIS analyses are not randomly distributed, but are more likely to be detected over snow areas. One possible reason for this is that even when using the best available instruments and methods, there is always some uncertainty in discriminating between low clouds and snow and the cloud mask is designed to be cloud biased. But in addition to this, there probably exists a physical reason for this difference in snow cover in cloud-free and cloudy conditions. This would be an interesting topic for a future study. In cloud-free areas, the difference between MODIS and IMS is not as evident as the difference between ECMWF and IMS.

The absolute differences between analyses are quite small and PC is over 0.95 for all comparisons, except for ECMWF and IMS in the highlands where it is slightly lower, around 0.85 (not shown). These results might be a little optimistic, and HSS gives a more realistic view. The HSS for comparison of ECMWF and MODIS against IMS is shown in Fig. 6. Both ECMWF and MODIS agree better with IMS in the lowlands (Figs. 6a,c) than in the highlands (Figs. 6b,d). MODIS agrees with IMS better than ECMWF both in the lowlands and highlands, even when there is more scatter in values of MODIS in the highlands (Fig. 6d). Results are still rather stable, with some downward trend in the lowlands from the beginning of April (Fig. 6a).

For Sammon mapping, the HSS values are combined into the HSS matrix. It is almost complete; only HSS between ECMWF and MODIS is missing and has to be computed. After that the values are divided into two clusters using $k$-means, and the resulting classification of days is shown in Fig. 6. In the lowlands the first cluster includes days from the middle of the study period while the second cluster has days at the start and end of the period. In the highlands, the first cluster has more days at the end of the study period and the second cluster at the start of the period.
With only three members, the HSS matrix is quite simple, and it is helpful to look at in more detail how Sammon mapping compares to the matrix before moving to the more complex HSS matrix in the next section. In the first cluster of lowlands (Fig. 7a), IMS and MODIS are very similar (HSS $=0.97)$, IMS and ECMWF are still quite similar (HSS $=0.93$ ), and even between ECMWF and MODIS the similarity is high (HSS $=0.90)$. In Sammon mapping this means MODIS and IMS are nearer to each other than to ECMWF. The distance in between IMS and MODIS in Sammon mapping should be 0.03 (i.e., 1 - 0.97), between IMS and ECMWF 0.07, and between MODIS and ECMWF 0.10. Had all analyses been identical (HSS $=1$ ), all points would have collocated at the center. For a more complex matrix, it cannot be guaranteed that distances are exactly preserved in lower-dimensional Sammon mapping. Compared to the first cluster of lowlands, the similarity of IMS and ECMWF does not change much (from HSS $=0.93$ to HSS $=0.90$ ) in the second cluster of lowlands (Fig. 7b), but the similarity of MODIS with others drops, especially the similarity of MODIS and ECMWF (from HSS $=0.90$ to HSS $=0.78$ ). In Sammon mapping, MODIS moves some distance away from IMS analysis and much farther away from ECMWF. Actually, in all clusters, the IMS is more similar to ECMWF and MODIS than ECMWF and MODIS are to each other. Thus in Sammon mapping, IMS is more or less in the middle of the other two analyses. Both in the lowlands (Fig. 7) and highlands (Fig. 8), there is not much temporal change in the difference between IMS and ECMWF. The greatest differences and changes in differences come from MODIS and ECMWF, which could not be seen in Fig. 6. In the lowlands, all analyses were rather similar in the middle of the period as HSS is greater than 0.90 for all comparison (Fig. 7a), but MODIS deviates from the other two at the start and end of the study period as HSS drops from 0.97 (0.90) to 0.89 (0.78) with the comparison with IMS (ECMWF) (Fig. 7b). In Highlands MODIS came much closer to IMS and ECMWF at the end of the study period (Fig. 8b). Both in the lowlands and highlands, the physical interpretation of clusters is that days are partitioned to cases of lesser and greater agreement between analyses. With only two clusters, this is the rather obvious solution we could find by hand, but the use of a clustering algorithm like $k$-means is motivated by the fact that the partitioning can be done objectively and consistently.

\section{Comparison of snow analyses in northern Europe}

An example (Fig. 9) shows a comparison of analyses against IMS for day 99, 9 April. Day 99 was subjectively 
(a)

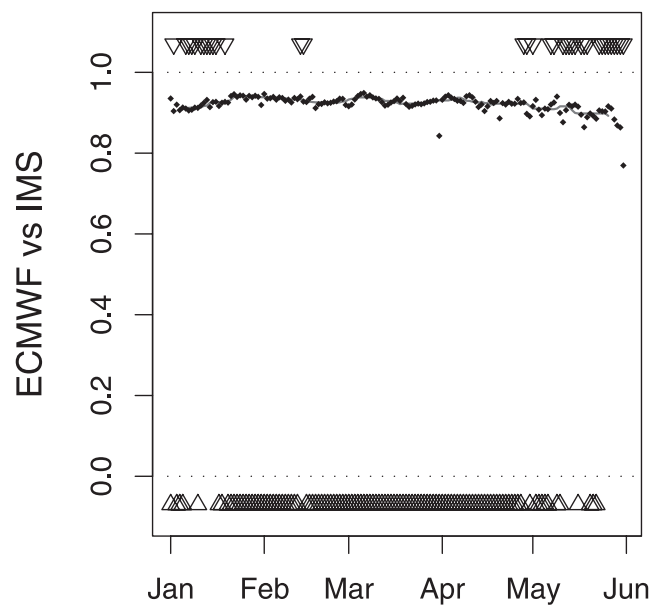

(c)

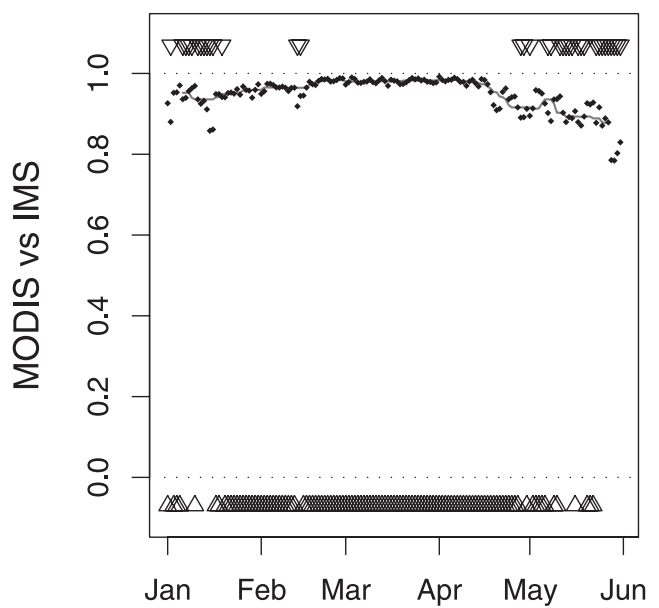

(b) $h>600 m$

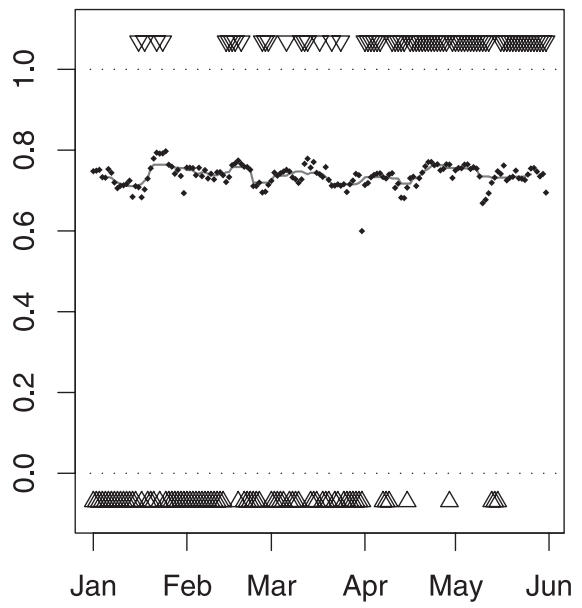

(d)

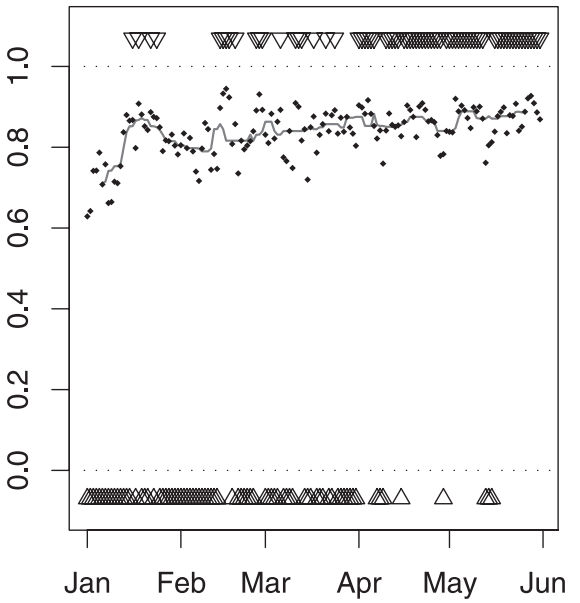

FIG. 6. Temporal evolution of the HSS with IMS as the baseline from January to June 2006 for the NH in the lowlands and highlands. The gray line is a result of a median filter to values. Up and down triangles mark one of the clusters to which a day was classified by $k$-means algorithm.

chosen as it was relatively cloud free in MODIS with about half of the snow cover still remaining. ECMWF and IMS agreed for the most part, even though ECMWF had more snow (Fig. 9b), especially spotty areas of snow in central Europe. MODIS looked quite similar to IMS in cloud-free areas but, again, overall visual comparison is difficult as the area is very much obscured by clouds (Fig. 9c). LSA SAF was obscured by clouds to a lesser degree, but in Scandinavia its analysis had large areas of no snow where other analyses detected snow (Fig. 9d). Similarly, HIRLAM had large areas of snow where there was no snow in IMS as well as areas of no snow where there was snow in IMS (Fig. 9e). HIRLAM suffers from the unfortunate practice that SYNOP stations often do not report no-snow conditions, so for large areas no observations of no-snow are available. In our example, this can be seen in Baltic countries, where information of snow observations in the north is spread too far south.

In contrast to the Northern Hemisphere (Fig. 5), there is more snow in northern Europe at the start of the study period and almost no snow at the end of the period (Fig. 10: unfortunately, HIRLAM analyses in January 2006 were unavailable, and only days from February 
(a) HSS h<600 Cluster \# 1

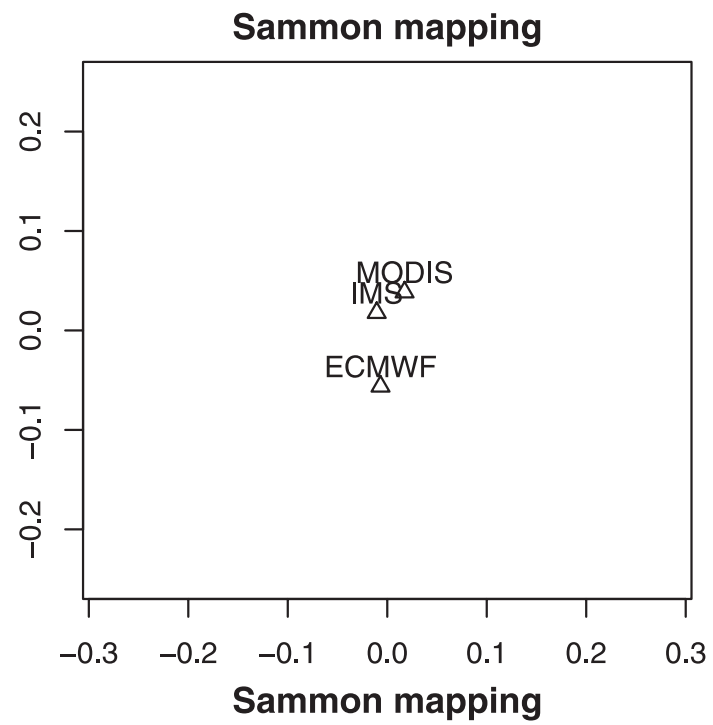

(b) HSS $\mathrm{h}<600$ Cluster \# 2

IMS

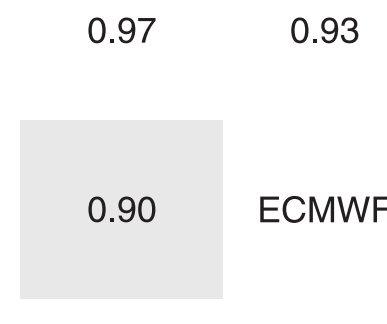

MODIS

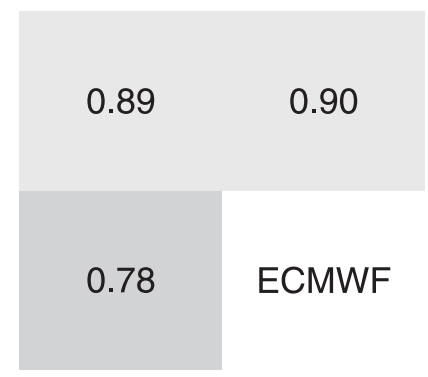

IMS

MODIS

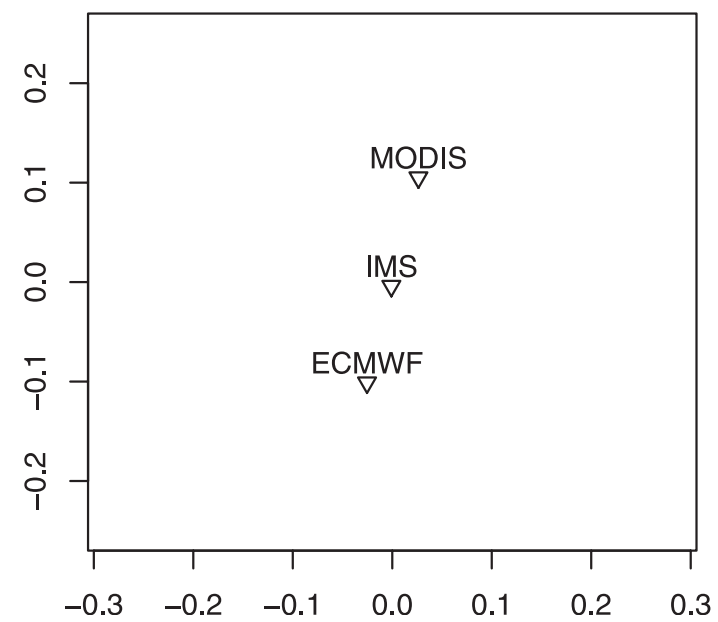

FIG. 7. Similarity matrix of analyses by HSS and its multidimensional scaling plot for the NH in the lowlands. Matrix elements are shaded by increasing HSS from dark to light.

onward are shown). Nearly the entire region was covered by snow before the end of March, so there was little difference between most analyses, except HIRLAM in the highlands (Fig. 10h) and LSA SAF (Figs. 10e,f). As the snow melts away the differences can be more clearly seen. The snow started to melt in April as the spring progressed, a little later than in the whole hemisphere data, and most of the snow was gone by the middle of May in the lowlands. As in the Northern Hemisphere, MODIS and LSA SAF analyses with clouds detected much less surface than snow analyses of IMS, ECMWF, and HIRLAM with no clouds, and most of the time the ratio of snow-free and snow-covered areas was higher in
MODIS and LSA SAF analyses than in other analyses. LSA SAF sees much more cloud-free area than MODIS, as it aggregates information from all SEVIRI images for a day. Both in MODIS (Fig. 10c) and LSA SAF (Fig. 10e), the less cloudy period can be seen in the beginning of May in the lowlands. ECMWF detected more snow than IMS analyses both in the lowlands (Fig. 10a) and highlands (Fig. 10b). The small amount of cloudfree area that MODIS sees, especially in the highlands (Fig. 10d), makes the behavior of MODIS rather erratic, and sometimes MODIS and IMS disagree greatly but the sign of the difference can change from day to day. For the entire period and in both areas, LSA SAF saw much less 
(a) HSS h>600 Cluster \# 1

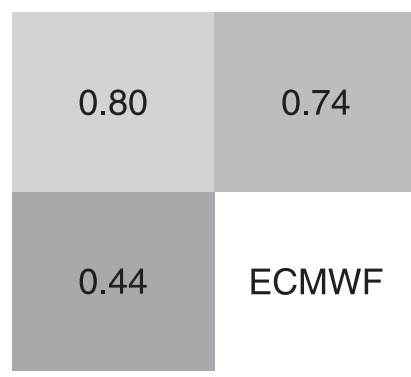

MODIS

(b) HSS h>600 Cluster \# 2

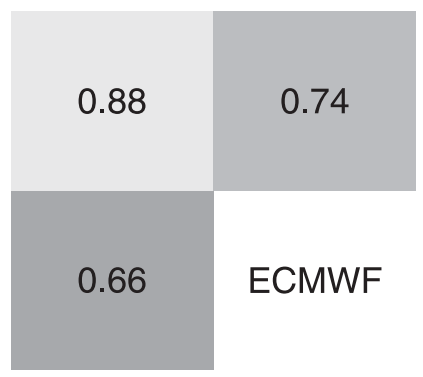

MODIS
Sammon mapping

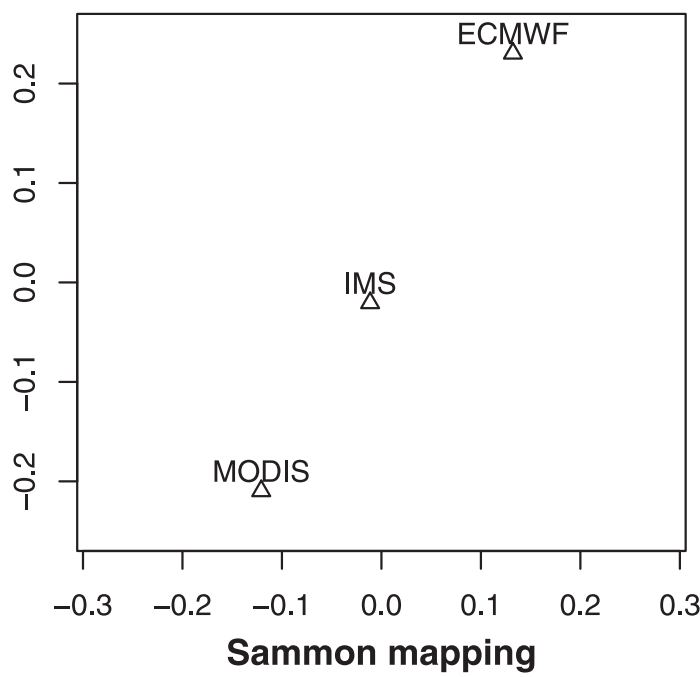

IMS

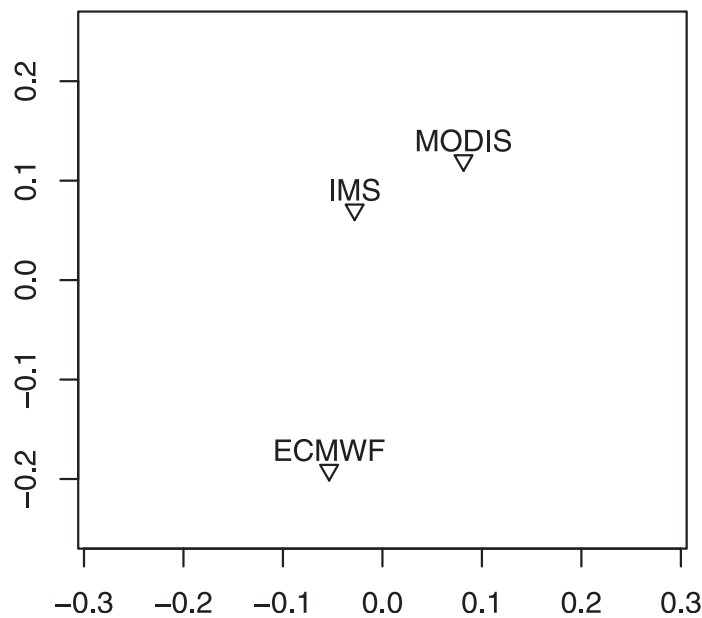

FIG. 8. Similarity matrix of analyses by HSS and its MDS plot for the NH in the highlands. Matrix elements are shaded by increasing HSS from dark to light.

snow than IMS. In the highlands (Fig. 10h), HIRLAM detected less snow than IMS analyses; in the lowlands (Fig. 10g) this was not as apparent.

Agreement between analyses measured with $\mathrm{PC}$ is good (not shown). For MODIS and ECMWF, PC values were around 0.8 , near an optimum 1.0, as it also was in the Northern Hemisphere. Disagreement was larger for HIRLAM and for LSA SAF, but in the lowlands PC tended to optimum as the snow melted away. Again, PC was too optimistic, because the dominance of snow in early spring and snow-free areas in later spring will influence the results, and HSS gives a more realistic view (Fig. 11). HSS fluctuated greatly during the study period and values were lower than in the Northern Hemisphere. All comparisons showed results of no skill in March in the highlands, when almost the whole area was snow covered. Additionally, at the end of the study period in the lowlands, when PC reached optimum values, HSS had much lower values.

According to HSS, MODIS and ECMWF agreed for the most part with IMS. For MODIS in the lowlands, results were good except at the very end of the study period (Fig. 11c). In the highlands the values were low at the start of the study period, but improved as the melting started (Fig. 11d). In both cases the results fluctuated a lot, probably because only small portions of 
(a) IMS

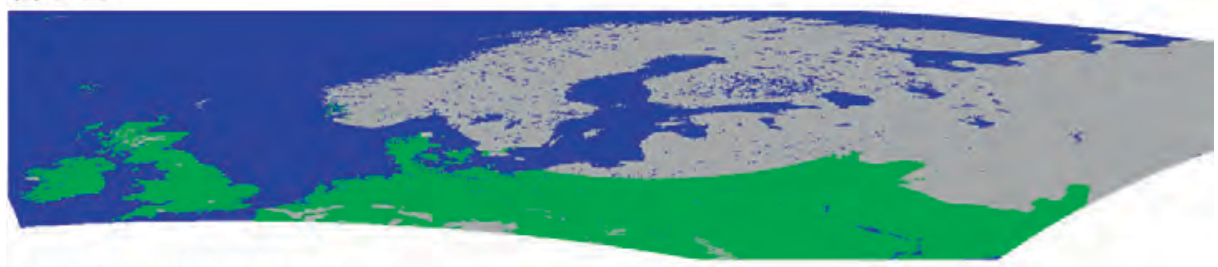

(b) IMS vs. ECMWF

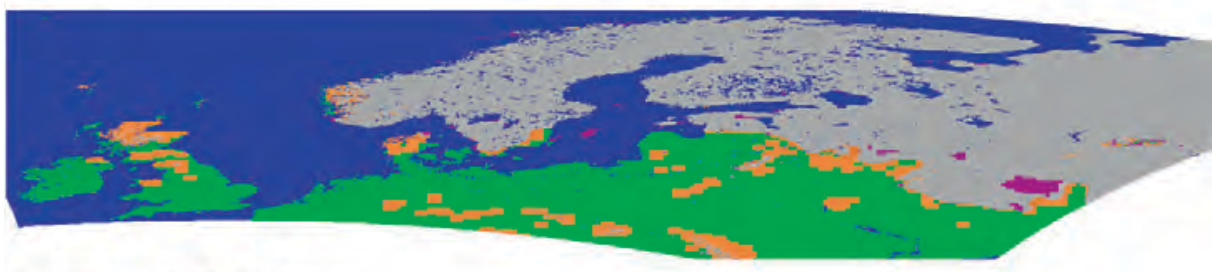

(c) IMS vs. MODIS

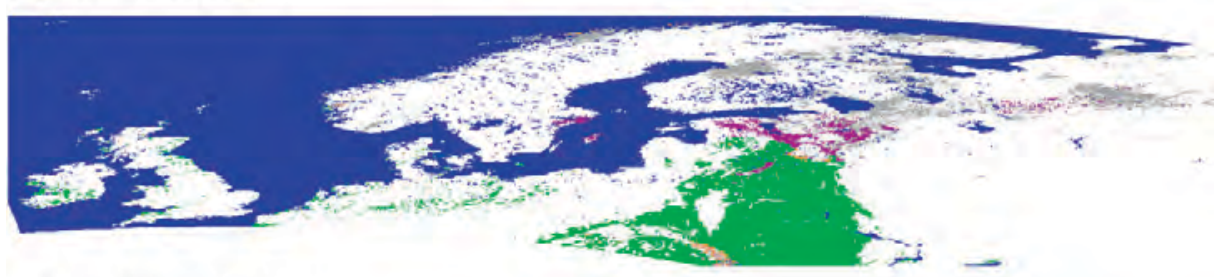

(d) IMS vs. LSA SAF

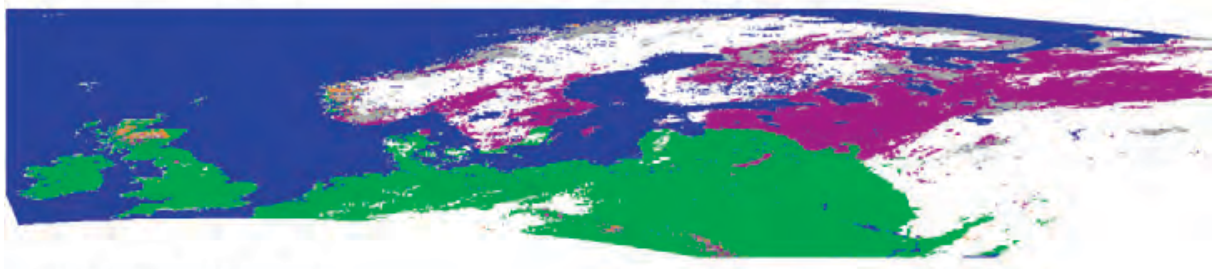

(e) IMS vs. HIRLAM

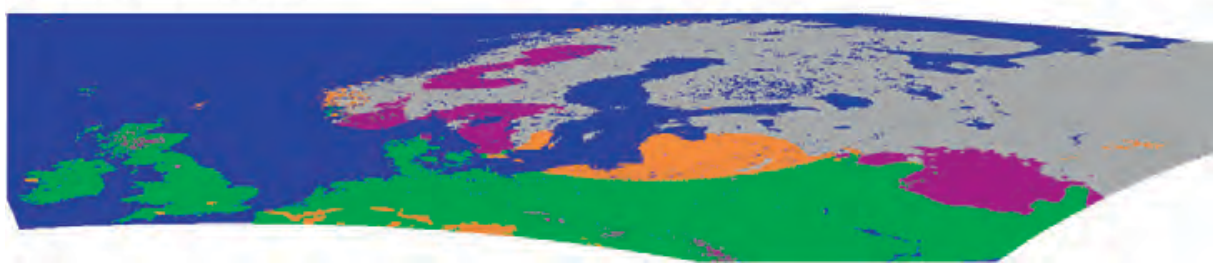

FIG. 9. Comparison between different analyses in day 99, 9 Apr 2006, in northern Europe. (a) Actual IMS analysis, and comparisons between IMS and (b)-(e) ECMWF, Terra MODIS, LSA SAF, and HIRLAM. Color codes are gray for snow in both analyses, green for no snow in any analyses, purple for snow only in IMS, and orange for snow only in the other analyses. Clouds and areas of no data are white. 
(a)

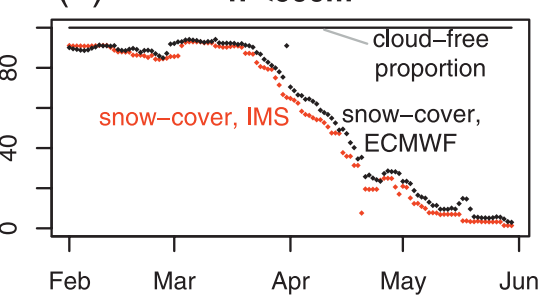

(c)

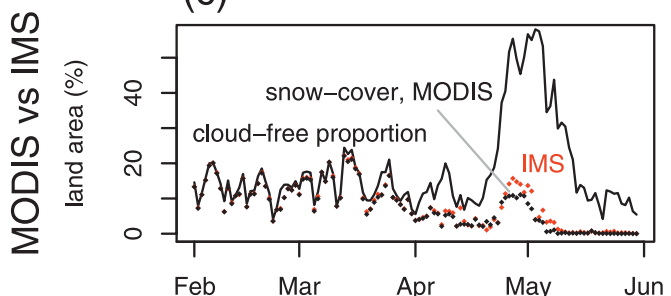

(e)

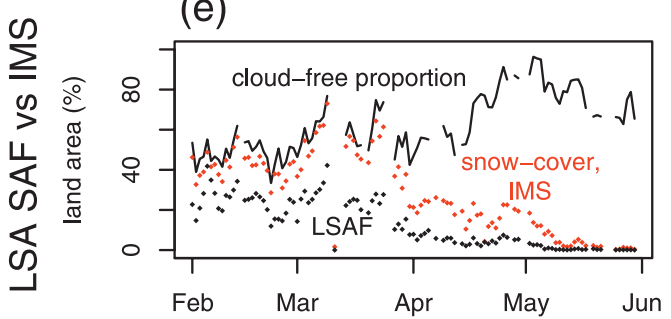

(g)

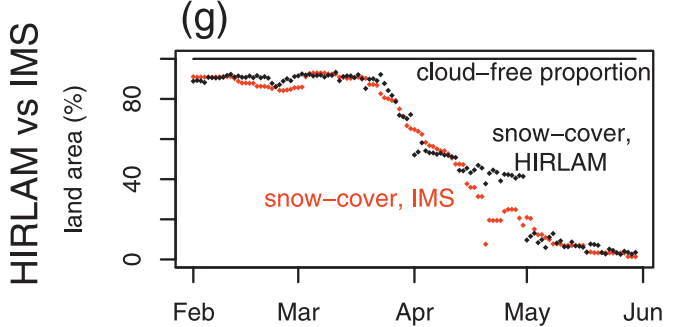

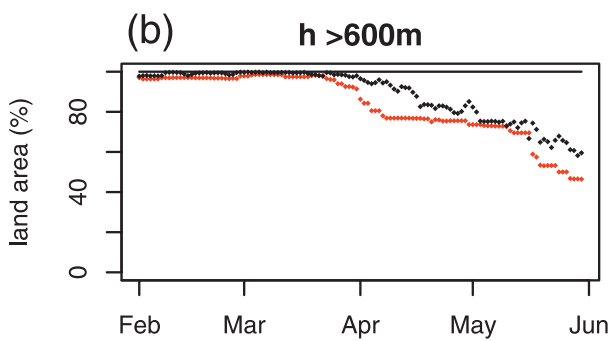

(d)

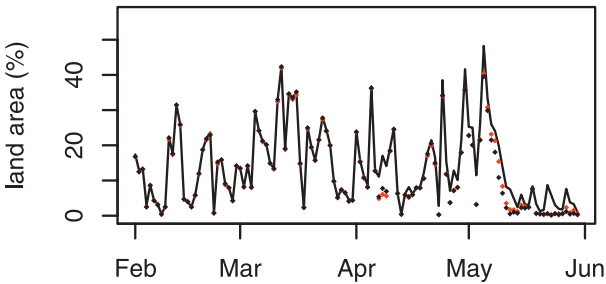

(f)

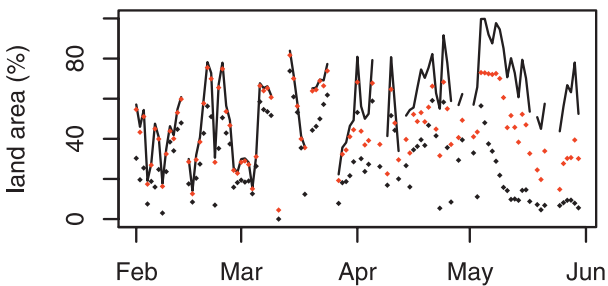

(h)

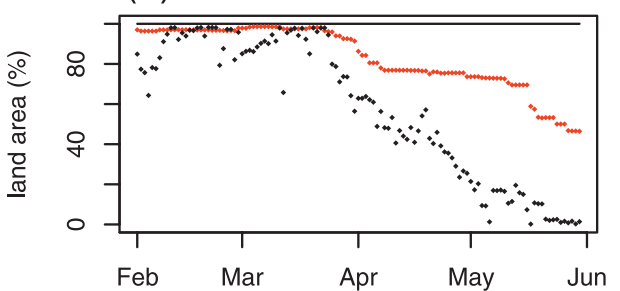

FIG. 10. Percentage of total cloud-free surface (solid line) and snow covered cloud-free surface (dotted line) in analyses for northern Europe. Red dots show the snow-covered area in IMS and black dots show the snow-covered area in the other analyses in cloud-free proportion to the compared analysis (ECMWF 1200 UTC, MODIS Terra, LSA SAF, and HIRLAM 1200 UTC). In comparisons of IMS with ECMWF and HIRLAM, the cloud-free proportion remains constant at $100 \%$, but the proportion varies in comparisons with MODIS and LSA SAF.

the earth's surface could be seen because of clouds. ECMWF had slightly lower values but not as much noise in the results (Figs. 11a,b). LSA SAF had consistently mediocre results both in the lowlands and highlands (Figs. 11e,f). HIRLAM had the biggest differences in the highlands (Fig. 11h).

Looking at the HSS values of comparisons with IMS as the baseline (Fig. 11), we can see how the highlands are easier to subjectively divide into two clusters than the lowlands. In the highlands HSS had much lower values before the snow melted than after the melting started. This kind of behavior is not as easily seen in the lowlands. The $k$-means follows this reasoning and two clusters it found in the highlands are reasonably the same as what we would choose by hand if we used only the information in Fig. 11. In the lowlands the second cluster is much smaller and contains mainly days at the end of the study period when most of the snow had melted away. As in the previous section, these HSS clusters represent the situations of larger and lesser 
(a)

$\sum_{\substack{\infty \\ \infty}}^{\infty}$

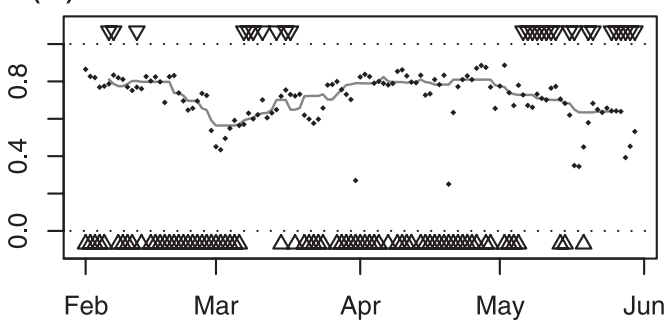

(c)

$\infty$
$\sum$
$\infty$
$\infty$
$\frac{0}{2}$

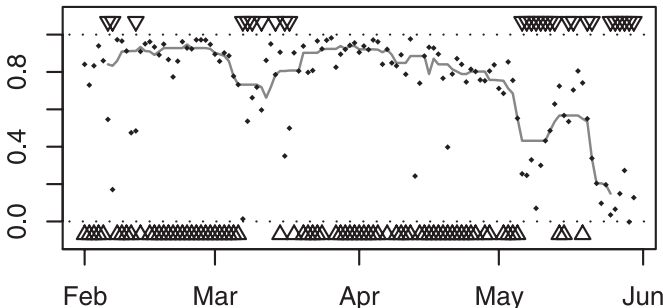

(e)

0
3
0
$\vdots$
0
0
0
0
0

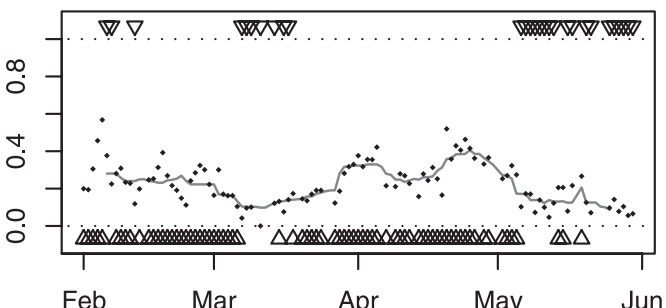

(g)

(b)

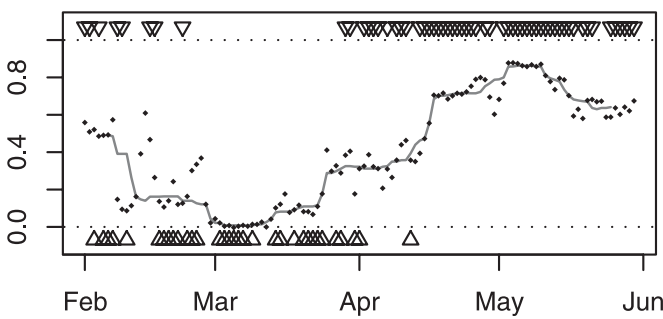

(d)

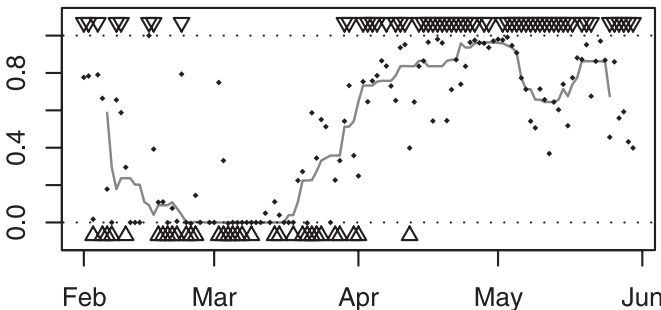

(f)

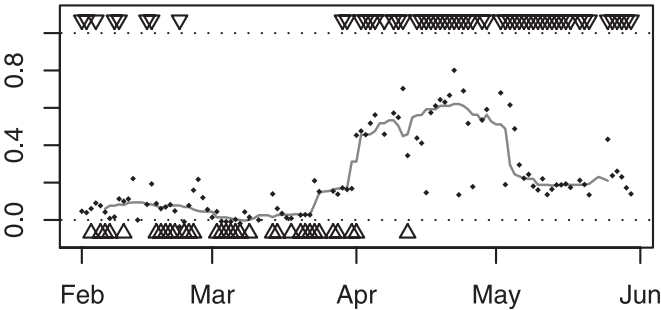

(h)

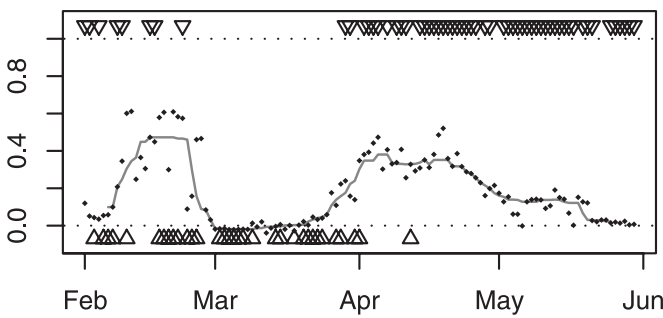

FIG. 11. Temporal evolution of the HSS with IMS as the baseline from January to June 2006 for northern Europe in the lowlands and highlands when MODIS, ECMWF, HIRLAM, and LSA SAF analyses are compared with IMS analysis. Only MODIS Terra analysis and 1200 UTC analysis times for NWP are used. The gray line is a result of a median filter to values. Up and down triangles mark one of the clusters to which a day was classified by $k$-means algorithm.

agreement between analyses. In the lowlands (Fig. 12) agreement between analyses is best when the most snow is present, while in the highlands (Fig. 13) agreement is highest when most snow had melted away.

With IMS as the baseline, it can be seen how LSA SAF and HIRLAM deviated most from IMS, while the other two analyses were close to IMS. The broader view can be seen with Sammon mapping. In the lowlands, the larger cluster (Fig. 12a), when most snow was present, has MODIS, IMS, and ECMWF reasonably close to each other (HSS > 0.60), while HIRLAM and LSA SAF deviated more from the other three and from each other (HSS $<0.60$ ). The second cluster (Fig. 12b) with less snow represents days where the disagreement between 
(a) HSS h<600 Cluster \# 1

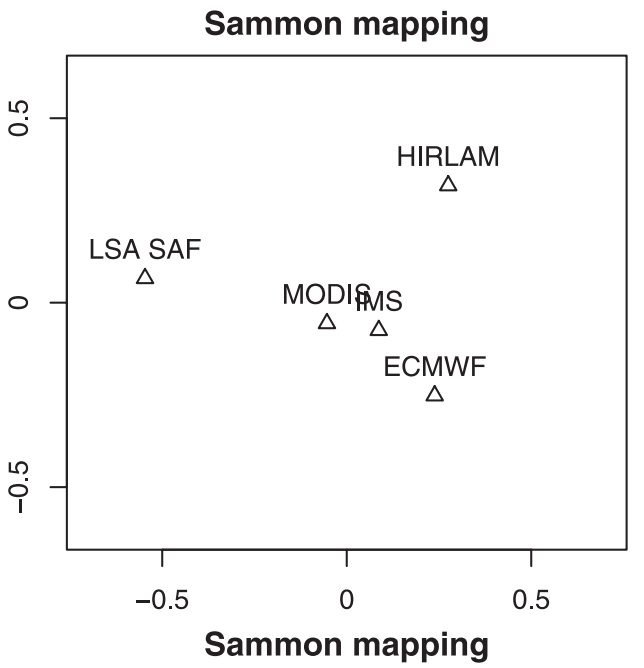

(b) HSS h<600 Cluster \# 2

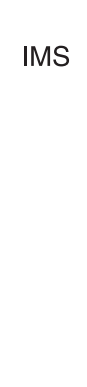

\begin{tabular}{|l|l|l|l|}
\hline 0.51 & 0.72 & 0.27 & 0.85 \\
\hline 0.52 & 0.67 & 0.51 & MODIS \\
\hline 0.16 & 0.20 & LSA SAF \\
\hline 0.47 & ECMWF
\end{tabular}

HIRLAM
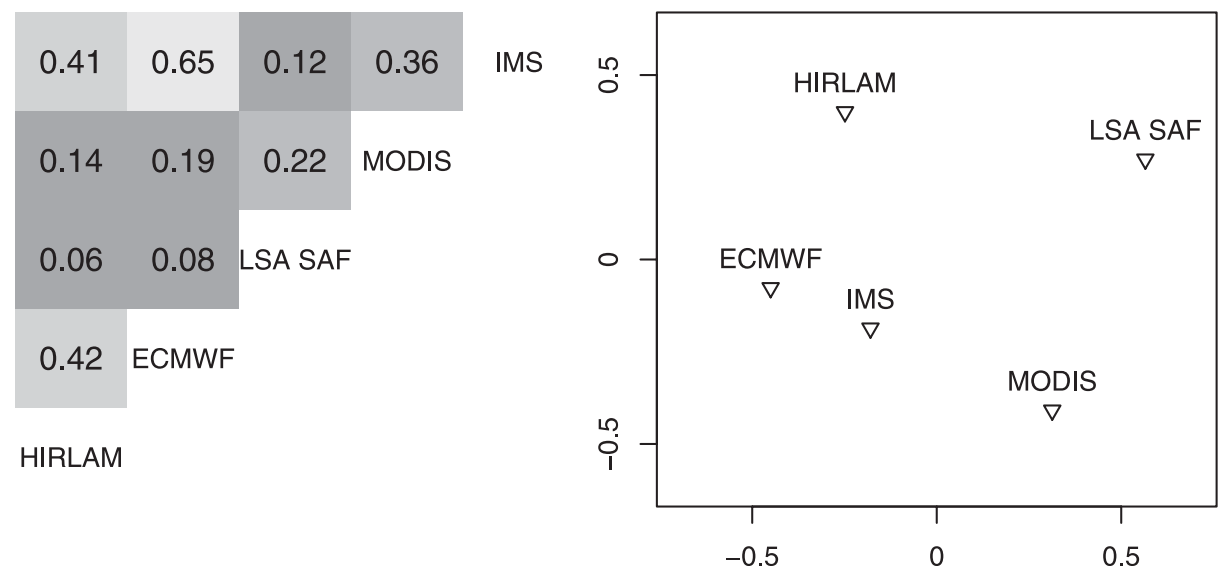

FIG. 12. Similarity matrix of analyses by HSS and its MDS plot for northern Europe in the lowlands. Matrix elements are shaded by increasing HSS from dark to light.

analyses was greatest. Most notably, MODIS that agreed well with IMS and ECMWF in the first cluster disagreed with others, and only ECMWF and IMS agreed well with each other $(\mathrm{HSS}=0.65)$. In the highlands, at the start of the study period (Fig. 13a), there was not much consensus between analyses (HSS $<0.20$ ), and at the end of the period (Fig. 13b) the agreement was better. The best agreements (HSS $>0.60$ ) are between IMS and MODIS, between IMS and ECMWF, and surprisingly, between MODIS and LSA SAF.

\section{Summary}

In this paper, satellite-based snow cover analyses were compared with NWP snow analyses. The major require- ment of any validation is the independent validation data or ground truth. However, we did not have any independent data for validation. The IMS snow analysis from NOAA uses data from the MODIS and SEVIRI instruments; that is the basis for snow analyses from NASA and LSA SAF. The snow analysis of ECMWF uses IMS as an input. Although the snow analysis of HIRLAM does not use any satellite data, it uses the same SYNOP observations as ECMWF. So we could only compare the consistency between analyses. To this end, we calculated the Heidke skill score between all analyses.

The snow analyses were generally consistent with each other. IMS and ECMWF analyses were quite similar, though ECMWF had more snow. Terra MODIS 
(a) HSS h>600 Cluster \# 1

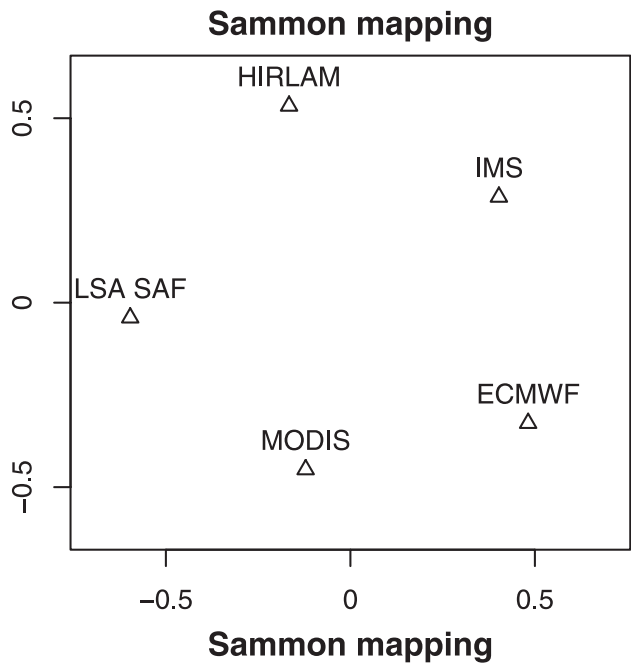

(b) HSS h>600 Cluster \# 2

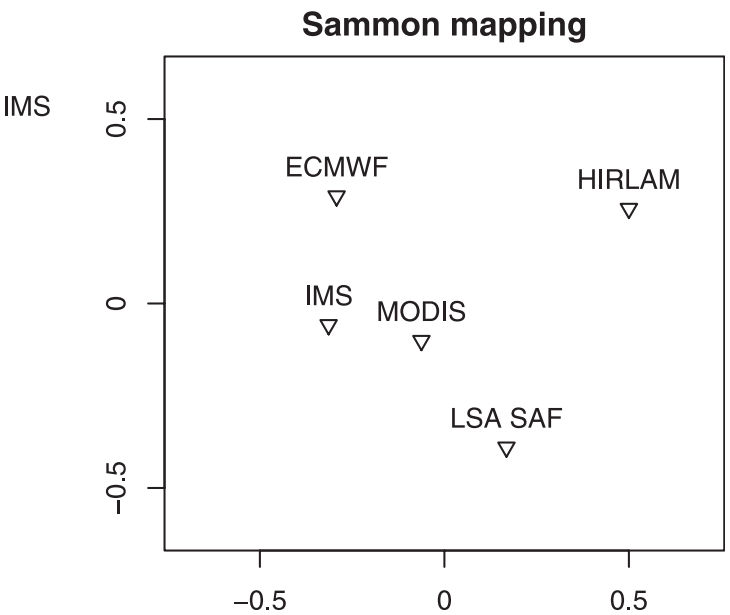

FIG. 13. Similarity matrix of analyses by HSS and its MDS plot for northern Europe in the highlands. Matrix elements are shaded by increasing HSS from dark to light.

snow and IMS snow were also quite consistent most of the time, but MODIS was greatly hampered by clouds. This seriously decreases the usefulness of MODIS data in NWP, especially because the cloud problems seem to be concentrated in snow-covered areas. LSA SAF was often the least consistent with other analyses. However, LSA SAF was at the preoperational stage, and improved soon after [preliminary new results have been presented in Siljamo and Hyvärinen (2008)].

Based only on in situ measurements and thus hampered by the lack of observations of no snow, HIRLAM had problems in defining the snow edge and behaved rather erratically during the snow melting season. The surface analysis schemes in ECMWF and HIRLAM are quite similar and the biggest difference is the use of IMS in ECMWF. The use of IMS data in ECMWF analysis helps to analyze more accurately the snow edge. In the HIRLAM analysis, the snow edge is often analyzed too far into the no-snow areas because of the practice of not reporting no snow in the SYNOP reports. This suggests that the HIRLAM, or any other NWP snow analysis based only on in situ measurements, would greatly benefit from the inclusion of satellite-based snow/nosnow information. This information can be, for example, IMS, or at a later stage, the improved LSA SAF snow cover analysis.

Acknowledgments. We thank Drs. Carl Fortelius, Sylvain Joffre, and David M. Schultz for providing comments and suggestions on early versions of this manuscript. 
We also thank three anonymous reviewers for their comments on the manuscript.

\section{REFERENCES}

Brubaker, K. L., R. T. Pinker, and E. Deviatova, 2005: Evaluation and comparison of MODIS and IMS snow-cover estimates for the continental United States using station data. J. Hydrometeor., 6, 1002-1017.

Comiso, J., D. Cavalieri, and T. Markus, 2003: Sea ice concentration, ice temperature, and snow depth using AMSR-E data. IEEE Trans. Geosci. Remote Sens., 41, 243-252.

Congalton, R. G., and K. Green, 1998: Assessing the Accuracy of Remotely Sensed Data: Principles and Practices. CRC, $160 \mathrm{pp}$.

Derrien, M., and H. Le Gléau, 2005: MSG/SEVIRI cloud mask and type from SAFNWC. Int. J. Remote Sens., 26, 4707-4732.

Drusch, M., D. Vasiljevic, and P. Viterbo, 2004: ECMWF's global snow analysis: Assessment and revision based on satellite observations. J. Appl. Meteor., 43, 1282-1294.

Frei, A., R. Brown, J. A. Miller, and D. A. Robinson, 2005: Snow mass over North America: Observations and results from the second phase of the atmospheric model intercomparison project. J. Hydrometeor., 6, 681-695.

Hall, D. K., and G. A. Riggs, 2007: Accuracy assessment of the MODIS snow products. Hydrol. Processes, 21, 1534-1547.

_ — - a and V. V. Salomonson, 1995: Development of methods for mapping global snow cover using moderate resolution imaging spectroradiometer data. Remote Sens. Environ., 54, $127-140$.

, N. E DiGirolamo, and K. J. Bayr, 2002: MODIS snow-cover products. Remote Sens. Environ., 83 (1-2), 181-194.

Helfrich, S. R., D. McNamara, B. H. Ramsay, T. Baldwin, and T. Kasheta, 2007: Enhancements to, and forthcoming developments in the Interactive Multisensor Snow and Ice Mapping System. Hydrol. Processes, 21, 1576-1586.
Jolliffe, I. T., and D. B. Stephenson, Eds., 2003: Forecast Verification: A Practitioner's Guide in Atmospheric Science. John Wiley and Sons, $240 \mathrm{pp}$.

Parajka, J., and G. Blöschl, 2006: Validation of MODIS snow cover images over Austria. Hydrol. Earth Syst. Sci., 10, 679-689.

Pulliainen, J., 2006: Mapping of snow water equivalent and snow depth in boreal and subarctic zones by assimilating spaceborne microwave radiometer data and ground-based observations. Remote Sens. Environ., 101, 257-269.

Ramsay, B. H., 1998: The interactive multisensor snow and ice mapping system. Hydrol. Processes, 12, 1537-1546.

Ripley, B. D., 1996: Pattern Recognition and Neural Networks. Cambridge University Press, 403 pp.

Siljamo, N., and O. Hyvärinen, 2008: Operational mapping of snow cover using MSG/SEVIRI data. Proc. EUMETSAT Meteorological Satellite Conference, Darmstadt, Germany, European Organisation for the Exploitation of Meteorological Satellites. [Available online at http://www.eumetsat.int/ groups/cps/documents/document/pdf_conf_p_s10_39_siljamo_p. pdf.]

Sorman, A. U., Z. Akyürek, A. Sensoy, A. A. Sorman, and A. E. Tekeli, 2007: Commentary on comparison of MODIS snow cover and albedo products with ground observations over the mountainous terrain of Turkey. Hydrol. Earth Syst. Sci., 11, 1353-1360.

Ulaby, F. T., R. K. Moore, and A. K. Fung, 1986: From Theory to Applications. Vol. III, Microwave Remote Sensing, Active and Passive, Addison Wesley, $1120 \mathrm{pp}$.

Undén, P., and Coauthors, 2002: HIRLAM-5 scientific documentation. HIRLAM-5 Project Tech. Rep., 146 pp. [Available online at http://hirlam.org/open/publications/SciDoc_Dec2002.pdf.]

Wang, X., H. Xie, and T. Liang, 2008: Evaluation of MODIS snow cover and cloud mask and its applications in northern Xinjiang, China. Remote Sens. Environ., 112, 1497-1513.

Wilks, D. S., 2006: Statistical Methods in the Atmospheric Sciences. 2nd ed. Academic Press, 627 pp.

World Meteorological Organization, 1995: Manual on codes: International codes. Volume I.1, WMO Publication 306, 229 pp. 
(C) 2014 Wiley and Sons,

Reprinted with permission from Wiley and Sons, License Number 4750181039261

K. Anttila, T. Manninen, T. Karjalainen, P. Lahtinen, A. Riihelä and N. Siljamo (2014). 'The temporal and spatial variability in submeter scale surface roughness of seasonal snow in Sodankylä Finnish Lapland in 2009-2010'. J. Geophys. Res. Atmos. 119: pp. 9236-9252. DOI: 10.1002/2014JD021597 



\section{Journal of Geophysical Research: Atmospheres}

\author{
RESEARCH ARTICLE \\ 10.1002/2014JD021597 \\ Key Points: \\ - Seasonal snow surface roughness \\ depends on measured length \\ and direction \\ - Multiscale parameters derived from rms \\ height and correlation length are used \\ - The parameters can distinguish \\ between different snow types
}

\author{
Correspondence to: \\ K. Anttila, \\ kati.anttila@fmi.fi
}

\section{Citation:}

Anttila, K., T. Manninen, T. Karjalainen, P. Lahtinen, A. Riihelä, and N. Siljamo (2014), The temporal and spatial variability in submeter scale surface roughness of seasonal snow in Sodankylä Finnish Lapland in 2009-2010, J. Geophys. Res. Atmos., 119, 9236-9252, doi:10.1002/ 2014JD021597.

Received 3 FEB 2014 Accepted 26 JUN 2014 Accepted article online 30 JUN 2014 Published online 4 AUG 2014

\author{
The temporal and spatial variability in submeter \\ scale surface roughness of seasonal snow \\ in Sodankylä Finnish Lapland in 2009-2010
}

Kati Anttila ${ }^{1,2}$, Terhikki Manninen ${ }^{1}$, Tuure Karjalainen ${ }^{3}$, Panu Lahtinen ${ }^{1}$, Aku Riihelä', and Niilo Siljamo ${ }^{1}$

${ }^{1}$ Finnish Meteorological Institute, Helsinki, Finland, ${ }^{2}$ Finnish Geodetic Institute, Kirkkonummi, Finland, ${ }^{3}$ Mericon Oy, Espoo, Finland

\begin{abstract}
Seasonal snow surface roughness is an important parameter for remote sensing data analysis since it affects the scattering properties of the snow surface. To understand the phenomenon, snow surface roughness was measured near the town of Sodankylä, in Finnish Lapland, during winters 2009 and 2010 using a photogrammetry-based plate method. The images were automatically processed so that an approximately $1 \mathrm{~m}$ long horizontal profile was extracted from each image. The data set consists of 669 plate profiles from different times and canopy types. This large data set was used to study the temporal and spatial variability of seasonal snow surface roughness. The profiles were analyzed using parameters derived from the root mean square height $(\sigma)$ and correlation length $(L)$ as functions of measured length. Also, the autocorrelation functions were calculated and analyzed. The $(\sigma)$ and $(L)$ were found to be so strongly correlated $\left(R^{2} \sim 0.97\right)$ that a more detailed analysis was made using only the scaling parameters derived from $\sigma$. These parameters are related to the distance dependence of the rms height. The results show that they react to different characteristics of the profiles and are therefore well able to distinguish between different types of snow. They also show a clear difference between midwinter snow and melting snow, and the effects of snowfall events and slower melting in forested areas are evident in the data.
\end{abstract}

\section{Introduction}

The albedo and extent of the seasonal snow cover react rapidly to the changes in the climate and weather. These in turn affect the surface albedo and the radiation budget of the Earth. Currently, at the beginning of the $21^{\text {st }}$ century, half of the Earth's continental surface is seasonally occupied by snow. Remote sensing enables studying the change in snow cover properties over large areas [e.g., Takala et al., 2011; Nolin, 2010; Hall et al., 1995].

Surface roughness is one of the key variables affecting the remote sensing data of snow-covered areas. According to Williams and Gallagher [1987] the microwave backscatter and emission from wet snow cover depend mostly on surface roughness. Microwave satellite data are particularly important in the polar regions because of the cloudiness and the lack of sunlight during the winter. Nagler and Rott [2000] stated that the strong seasonal variations in the synthetic aperture radar (SAR) backscattering from wet snow are mainly due to changes in the liquid water content and surface roughness. The bidirectional reflectance distribution function (BRDF) of snow is also significantly affected by the roughness of the snow surface [Peltoniemi et al., 2010b; Warren et al., 1998]. In radiative models the albedo of a snow layer is reduced when surface roughness is taken into account [Zhuravleva and Kokhanovsky, 2011]. Understanding how roughness affects the signal received by satellite instruments and knowing the connections between surface roughness and the geophysical properties of the snow pack (for example crystal size and shape, density, specific surface area, and state of crystal metamorphosis) could support the use of surface roughness information in interpreting the state of snow cover from remote sensing data, e.g., the level of melting. The surface roughness of snow is affected by several factors. The type of snow deposited on the surface and the metamorphism of these crystals by temperature and wind determines the microscale roughness. Löwe et al. [2007] pointed out that because of cohesion between the snow crystals the falling snow attaches to the surface immediately at first contact, instead of being rearranged to a position of minimum potential energy. The local climate and weather conditions near the surface determine the dominating processes affecting the snow surface features. In areas where the winter air temperatures rise close to freezing point, the snowpack is 
restructured by melting and freezing. In colder climates, where the winter air temperatures stay constantly below the freezing point, melting only takes place at the end of the snowy season and most of the surface evolution is caused by wind which redistributes and breaks individual snow crystals [Sturm et al., 1995].

The landscape, including topography and canopy type, has a clear impact on the snow as well [Eveland et al., 2013; Deems et al., 2006, Grünewald et al., 2013, Scipión et al., 2013; Schirmer and Lehning, 2011; Veitinger et al., 2013]. The structure and vicinity of canopy further complicate the surface forming processes. Tree trunks affect the snow in several ways. For example, snow accumulates less next to the tree trunks than further away from them because the branches above keep the snow from falling all the way to the ground and the trunk inhibits transportation by the wind. In addition, at melting temperatures the snow falling from the branches generates local depressions in the snow surface. The canopy affects the snow water equivalent (SWE) and depth, and also the density, though less clearly [Adams, 1976; Winkler et al., 2005]. It decreases the amount of direct solar radiation that reaches the snow surface and the amount of upwelling radiation from under the trees. It affects the wind speed and keeps the air temperatures near the surface more stable. All these in turn affect the temporal evolution of the snowpack [Gelfan et al., 2004]. In open areas wind is often the dominant process affecting the distribution of snow cover [Lehning et al., 2008]. The changes inside the snow pack affect the surface in several scales by reforming the bed on which the surface forms. In all, snow surface roughness is affected by several processes, which makes it a complex feature to model.

There are a large number of established parameters used to describe surface roughness [Church, 1988; Manes et al., 2008; Manninen, 2003; Fassnacht et al., 2009a; Hollaus et al., 2011; Lacroix et al., 2008; Rees and Arnold, 2006, a good overview in Dong et al., 1992, 1993, 1994a, 1994b]. The material of the surface and the feature that is crucial for the application of interest defines which parameters are used. For snow surface roughness studies there are two main motivators with two different sets of parameters typically used. First, surface roughness affects the interface between atmosphere and snow surface, which has an impact on wind speed and exchange of chemicals and latent and sensible heat between these two. These studies typically use atmospheric roughness length as the main parameter since it is used in most models on surface-atmosphere interaction [Manes et al., 2008; Gromke et al., 2011].

The second motivator is the effect of snow surface roughness on the radiative properties of snow, which in turn affects the energy budget of the Earth and optical and microwave remote sensing data. These studies typically use geometrical roughness with correlation length $(L)$ and root mean square height $(\sigma)$ as parameters. The problem with using these parameters is that their values depend on the scale and direction and are thus not fully capable of describing surface roughness if a single scale is selected [Keller et al., 1987; Church, 1988; Manninen, 1997a; Manninen et al., 1998; Fassnacht and Deems, 2006]. The surface radiative characteristics (incl. BRDF) are affected by surface roughness from scales of fractions of the used wavelength upward [Rees and Arnold, 2006; Ulaby et al., 1982; Fung, 1994]. Therefore, it is important to take all the necessary scales into account. Some multiscale parameters have been developed [Manninen, 1997a, 1997b, 2003; Davidson et al., 2000; Löwe et al., 2007; Manes et al., 2008; Fassnacht et al., 2009a], but the number of attempts to capture the directionality of the surface roughness is considerably smaller. Herzfeld [2002] investigated the use of higher order vario functions in snow surface roughness descriptions, and Trujillo et al. [2007] made a directional spectral analysis on the spatial distribution of snow.

Lacroix et al. [2008] provide an overview of the history of measuring snow surface roughness. The measurements based on a plate inserted into the snow have first been made in the 1980's by Rott [1984] and Williams et al. [1988]. Since then some versions with improvements on the accuracy and resolution have been made [Rees, 1998; Rees and Arnold, 2006; Löwe et al., 2007; Manes et al., 2008; Elder et al., 2009; Fassnacht et al., 2009a, 2009b; Gromke et al., 2011; Manninen et al., 2012]. Fassnacht et al. [2009a] measured the snow surface roughness with a plate method using a fixed optics lens. The advantage of this approach is that the setup can be calibrated in laboratory conditions. Löwe et al. [2007] used a plate method to measure the growth and evolution of snow surface during a single snowfall event. They wanted to study the role of settling snow crystals in surface formations and therefore made the measurements in conditions where the wind could not affect the snow surface. 
The measurements were made during and after snowfalls that consisted of homogeneous snow crystals. Gromke et al. [2011] investigated the connection between aerodynamic roughness length and geometrical roughness using wind tunnel experiments. Manninen et al. [2012] have developed a fully automatic algorithm for deriving the profile from plate imagery. The optics used in this method had a zoom lens to enable measuring in various conditions, such as dense forests. The measured surface was natural snow, including the effects of all the surface forming processes present. This method has been used in the study presented here.

In addition to the plate measurements some methods based on laser scanning have been developed for measuring the snow surface roughness. These have larger spatial coverage than the plate methods and form truly three-dimensional data sets which show great potential for the analyses of the directionality of snow surfaces. Because these laser scanning methods are non-destructive, measurements can be repeated in the same area allowing better temporal analysis. However, the resolution and accuracy are typically not yet as high as with the photogrammetry-based plate methods. Aerial laser scanning and radar-based measurements have good spatial coverage, but the resolution and accuracy are not very high [Höfle et al., 2007; Hollaus et al., 2011; Van der Veen et al., 2009; Rees and Arnold, 2006; Lehning et al., 2011]. The resolution of a typical airborne laser scanning data acquired in a scanning mode is $1 \mathrm{~m}$. Terrestrial laser scanning data have better resolution but can cover only relatively small areas. In addition to these, first attempts have been made to use mobile laser scanning in obtaining snow surface roughness data [Kukko et al., 2013; Lacroix et al., 2008]. The preliminary results on snow surface roughness obtained using the method developed in the Finnish Geodetic Institute [Kukko et al., 2013] were validated using a subset of the plate measurements presented here.

In this paper, we study the use of multiscale parameters derived from root mean square (rms) height $(\sigma)$ and correlation length (L) [Manninen, 1997b, 2003] in describing the effect of metamorphism, weather, and canopy on seasonal snow surface roughness. The autocorrelation functions (ACF) were also calculated and analyzed. The reason for choosing these surface roughness parameters is that they are the surface roughness descriptors used in microwave surface backscattering models [Ulaby et al., 1982; Fung, 1994]. The plate photography method of Manninen et al. [2012] mentioned earlier was used in the measurements. The method is based on photographing a black plate with scales on the sides. The scales are used for calibration and automatic extraction of the profile of the plate-snow interface profile. The extracted profile is approximately $1 \mathrm{~m}$ long. This scale is particularly useful for data from the C-band microwave satellite instruments, such as ERS-1, ERS-2, Radarsat and Radarsat-2, Sentinel-1, and ENVISAT/ASAR. Because the method is easy to use in the field and the extraction of the profile from the photograph is automatic, this method enables large data sets to be gathered and analyzed. The good areal coverage of the ground data is particularly important for interpreting coarse resolution remote sensing data. The data set consists of 669 plate measurements made in varying conditions and locations. The data were collected along other daily measurements of snow geophysical and radiative properties. Standard snow pit measurements were made in all locations to characterize the snow pack. This data set gives good coverage on temporal, spatial, and scale variability of the snow of the study area.

The second section of this paper provides details of the algorithms and theoretical background of the analysis. In the third section we introduce the measurement settings including the locations, measuring conditions, and methods used. The fourth section presents the results, and in the fifth section we discuss the results and conclusions in more detail.

\section{The Theoretical Basis for Multiscale Surface Roughness Parameters}

The parameters used here are based on the root mean square height $(\sigma)$ and correlation length $(L)[$ Manninen, 1997a, 1997b, 2003, Manninen et al., 1998]. Because the roughness of snow surface is scale dependent, the parameters were calculated as function of measured length. A single $\sigma$ was replaced with the mean value $\langle\sigma\rangle$ of the measured subprofile of equal length derived along the whole profile at all the measured parts of the profile. This is performed with a method similar to a sliding window technique where a window/ subprofile of fixed length is moved along a profile, $\sigma$ is calculated for each location, and in the end the mean value of all the $\sigma$ values of the same window size/subprofile length is used. 
The rms height $\left\langle\sigma_{i}\right\rangle$, autocorrelation function $\left\langle\rho_{i}(\xi)\right\rangle$, and correlation length $\left\langle L_{i}\right\rangle$ of a profile as functions of measured length are calculated as described above using the following equations [Manninen, 1997b, 2003]:

$$
\begin{gathered}
\left\langle\sigma_{i}\right\rangle=\frac{1}{\left(n-i n_{0}\right)} \sum_{j=1}^{n-i n_{0}} \sigma_{i j}, \quad \mathrm{i}=1, \ldots, n_{i} \\
\left\langle\rho_{i}(\xi)\right\rangle=\frac{1}{\left(n-i n_{0}\right)} \sum_{j=1}^{n-i n_{0}} \rho_{i j}(\xi), \quad i=1, \ldots, n_{i} \\
\left\langle L_{i}\right\rangle=\left\langle\rho_{i}^{-1}\left(e^{-1}\right)\right\rangle,
\end{gathered}
$$

where $\sigma_{i j}$ is the rms height and $\rho_{i j}(\xi)$ the autocorrelation function corresponding to a subprofile of $i n_{0}$ points. Here $\xi$ is a variable of distance. The size of the smallest subprofile is $n_{0}$, and it is enlarged with an increment of $i$ so that the size of a subprofile is $i n_{0}$, where $i=1, \ldots, n_{i}$ and $n_{i}$ is the number of different subprofile lengths. The subprofile is moved from e beginning of the whole profile by an increment of $j$. The total number of points in the $1 \mathrm{~m}$ profile is $n . L_{i}$ is the point where $\rho_{i}(\xi)$ gets the value of $e^{-1}$, with $e$ being the Napier's constant. Here $\rho_{i}^{-1}$ denotes the inverse function of $\rho_{i}$. More detailed definitions are available in the Appendix A.

For natural surfaces the logarithm of the rms height $\sigma$ is usually linearly dependent on the logarithm of the length $x$ for which it is determined [Keller et al., 1987], which gives

$$
\sigma(x)=e^{a} x^{b}
$$

where $a$ and $b$ are constant parameters. They will be used as the basis of surface roughness analysis [Manninen, 1997b].

Correlation length of natural surfaces is typically linearly dependent on the length $x$ for which it is determined [Church, 1988]:

$$
L=\alpha+\beta x
$$

where $\alpha$ and $\beta$ are regression parameters. For an ideal Brownian fractal surface $\alpha=0$ and the correlation length $L=L_{B}$, which is related to the surface roughness parameter $b$ (equation (4)) according to [Manninen, 2003]

$$
L_{B}=\frac{2 b^{2}}{1+4 b} x \text {. }
$$

With short subprofiles the number of points in each subprofile is so low that it causes statistical uncertainty. On the other hand, for very long subprofiles the number of different subprofiles derived from the profile is small. Consequently, when the length of the subprofile exceeds $60 \%$ of the maximum length of the profile the individual values for correlation length are not statistically reliable. This can be seen in the behavior of correlation length values for different subprofile lengths. Due to these inner and outer scale effects the values of $a$ and $b$ calculated using $\sigma$ values for the first $60 \%$ of the maximum profile length were found to be the most representative [Manninen et al., 1998] for the whole profile.

\section{Data}

\subsection{Campaign}

The snow surface roughness measurements were made as part of the SNORTEX (Snow Reflectance Transition Experiment) campaign [Roujean et al., 2010; Manninen and Roujean, 2014] in the Sodankylä region in the Finnish Lapland $\left(67.4^{\circ} \mathrm{N}, 26.6^{\circ} \mathrm{E}\right)$. During the field measurement periods the base of the campaign was in the premises of the Arctic Research Centre of Finnish Meteorological Institute (FMI-ARC). The campaign was led by the Finnish Meteorological Institute (FMI) and Météo-France. Other institutes involved were the Finnish Geodetic Institute (FGI), University of Helsinki, University of Eastern Finland, the Laboratoire de Glaciologie et Géophysique de l'Environnement (LGGE), and the Finnish Environment Institute (SYKE). The aim of the campaign was to study how various snow-related parameters affect boreal forest albedo during the melting season. Extensive airborne and ground-based measurements were carried out [Karjalainen, 2010; Peltoniemi et al., 2009, 2010a, 2010b; Domine et al., 2010; Hakala et al., 2010; Anttila et al., 2011; Kaasalainen et al., 2011; Manninen et al., 2012; Kukko et al., 2013]. 


\section{AGU Journal of Geophysical Research: Atmospheres}

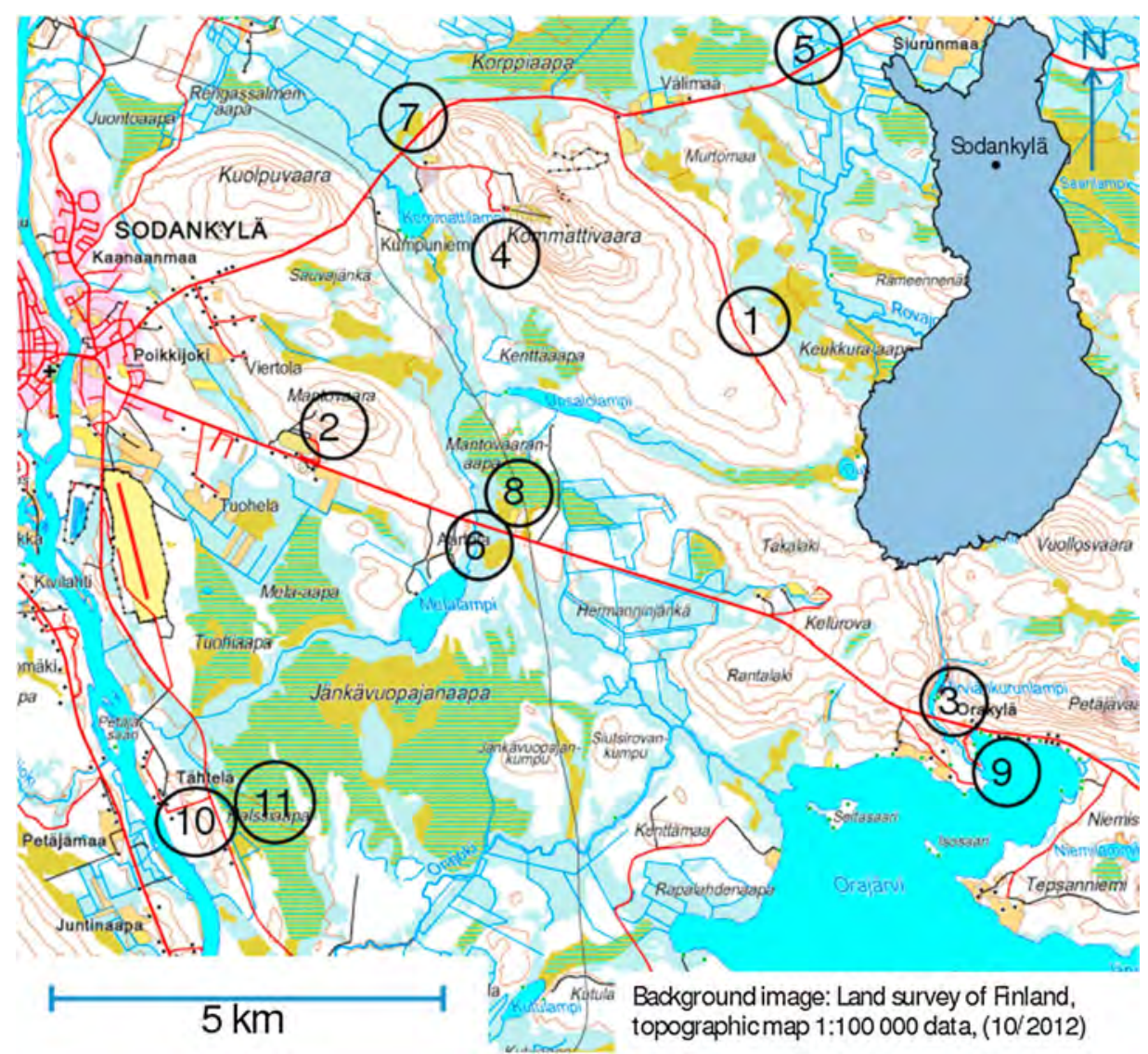

Figure 1. Map of snow surface roughness measurement sites. The indices correspond to the indices in Table 1. The location of the Sodankylä area is shown in the blue subimage of Finland. The meteorological station is located at index 10.

In 2009 the snow measurements were carried out in more than 50 locations in the campaign area of $10 \mathrm{~km}$ in diameter [Manninen and Roujean, 2014]. Each day the measurement team moved to a predefined test site and conducted the daily ground-based measurements including the plate and tachymeter (total station) profiles of surface roughness and snow pits for snow properties. Values for snow depth, density, and SWE were obtained. Profiles of snow temperature, volumetric moisture content, density, and grain size were also obtained at each location. Most of the places were measured twice, first in March 2009, then in April 2009. In April, albedo and spectrometer measurements were also carried out in the test sites. In 2010 more than 20 of these places were remeasured. The plate measurement test sites (Figure 1) were of varying land cover classes including open and semi-open bogs, several types of forests with varying densities and undergrowth, and snow-covered lake ice.

The weather conditions varied from sunny to snow fall and from $+9.6^{\circ} \mathrm{C}$ to $-29.6^{\circ} \mathrm{C}$. Table 1 shows the locations of the measurements, and Table 2 shows the measurement days and overall weather conditions for the days. In 2009 the study area was first covered by snow in 8 October 2009. The temperatures before the campaign in March were colder than freezing, and some $2 \mathrm{~cm}$ of new snow had fallen 2 March 2009. In 2010 first snow of the season fell 24 October 2010. The air temperatures in February varied from $-5^{\circ} \mathrm{C}$ to $-38^{\circ} \mathrm{C}$. There were several snowfall events at the beginning of the month and one at 14 and 15 of February 
Table 1. The Plate Measurement Sites of SNORTEX and NoSREx With Coordinates and Canopy Types ${ }^{a}$

\begin{tabular}{|c|c|c|c|c|c|}
\hline Index & Name & Coordinate $\mathrm{N}$ & Coordinate $\mathrm{E}$ & Canopy & Other \\
\hline 1 & Kommattivaara & 6725.3 & 2647.7 & Pine forest & Sandy soil \\
\hline 2 & Ravirata & 6724.4 & 2640.4 & Cultivated pine forest & Sandy soil \\
\hline 3 & Hirviäkuru & 6722.6 & 2651.3 & Mixed forest & Steep topography \\
\hline 4 & Kommattilampi & 6725.8 & 2643.4 & Pine forest & On a hillside \\
\hline 5 & Siurunmaa & 6726.9 & 2649.2 & Birch forest & \\
\hline 6 & Melalampi & 6723.6 & 2643.8 & Semi-open bog & Peat soil \\
\hline 7 & Korppiaapa & 6726.4 & 2641.9 & Open bog & Peat soil \\
\hline 8 & Mantovaaranaapa & 6724.0 & 2643.8 & Open bog & Peat soil \\
\hline 9 & Orajärvi & 6722.4 & 2651.9 & Lake ice & \\
\hline 10 & Tähtelä & 6721.8 & 2637.9 & Open with small pines & Sandy soil, flat \\
\hline 11 & Halssiaapa & 6722.0 & 2638.9 & Open bog & Peat soil \\
\hline
\end{tabular}

a The indices correspond to the ones in Figure 1. The coordinates are in EUREF-FIN ( WGS84). The trees in sites 1, 2, 4, 6 , and 10 are pines (Pinus sylvestris), in site 5 birch (Betula pubescens), and for site 3 a mixture of these two with pine as the dominant species. For the open bogs the vegetation is typical aapa mire vegetation.

that each added snow depth with a few centimeters. In March the air temperatures varied between $-35^{\circ} \mathrm{C}$ and melting point having a strong diurnal cycle caused by the warming effect of the sun during the day and radiative cooling during the nights. The average temperature was well colder than freezing. At the beginning of April 2009 the air temperatures remained similar to March, but from 10 April onward the air temperatures varied around melting point. There were no significant snowfall events during the month, and the snow

Table 2. The Measuring Days and Corresponding Test Sites Indicated With Same Indices As in Table 1 and Figure $1^{\text {a }}$

\begin{tabular}{|c|c|c|c|c|c|c|c|}
\hline Date & $\begin{array}{l}\text { Index in } \\
\text { Figure } 1\end{array}$ & $\begin{array}{l}\text { Daily Max Air } \\
\qquad \mathrm{T}\left({ }^{\circ} \mathrm{C}\right)\end{array}$ & $\begin{array}{l}\text { Daily Min Air } \\
\qquad \mathrm{T}\left({ }^{\circ} \mathrm{C}\right)\end{array}$ & $\begin{array}{c}\text { Daily Mean Air } \\
\mathrm{T}\left({ }^{\circ} \mathrm{C}\right)\end{array}$ & $\begin{array}{l}\text { Snowfall } \\
\text { Observed }\end{array}$ & $\begin{array}{c}\text { Snow Depth } \\
\text { (mm, } 8 \text { pm Local Time) }\end{array}$ & $\begin{array}{l}\text { Number of } \\
\text { Profiles }\end{array}$ \\
\hline \multicolumn{8}{|l|}{2009} \\
\hline March 11 & 1 & -6.8 & -24.4 & -14.2 & No & 60 & 41 \\
\hline March 12 & 2 & -2.8 & -11.9 & -6.1 & No & 60 & 39 \\
\hline March 13 & 3 & 0 & -4.3 & -2 & No & 60 & 34 \\
\hline March 14 & 4 & 0.6 & -2.6 & -1.1 & No & 60 & 25 \\
\hline March 15 & 5 & 1.2 & -1.3 & -0.1 & No & 59 & 15 \\
\hline March 16 & 6 & 0.6 & -2.3 & -0.9 & Yes & 59 & 40 \\
\hline March 17 & 7 & 3.7 & -10.9 & -3.5 & Yes & 60 & 20 \\
\hline March 18 & 8 & 2.1 & -15.5 & -5.4 & No & 58 & 29 \\
\hline March 19 & 10 & $-1,7$ & $-15,4$ & $-7,1$ & No & 60 & 2 \\
\hline April 20 & 1 & 0.5 & -7.2 & -3.4 & No & 48 & 11 \\
\hline April 21 & 6 & 5.1 & -7 & 0.4 & No & 47 & 24 \\
\hline April 22 & 8 & 9 & -4.8 & 3.5 & No & 46 & 27 \\
\hline April 23 & 7 & 9.5 & -3.1 & 3.8 & No & 43 & 33 \\
\hline April 24 & 4 & 8.4 & -3.3 & 3.2 & No & 41 & 25 \\
\hline April 25 & 3 & 9.7 & -2.3 & 5 & No & 38 & 18 \\
\hline April 26 & 5 & 9.6 & 1.7 & 5.7 & No & 36 & 15 \\
\hline April 27 & 2 & 6.6 & -2.7 & 2.3 & No & 33 & 15 \\
\hline April 28 & 10 & 4.3 & -0.6 & 2.1 & No & 34 & 3 \\
\hline \multicolumn{8}{|l|}{2010} \\
\hline February 23 & 10 & -16.6 & -29.6 & -23.8 & No & 70 & 54 \\
\hline February 24 & 11 & -14.2 & -27.6 & -18.1 & Yes & 71 & 42 \\
\hline March 16 & 10 & -6 & -35 & -19.3 & No & 78 & 23 \\
\hline March 17 & 8 & -3.7 & -27.4 & -15.3 & No & 78 & 22 \\
\hline March 18 & 6 & -3.7 & -29.6 & -17.4 & No & 77 & 13 \\
\hline March 19 & 4 & -3.3 & -28.8 & -13.8 & No & 77 & 12 \\
\hline March 20 & 2 & -3.2 & -6.3 & -5.8 & Yes & 81 & 6 \\
\hline March 21 & 9 & -2.3 & -17.5 & -9.9 & No & 83 & 10 \\
\hline March 22 & 7 & -2 & -20.7 & -8.5 & No & 82 & 10 \\
\hline March 23 & No measurements & -0.7 & -6.5 & -4.1 & No & 82 & 0 \\
\hline March 24 & 9,3 & -0.6 & -14.8 & -7.8 & No & 81 & 3 \\
\hline
\end{tabular}

${ }^{a}$ In addition to these measurements were made at the end of each day in Tähtelä. The weather data are from the Finnish Meteorological Institutes weather station located at Tähtelä. The snowfall information is based on in situ observations made by the field team. 
a)
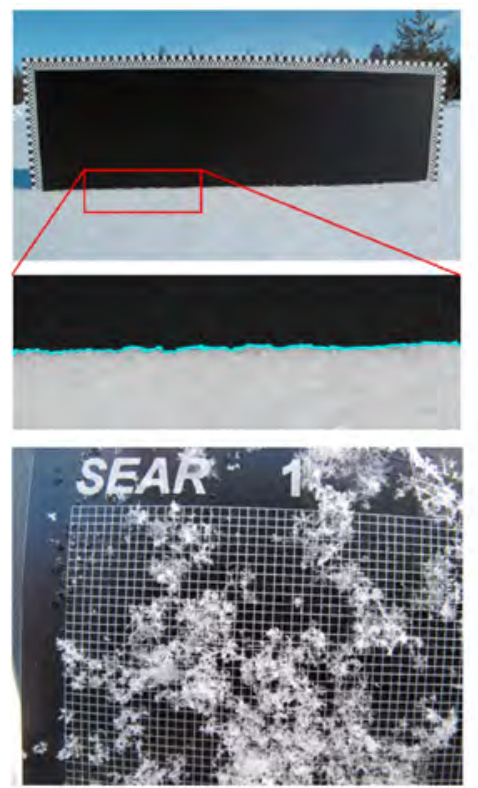

b)
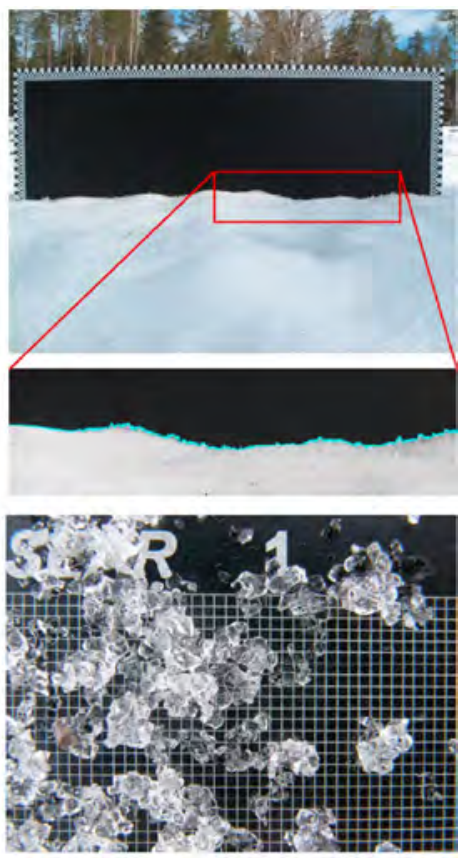

c)
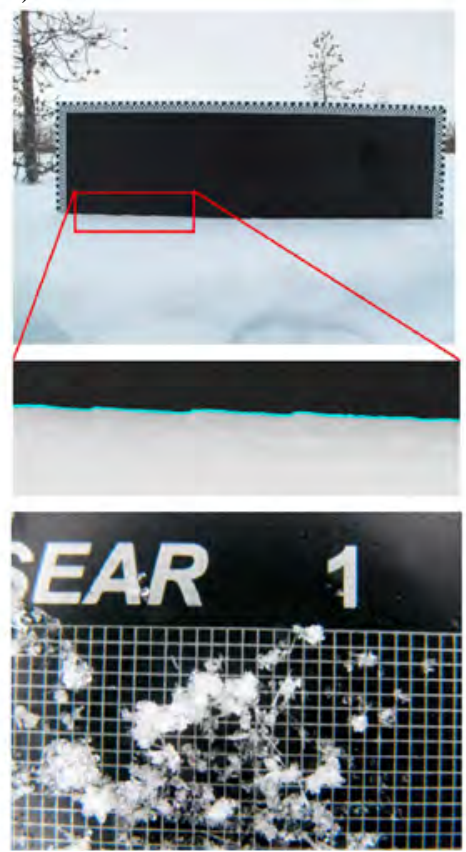

Figure 2 
depth started to drop at 10 April continuing to drop for the rest of the month. The snow in the Sodankylä region is typical taiga snow with thick layers of depth hoar at the bottom of the snow pack and metamorphosed crystals on the top with wind having only a limited role in the metamorphosis of the crystals [Sturm et al., 1995].

\subsection{Small-Scale Surface Roughness Measurements}

The snow surface roughness measurements were made alongside other daily field measurements in different test sites every day (Figure 1). Several profiles were measured at all test sites to have better spatial and statistical coverage, since one single profile is not fully capable of capturing the 3D surface characteristics of the measurement area even below the 1 meter scale. A single profile may also be dominated by some random features of the surface, such as snow that has fallen from a tree, footsteps of animals, or uneven melting caused by an individual piece of vegetation that has fallen to the snow surface. Since the location of the measurements changed daily, a set of surface roughness measurements was repeated every day at Tähtelä (site number 10 in Figure 1) near the FMI-ARC premises. These measurements were made as the last measurements of the day. The Tähtelä time series gives information on the temporal evolution of the surface structure.

In 2009 the plate profiles were measured along tachymeter profiles. The tachymeter data will be introduced here only to give an idea of the plate profile measurement settings. The data itself will not be analyzed in this article in more detail. In each location two to five tachymeter lines were measured resulting in 75 lines for the whole campaign. The lines at each site were perpendicular to each other and were typically about $100 \mathrm{~m}$ long. Due to the field conditions in some cases the lines were reduced to 50 or $25 \mathrm{~m}$. This has been the case if the vegetation did not permit a clear line of $100 \mathrm{~m}$ or the snow had already melted in some parts of a profile. Due to the roads and trees present, the length of the Tähtelä tachymeter line was reduced to 80 meters. The orientation of the tachymeter lines determined also the orientation of the plate profiles, which were measured every 10 or $20 \mathrm{~m}$ along the $100 \mathrm{~m}$ lines, every $10 \mathrm{~m}$ along the $50 \mathrm{~m}$ lines and every $5 \mathrm{~m}$ along the $25 \mathrm{~m}$ lines. Since no tachymeter data were measured in March 2010, the plate measurements were made in the vicinity of the other daily measurements (next to snow pits, spectrometer, albedometer, unmanned aerial vehicle (UAV), and bidirectional reflectance function (BRF) measurements) and along mobile laser scanning routes [Kukko et al., 2013]. Some additional plate measurements were made as transections in two locations (sites 10 and 11) near FMI-ARC during the Nordic Snow Radar Experiment (NoSREx) [Lemmetyinen et al., 2010] in February 2010. In total, the snow surface roughness data set consist of 459 plate profiles and 75 tachymeter lines measured in March and April 2009, 96 plate profiles measured in February 2010, and 114 plate profiles measured in March 2010. In March 2009, February 2010, and March 2010 the air temperatures stayed colder than freezing and little or no melting taking place in the snowpack. In April 2009 the temperatures varied from $-6.8^{\circ} \mathrm{C}$ to $+9.5^{\circ} \mathrm{C}$, the melting was already rapid and the snow cover was patchy.

The plate measurements were made using a black board of $1.06 \mathrm{~m} \times 0.4 \mathrm{~m}$ with scales on the sides. The black area from which the profile is extracted is $1 \mathrm{~m}$ wide [Manninen et al., 2012]. The plate is a layered $3 \mathrm{~mm}$ thick aluminum plate, and the surface of the plate is covered with a matt black tape. The plate was carefully inserted into the snow so that the snow surface was altered as little as possible. The plate with the snow-plate interface was photographed with a Canon PowerShot G10 digital pocket camera. The camera has a sensor of 4416 by 3312 pixels and a zoom lens from 6.1 to $30.5 \mathrm{~mm}$ having an optical image stabilizer. Three images were taken of every profile to ensure good image quality and correct focus. Figure 2 shows the plate with three examples of plate images having different kinds of snow characteristics. Figure 2a shows a fresh snow surface with dry snow, Figure $2 \mathrm{~b}$ shows a typical melting season surface with irregular shapes and smoother

Figure 2. Plate photographs with enlargements of each image including the captured surface profile for closer detail. Each image represents a different type of snow surface. The images are from (a) Tähtelä, site index 10, 16 March 2010 with fresh snow, (b) Ravirata, site index 2, 27 April 2009 with melting season snow, and (c) Melalampi, site index 6, 16 March 2009 , with wind formed ripples at an open marsh. Photos of the snow crystals were taken from the surface layers at snow pits near the profiles. The scale of the grids at the images is $1 \mathrm{~mm}$. 
a)

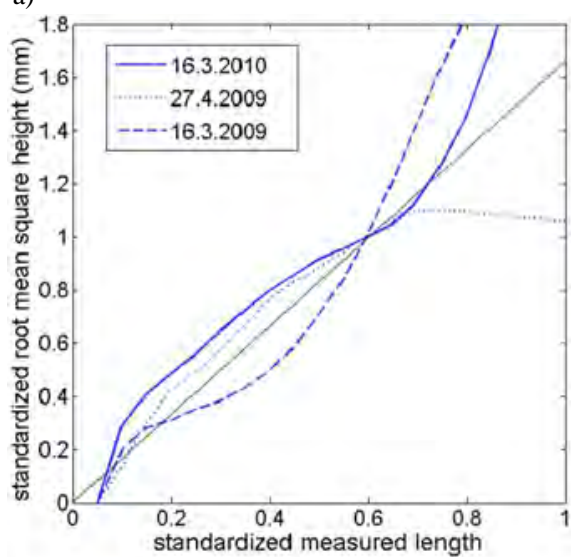

b)

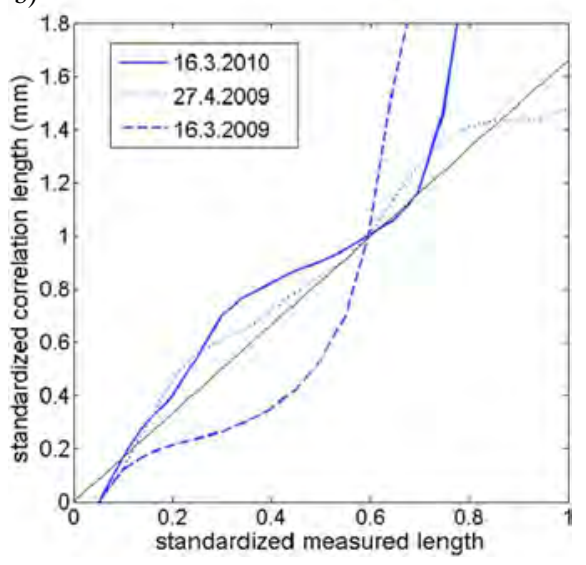

Figure 3. Examples of (a) rms height $(\sigma)$ and (b) correlation length $(L)$ variation with distance of profiles extracted from plate photographs from 16 March 2010, 27 April 2009, and 16 March 2009 presented in Figure 2. The rms height and correlation length have been standardized using the values for 0 and $60 \%$ of maximum measured length and distance using the minimum and maximum measured length. surface at crystal level, and Figure 2c shows an image taken at a marshland with wind induced ripples. Crystal images of snow surfaces taken at snow pits near the profiles have also been included in the figures.

The images were later automatically analyzed in the office, and the profile from the snow-plate interface was extracted using an automatic algorithm. The algorithm first finds the black area of the plate, then the corner points. The images go through several corrections including the barrel distortion of the lens used and the errors caused by the orientation and location of the plate in the image. This was made by fitting polynomials to the grids on the sides of the plate by first finding the corner points of the plate and then using the corner points of the vertical and horizontal $5 \mathrm{~mm}$ scales surrounding the plate in fitting the polynomials. The resolution of the profiles depends on how close to the plate the image was taken but was on average $0.27 \mathrm{~mm}$. A thorough description of how the profile is extracted from the photograph as well as validation analysis of the photogrammetric method can be found in Manninen et al. [2012].

\section{Results}

We studied the use of multiscale parameters derived from $L$ and $\sigma$ in describing the temporal and spatial change and canopy effect on seasonal snow surface roughness. Examples of $\sigma$ and $L$ as function of measured length for three different profiles are shown in Figure 3. They show that the measured values depend heavily on the measured length and that the shape of the curves depends on the type of the surface. The reason to restrict the use of the profile to $60 \%$ of the total measured length can be seen in the behavior of the $\sigma$ and $L$ values. The restrictions related to the shortest lengths are also evident (see section 2).

\subsection{Correlation Length and Autocorrelation Functions}

We compared the calculated values of $L$ (the distance $L$ at which $\operatorname{ACF}(L)=e^{-1}$ ) from the plate profiles to the theoretical values of $L_{B}$. The results are shown in Figure $4 a$. It seems that short correlation lengths of snow surfaces before the start of the spring melting have a Brownian character (the values of $L$ and $L_{B}$ are close), but for longer correlation length values, as well as melting snow, the surface is not purely Brownian. This may imply that the surface structures caused by crystals and their metamorphosis form Brownian structure, but for longer scales, with structures caused mainly by melting and wind, the surface is not Brownian. A closer look at the data reveals that the fresh snow surfaces have very small values for $L$. As the snow starts to age the range of the values for $L$ grows, but the range of the values for $L_{B}$ grow even faster and eventually surface profiles lose the Brownian character completely. This can be seen in Figure $4 \mathrm{~b}$, which shows the $L$ values for profiles of three different days in March 2009. These days represent surfaces before and after a snow fall. The snowfall event 


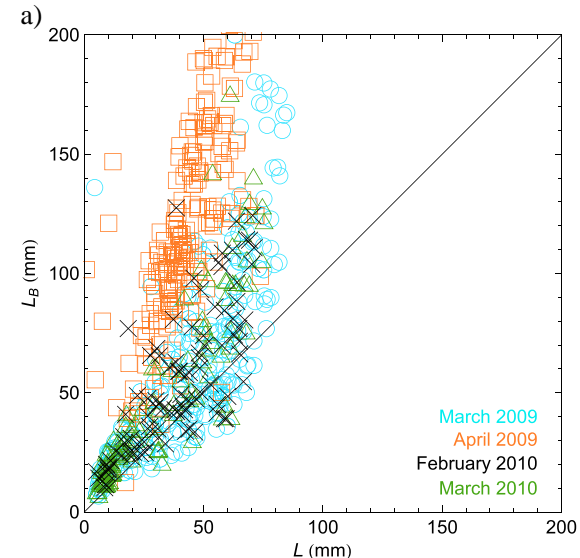

b)

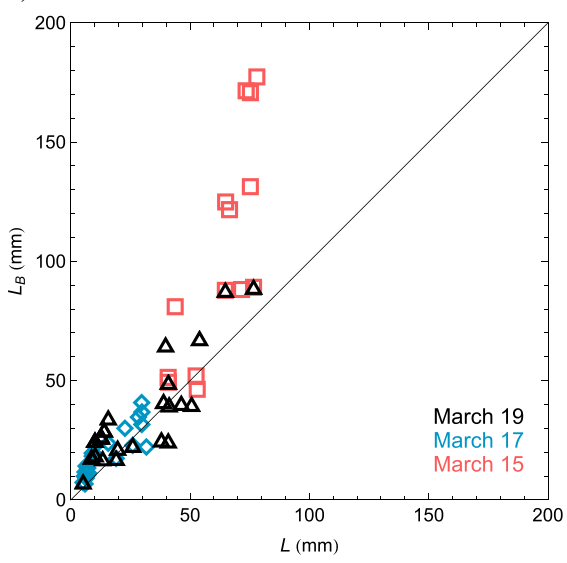

Figure 4. The measured values of $L$ for the profiles compared to a Brownian surface correlation length $L_{B}$. Figure 4 a shows all the profiles. The blue circles are the values for March 2009, red squares for April 2009, grey crosses for February 2010, and green triangles for March 2010. Figure 4b shows the $L$ values for the profiles measured in 15 March 2009 (before snow fall, red squares), 17 March 2009 (after snowfall, blue diamonds), and 19 March 2009 (after snowfall, black triangles). started gradually at the evening of 15 March, continued until 17 of March and added $5 \mathrm{~cm}$ of fresh snow to the snow pack.

The autocorrelation functions for the profiles were also calculated. They were compared with three commonly used ACF types both in single scale and multiscale form. Table 3 shows the number of experimental autocorrelation functions that fit best to each type tested. The fitting was made by minimizing the rms error by using linear regression, and the case having the highest value of the coefficient of determination $R^{2}$ was considered the best alternative. The part of the ACF included in the regression covered the distance from zero to the correlation length. In midwinter (February and March) the autocorrelation functions of most of the profiles were of the multiscale exponential type [Manninen, 2003]. In March 2009 the multiscale Gaussian ACF was equally common as the single scale exponential, whereas in 2010 the single scale exponential was more typical. At the melting time (April) the single scale Gaussian type ACF was the most common and the multiscale Gaussian the second most common ACF type. Only a few profiles of the melting period showed exponential (single or multiscale) type autocorrelation. The multiscale power law ACF was the best fitting in only a few cases, and no profile showed single scale power law autocorrelation characteristics. The differences in $R^{2}$ between the best fit and the second best fit were typically small $(<0.01)$. Examples of the most common ACF types are shown in Figure 5. Even though the differences in the $R^{2}$ values are small the difference between two ACF types can be significant due to the locations of large root mean square errors. For instance, if the experimental ACF curve deviates markedly from the ideal ACF curve at the shortest distances when the ACF is close to unity, it can have a significant role in modeling the scattering behavior of snow surface. The change of snow characteristics with time is also manifested in Figure 5 as the distance needed for decreasing the ACF value to $1 / \mathrm{e}(\sim 0.37)$ is about five times longer in April than in March.

Table 3. Number of ACFs of Measured Profiles That Best Fit Each ACF Type Tested ${ }^{\mathrm{a}}$

\begin{tabular}{lcccccc} 
& Exponential & $\begin{array}{c}\text { Multiscale } \\
\text { Exponential }\end{array}$ & Gaussian & $\begin{array}{c}\text { Multiscale } \\
\text { Gaussian }\end{array}$ & $\begin{array}{c}\text { POWER } \\
\text { LAW }\end{array}$ & $\begin{array}{c}\text { Multiscale Power } \\
\text { Law }\end{array}$ \\
\hline March 2009 & 58 & 134 & 7 & 62 & 0 & 3 \\
April 2009 & 22 & 9 & 88 & 73 & 0 & 3 \\
March 2010 & 25 & 67 & 9 & 12 & 0 & 1 \\
February 2010 & 16 & 67 & 0 & 13 & 0 & 0 \\
\hline
\end{tabular}

\footnotetext{
${ }^{a}$ The total number of profiles is 669 (2009 March: 264, 2009 April: 195, 2010 March: 114, 2010 February: 96).
} 

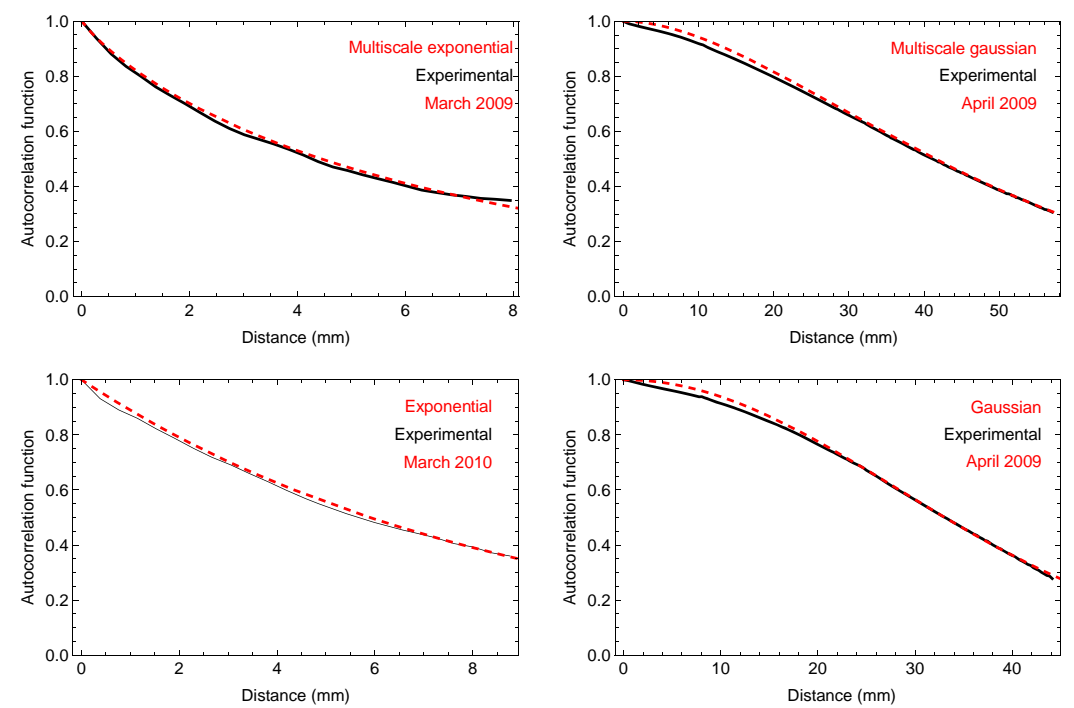

Figure 5. Examples of common autocorrelation function shapes measured in March 2009, April 2009, and March 2010. The best fit curves of single and multiscale exponential and Gaussian types are shown for comparison. The example for multiscale exponential type is from 16 March 2009 (Tähtelä, site 10), for Multiscale Gaussian from 23 April 2009 (Tähtelä, site 10) for exponential from 18 March 2010 (Melalampi site 6), and for Gaussian from 21 April 2009 (Melalampi, site 6).

\subsection{Rms Height}

\subsubsection{Sensitivity to Changes in the Snow Surface}

The measured values of $L$ proved to be strongly correlated with the measured values of $\sigma\left(R^{2} \sim 0.97\right)$.

Therefore, the remaining analysis will concentrate on the parameters derived from $\sigma$. The chosen parameters $a$ and $b$ (equation (4)) react differently to the changes in the surface characteristics. The higher the values are, the rougher the surface is. The parameter $a$ is more sensitive to the shorter wavelength/scale variation and $b$ to the regularity of the surface structure. Therefore, $a$ reacts rapidly to crystal size changes. Fresh snow crystals form a surface with more crystal level height variation than older snow surfaces which consist of old rounded crystals or wind broken and packed crystals. This causes fresh snow surfaces to get higher values for

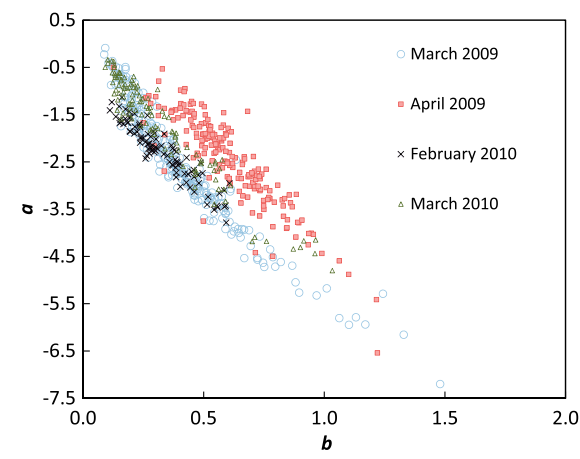

Figure 6. Temporal variation of snow surface roughness parameters of equation (4) for $60 \%$ of the maximum length. a. Parameter $b$ reacts to longer wavelength characteristics and the irregularity of their position along the profile. Its value is restricted to be in the range $0 \ldots 1$, because the fractal dimension of the profile equals $2-b$ [Manninen, 2003]. Older snow surfaces have more irregular shapes caused by, e.g., melting of the snow, impurities, and scars made by animals. These features are typically unevenly distributed on the surface, and therefore the values for $b$ tend to be higher for older snow, such as snow during the melting season, at least in the boreal forest zone. During snowfalls and directly after them new fallen snow tends to be redistributed by wind so that it gathers in pits of the surface and thus smoothens the irregular features. This as well causes the values of $b$ to be lower for fresh snow surfaces than for the same surface just before the 
a)

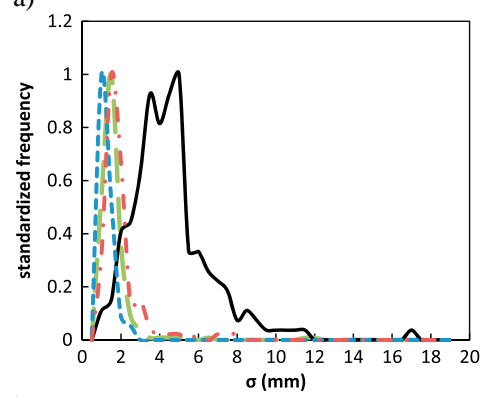

b)

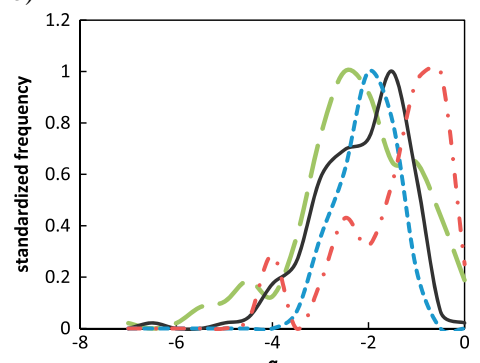

c)

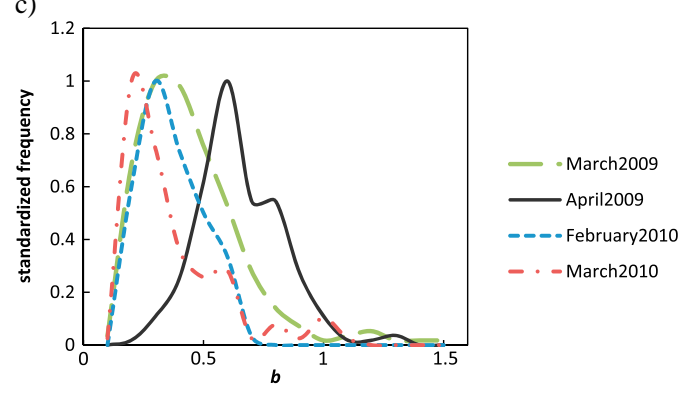

Figure 7. Standardized frequencies of (a) $\sigma$ (equation (4)), (b) parameter $a$, and (c) parameter $b$ values for $60 \%$ of the maximum length. snow fall. All metamorphic processes that affect the height variation affect also the values of these parameters. Sintering between crystals and the rounding of crystal gaps cannot be seen using data with this resolution before it starts to affect the crystals in millimeter scale.

\subsubsection{Fresh Snow Versus}

\section{Melting Snow}

The temporal change of snow surface roughness can be seen in Figure 6. The profiles for April 2009 get higher values for $b$ corresponding to $60 \%$ of the maximum length than the March 2009 profiles. This is because in March 2009 the weather and snow conditions were typical for midwinter with temperatures colder than freezing, whereas in April 2009 the melting had already started. During the melting season irregular shapes begin to form on the snow as a consequence of faster melting and larger amount of liquid water in the snow pack. In February 2010 the air temperature was permanently colder than freezing and the Sun caused hardly any melting in the snowpack. In March 2010 there was some melting but not as much as in April 2009. Figure 7 shows the distributions of $\sigma$ and parameters $a$ and $b$ for different months. The values were determined for $60 \%$ of the profile length. Here it can be seen again that the values of $\sigma$ and $b$ differ between the melting season and midwinter, but the values of $a$ show no clear difference for the different months. The data sets for the different months differ considerably in size, the data sets of 2010 being smaller than the data sets of 2009. This can affect the standardized distributions. Since parameter $a$ reacts faster to the changes in roughness, it may seem that using parameter $b$ is not necessary. However, using only parameter $a$, or $b$, it would not be possible to distinguish between the midwinter and melting season surfaces as the values of both $a$ and $b$ overlap for the two snow surface types. 4.2.3. Effect of Snowfall

The large distribution of $a$ and $b$ can be explained by a single snow fall event. Figure 8 shows the values for parameters $a$ and $b$ for Tähtelä (site 10) for March and April 2009. At the beginning of the field measurements in March 2009 the snow was aging. In the evening of 15 March it began to snow in short periods continuing until the morning of 18 March. This causes the values of parameter $a$ to increase and parameter $b$ to decrease, as fresh snow adds microscale edginess and evens out the larger scale irregularities of the surface. After the snowfall, as the surface snow begins to age, the values of parameter $a$ gradually decrease and $b$ increase. The values for $a$ for March 2009 get values between -4 and -0.5 .

This is also the distribution of $a$ for all the profiles measured in all locations in March 2009. Since the values of $a$ in one location in a few days cover the whole variation range of $a$, it can be said that the weather conditions alone can, to a large extent, explain the distribution of $a$. The role of weather on the values for $b$ is 


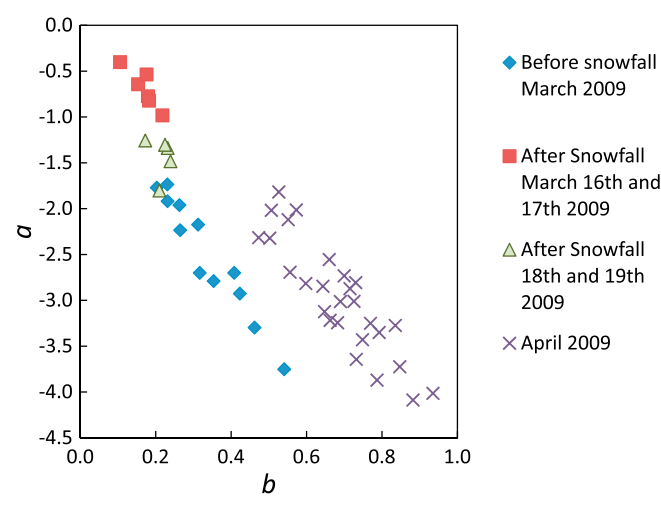

Figure 8. Temporal variation of parameters of equation (4) in Tähtelä from 11 March 2009 to 28 April 2009. these and form a separate class. All the test sites are in the vicinity of Tähtelä. Therefore, it can be assumed that the weather conditions at the test sites are similar to the conditions in Tähtelä and the time series of all the locations should show a similar trend to the time series of Tähtelä. Figure 9 shows a growing trend for the $\sigma$ values for all three classes (Tähtelä, forest, open) supporting the view that all the test sites have similar weather conditions.

The slower melting of forested sites can be seen while comparing the parameters $a$ and $b$ of the measurements at forested test sites to the time series measured at Tähtelä (Figure 10). The median values of parameter $a$ for forested and open areas is below the trend of daily averages of Tähtelä in March 2009, whereas in April it shifts above it (Figure 10a). A similar shift can be seen with parameter $b$, only in the opposite direction (Figure 10b). The measurements at open areas are so few that they are not used in further analysis. The difference between the parameter value evolution at the forested sites and the Tähtelä time series can be explained by the slower melting of the forested sites. The canopy keeps the temperatures more stable at the surface level by preventing the incoming solar radiation from reaching the surface and hindering the thermal outflow and radiative cooling. This also keeps the temperature gradients in forested sites less steep and slows down the melting in spring, which causes slower changes in the parameter values toward the melting season values in forested sites than in open areas. That is, the values of $a$ decrease, and

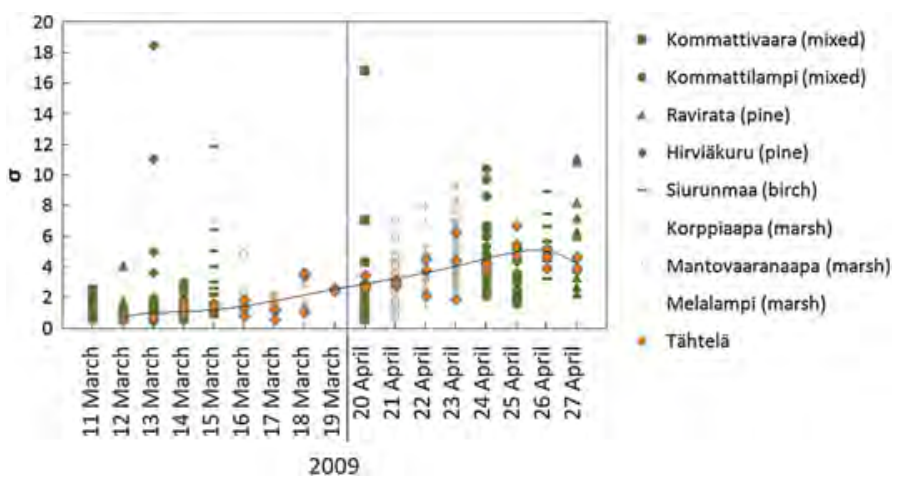

Figure 9. The values of $\sigma$ for $60 \%$ of the maximum length for daily measurements per day in 2009 . The values for forested sites are marked with green markers with fill, and the lighter grey markers are sites with open canopy. The measurements carried out in Tähtelä are shown in orange rhombuses. 
a)

b)

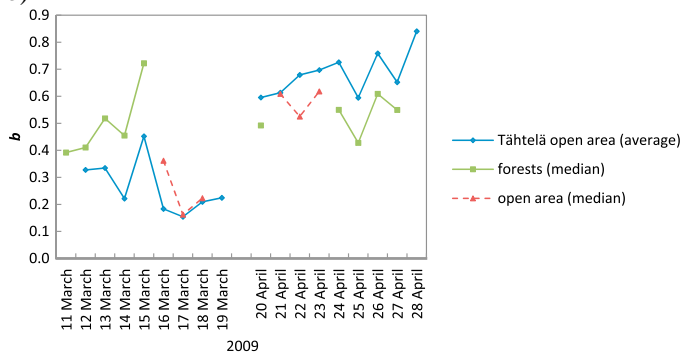

Figure 10. The median values for parameters (a) $a$ and (b) $b$ of equation (4) for daily measurements in 2009 using the length $60 \%$ of the maximum. The sites are classified as open or forested, and Tähtelä values are excluded from the other two classes. For Tähtelä, average values are used instead of median.

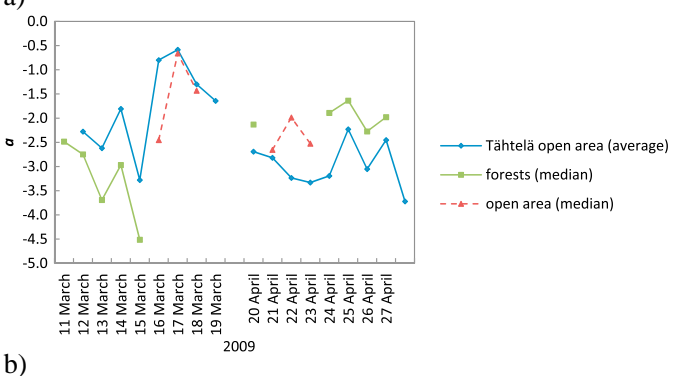

the values of $b$ increase later in the forested sites than in the open areas. A similar trend cannot be detected in the evolution of $\sigma$. The behavior of the parameters showed no other connections to the weather data (air temperature and humidity) than the one with snow fall and the difference between the forested and open areas.

\section{Discussion}

Natural surfaces have different roughness characteristics in different scales. Therefore, using $\sigma$ of one single scale is not appropriate for describing the surface. The multiscale roughness parameters $a$ and $b$ used in this study include information on all the scales measured. They are independent of the plate method and can be modified to be used in 3D analysis of snow surface roughness, such as made in Kukko et al. [2013]. They can be directly used for profiles of different lengths. Using a smaller plate with better resolution shows great potential for studying microscale metamorphosis processes. However, since the profile can be measured only once from each exact spot a statistical approach to the analysis seems more applicable. For remote sensing this is often the more desired way, since data sets with large areal coverage are needed instead of small details of one spot. The parameters $a$ and $b$ can also be used to further study the snow surface roughness in different parts of the world. The applicability of their absolute values for the snow geophysics presented in this paper for other types of snow in different areas of the world should be studied further. The snow cover in the Alps for instance is somewhat different of the taiga snow.

So far the plate measurement method has been used only at daylight, but possibly replacing the white paint used in the scales with a highly reflecting paint would enable measurements also in darkness. Preliminary studies have shown that a smaller plate and higher resolution photos can be used to capture the fine scale micro structural evolution of the crystals, which may be one significant difference between forested and open areas. It can also be used to study the relationship between falling snow flake types and the surface they form. The whole evolution of snow surface from snow fall to melting could be measured using a combination of different methods, such as the plate photography and mobile laser scanning, to obtain information on different scales. This would make it possible to study the whole range of scales and their scaling behavior, as well as the directionality of the surface features.

The effect of canopy on snow surface roughness provides a number of questions to study in the future. It is difficult to determine when an area should be defined as open or forested. Is one tree or shrub enough to make a forest from the snow surface roughness point of view? What is the role of the tree/shrub height and shape? What distance to a forest still has an effect on the snow accumulation and metamorphosis? Does a power line pole have a similar effect as a tree? The Tähtelä test site, for instance, is a relatively small opening with small pines surrounded by pine forest. It can be argued whether this site should have been classified as open or forested site. Similar problems exist also with the other open test sites, since there was some vegetation even at the most open sites. However, the sites classified as forested sites in Figures 9 and 10 have clearly more trees than present at Tähtelä. Therefore, the effect of canopy should be stronger at sites 
classified as forests. Other remaining questions related to canopy are the role of the type of canopy, including the different species, the shape and leaf type of the trees, the forest density, etc. Also, the distance to tree trunks affects snow accumulation and melting. Understanding the canopy effect better would provide valuable information for interpreting remote sensing data used to monitor the snow cover in boreal forest zone that includes different types of vegetation from thick forests to open marshlands.

Satellite data often cover large areas with different snow types. Therefore, it is important to gain knowledge on the spatial variation of snow surface features and their effect on the radiative properties. The differences in surface roughness characteristics also affect the Earth's energy budget via albedo and therefore climate. The parameters used here can be incorporated in radiation models and thus help improve the interpretation of remote sensing data. This in turn can give knowledge on the snow-climate interactions and improve the climate and weather models.

\section{Conclusions}

Microscale seasonal snow surface roughness was measured with a method based on plate photography to study spatial and temporal variation of the surface roughness. The method is easy to apply and use wherever measurements need to be made. The results show that the rms height variation values of seasonal snow surface roughness vary significantly depending on the scale used. The parameters of equation (4), $a$ and $b$, determined from the rms height values, bring additional information on the surface evolution as compared to using only rms values. Using both the parameters together gives additional information on the surface.

1. The results show a clear difference in snow surface roughness between the melting season and midwinter.

2. The aging of the snow shows decreasing values for parameter $a$ and increasing values for $b$.

3. A snowfall event causes the values for parameter $a$ to increase and parameter $b$ to decrease.

4. The canopy effect is less clear, but the slower evolution toward melting season in forested sites is visible when using the multiscale parameters derived from the rms height variation.

More information is needed on the relationship between falling snow crystal types and the roughness of the surface formed. The usability of the parameters tested here should be studied in other regions of the world. Having parameters that are able to distinguish between different types of snow gives means to further study the geophysical features of snow and better interpret the properties of snow-covered areas observed by remote sensing means.

\section{Appendix A: Definitions for Multiscale Root Mean Square Height Variation and Autocorrelation Function Types}

The rms height $\sigma_{i j}$ of the subprofile $i j$ consisting of $i n_{0}$ points and starting from point $j$ of the whole profile is defined as

$$
\sigma_{i j}=\sqrt{\frac{1}{i n_{0}} \sum_{k=0}^{i n_{0}-1}\left(y_{j+k}-\bar{y}\right)^{2}}
$$

where $y_{j+k}$ is the height of point $x_{j+k} \bar{y}$ is the average height of the subprofile $i j$, and $n_{0}$ is the increment of points in successive subprofile lengths. The autocorrelation function $\rho_{i j}(\xi)$ of the subprofile $i j$ depends on distance $\xi$ according to

$$
\rho_{i j}(\xi)=\frac{\frac{1}{i n_{0}-1-n_{\xi}} \sum_{k=0}^{i n_{0}-1-n}\left(y\left(x_{j+k}+\xi\right)-\bar{y}\right)\left(y\left(x_{j+k}\right)-\bar{y}\right)}{\frac{1}{i n_{0}} \sum_{k=0}^{i n_{0}-1}\left(y\left(x_{j+k}\right)-\bar{y}\right)^{2}}
$$

where $y\left(x_{j+k}\right)=y_{j+k}$ is the height of point $x_{j+k}$ and $y\left(x_{j+k}+\xi\right)$ is the height of point $x_{j+k}+\xi$. Here $n_{\xi}$ is the number of points corresponding to length $\xi$. 
Common one-dimensional single scale autocorrelation function types and the corresponding semi-infinite multiscale autocorrelation functions are [Manninen, 2003]

Gaussian, single scale

Gaussian, multiscale

Exponential, single scale

Exponential, multiscale

Transformed exponential, single scale

Transformed exponential, multiscale

$$
\begin{aligned}
& \rho(\xi)=\exp \left[-\xi^{2} / L^{2}\right] \\
& \rho(\xi)=\frac{1}{2}(1+2 b)\left(\frac{\xi^{2}}{k_{0}^{2} x_{0}^{2}}\right)^{\frac{1}{2}+b} \Gamma\left(-\frac{1}{2}-b, \frac{\xi^{2}}{k_{0}^{2} x_{0}^{2}}\right) \\
& \rho(\xi)=\exp \left[-\sqrt{\xi^{2} / L^{2}}\right] \\
& \rho(\xi)=(1+2 b)\left(\frac{\sqrt{\xi^{2}}}{k_{0} x_{0}}\right)^{1+2 b} \Gamma\left(-1-2 b, \frac{\sqrt{\xi^{2}}}{k_{0} x_{0}}\right) \\
& \rho(\xi)=1 /\left[1+\xi^{2} / L^{2}\right]^{3 / 2} \\
& \rho(\xi)=\frac{(1+2 b)}{2(2+b)}\left(\frac{\xi^{2}}{k_{0}^{2} x_{0}^{2}}\right)^{-\frac{3}{2}}{ }_{2} F_{1}\left(\frac{3}{2}, 2+b ; 3+b ;-\frac{k_{0}^{2} x_{0}^{2}}{\xi^{2}}\right)
\end{aligned}
$$

\section{Acknowledgments}

The authors would like to thank Sanna Kaasalainen for all support with the paper, the staff of FMI-ARC for providing infrastructure and equipment for the SNORTEX-campaign, and Ali Nadir Arslan for help with the measurements during the NoSREx campaign. The study was financially supported by the EUMETSAT H-SAF project and the Academy of Finland (project "New techniques in active remote sensing: hyperspectral laser in environmental change detection" (255534). The measured surface roughness profiles are available upon request from the corresponding author.

\section{References}

Adams, W. P. (1976), Areal differentiation of snow cover in East Central Ontario, Water Resour. Res., 12(6), 1226-1234, doi:10.1029/ WR012i006p01226.

Anttila, K., S. Kaasalainen, A. Krooks, H. Kaartinen, A. Kukko, T. Manninen, P. Lahtinen, and N. Siljamo (2011), Radiometric calibration of TLS intensity: Application to snow cover change detection, International Society for Photogrammetry and Remote Sensing, The International Archives of the Photogrammetry, Remote Sensing and Spatial Information Sciences, ISPRS Workshop, Part 5 / W12, volume XXXVIII, Commission VI, WG Vl/4.

Church, E. L. (1988), Fractal surface finish, Appl. Opt., 27(89), 1518-1526.

Davidson, M., T. Le Toan, F. Mattia, T. Manninen, and M. Borgeaud (2000), On the characterisation of agricultural random roughness for radar remote sensing studies, IEEE Trans. Geosci. Remote Sens., 38(2), 630-640.

Deems, J. S., S. R. Fassnacht, and K. J. Elder (2006), Fractal distribution of snow depth from LiDAR data, J. Hydrometeorol., 7(2), 285-297.

Domine, F., G. Krinner, M. Menegoz, J. Bock, J.-C. Gallet, and K. Anttila (2010), Snow-climate feedbacks driven by changes in snow thermal conductivity, IPY Oslo Science Conference.

Dong, W. P., P. J. Sullivan, and K. J. Stout (1992), Comprehensive study of parameters for characterizing three-dimensional surface topography I: Some inherent properties of parameter variation, Wear, 159, 161-171.

Dong, W. P., P. J. Sullivan, and K. J. Stout (1993), Comprehensive study of parameters for characterizing three-dimensional surface topography II: Statistical properties of parameter variation, Wear, 167, 9-21.

Dong, W. P., P. J. Sullivan, and K. J. Stout (1994a), Comprehensive study of parameters for characterizing three-dimensional surface topography III: Parameters for characterising amplitude and some functional properties, Wear, 178, 29-43.

Dong, W. P., P. J. Sullivan, and K. J. Stout (1994b), Comprehensive study of parameters for characterizing three-dimensional surface topography IV: Parameters for characterising spatial and hybrid properties, Wear, 178, 45-60.

Elder, K., D. Cline, G. Liston, and R. Armstrong (2009), NASA Cold Land Processes Experiment (CLPX 2002/03): Field measurements of snowpack properties and soil moisture, J. Hydrometeorol., 10, 320-329.

Eveland, J. W., M. N. Gooseff, D. J. Lampkin, J. E. Barrett, and C. D. Takacs-Vesbach (2013), Seasonal controls on snow distribution and aerial ablation at the snow patch and landscape scales McMurdo Dry Valleys, Antarctica, Cryosphere, 7, 917-913.

Fassnacht, S. R., and J. S. Deems (2006), Measurement sampling and scaling for deep montane snow depth data, Hydrol. Processes, 20, 829-838.

Fassnacht, S. R., J. D. Stednick, J. S. Deems, and M. V. Corrao (2009a), Metrics for assessing snow surface roughness from digital imagery, Water Resour. Res., 45, W00D31, doi:10.1029/2008WR006986.

Fassnacht, S. R., M. W. Williams, and M. V. Corrao (2009b), Changes in the surface roughness of snow from millimetre to metre scales, Ecol. Complexity, 6, 221-229.

Fung, A. K. (1994), Microwave Scattering and Emission Models and Their Applications, pp. 573, Artech House, Boston.

Gelfan, A. N., J. W. Pomeroy, and L. S. Kuchment (2004), Modeling forest cover influences in snow accumulation, sublimation and melt, J. Hydrometeorol., 5, 785-803.

Gromke, C., C. Manes, B. Walter, M. Lehning, and M. Guala (2011), Aerodynamic roughness length of fresh snow, Boundary Layer Meteorol., $141,21-34$.

Grünewald, T., J. Stötter, J. W. Pomeroy, R. Dadic, I. Moreno Baños, J. Marturià, M. Spross, C. Hopkinson, P. Burlando, and M. Lehning (2013), Statistical modelling of the snow depth distribution in open alpine terrain, Hydrol. Earth Syst. Sci., 17, 3005-3021.

Hakala, T., J. Suomalainen, and J. Peltoniemi (2010), Acquisition of Bidirectional Reflectance Factor Dataset Using a Micro Unmanned Aerial Vehicle and a Consumer Camera, Remote Sens., 2(3), 819-832.

Hall, D., G. A. Riggs, and V. Salomonson (1995), Development of methods for mapping global snow cover using moderate resolution imaging spectroradiometer data, Remote Sens. Environ., 54(2), 127-140.

Herzfeld, U. C. (2002), Vario functions of higher order - Definition and application to characterization of snow surface roughness, Comput. Geosci., 28, 641-660.

Höfle, B., T. Geist, M. Rutzinger and N. Pfeifer (2007), Glacier surface segmentation using airborne laser scanning point cloud and intensity data, Proceedings of ISPRS Workshop Laser Scanning SilviLaser, vol. 36, pp. 195-200, International Archives of Photogrammetry and Remote Sensing, Espoo, Finland part 3/W52.

Hollaus, M., C. Aubrecht, B. Höfle, K. Steinnocher, and W. Wagner (2011), Roughness mapping on various vertical scales based on fullwaveform airborne laser scanning data, Remote Sens., 3, 503-523.

Kaasalainen, S., H. Kaartinen, A. Kukko, K. Anttila, and A. Krooks (2011), Brief communication: Application of mobile laser scanning in snow cover profiling, Cryosphere, 5, 135-138, doi:10.5194/tc-5-135-2011.

Karjalainen, T. (2010), Lumen pinnankarkeudenmittaaminen (measuring the surface roughness of snow), Insinöörityö. Metropolia Ammattikorkeakoulu, $48 \mathrm{pp}$. 
Keller, J. M., R. M. Crownover, and R. Y. Chen (1987), Characteristics of natural scenes related to the fractal dimension, IEEE Trans. Pattern Anal. Mach. Intell. PAMI, 9, 621-627.

Kukko, A., K. Anttila, T. Manninen, H. Kaartinen, and S. Kaasalainen (2013), Snow surface roughness from mobile laser scanning data, Cold Reg. Sci. Technol., 96, 23-35.

Lacroix, P., B. Legrésy, K. Langley, S. E. Hamran, J. Kohler, S. Roques, F. Rémy, and M. Dechambre (2008), Instruments and methods: In situ measurements of snow surface roughness using a laser profiler, J. Glaciol., 54(187), 753-762.

Lehning, M., H. Löwe, M. Ryser, and N. Raderschall (2008), Inhomogeneous precipitation distribution and snow transport in steep terrain, Water Resour. Res., 44, W07404, doi:10.1029/2007WR006545.

Lehning, M., T. Grünewald, and M. Schirmer (2011), Mountain snow distribution governed by an altitudinal gradient and terrain roughness, Geophys. Res. Lett., 38, L19504, doi:10.1029/2011GL048927.

Lemmetyinen J., A. Kontu, J. Pulliainen, A. Wiesmann, C. Werner, T. Nagler, H. Rott and M. Heidinger (2010), Technical assistance for the deployment of an X to Ku band scatterometer during the Nosrex [2010] experiment, final report, ESA ESTEC contract 22671/09/NL/JA.

Löwe, H., S. Egli, S. Bartlett, J. M. M. Guala, and C. Manes (2007), On the evolution of the snow surface during snowfall, Geophys. Res. Lett., 34 , L21507, doi:10.1029/2007GL031637.

Manes, C., M. Guala, H. Löwe, S. Bartlett, L. Egli, and M. Lehning (2008), Statistical properties of fresh snow roughness, Water Resour. Res., 44 , W11407, doi:10.1029/2007WR006689.

Manninen, A. T. (1997a), Multiscale surface roughness and backscattering, Prog. Electromagnet. Res. PIER, 16, 175-203.

Manninen, A. T. (1997b), Surface roughness of Baltic sea ice, J. Geophys. Res., 102(C1), 1119-1139, doi:10.1029/96JC02991.

Manninen, A. T. (2003), Multiscale surface roughness description for scattering modeling of bare soil, Phys. A, 319, 535-551.

Manninen, T., and J.-L. Roujean (Eds.) (2014), SNORTEX field campaigns 2008-2010, Finnish Meteorological Institute Reports 2014(7), in press.

Manninen, T., M. Rantasuo, T. Le Toan, M. Davidson, F. Mattia, and M. Borgeaud (1998), Multiscale surface roughness of bare soil, in Proceedings of the IGARSS'98, pp. 1203-1206, IEEE International, Seattle, 6-10 July.

Manninen, T., K. Anttila, T. Karjalainen, and P. Lahtinen (2012), Automatic snow surface roughness estimation using digital photos, J. Glaciol., 58(211), 993-1007.

Nagler, T., and H. Rott (2000), Retrieval of wet snow by means of multitemporal SAR data, Trans. Geosci. Remote Sens., 38(2), 754-765.

Nolin, A. W. (2010), Recent advances in remote sensing of seasonal snow, J. Glaciol., 56(200), 1141-1150.

Peltoniemi, J., T. Hakala, J. Suomalainen, and E. Puttonen (2009), Polarised bidirectional reflectance factor measurements from soil, stones, and Snow, J. Quant. Spectros. Radiat. Transfer, 110, 1940-1953, doi:10.1016/j.jqsrt.2009.04.008.

Peltoniemi, J. I., T. Manninen, J. Suomalainen, T. Hakala, E. Puttonen, and A. Riihelä (2010a), Land surface albedos computed from BRF measurements with a study of conversion formulae, Remote Sens., 2(8), 1918-1940.

Peltoniemi, J. I., J. Suomalainen, T. Hakala, E. Puttonen, J. Näränen, S. Kaasalainen, J. Torppa, and M. Hirschmugl (2010b), Reflectance of various snow types: Measurements, modelling and potential for snow melt monitoring, in Light Scattering Reviews 5: Single Light Scattering and Radiative Transfer, Springer Praxis Books, chap. 9, pp. 393-450, Springer, Berlin, Heidelberg, doi:10.1007/978-3-642-10336-0.

Rees, W. G. (1998), A rapid method for measuring snow surface profiles, J. Glaciol. Correspondence, 44(148), 674-675.

Rees, W. G., and N. S. Arnold (2006), Scale-dependent roughness of a glacier surface: Implications for radar backscatter and aerodynamic roughness modelling, J. Glaciol., 52, 214-222.

Rott, H. (1984), The analysis of backscattering properties from SAR data of mountain regions, J. Oceanic Eng., OE-9(5), 347-355.

Roujean, J.-L., et al. (2010), SNORTEX (Snow Reflectance Transition Experiment): Remote sensing measurement of the dynamic properties of the boreal snow-forest in support to climate and weather forecast, Report of IOP-2008, in Proceedings of IGARSS 2009.

Schirmer, M., and M. Lehning (2011), Persistence in intra-annual snow depth distribution: 2. Fractal analysis of snow depth development, Water Resour. Res., 47, W09517, doi:10.1029/2010WR009429.

Scipión, D. E., R. Mott, M. Lehning, M. Schneebeli, and A. Berne (2013), Seasonal small-scale spatial variability in alpine snowfall and snow accumulation, Water Resour. Res., 49, 1446-1457, doi:10.1002/wrcr.20135.

Sturm, M., J. Holmgren, and G. Liston (1995), A seasonal snow cover classification system for local to global applications, J. Clim., 8, $1261-1283$. Takala, M., K. Luojus, J. Pulliainen, C. Derksen, J. Lemmetyinen, J.-P. Kärnä, J. Koskinen, and B. Bojkov (2011), Estimating northern hemisphere snow water equivalent for climate research through assimilation of space-borne radiometer data and ground-based measurements, Remote Sens. Environ., 115(12), 3517-3529.

Trujillo, E., J. A. Ramírez, and K. Elder (2007), Topographic, meteorological, and canopy controls on the scaling characteristics of the spatial distribution of snow depth fields, Water Resour. Res., 43, W07409, doi:10.1029/2006WR005317.

Ulaby, F. T., R. K. Moore, and A. K. Fung (1982), Microwave Remote Sensing, vol. II, Addison-Wesley, Reading.

Van der Veen, C. J., Y. Ahn, M. Csatho, E. Mosley-Thompson, and W. B. Krabill (2009), Surface roughness over the northern half of the Greenland Ice Sheet from airborne laser altimetry, J. Geophys. Res., 114, F01001, doi:10.1029/2008JF001067.

Veitinger, J., B. Sovilla, and R. S. Purves (2013), Influence of snow depth distribution on surface roughness in alpine terrain: A multi-scale approach, Cryosphere Discuss., 7, 4633-4680.

Warren, S., R. Brandt, and P. Hinton (1998), Effect of surface roughness on bidirectional reflectance of Antarctic snow, J. Geophys. Res., 103(E11), 25,789-25,807, doi:10.1029/98JE01898.

Williams, L. D., and J. G. Gallagher (1987), The relation of millimetre-wavelength backscatter to surface snow properties, IEEE Trans. Geosci. Remote Sens., GE-25(2), 188-193.

Williams, L. D., J. G. Gallagher, D. E. Sugden, and R. V. Birnie (1988), Surface snow properties effects on millimeter-wave backscatter, Trans. Geosci. Remote Sens., 26(3), 300-306.

Winkler, R. D., D. L. Apittlehouse, and D. L. Golding (2005), Measured differences in snow accumulation and melt among clearcut, juvenile and mature forests in southern British Columbia, Hydrol. Processes, 19, 51-62.

Zhuravleva, T. B., and A. A. Kokhanovsky (2011), Influence of surface roughness on the reflective properties of snow, J. Quant. Spectrosc. Radiat. Transfer, 112, 1353-1368. 
FINNISH METEOROLOGICAL INSTITUTE

Erik Palménin aukio 1

P.O. Box 503

FI-O0560 HELSINKI

tel. +358295391000

\section{WWW.FMI.FI}

FINNISH METEOROLOGICAL INSTITUTE CONTRIBUTIONS NO. 171

ISSN 0782-6117

ISBN 978-952-336-119-5 (paperback)

ISBN 978-952-336-120-1 (pdf)

https://doi.org/10.35614/isbn.9789523361201

$\because \because \cdots$
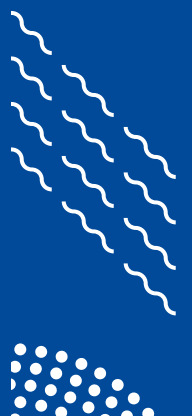